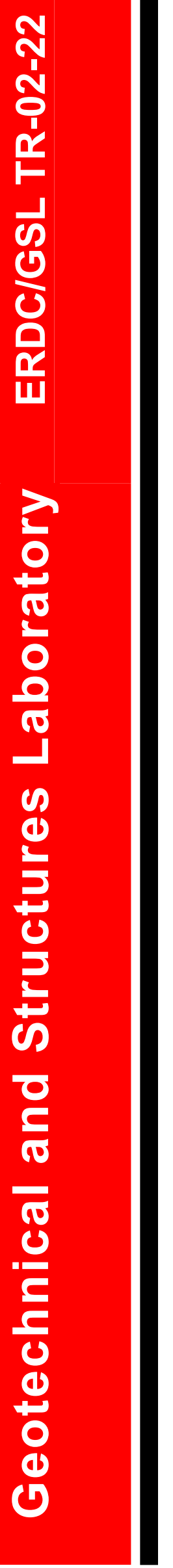

Innovations for Navigation Projects Research Program

\title{
Positioning Systems for Float-In and Lift-In Construction in Inland Waterways
}

Sam X. Yao and Ben C. Gerwick

December 2002 
The contents of this report are not to be used for advertising, publication, or promotional purposes. Citation of trade names does not constitute an official endorsement or approval of the use of such commercial products.

The findings of this report are not to be construed as an official Department of the Army position, unless so designated by other authorized documents. 


\section{Positioning Systems for Float-In and Lift-In Construction in Inland Waterways}

by Sam X. Yao, Ben C. Gerwick

Ben C. Gerwick, Inc.

20 California Street, Suite 400

San Francisco, CA 94111

Final report

Approved for public release; distribution is unlimited.

Prepared for U.S. Army Corps of Engineers

Washington, DC 20314-1000

Under INP Work Unit 33274

Monitored by Geotechnical and Structures Laboratory

U.S. Army Engineer Research and Development Center 3909 Halls Ferry Road

Vicksburg, MS 39180-6199 


\section{Contents}

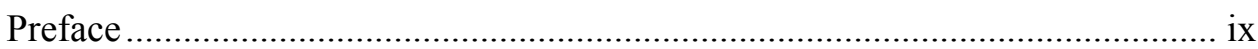

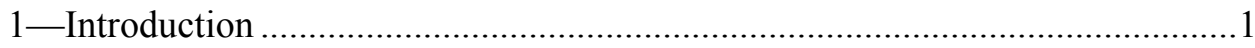

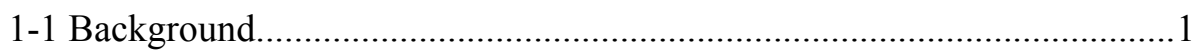

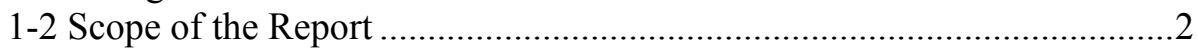

2-Fundamentals of Positioning Operations.....................................................4

2-1 Basic Considerations ........................................................................

2-2 Evaluation of Environmental Effects on Positioning ...............................8

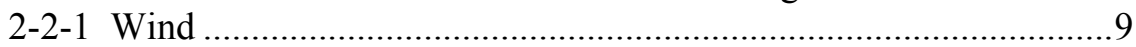

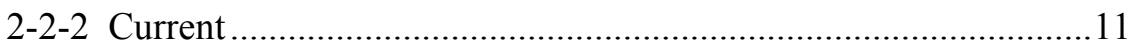

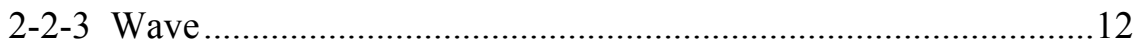

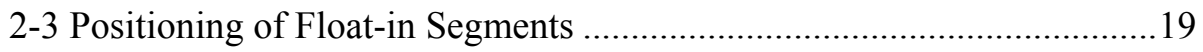

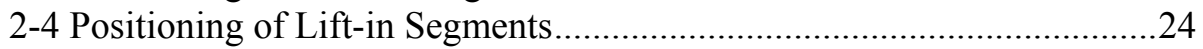

2-4-1 Control of crane barge ........................................................29

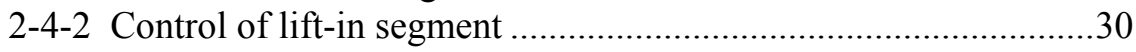

2-5 Engineering Specifications for Positioning and Setting Operations.........31

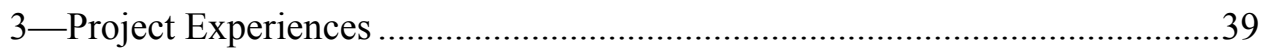

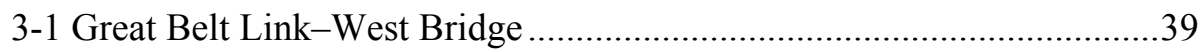

3-2 Great Belt Link-East Bridge …........................................................45

3-3 Oresund Crossing-Immersed Tunnel ................................................50

3-4 Braddock Dam-Float-in Construction................................................53

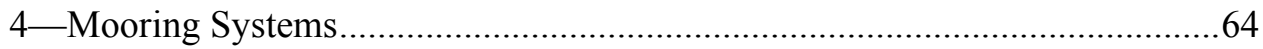

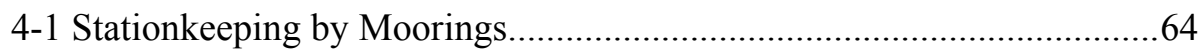

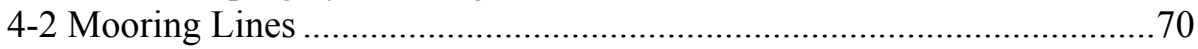

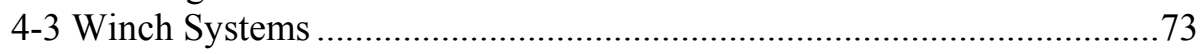

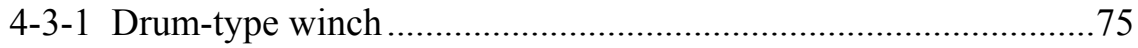

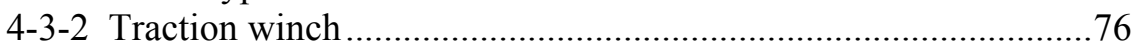

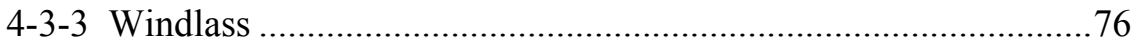

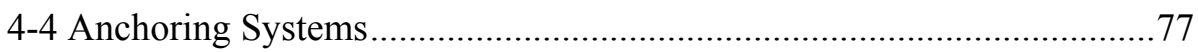

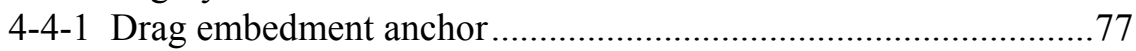

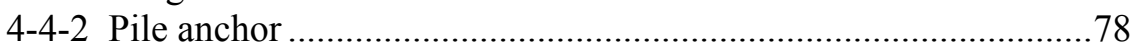




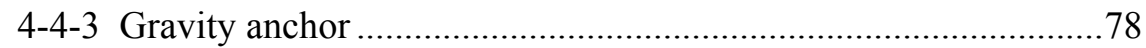

4-4-4 Caisson foundation (suction anchor) ............................................79

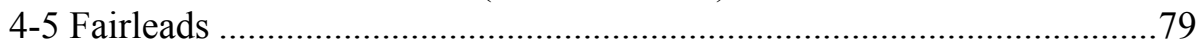

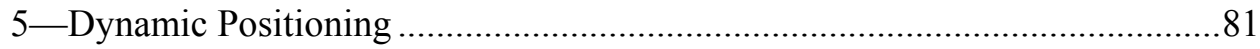

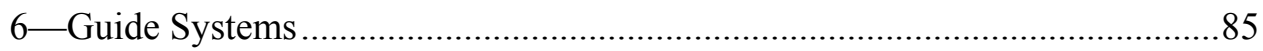

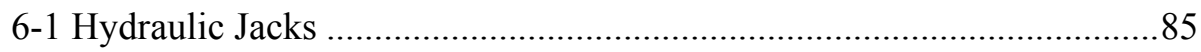

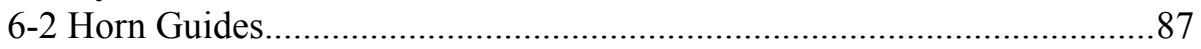

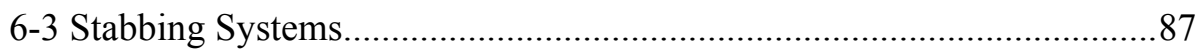

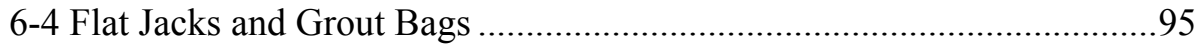

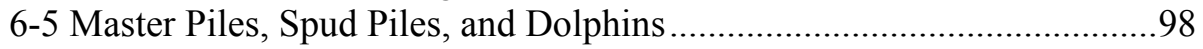

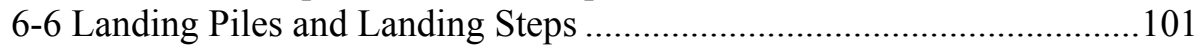

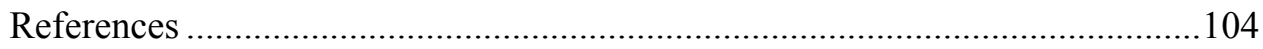

SF 298

\section{List of Figures}

Figure 2-1. Six degrees of motion of a vessel in water................................. 5

Figure 2-2. Moorings are used to position a float-in dam segment ................6

Figure 2-3. Moorings are used to position a catamaran crane, a piledriving barge, and a screed barge in the lift-in construction of a navigation dam. 7

Figure 2-4. Three components of the environmental forces ......................... 8

Figure 2-5. Flow velocity variations over a cross section of the river...........12

Figure 2-6. Current-induced uplift/downward force on a float-in segment ..13

Figure 2-7. Definition of the effective fetch ............................................. 14

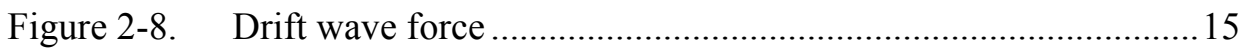

Figure 2-9. Vortex-shedding around a moored floating segment..................16

Figure 2-10. Hydraulic model tests for float-in modular segments .................16

Figure 2-11. Wave pressure distribution for nonbreaking waves...................17

Figure 2-12. Wave force (P) and current force (U) distribution on a float-in segment .18 
Figure 2-13. Tugs and mooring arrangement to position a float-in bridge anchor block

Figure 2-14. Display of real-time position data during underwater installation.....

Figure 2-15. Effect of metacentric height. .23

Figure 2-16. Installation of bridge caissons and deck with shear-leg cranes...25

Figure 2-17. A catamaran picks a deck box girder from a jetty and places it onto a pier .25

Figure 2-18. A jack-up barge places immersed tunnel segments with strand jacks

Figure 2-19. A 2,100-ton caisson was placed with jack-up barge $L i s a-A$......28

Figure 2-20. Moorings used to position a shear-leg crane barge for lift-in

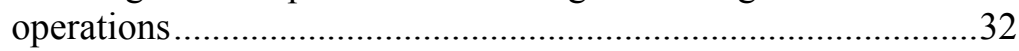

Figure 2-21. Mooring layout for a catamaran for lift-in operations ................32

Figure 2-22. Erection plan and flat-shaped lift-in segments...........................33

Figure 2-23. A shear-leg positions lift-in dam segment with lift frame and tag lines

Figure 2-24. A catamaran positions bridge girder segment with tag lines at both ends 34

Figure 3-1. Great Belt Link-West Bridge and East Bridge .40

Figure 3-2. A caisson (West Bridge) was placed by the Svanen with an eight-point mooring . .41

Figure 3-3. Deck winches and mooring arrangement on the Svanen .42

Figure 3-4. Real-time positioning data on the bridge caisson, on a monitoring screen

Figure 3-5. Placing a 5,500-ton girder segment with the Svanen

Figure 3-6. Hydraulic jacks as temporary support for positioning the box girders . .44

Figure 3-7. Survey positioning of the girders ............................................ 44

Figure 3-8. East Bridge under construction ...............................................45 
Figure 3-9. At the site, caisson is held in position with mooring lines

Figure 3-10. Mooring arrangement for placing a pier segment with two shear-leg cranes. .48

Figure 3-11. Transporting and placing a pier segment with two cranes .49

Figure 3-12. Pier shaft—from barge deck to permanent pier base .49

Figure 3-13. Jack-up platforms were used as "anchor islands" for positioning 50

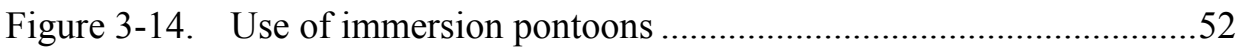

Figure 3-15. Schematic representation of immersion operation ......................53

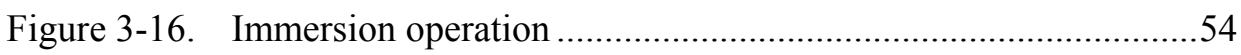

Figure 3-17. Construction sequences for positioning Segment 1 ...................56

Figure 3-18. Construction sequences for positioning Segment 2 ..................56

Figure 3-19. Mooring arrangement for placing Segment 1 ..........................57

Figure 3-20. Mooring arrangement for placing Segment 2 ..........................57

Figure 3-21. Details of anchor pile type "A"

Figure 3-22. Layout of upstream mooring lines for Segment 1.....................58

Figure 3-23. Winches on pier 1 of Segment 1 .............................................60

Figure 3-24. Positioning Segment 1 against the guide wall with a horn guide .60

Figure 3-25. Horn guide used for positioning Segment 1 during setdown......61

Figure 3-26. Ballasting pipes on the work deck of Segment 1 ......................62

Figure 3-27. Survey instrument on the lock wall .......................................63

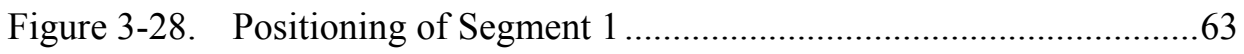

Figure 4-1. Mooring systems: catenary versus taut-line ..............................64

Figure 4-2. Application of catenary mooring system ..................................65

Figure 4-3. Application of a taut-line mooring system ................................66 
Figure 4-4. Eight-point spread mooring system used together with a survival mooring

Figure 4-5. A platform joins its top deck using both taut and catenary lines .68

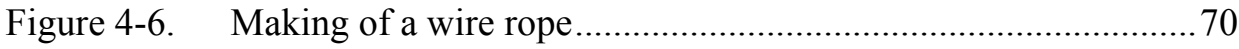

Figure 4-7. Definition for analysis of catenary line....................................72

Figure 4-8. Efficiency of wire rope strength when bent over various radii...73

Figure 4-9. Lantec Model 750 winch and its power unit on Braddock Dam, Segment 1 .....................................................74

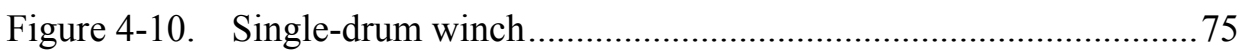

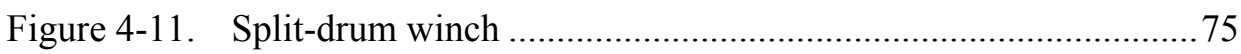

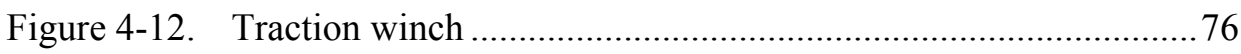

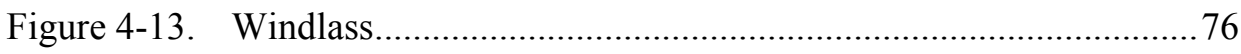

Figure 4-14. Installation of suction anchor ..................................................

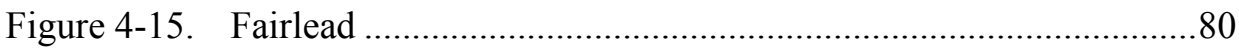

Figure 5-1. Flow diagram of a dynamic positioning system .......................81

Figure 5-2. Typical ducted propeller .....................................................8

Figure 5-3. Typical ducted propeller in a tunnel type installation.................83

Figure 5-4. Common thrust configurations in ships and catamaran ..............83

Figure 6-1. Mating of immersed tunnel segments ......................................86

Figure 6-2. Use of hydraulic jacks to realign two adjacent tunnel

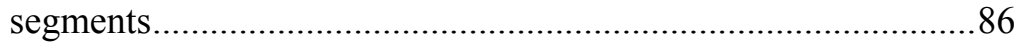

Figure 6-3. Details of a hydraulic jack as used in alignment of immersed

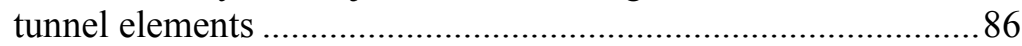

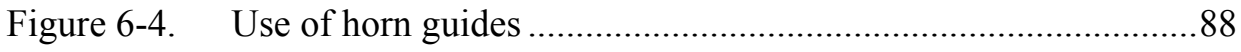

Figure 6-5. Horn guides are used in immersed tube segments (Oresund Crossing) ........................................................... 88

Figure 6-6. Horn guide was used in positioning Braddock Dam float-in

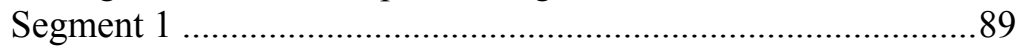


Figure 6-7. Pintle/cone stabbing device used to join FlexiFloat units

Figure 6-8. Pintles mounted on precast concrete pontoons for joining offshore (floating Valdez container terminal, Alaska)..... .90

Figure 6-9. Joining concrete pontoons over water by use of stabbing connection 90

Figure 6-10. Pintle/receptacle for joining concrete pontoons........................91

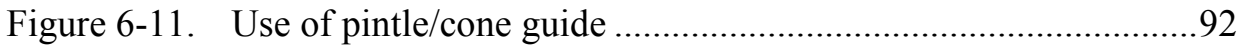

Figure 6-12. Alignment of a 5,000-ton integrated deck module with stabbing cones

Figure 6-13. Installation of fully integrated deck module onto a preinstalled jacket .94

Figure 6-14. Stabbing guide assembly details .............................................95

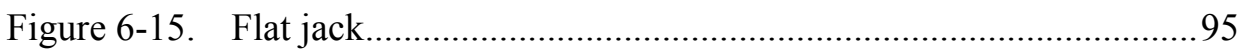

Figure 6-16. Use of flat jacks on a landing pile...........................................96

Figure 6-17. Use of flat jacks to control the leveling of an immersed tunnel

Figure 6-18. Bridge pier and superstructure rest on three hard pads. .98

Figure 6-19. Preconstruction trial resting of grout bags as a leveling device .98

Figure 6-20. Placement of hard pads, with grout bag attachment, by three-legged frame

Figure 6-21. Use of master piles and taut line/winches to position miter gate sill 100

Figure 6-22. Positioning construction vessels with spud piles..... 101

Figure 6-23. Two adjacent lock wall modules on landing piles and landing pads 102

Figure 6-24. Lock wall module on landing pile and its connection to lock floor 103

Figure 6-25. Landing pile with flat jacks. 103 


\section{Preface}

The work described in this report was authorized by Headquarters, U.S. Army Corps of Engineers (HQUSACE), as part of the Innovations for Navigation Projects (INP) Research Program. The study was conducted under Work Unit 33274, "Positioning and Placement of Underwater Structural Components," managed at the U.S. Army Engineer Research and Development Center (ERDC) Geotechnical and Structures Laboratory (GSL). Mr. James E. McDonald, ERDC GSL, was the Principal Investigator.

Dr. Tony C. Liu was the INP Coordinator at the Directorate of Research and Development, HQUSACE; Research Area Manager was Mr. Barry Holliday, HQUSACE; and Program Monitor was Mr. Mike Kidby, HQUSACE.

Mr. William H. McAnally, ERDC Coastal and Hydraulics Laboratory was the Lead Technical Director for Navigation Systems; Dr. Stanley C. Woodson, ERDC GSL, was the INP Program Manager.

This report was prepared by Drs. Sam X. Yao and Ben C. Gerwick of Ben C. Gerwick, Inc., San Francisco, CA.

The research was monitored by Mr. McDonald, under the supervision of Dr. Albert J. Bush III, Chief, Engineering Systems and Materials Division, and Dr. David W. Pittman, Acting Director, GSL.

At the time of publication of this report, Dr. James R. Houston was Director of ERDC, and COL John W. Morris III, EN, was Commander and Executive Director.

The contents of this report are not to be used for advertising, publication, or promotional purposes. Citation of trade names does not constitute an official endorsement or approval of the use of such commercial products. 


\section{Conversion Factors, Non-SI to SI Units of Measurement}

Non-SI units of measurement used in this report can be converted to SI units as follows:

\begin{tabular}{||l|l|l||}
\hline \hline Multiply & By & To Obtain \\
\hline \hline degrees (angle) & 0.01745329 & radians \\
\hline feet & 0.3048 & meters \\
\hline inches & 25.4 & millimeters \\
\hline knots (international) & 0.5144444 & meters per second \\
\hline miles (U.S. statute) & 1.609347 & kilometers \\
\hline pounds (force) & 4.448222 & newtons \\
\hline pounds (force) per square foot & 47.88026 & pascals \\
\hline pounds (mass) per cubic foot & 16.01846 & kilograms per cubic meter \\
\hline square feet & 0.09290304 & square meters \\
\hline tons (short, 2000 lb) & 907.1847 & kilograms \\
\hline \hline
\end{tabular}




\section{Introduction}

\section{1-1 Background}

In terms of the construction method for installation of prefabricated structural modules, in-the-wet construction can be generally categorized into the float-in and lift-in methods. Float-in construction involves transportation of prefabricated structural modules from their fabrication site to the project site by flotation. The modules are usually thin-shelled floating structures with internal ballasting compartments. Once the float-in modules arrive onsite, they are maneuvered and precisely positioned with engineered positioning systems and then ballasted down onto prepared foundations.

For lift-in construction, prefabricated modules themselves do not float. Towed barges are often used to transfer the modules from the prefabrication site to the project site. Floating cranes are used to install them to their positions.

Although onsite installation of a structural module typically takes only a very short period of time (1-2 days), it is one of the most critical construction operations. The essential requirement for the onsite installation is to correctly position the modules to achieve acceptable position alignments and elevations. For many navigation projects, the engineering requirements for installation of prefabricated modules impose tight positioning tolerances. In many cases, the key to achieve the required alignment tolerances depends largely on the project site conditions, the size and shape of individual modular segments, and the means and methods used for installation. The erection criteria and installation procedures specified must be economically attainable with the current technologies and marine construction practice.

Installation and positioning of float-in or lift-in segments also have significant implications to the structural design of the prefabricated modules. Construction loadings on the segments highly depend on the method and sequence of installation used. Any substantial change in the actual installation from the procedures assumed in the design could potentially overstress the segments. Thus, it is important that all of the work sequences for the launch, transport, and installation of the segments be fully integrated in the design.

Past experience shows that successful installation of large prefabricated modules requires well-planned procedures, stringent control, and close coordination among several marine construction operations, including operations of the 
positioning systems, operations of ballasting and deballasting systems, operations of heavy-lift equipment, and positioning surveys. In modern marine construction, all of these operations must be planned and engineered in advance.

Traditionally, the marine construction industry depended upon divers to help underwater positioning. For most underwater operations, the reliance upon divers has not been effective for several reasons. First, divers have very limited visibility in muddy waterways. They can easily become disorientated and lose their reference points. Second, divers are in a state of near neutral buoyancy and, consequently, have little capability to move objects underwater. Only when divers can plant their feet firmly on the bottom or against a structure can they exert about 20 to $60 \mathrm{lbf}^{1}$ in push or pull. Finally, the diving depth and river currents may create safety concerns for the divers. For a water depth of $50 \mathrm{ft}$ or more, safe diving would impose limitations in diving time and may require decompression. When the water velocity is greater than 1 to $2 \mathrm{fps}$, a safety cage or safety line is required for divers. For these reasons, modern marine construction uses little diving assistance for positioning, except for necessary underwater inspection of critical clearances.

The state of practice in float-in or lift-in construction is to employ a synergistic combination of the stationkeeping and guide systems to install large modular segments to the required alignment accuracy. The primary stationkeeping systems used in marine construction are anchor-moorings, mooring dolphins, and dynamic positioning. The guide systems are various and often inventive. The common guide systems include horn guides, stabbing guides, flat jacks, and hydraulic rams.

Selection and design of proper stationkeeping and guide systems are a critical part of the float-in or lift-in construction. A thorough understanding of the mechanism, applicability, and limitations of various positioning systems is of significant value for both the engineers and contractors involved in innovative in-the-wet navigation projects. On one hand, the design engineers need to integrate the installation methods into the design of prefabricated modular segments and establish the critical installation loads and load cases that the modular segments must withstand. On the other hand, the contractor must meet the engineering specifications and load conditions in the development of reliable and effective positioning and guide systems that minimize construction risks.

\section{1-2 Scope of the Report}

This report is prepared as an introduction to the positioning construction techniques used in marine construction. It is intended to provide guidance for development and evaluation of the positioning systems used for in-the-wet construction of navigation structures. The focus of this report is to assess various means and methods for positioning large prefabricated segments, including the stationkeeping and guide systems.

\footnotetext{
${ }^{1}$ A table of factors for converting non-SI units of measurement to SI (metric) units is presented on page $\mathrm{x}$.
} 
The report is divided into two parts. The first part (Chapters 2 and 3) provides an overview of positioning operations and general engineering requirements for the design and specifications of positioning systems. Chapter 2 covers the basic process of positioning operations in float-in and lift-in construction. Chapter 3 discusses the applications of various positioning systems in several recent in-the-wet civil works projects. The second part (Chapters 4-6) provides descriptions and evaluation of the most common stationkeeping and guide systems that are used to position prefabricated modules in marine construction. The evaluation of each method will include essential equipment, operation requirements, general applicability, and constraints for lift-in and float-in construction in the inland waterways.

Positioning surveys during float-in or lift-in installation require a high degree of accuracy on a real-time basis. Significant advances have been made in the last two decades in survey technologies and instrumentation, such as laser, global positioning system (GPS), and sonic measurements. This report does not cover the subject of positioning survey instrumentation; however, readers may refer to other publications for this information (e.g., Mann and Chiarito 2000). 


\section{Fundamentals of Positioning Operations}

\section{2-1 Basic Considerations}

A floating vessel will typically experience six degrees of motion in response to environmental forces. In marine engineering, these are conveniently expressed as (1) heave, (2) pitch, (3) roll, (4) sway, (5) surge, and (6) yaw, as illustrated in Figure 2-1. Motions of vessels in inland waterways are sometimes described in other terms, such as list and trim. This report, however, uses the standard marine engineering terms (heave, pitch, etc.) to describe positioning of a floating structure or a vessel.

In general, the greater the environmental forces, the larger are the motions of the vessels. However, not all vessels will respond the same way to their environments. For example, if the waterway consists mostly of waves of short lengths, then a small vessel of comparable length will experience significant motions. But a barge with a length much longer than the average wavelength may experience much less motion.

A floating vessel has its natural period of resonance for each of the six degrees of freedom. When the vessel is subjected to external excitation at the same frequency as its natural frequency, the motion will be steadily increased by amplification. For a barge, the heave and pitch motions are heavily damped so that the resonance is barely perceptible. Because roll motions usually have little damping, roll resonance of a barge could be very pronounced.

Vessels in rivers are subjected primarily to lateral loads such as wind and currents. Thus, their sway, surge, and yaw usually represent the three most important motions. For shear-leg crane barges or derrick barges, on the other hand, their pitch and roll will significantly influence the motions of the boom tip and, consequently, positions of the lifting load. Thus, positioning control of pitch/roll of a crane barge is essential for the lift-in construction. Although the other motions are present, they usually do not cause as much difficulty as pitch and roll motions.

Positioning of a vessel or a floating module is to hold it to a position defined in all six degrees of freedom. In general, positioning operations mainly depend upon moorings, guides, and surveying instrumentation. The mechanical system 


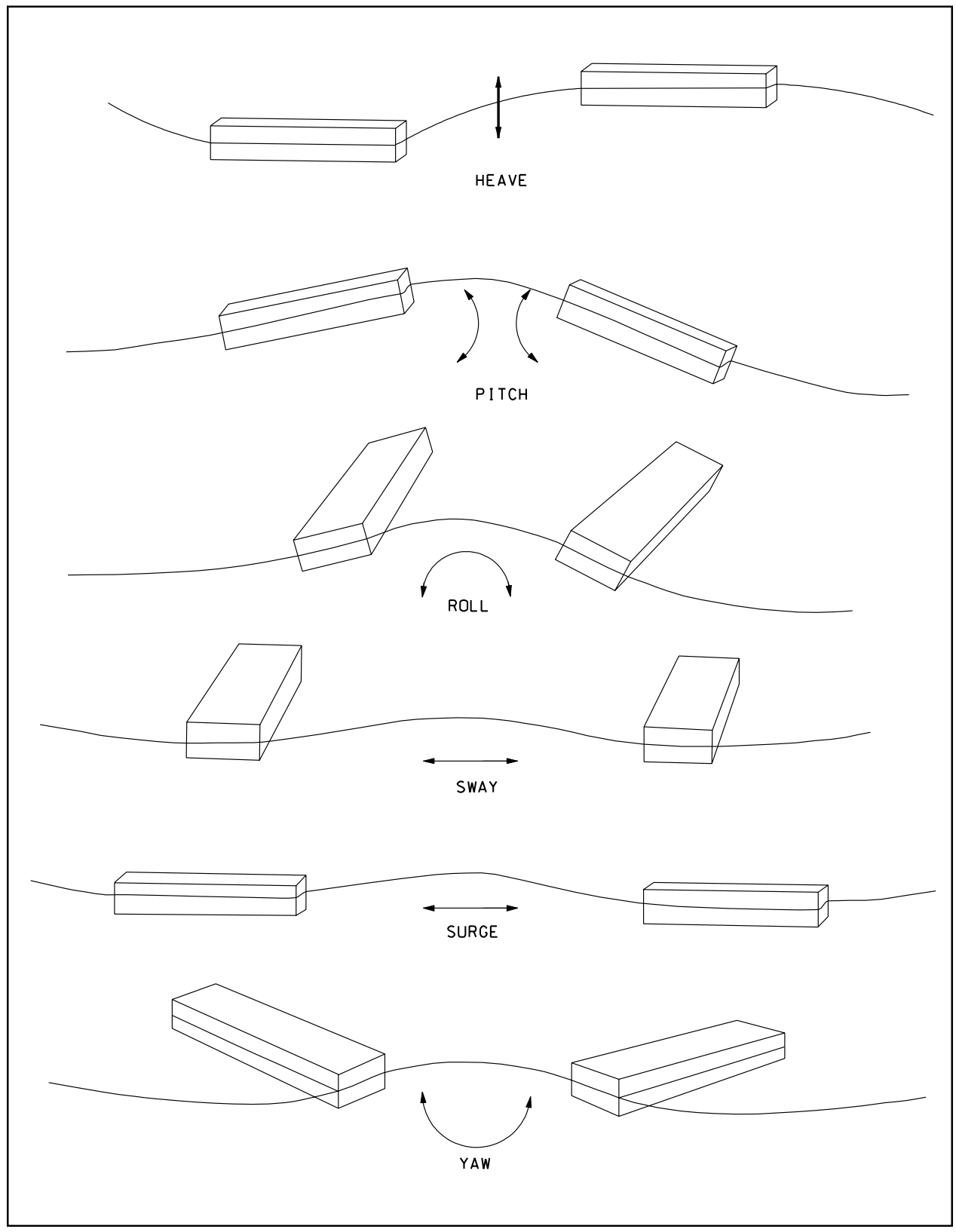

Figure 2-1. Six degrees of motion of a vessel in water

used to keep a floating structure in station against environmental forces is known as the "stationkeeping system." The most common stationkeeping system is the mooring system. The mooring dolphin, tugboats, and dynamic positioning are sometimes also used for stationkeeping.

Spread moorings are the most common stationkeeping system for marine construction. In float-in construction, moorings are used to hold a float-in segment in position while it is being ballasted down onto prepared foundation. Figure 2-2 presents an example of using the mooring system for installation of a float-in dam segment. 


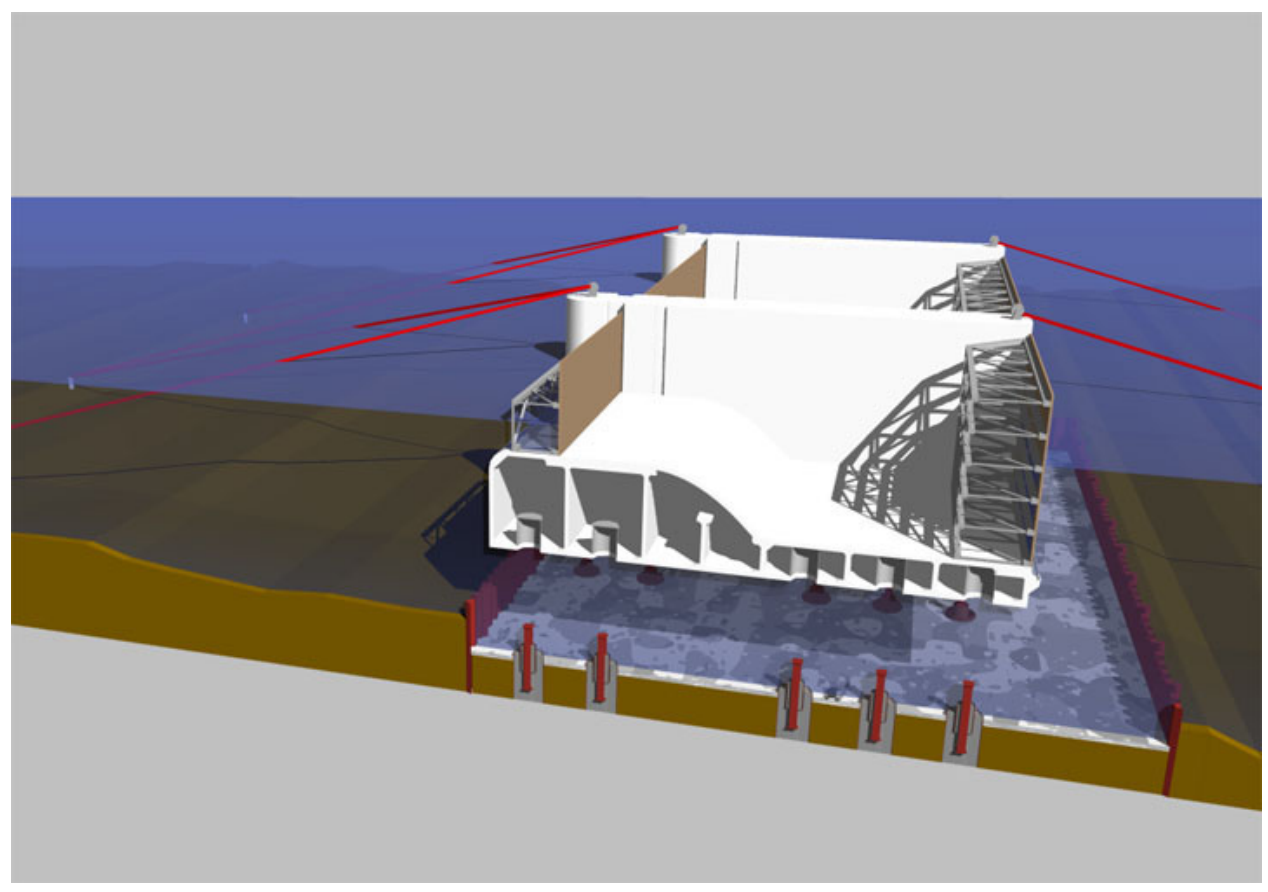

Figure 2-2. Moorings are used to position a float-in dam segment

In lift-in construction, moorings are used for positioning crane barges as well as other construction vessels. Figure 2-3 illustrates use of a spread mooring system for positioning of various construction barges in the lift-in construction of a navigation dam.

Stationkeeping maintains a vessel or a floating structure within a specified range of positions, but it cannot hold it to a fixed position for an extended period of time. The vessel will oscillate under the influence of dynamic environmental forces. The deviation from a specified location is called "offset." In inland waterways, offsets of a moored vessel typically range from several inches to a few feet, depending on environmental conditions.

In float-in or lift-in construction, large prefabricated structural segments need to be held in a fixed position for an extended time while "tie-in" of the segments to foundation is being constructed. Stationkeeping systems alone may not accomplish this objective. This necessitates use of mechanical devices to guide, adjust, and lock these segments to their installed positions. The mechanical device used for guiding the positioning is known as the "guide system." Typical guide systems are horn guides, flat- jacks, hydraulic rams, stabbing guides, master piles, and dolphins. Many of these guides incorporate cushions or bumpers to reduce the impact.

Selection and design of proper stationkeeping and guide systems are a critical part of the float-in or lift-in construction. The designer should check the holding capacity of the positioning system against the specified alignment requirements. A practical approach is for the designer to consult with local towing groups to 


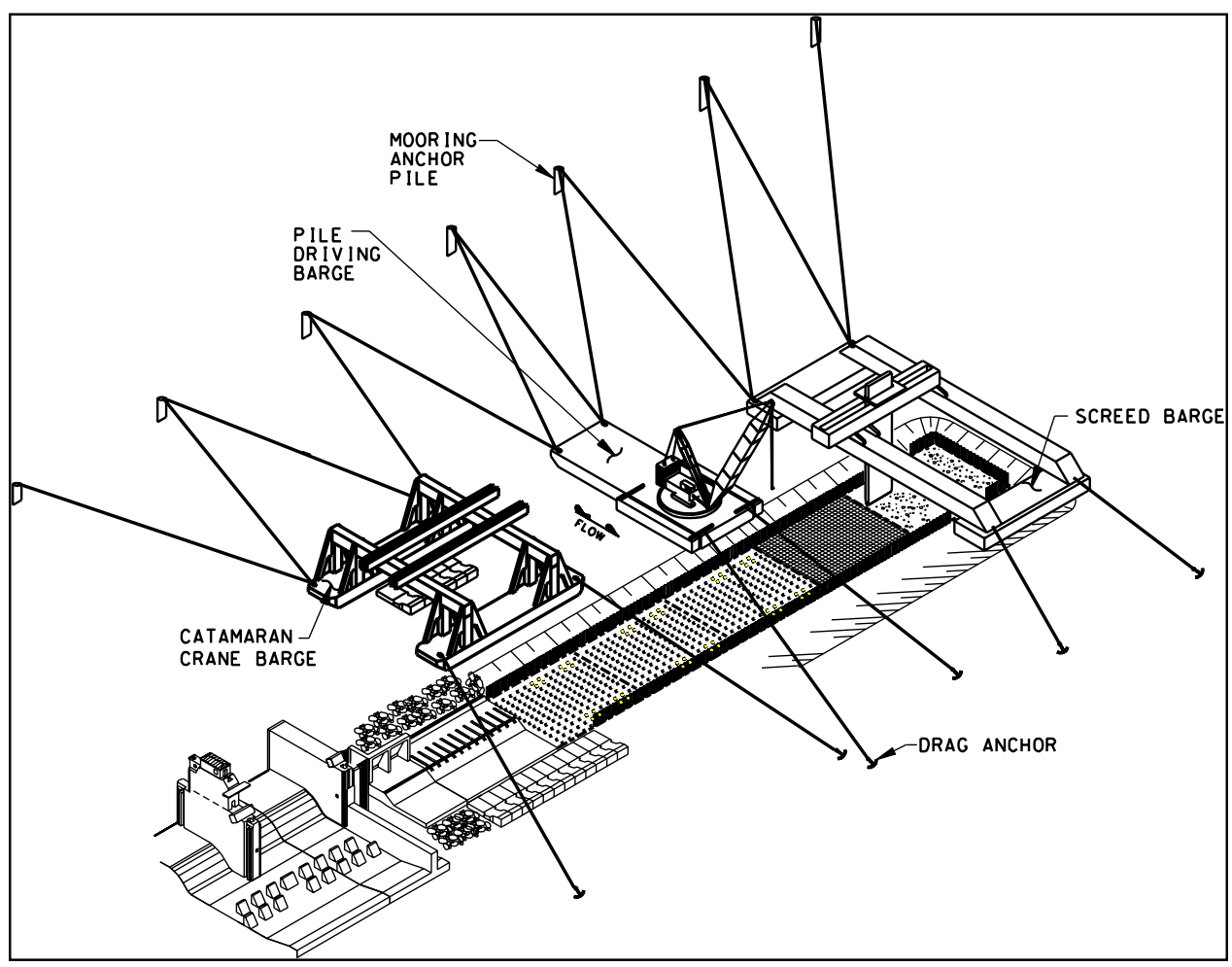

Figure 2-3. Moorings are used to position a catamaran crane, a pile-driving barge, and a screed barge in the lift-in construction of a navigation dam

develop an understanding of the mooring practices used in the particular region. The designer can then compare the results of this research with what the analytical results provide.

Adequate design consideration should be given to the environmental conditions, and possible interaction between the stationkeeping and guide systems. During underwater installation, a prefabricated segment is often engaged onto one or more guide systems. At this stage, the relative stiffness of these systems will at least in part determine the load sharing and internal force distribution of the segment. Overloading either the mooring system or guide system, especially by impact, could lead to breakup of the guides and loss of segment control.

Positioning operations require accurate position surveys on a real-time basis. Past experience shows that, in inland waterways, it is more reliable and expedient to employ land-based survey methods (e.g., lasers, total stations, GPS) than to use sonic devices underwater. Survey towers are mounted onto the corners of the segment and project above water. The land-based survey instrument spots predetermined targets on the towers to determine the real-time location of the segment. The segment's attitude can also be monitored by using a dual-axis inclinometer and its heading determined using multiple GPS receivers.

For vertical positioning control, level instruments on land are often used to spot marked projections above water. Alternatively, multifrequency, narrowbeam transducers may be used to detect the depth to the riverbed. The underwater 
survey provides real-time monitoring of the riverbed condition within the footprint of the segment.

\section{2-2 Evaluation of Environmental Effects on Positioning}

For the design of positioning systems, environmental data are mainly historical records of wind, current, and waves at the project site. Statistical models are often applied to assess the maximum and operating conditions. When collecting data, the site-specific relationships must be considered, because the assumption of taking the combined maximum of each environmental force usually produces overly conservative designs.

The direction and frequency content of wind force, current force, and, possibly, wave force, have a decisive impact on selection of suitable positioning systems. In general, environmental effects can be divided into three categories for analysis and design:

a. Mean drift forces.

b. Low-frequency forces.

c. High-frequency forces.

Figure 2-4 shows these three components of environmental forces. The mean drift motions are induced by the steady-state components of environmental forces. For a given stationkeeping system, the "mean offset" is defined as the vessel displacement from a specified position due to a set of steady environmental forces.

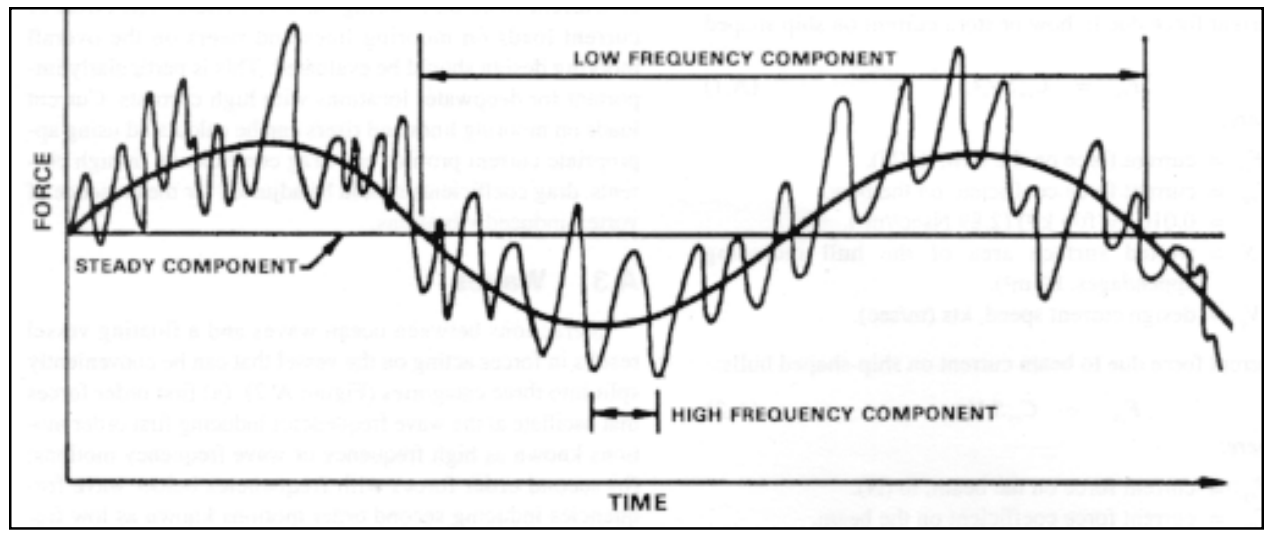

Figure 2-4. Three components of the environmental forces 
Low-frequency motion is slow oscillation of a vessel. It is typically narrowbanded in frequency. The motion amplitude of a moored vessel is dependent on the stiffness and damping of the mooring system. In inland waterways, the lowfrequency forces do not play a significant role for the vertical motions (i.e., roll, pitch, and heave motions). However, the low-frequency forces may sometimes be substantial for the horizontal motions (surge, sway, and yaw), since the only restoring force present is mooring line forces.

High-frequency motions are primarily caused by high-frequency waves. In inland waterways, waves are mainly caused by wind or passing vessels. Since wave forces in rivers are generally much smaller than current or wind forces, wave forces are sometimes empirically accounted for in design of positioning systems by use of high safety factors. However, the dynamic effects of waves on positioning accuracy for installation of float-in or lift-in segments cannot be overestimated.

In general, accurate determination of the high- and low-frequency environmental forces requires computer analysis of these dynamic motions. In practice, however, sophisticated computer programs are rarely used in the design of positioning systems for inland waterways. Quasi-static analysis is usually sufficient for the design.

The quasi-static analysis treats the design force as a sum of steady (static) loads and unsteady (dynamic) loads. The steady loads are mainly the steady wind, current, and wave drift forces. The unsteady loads may arise during positioning as a result of wind gust, clapotis (obstruction of wave by a large segment), vortex shedding, or the Bernoulli effects.

The design load criteria for quasi-static analysis usually follow the prevailing criteria for barges or vessels in a given environment. The load criteria in the following sections are based primarily upon the relevant criteria from the American Bureau of Shipping (ABS 1985) and U.S. Army Corps of Engineers (USACE 1984).

\section{2-2-1 Wind}

Wind forces are usually estimated with one of the following two methods:

a. Wind forces are treated as constant and calculated on the basis of a 1-min sustained wind speed.

$b$. Fluctuating wind force is calculated on the basis of a steady component (on the 1-hr average velocity), plus a time-varying component calculated from an appropriate empirical wind gust spectrum. The time-varying component in the second method is also known as low-frequency wind force. 
Although the analysis method for calculating low-frequency wind force has been extensively studied, there is still a substantial degree of uncertainty with the method, particularly in the wind energy spectrum derived from wind data.

For quasi-static mooring analysis, wind force is typically treated as a steady force on the basis of statistical analysis of wind data. The 1-min sustained wind speed may be increased by up to 12 percent for gusts, depending on the statistical analysis.

The design wind loads for both operating and survival conditions can be calculated as follows:

$$
\begin{aligned}
& P=0.615 V^{2} C_{h} C_{s} \quad\left(P=0.0034 V^{2} C_{h} C_{s} \text { in non-SI units }\right) \\
& F_{w}=P A_{w}
\end{aligned}
$$

where

$P=$ wind pressure, $\mathrm{Pa}(\mathrm{psf})$

$V=$ design wind speed based on the average velocity, $\mathrm{m} / \mathrm{s}$ (knots)

$C_{h}=$ height coefficient, as defined in Table 2-1

$C_{s}=$ shape coefficient, as defined in Table 2-2

$F_{w}=$ current forces, $\mathrm{N}(\mathrm{lb})$

$A_{w}=$ vertical projected area of the segment above water, $\mathrm{m}^{2}\left(\mathrm{ft}^{2}\right)$

In using Equation 2-1, the following procedures are recommended:

a. The projected area exposed to the wind $\left(A_{w}\right)$ should include all columns, deck members, deckhouses, and cranes.

$b$. Areas exposed due to heel, such as underdecks, etc., are to be included using appropriate shape coefficients in Table 2-2.

c. While isolated houses, cranes, etc. are to be calculated individually using the shape coefficient in Table 2-2, a clustering of deckhouses may be accounted for by using a projected block area, assuming a shape coefficient of 1.1 .

Open truss work commonly used for derrick towers or booms may be approximately accounted for by taking 30 percent of the projected block area of both the front and back sides, i.e., 60 percent of the projected block area of one side for double-sided truss work. 
Table 2-1

Values of Height Coefficient, $C_{h}$

\begin{tabular}{||l|l|l|l|l||}
\hline \multirow{2}{*}{ Description } & \multicolumn{4}{|c||}{ Value of $\boldsymbol{C}_{\boldsymbol{h}}$} \\
\cline { 2 - 5 } & $\mathbf{1 . 0 0}$ & $\mathbf{1 . 1 0}$ & $\mathbf{1 . 2 0}$ & $\mathbf{1 . 3 0}$ \\
\hline \hline \multirow{2}{*}{$\begin{array}{l}\text { Height from water surface to center } \\
\text { of design surface area }\end{array}$} & $0-15 \mathrm{~m}$ & $15-50 \mathrm{~m}$ & $30-46 \mathrm{~m}$ & $46-61 \mathrm{~m}$ \\
$(0-50 \mathrm{ft})$ & $(50-100 \mathrm{ft})$ & $(100-150 \mathrm{ft})$ & $(150-200 \mathrm{ft})$ \\
\hline \hline
\end{tabular}

\section{Table 2-2}

Values of Shape Coefficient, $C_{s}$

\begin{tabular}{||l|l||}
\hline \hline Shape of Components & Shape Coefficient, $\boldsymbol{C}_{\boldsymbol{s}}$ \\
\hline \hline Hull & 1.0 \\
\hline Deckhouse & 1.0 \\
\hline Isolated structural shape (cranes, angles, channels, etc.) & 1.5 \\
\hline Cylindrical shape (all sizes) & 0.5 \\
\hline Rig derrick & 1.25 \\
\hline Keel plate (smooth) & 1.0 \\
\hline Keel plate (exposed beams and girders) & 1.3 \\
\hline \hline
\end{tabular}

\section{2-2-2 Current}

Although the river current velocity varies over the depth (Figure 2-5), the mean cross-sectional velocity is frequently used as the basis for calculation of the current forces. The mean velocity is defined as the riverflow rate divided by the cross-sectional area of the river at a project location.

Current force is normally treated as a steady-state force. In inland waterways, current is often the most influential environmental force on vessels and floating segments. Current forces can be estimated as follows:

$$
\begin{aligned}
& C=C_{s} \frac{W V^{2}}{2} \\
& F_{c}=C A_{c}
\end{aligned}
$$

where

$$
\begin{aligned}
& C=\text { current pressure in } \mathrm{Pa}(\mathrm{psf}) \\
& C_{s}=\text { shape coefficient (taken from Table 2-2) } \\
& W=\text { specific weight of water in } \mathrm{kg} / \mathrm{m}^{3}(\mathrm{pcf}) \\
& V=\text { mean cross-sectional current velocity in } \mathrm{m} / \mathrm{s}(\mathrm{ft} / \mathrm{s})
\end{aligned}
$$




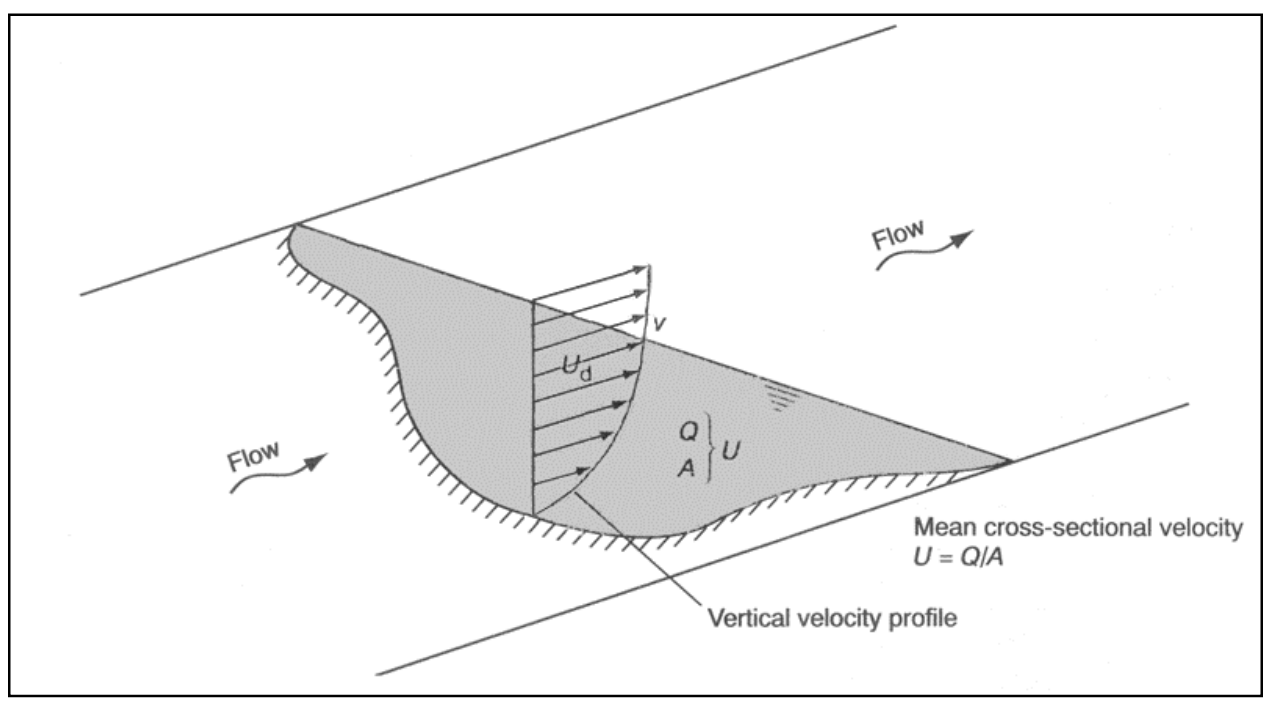

Figure 2-5. Flow velocity variations over a cross section of the river

$F_{c}=$ current force in $\mathrm{N}(\mathrm{ft} / \mathrm{s})$

$A_{c}=$ vertical projected area of the segment below water

In addition to exerting current pressure on vertical surfaces, current flowing over a submerged surface or under the base of a floating structure may create eddy flow patterns around its corners. Current may also produce a vertical uplift or downdrag forces on the horizontal surfaces due to the Bernoulli effect or vortex shedding. Figure 2-6 illustrates these vertical current pressures on an immersed tube. These vertical current pressures are transient in nature and often difficult to quantify. However, their effects on positioning of large prefabricated segments should be carefully considered in the design and in construction planning.

\section{2-2-3 Wave}

Waves in rivers are mostly driven by wind. Such waves can be typically characterized by significant wave height (average of the highest one-third wave heights) and significant wave period. Because of the complexity of actual wave patterns and the large number of variables involved, the wave design cannot generally achieve the same degree of accuracy as for wind and current.

The design significant wave height should be determined based on the hydrological and meteorological data and on the design recurrence period. The significant wave height may be empirically correlated with the wind speed and the fetch (the distance that the wind blows over open water) with the following formula (Gerwick 2000): 


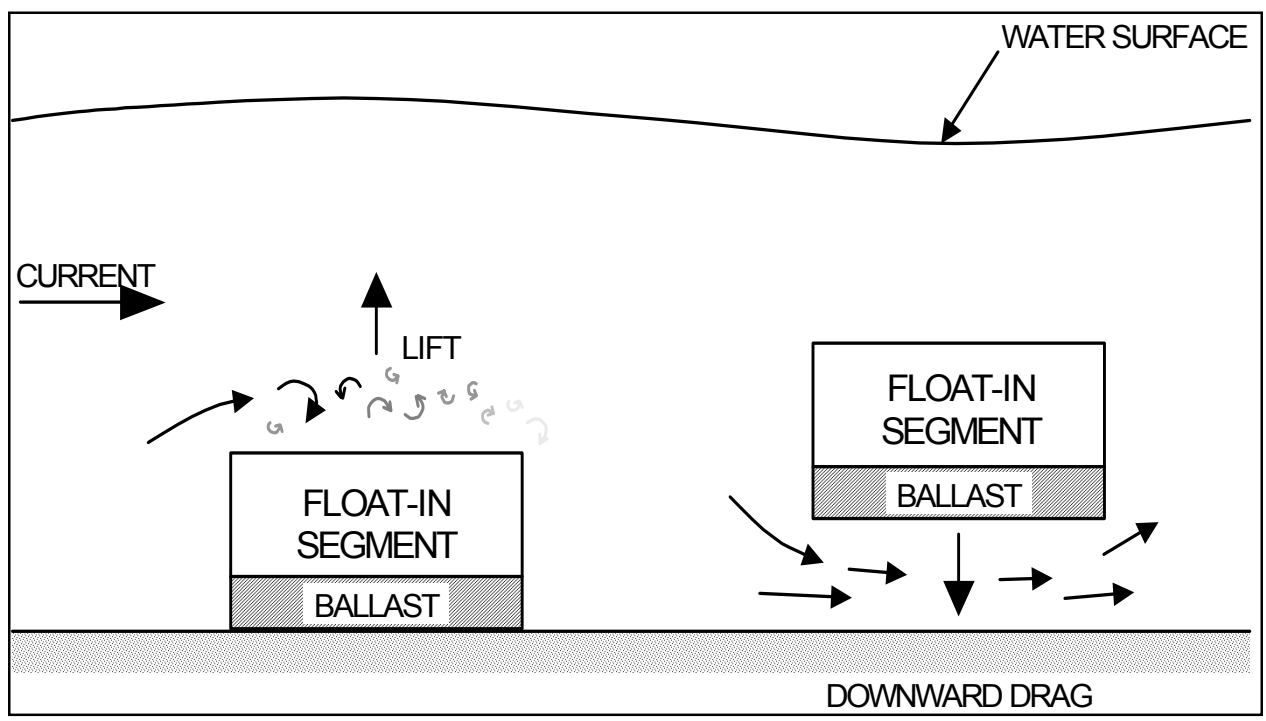

Figure 2-6. Current-induced uplift/downward force on a float-in segment

$$
H_{s}=\frac{\sqrt{V F}}{30} \quad\left(H_{s}=\frac{\sqrt{V F}}{6} \text { in non-SI units }\right)
$$

where

$$
\begin{aligned}
& H_{s}=\text { significant wave height, } \mathrm{m}(\mathrm{ft}) \\
& V=\text { wind velocity, } \mathrm{km} / \mathrm{hr}(\text { miles } / \mathrm{hr}) \\
& F=\text { fetch, } \mathrm{km} \text { (miles) }
\end{aligned}
$$

If wind blows over a fetch of 10 miles at a speed of $30 \mathrm{mph}$, the empirical equation gives a wave height of about $3 \mathrm{ft}$. In inland waterways, the wave effects on vessels vary greatly from site to site, depending on the fetch and wind speed. For example, at the Olmsted Locks and Dam site, located on the lower Ohio River in Illinois, fetch upstream is more than 10 miles. Strong wind at the site often creates 6- to 7-ft waves. On the other hand, the Braddock Dam site, located in the lower Monongahela River system in Pennsylvania, has little fetch in either direction. Thus, the wave effects can be neglected.

Most wave equations are derived from experimental studies and measurements in the open-sea conditions. In inland waterways, the fetch must be reduced to account for the river width restriction on the total amount of energy transferred from wind to water. The "effective fetch" can be calculated in accordance with the method shown in Figure 2-7 (USACE 1984). This method consists of constructing 15 radials from the wave station " $A$ " at intervals of 6 deg and extending these radials until they intersect the riverbank. The projected component of each radial length in the direction of the wind is calculated. The 


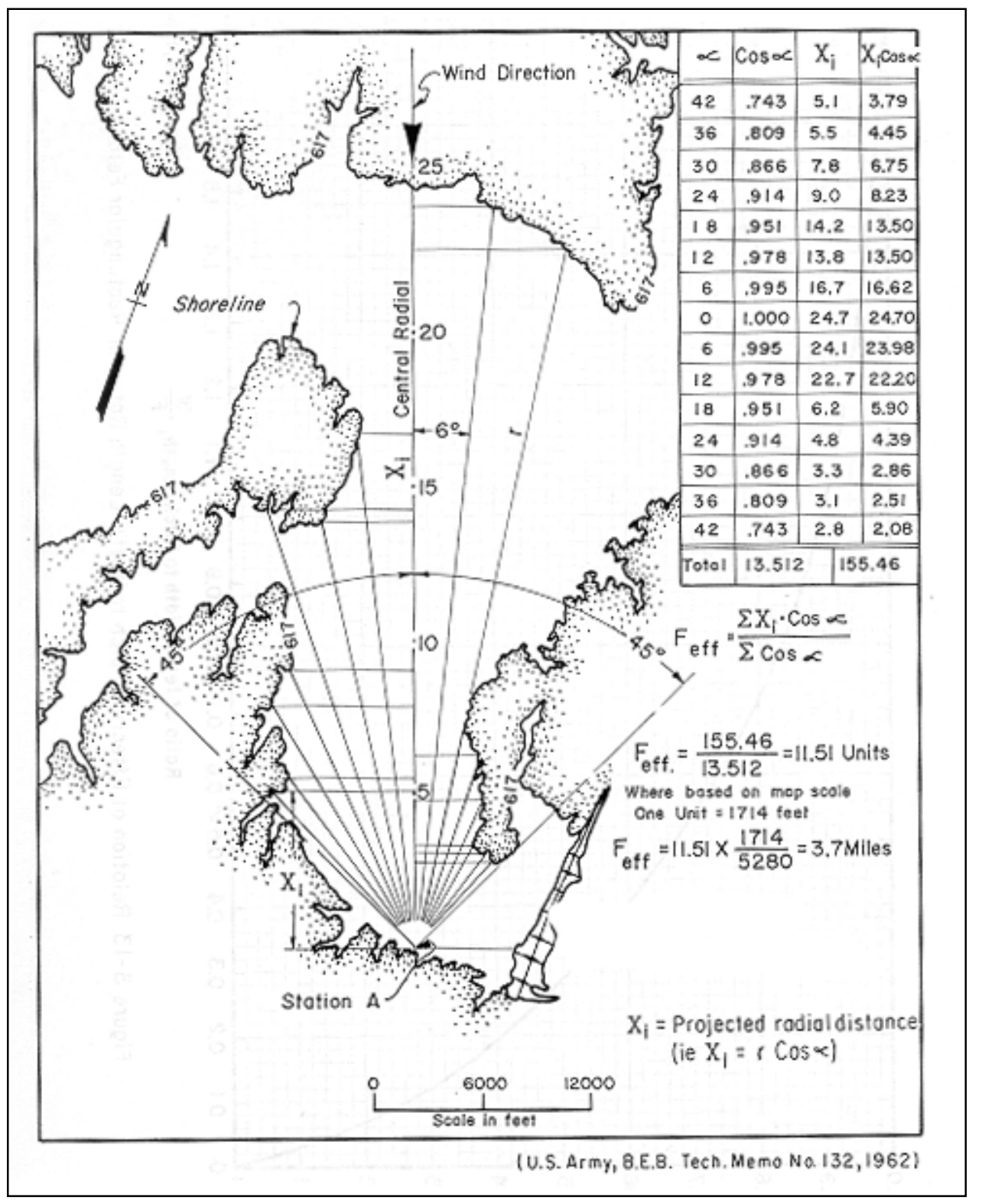

Figure 2-7. Definition of the effective fetch

effective fetch is the weighted sum of all the components of the radials with the cosine of the angle between the radial and the wind as the weighting factor.

The wave drift phenomenon is a result of the orbital motion displacement of the water particles in each wave cycle. The water particles move faster at the top of the circle than at the bottom, which causes a net forward horizontal movement of the water at the crest. Assuming no wind or current, waves would cause a vessel to slowly drift in the direction of the wave travel.

The wave drift force is a slowly varying force that is proportional to the square of wave heights. When the significant wave height exceeds $3 \mathrm{ft}$, the wave 
drift force should be considered for the design of moorings and positioning guides. The design wave drift force may be treated as a steady force and calculated based upon the Maruo's formula (Maruo 1960) as follows:

$$
F_{d r i f t}=\frac{1}{2} W g \frac{H_{s}^{2}}{4}\left(B \cos ^{2} \alpha+L \sin ^{2} \alpha\right)
$$

where

$$
\begin{aligned}
F_{d r i f t} & =\text { mean wave drift force }(\mathrm{N} \text { or } \mathrm{lb}) \\
W & =\text { specific weight of water }\left(\mathrm{kg} / \mathrm{m}^{3} \text { or } \mathrm{pcf}\right) \\
g & =\text { gravity }\left(\mathrm{m} / \mathrm{s}^{2} \text { or } \mathrm{ft} / \mathrm{s}^{2}\right) \\
H_{s} & =\text { significant wave height }(\mathrm{m} \text { or } \mathrm{ft}) \\
B & =\text { segment width }(\mathrm{m} \text { or } \mathrm{ft}) \\
\alpha & =\text { wave angle toward the vessel axis } \\
L & =\text { segment length }(\mathrm{m} \text { or } \mathrm{ft})
\end{aligned}
$$

Figure 2-8 illustrates the parameters in Equation 2-4.

The total resultant steady load $(F)$ on a vessel can be calculated as a sum of steady wind force, current force, and mean wave drift force:

$$
F=F_{w}+F_{c}+F_{d r i f t}
$$

Adequate considerations must be given to the unsteady effects in the design. For example, if a relatively narrow river is blocked by a large float-in segment, the current flow will increase and flow pattern changes substantially near the segment, creating ebb and vortex around the segment, as shown in Figure 2-9.

In swift-flowing rivers, rapid variations of current forces and directions are the main causes for dynamic oscillation of vessels. The level of turbulence is commonly defined in terms of turbulence intensity, which is basically a measurement that reflects the variation

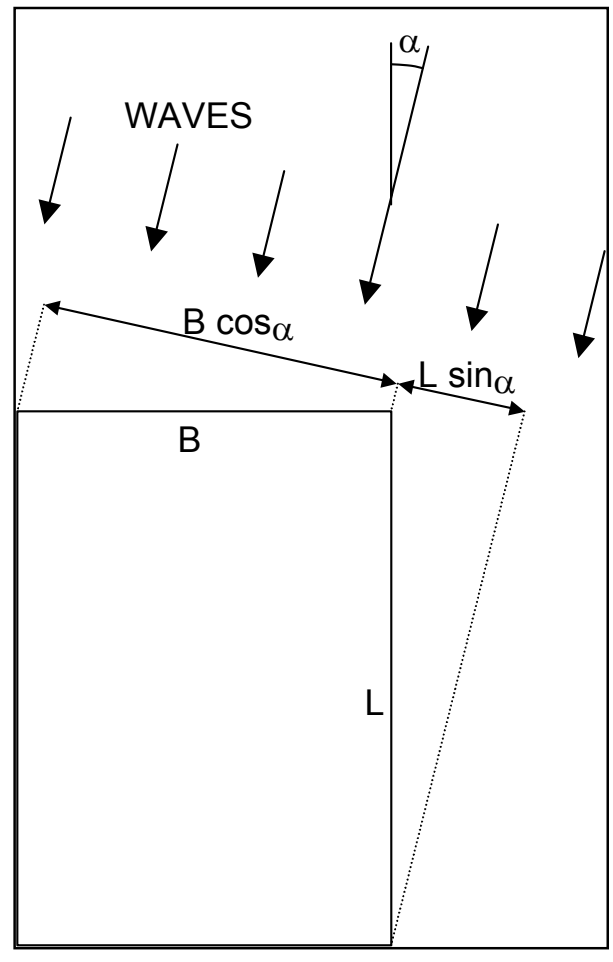

Figure 2-8. Drift wave force (from Maruo 1960) 


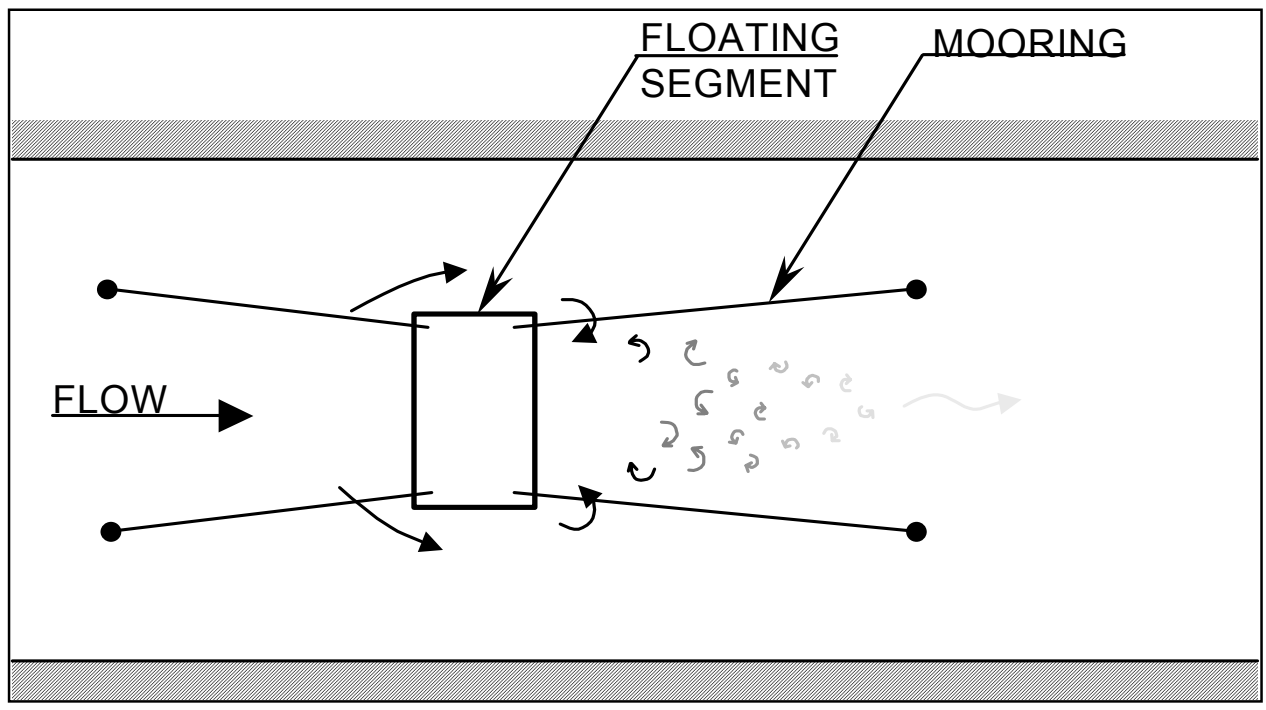

Figure 2-9. Vortex-shedding around a moored floating segment

of flow velocity relative to its mean. Quantification of the turbulence intensity usually requires hydraulic model tests.

Model tests have been conducted to evaluate the positioning of large float-in segments (Figure 2-10). Extensive studies show that a moored rectangular segment with around corners may be subjected to vortex-shedding with turbulence intensity of 0.35 to 0.5 . In this case, the vortex-shedding may induce excessive dynamic excursions. Past project experience, however, indicates that actual movements of large float-in segments are usually much less than those anticipated by model tests. This discrepancy is primarily contributed to the scale effects (e.g., the Reynolds number and skin friction) associated with the model tests. In general, it is difficult to correctly quantify the scale effects. Extrapolation of model test results to full scale often leads to safe and, sometimes, excessively conservative predictions.
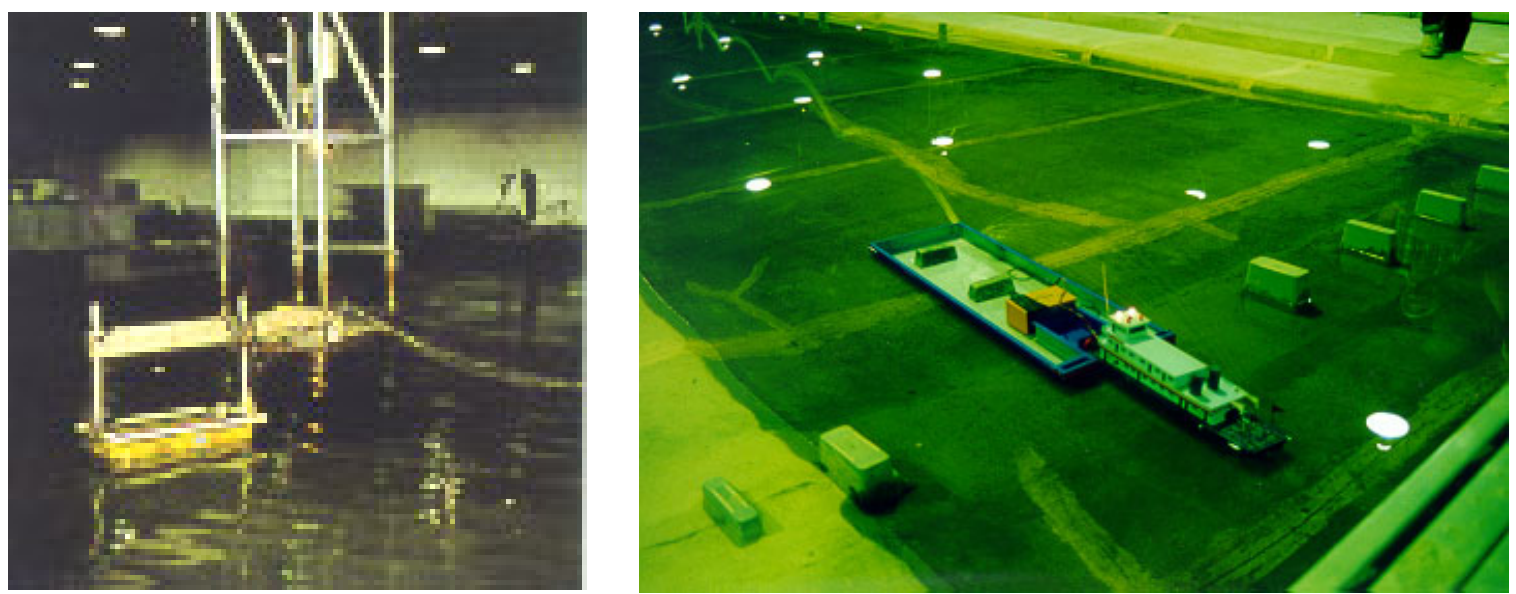

Figure 2-10. Hydraulic model tests for float-in modular segments 
When significant waves are present at a project site, wave surges may induce considerable unsteady force on a floating segment. The wave surge phenomenon is similar to the wave pressure against breakwater or seawalls. The wave pressure against vertical walls consists of (1) the hydrostatic pressure that varies as the wave rises and falls along the wall and (2) the dynamic pressure due to turbulent water and the compression of entrapped air pockets. Nonbreaking waves contain only the first component, while breaking waves comprise both components.

Waves in rivers are mostly nonbreaking waves. When waves impact against one side of a vessel, they are fully reflected, creating a standing wave known as clapotis. Figure 2-11 shows a typical wave clapotis and corresponding hydrostatic pressure on a float-in modular segment. The hydrostatic wave pressure due to the standing waves can be estimated according to the Miche-Rundgren formula as follows (USACE 1984):

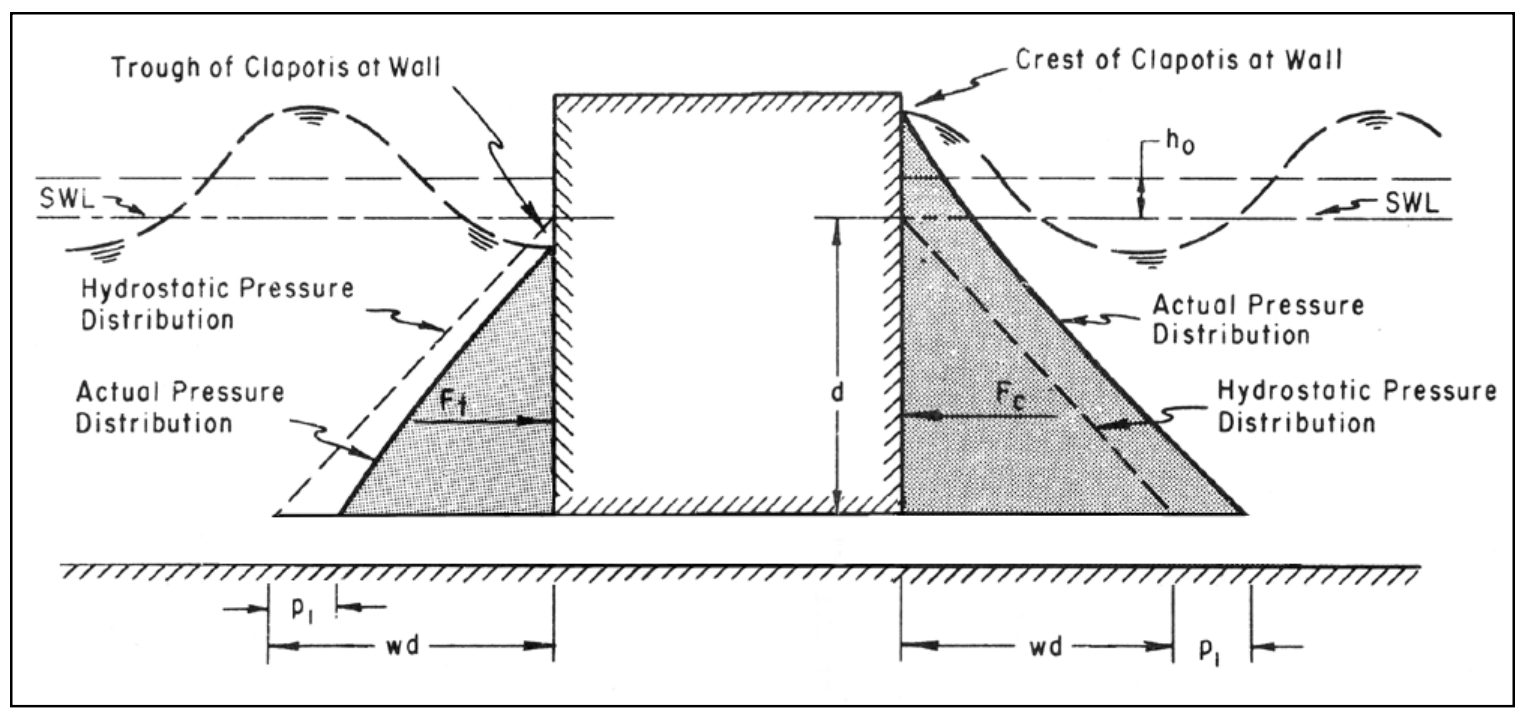

Figure 2-11. Wave pressure distribution for nonbreaking waves

$$
p_{1}=\left(\frac{1+\chi}{2}\right) \frac{w H_{i}}{\cosh (2 \pi d / L)}
$$

where

$$
\begin{aligned}
& p_{1}=\text { additional water pressure increase due to clapotis, } \mathrm{Pa}\left(\mathrm{lb} / \mathrm{ft}^{2}\right) \\
& \chi=\text { wave reflection coefficient (typically } 0.9-1.0) \\
& w=\text { water density } \\
& H_{i}=\text { wave height when the floating object does not exist, } \mathrm{m}(\mathrm{ft}) \\
& d=\text { depth from the keel to the still-water level, } \mathrm{m}(\mathrm{ft}) \\
& L=\text { wavelength, } \mathrm{m}(\mathrm{ft})
\end{aligned}
$$


The U.S. Army Corps of Engineers' "Shore Protection Manual" (USACE 1984) contains design aids for the above calculation method.

Breaking waves may occur during major storms or in a coastal environment. Figure 2-12 illustrates force distribution diagrams of the breaking waves and current on a float-in segment. The breaking wave force may be estimated on the basis of the Minikin's theory (USACE 1984) as follows:

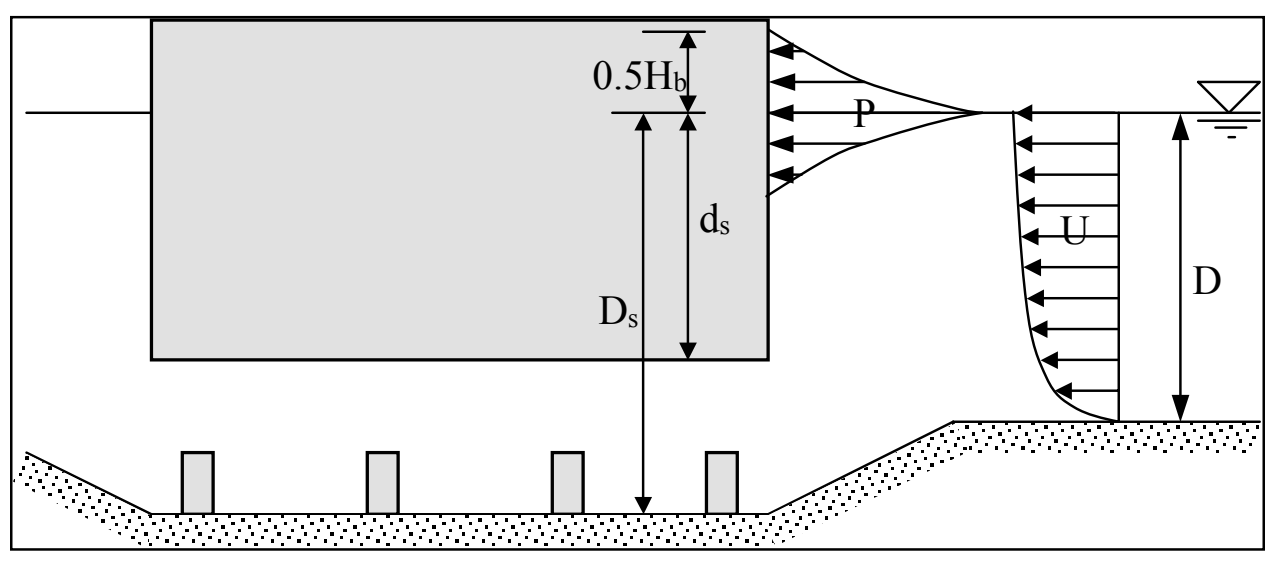

Figure 2-12. Wave force $(P)$ and current force $(U)$ distribution on a float-in segment

$$
\begin{aligned}
& p=101 w H_{b} \frac{d_{s}}{L}\left(1+\frac{d_{s}}{D_{s}}\right) \\
& F_{b w}=\frac{1}{3} H_{b} p
\end{aligned}
$$

where

$$
\begin{aligned}
p & =\text { peak wave pressure at the still-water level, } \mathrm{Pa}\left(\mathrm{lb} / \mathrm{ft}^{2}\right) \\
w & =\text { specific weight of water, } \mathrm{kg} / \mathrm{m}^{3}\left(\mathrm{lb} / \mathrm{ft}^{3}\right) \\
H_{b} & =\text { breaking wave height, } \mathrm{m}(\mathrm{ft}) \\
d_{s} & =\text { draft of the segment, } \mathrm{m}(\mathrm{ft}) \\
D_{s} & =\text { water depth, } \mathrm{m}(\mathrm{ft})
\end{aligned}
$$

$F_{b w}=$ breaking wave force per unit length of a segment, $\mathrm{N} / \mathrm{m}(\mathrm{lb} / \mathrm{ft})$

The breaking wave forces are generally used for design of contingency moorings against major storms or floods, rather than for positioning analysis. For contingency moorings, use $H_{b}=2 H_{s}$. 
In practice, the unsteady environmental effects are difficult to predict to an acceptable accuracy. A practical approach is to minimize the unsteady effects by selection of proper work windows for positioning and installation.

\section{2-3 Positioning of Float-in Segments}

Onsite installation of a float-in modular segment requires both horizontal and vertical positioning control to meet the alignment tolerance requirements. Alignment of the segment often refers both to the previously placed segment and to global coordinates. For a typical navigation structure, the alignment tolerances for a float-in segment are usually specified within $50 \mathrm{~cm}$ horizontally and 13 to $25 \mathrm{~cm}$ vertically.

Positioning of a float-in segment by stationkeeping systems entails two separate actions: adjusting the (time) average position of the segment and controlling its dynamic motions. The general requirements for these actions are that (1) the (time) average position of a float-in segment prior to the setdown should be exactly at the specified location and (2) the dynamic motions of the segment should be within the specified tolerances. These two actions are discussed in detail below.

Adjustment of the (time) average position is accomplished by active control of mooring lines with winches and/or tugs. In many cases, winches are mounted onto the float-in segment or on a nearby fixed structure. Alternatively, moored tugs pull the segment in opposite directions to facilitate fine adjustments of its average position.

The mooring pattern for positioning does not change during the setdown process. However, a float-in segment will be subjected to more current force and less wind force as the immersion proceeds. Therefore, engineering calculations of the pull forces from the winches or tugs should account for all the changes in the current force and wind force during the immersion process.

A moored float-in segment always oscillates around the average position under dynamic disturbance. In rivers, magnitudes of this oscillation usually range from a few inches to a few feet. Two common methods are used to limit the dynamic motions to an acceptable level: (1) choosing a work window that has relatively low environmental disturbance and (2) using a stiff mooring system.

The work window for the setdown of a float-in segment should be timed to ensure small wind and current. Typically, after a float-in segment is moored at the project site before its final setdown, a weather check is made. If mild weather and river conditions are forecast for the next 48 to $72 \mathrm{hr}$, ballasting will be initiated. If, on the other hand, unstable weather is forecast, the segment will be disconnected from the mooring lines and towed back to a contingency mooring site.

The concept of using a stiff mooring system for positioning control is discussed in detail in Chapter 4 of this report. In general, dynamic motions of a 
moored vessel are directly proportional to the stiffness of the mooring system. The stiffness of a mooring is to a large extent determined by the pretension force in the mooring lines. For onsite installation of float-in segments, winches or tugs are often used to pretension mooring lines. When the segments are subjected to environment loads, the dynamic loads are balanced by the pretension in the lines. As a result, the pretensioning significantly reduces dynamic deflections of the segment.

Tugs or towboats are sometimes used for positioning control. Figure 2-13 shows use of tugs for positioning an anchor block of the Great Belt Link East Bridge. The float-in anchor block had dimensions of 122 by 55 by $16 \mathrm{~m}$. Six tugs were used in tandem to exert up to 60-ton pulling forces. The pulling forces pretensioned the taut mooring lines to control positions of the block. To further minimize the dynamic motions, the tugs themselves are moored to preinstalled anchor piles. Chapter 3 contains detailed descriptions of the positioning methods used in this project.
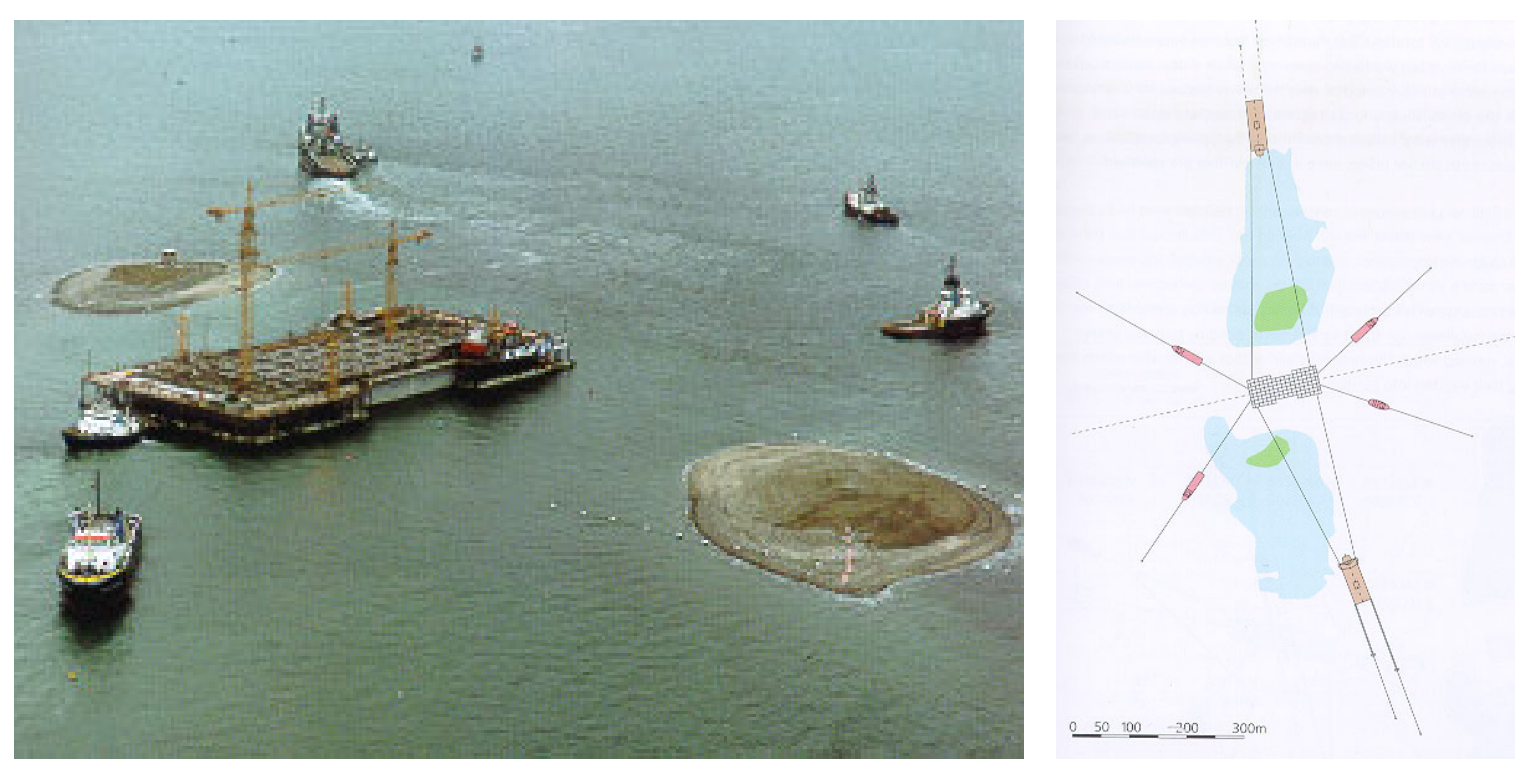

Figure 2-13. Tugs and mooring arrangement to position a float-in bridge anchor block

Underwater installation of a float-in segment is often controlled from a central control room. The positioning control is operated on the basis of real-time data, including (1) positions of the segment, (2) draft/trim of the segment, and (3) mooring line tension. For horizontal positioning, the instantaneous position of the moving segment and the average (mean) position over the last 3 to $5 \mathrm{~min}$ are recorded and displayed on the control board screen. An example of such realtime positioning survey feedback is shown in Figure 2-14 for a float-in bridge anchor block.

Table 2-3 provides the common survey methods and achievable accuracy for collecting the essential information during positioning and setdown of a float-in segment. 


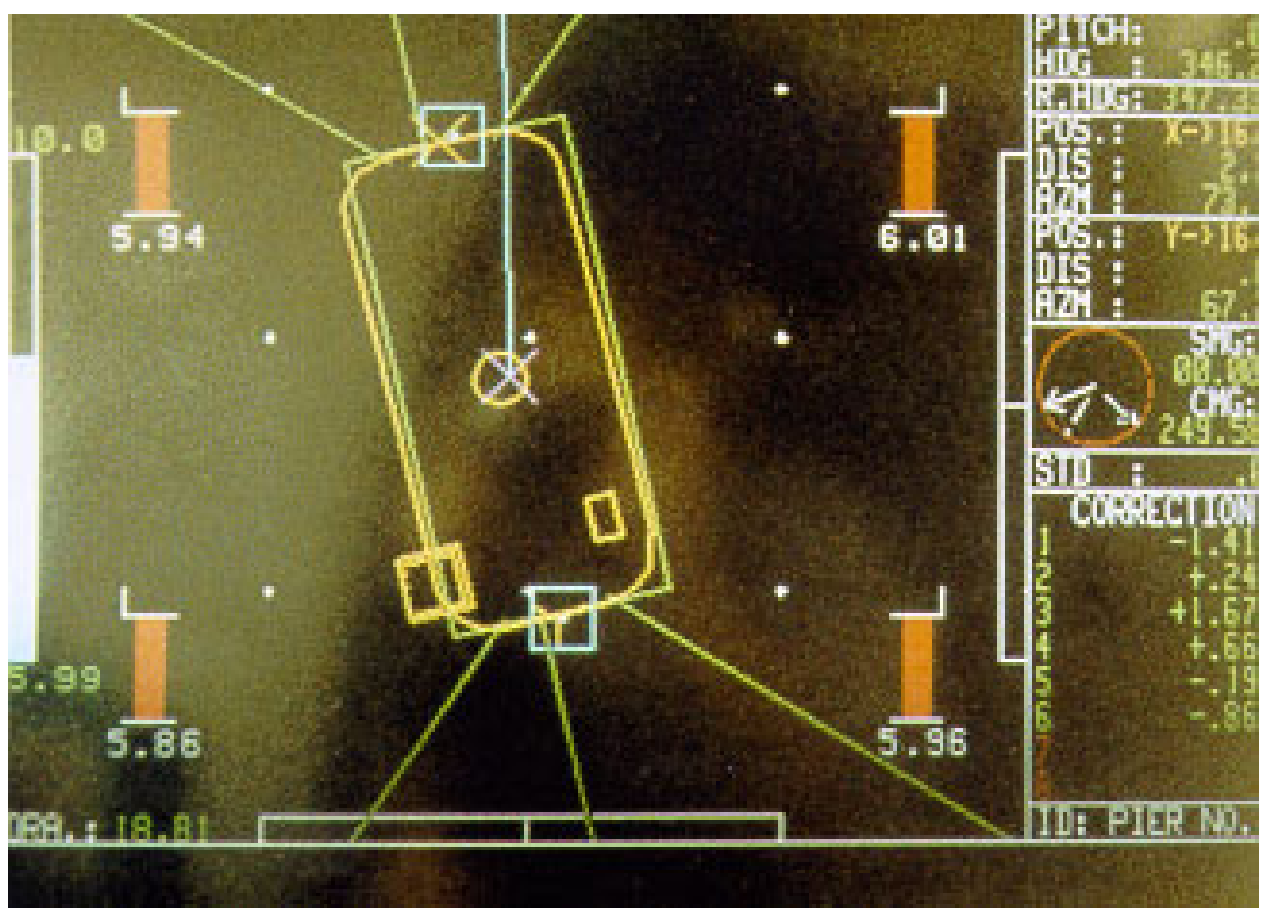

Figure 2-14. Display of real-time position data during underwater installation

\begin{tabular}{|c|c|c|}
\hline \multicolumn{3}{|c|}{$\begin{array}{l}\text { Table 2-3 } \\
\text { Summary of Common Survey Methods }\end{array}$} \\
\hline Measurements & Methods & Accuracy Required \\
\hline Compartment fill levels & $\begin{array}{l}\text { Paint-marked (floating or fixed) sounding } \\
\text { device } \\
\text { Piezometers }\end{array}$ & $1-5 \mathrm{~cm}$ \\
\hline Trim/heel & $\begin{array}{l}\text { Pendulum } \\
\text { Land-based survey of spotting targets on } \\
\text { float-in segments }\end{array}$ & $\pm 0.02 \mathrm{deg}$ \\
\hline Depth and bottom clearance & $\begin{array}{l}\text { Land-based survey of targets on survey } \\
\text { towers and/or underwater acoustic device }\end{array}$ & $\pm 1 \mathrm{~cm}$ \\
\hline Pump rate & Flowmeter & 1.5 percent \\
\hline Current and wind & $\begin{array}{l}\text { Hydrological and meteorological site } \\
\text { surveys }\end{array}$ & $\begin{array}{l} \pm 0.3 \mathrm{~m} / \mathrm{s} \text { for current; } \\
\pm 1 \mathrm{~m} / \mathrm{s} \text { for wind }\end{array}$ \\
\hline Bottom profile & Acoustic device & $\pm 10 \mathrm{~cm}$ \\
\hline
\end{tabular}

Draft, trim, and heel of a float-in segment are generally controlled by a ballasting and deballasting system during the setdown. In general, survey data such as the current and water depth below the keel need to be incorporated into the draft control system.

The setdown speed is typically slow, allowing time for adjustment of the average position of the segment during ballasting. The ballasting operations are generally divided into three phases: 
a. Ballasting to a keel clearance of 0.5 to $1 \mathrm{~m}$ above the touchdown bottom. The ballasting speed is typically in the range of $12 \mathrm{~m} / \mathrm{hr}$.

$b$. Trimming to a specified level tolerance both longitudinally and transversely using a ballasting process. The trimming tolerance is typically in the range of 0.03 to $0.06 \mathrm{deg}$. The final adjustments to the positioning are also performed at this time using moorings and/or guides. Before the touchdown, the installer should ensure that the segment is within the specified tolerances, accounting for transient oscillation due to various environmental effects.

c. Touchdown: the setdown should proceed decisively without any interruption. This is necessary to minimize the time of exposure to current variation. On the other hand, the ballasting speed should be moderate to allow the water trapped underneath the segment to escape. Once set on the bottom in a fixed position, the positioning of the segment can be measured to a high degree of accuracy by having multiple readings between the fixed points. These measurements will be used to verify the specified requirements for alignment tolerances.

Guides are often used together with moorings to achieve the required alignment tolerances. The guides provide mechanical restraints to transient movements of the segment. In principle, stationkeeping and guide systems are designed as two independent operation systems. The design, however, must account for potential load-transfer interaction between the two systems. For instance, should a mooring system not function as intended or fail because of unexpected dynamic surge motions or simply operational errors, the restrained mooring forces are likely to be transferred to the guide system that is engaged at the time. This could result in overloading and breakup of the guides. Thus, once the guides are fully engaged with the float-in segment, the mooring winches must be carefully controlled to ensure compatibility of the two positioning systems.

In the ballasting process, a float-in segment could lose its stability as the result of several destabilizing effects, such as unanticipated flooding of its compartments or failure of a mooring line. It is critical to check the stability under potential emergency conditions according to naval architecture principles. The basic stability requirement is that the segment should be able to remain floating upright for all afloat conditions, including launching, ballasting, and touchdown. Furthermore, a float-in segment should also have adequate reserves of stability when certain accidental damage occurs.

There are three important parameters controlling the stability of a float-in segment: (1) the center of gravity (G), (2) the center of buoyancy (B), and (3) the water plane moment of inertia (I), as shown in Figure 2-15(a). A reference point is established at midship of the keel $(\mathrm{K})$. When a floating structure heels or trims, the buoyancy force acts vertically upward through B to intersect the axis of the structure at the "metacentric point" (M), as shown in Figure 2-15(b). The buoyancy force also imposes a righting moment on the structure. The righting moment is the product of the displacement and the righting arm, (GM) $(\sin \theta)$ (Figure 2-15b). For small angles of list, $\sin \theta$ may be replaced by $\theta$. Stability of 


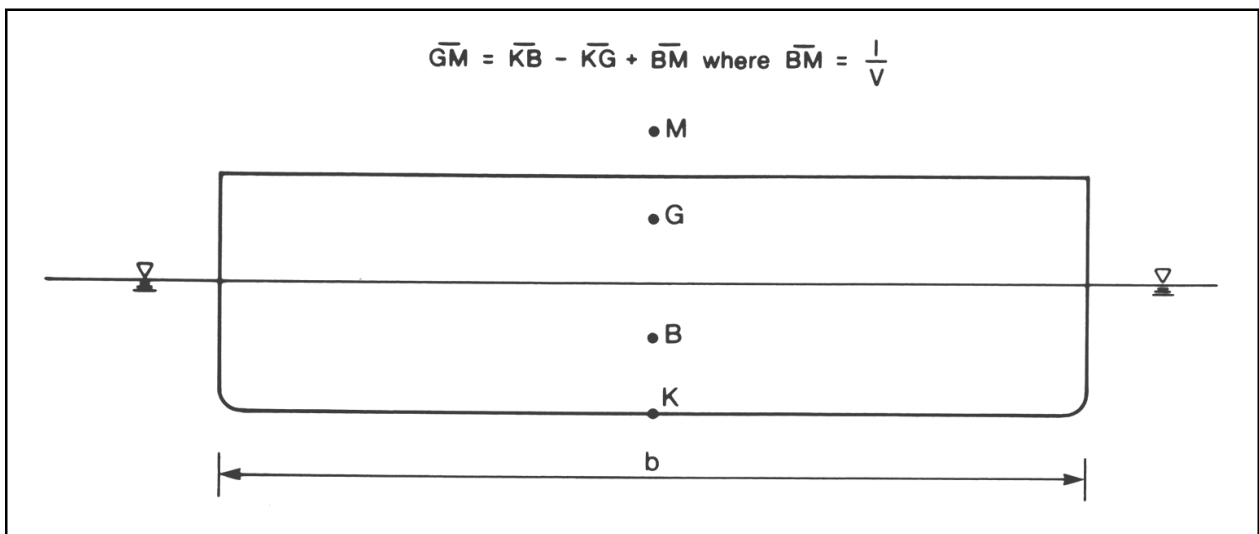

a. Center of buoyancy, center of gravity, and metacenter

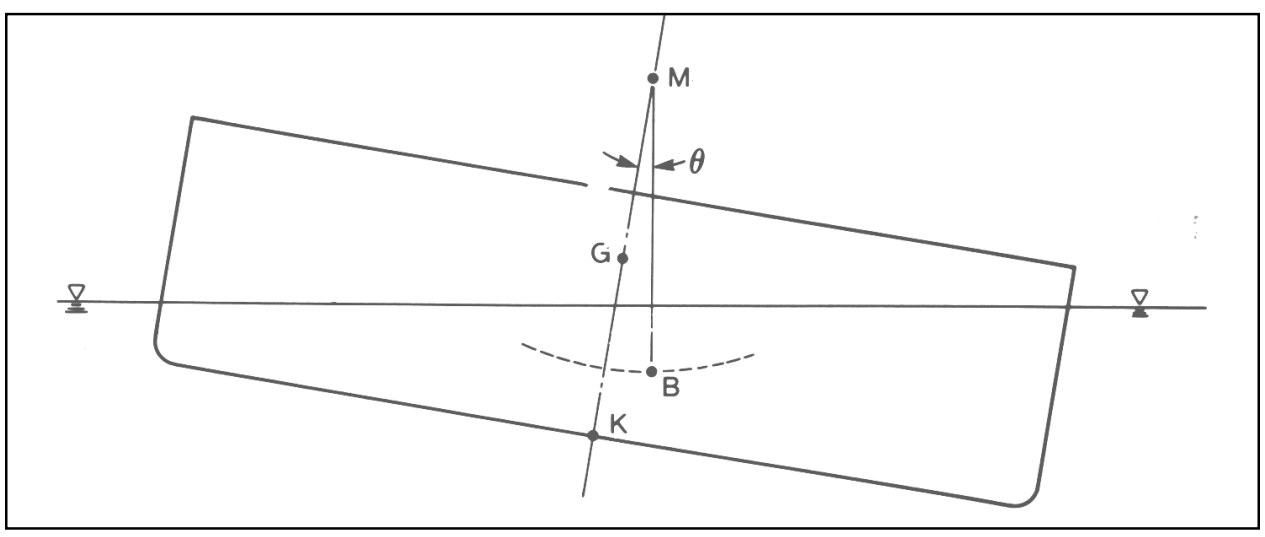

b. Effect of metacentric height

Figure 2-15. Parameters controlling stability of a float-in segment

the structure requires that the righting moment restore the structure to the upright floating position once external forces causing the heel or trim are removed. In other words, the metacentric height should always be positive.

In design, the stability requirement usually imposes that the metacentric height ( $\overline{G M}$ ) always exceed $1 \mathrm{~m}$ for all directions of inclination:

$$
\overline{G M}=\overline{K B}-\overline{K G}+\overline{B M} \geq 1.0 \text { meter }
$$

where

$$
\begin{aligned}
& \mathrm{KB}=\text { distance from the keel to the center of buoyancy } \\
& \mathrm{KG}=\text { distance from the keel to the center of gravity } \\
& \mathrm{BM}=\text { distance from the center of buoyancy to the metacentric point }
\end{aligned}
$$


and can be calculated as follows:

$\overline{B M}=\frac{I}{V}=\frac{\text { Moment of inertia of the water plane }}{\text { Displacement of the structure }}$

For any rectangular structure, $I=\frac{b^{3} l}{12}$ and $V=b l d$. Variable $b, l$, and $d$ are the beam, length, and draft of the structure, respectively.

One principal method of controlling stability is to subdivide a float-in segment into a sufficient number of small compartments so that accidental flooding is limited to a small part of the structure. If one or more compartments are partially filled with ballast water, the internal water planes will cause a shift of the center of gravity further away from the center of buoyancy upon heel or trim of the structure. The net effect, often referred to as "free surface effect," is a reduction in stability and the metacentric height. The free surface effect can be approximately accounted for by subtracting its contribution from BM as follows:

$$
\overline{B M}=\frac{I}{V}-\sum_{i} A_{i} r_{i}^{2}
$$

where

$A_{i}=$ free surface area in a partially filled compartment

$r_{i}=$ distance from the free surface to the axis of the water plane of the entire structure in the direction of rotation

To check the stability of a float-in segment during submergence, engineering calculations should be made to take into account (1) a sudden and significant reduction in the water plane area during its immersion, (2) dynamic stability of the segments during its immersion, (3) free water surface effects on the overall stability, and (4) effects of mooring lines. Proof of sufficient stability and reserve buoyancy should be established for all stages of marine operations. In general, the heel due to extreme wind, towing, and mooring loads should be within 2 and 5 deg.

\section{2-4 Positioning of Lift-in Segments}

Lift-in construction uses heavy-lift equipment to install prefabricated modules underwater. In general, the lift-in method is efficient when a large number of prefabricated segments have to be installed at site, or where environmental/river conditions impose restrictions on effective use of the float-in method. In the past, the lift-in method has provided cost-effective solutions for many major marine construction projects. Figures 2-16 to 2-18 illustrate lift-in placement of various structural components by crane barges. These marine projects have demonstrated the feasibility and economy of lifting and setting very large precast concrete modules underwater to meet very stringent engineering requirements. 

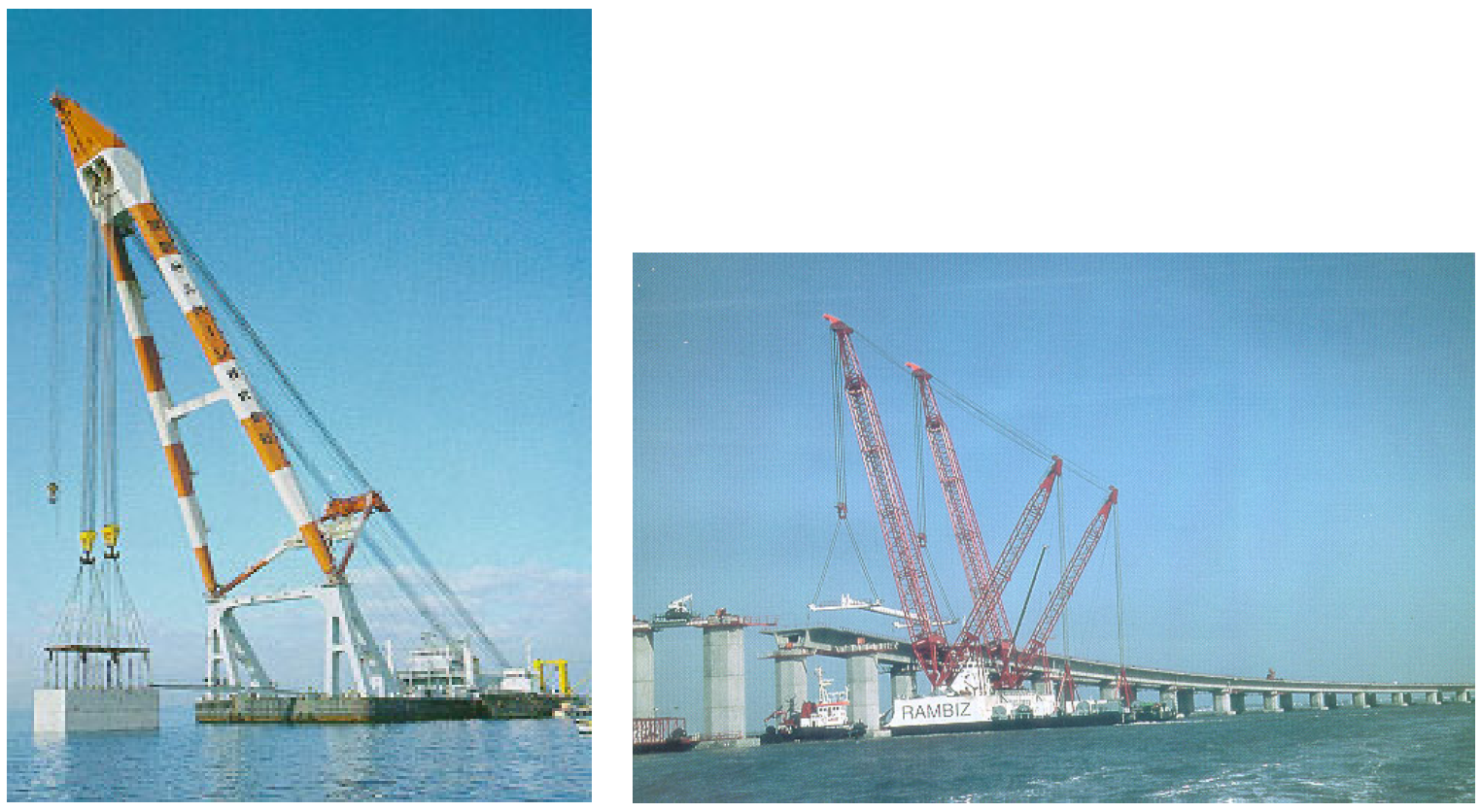

Figure 2-16. Installation of bridge caissons and deck with shear-leg cranes
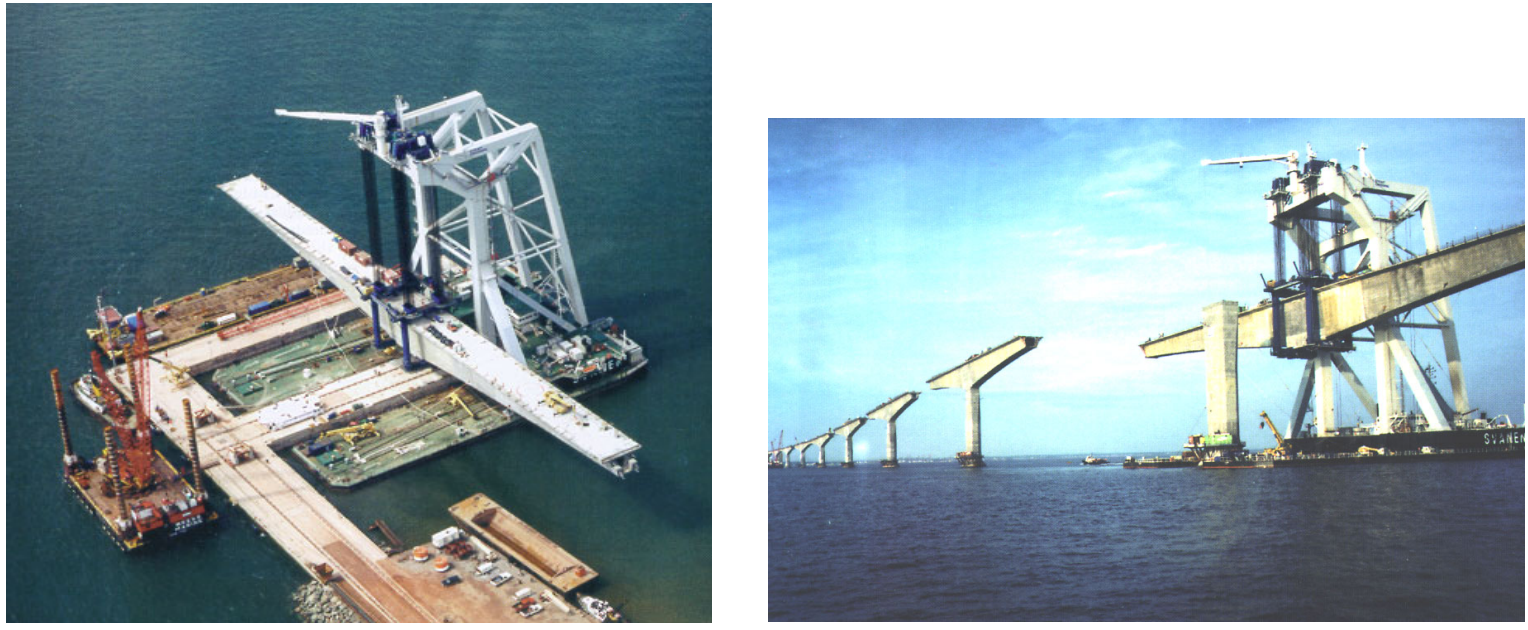

Figure 2-17. A catamaran picks a deck box girder from a jetty and places it onto a pier

Lift-in installation of prefabricated segments is largely independent of water level, but is sensitive to riverflow velocity and wind conditions. Typically, current limitations for lift-in operation are 1 to $2 \mathrm{~m} / \mathrm{s}$, and wind speed limitations are 6 to $10 \mathrm{~m} / \mathrm{s}$.

A complete lift-in operation does not have one well-defined load case, but represents a sequence of different load cases. In principle, the entire lifting sequence must be evaluated step-by-step to identify the critical load cases. Uncertainties with respect to internal force distribution and possible accident loads require adequate safety margins. Both static and dynamic forces must be considered. If a lift-in segment is not weighed in its as-built condition, the dead 

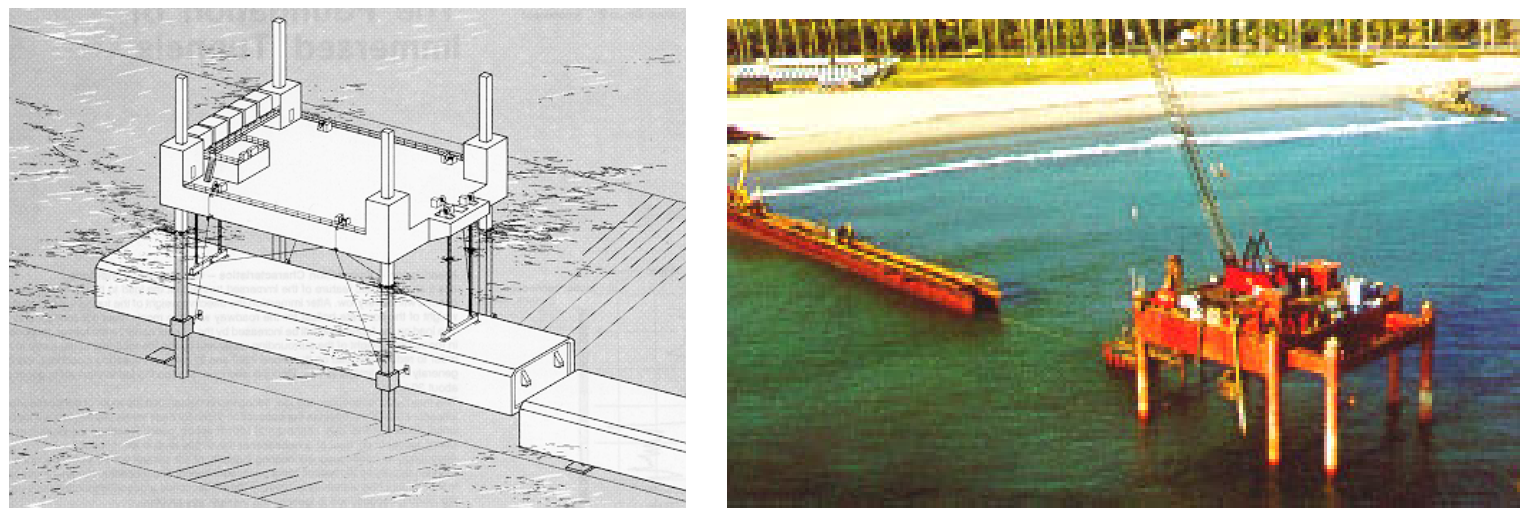

Figure 2-18. A jack-up barge places immersed tunnel segments with strand jacks

weight of the segment must be computed to include the design weight plus adequate allowances for overtolerance in member dimensions, welds, padeyes, and any supplement attachments. Static lifting loads must also include the slings, shackles, spreader beams, and/or lift frames.

Lifting and setting heavy objects involves motion and, hence, dynamic loading and impact effects. The dynamic loads are those due to both vertical and horizontal accelerations during lifting and setting weights, and during swing. The dynamic effects of lift operations can be influenced by a number of factors, such as (1) environmental conditions, (2) motions of crane barges, (3) stiffness of lifting gear/equipment, (4) lift weight, and (5) whether lift is in air or in water.

Lifting loads may substantially change the stability condition of the crane barge. For example, when a derrick barge picks up a load over the side, its center of gravity will be significantly raised and the metacentric height will decrease correspondingly. As a result, the stability becomes excessively sensitive to the instantaneous transverse moment of inertia of the barge. The crane barge must have the necessary beam to maintain the stability and constrain the roll to an acceptable limitation. Marine cranes usually maintain their rated capacities when subjected to less than 3-deg list. In stability calculations, the weight of the loads should be assumed to act at the height of the upper support point (i.e., the sheave blocks at the tip of the crane boom).

The most significant barge motions are often resonant responses. Several physical phenomena induce the resonance, including these:

a. Natural period of roll and pitch corresponding to that of the waves or wind.

$b$. Pendulum swing of the load hanging from the crane boom.

c. Slosh of ballasting water in the barge.

d. "Beat" effect of a barge swaying on elastic moorings responding to a multiple of the wave or wind period. 
A derrick barge could experience serious problems of instability if the load swings in resonance with the roll period of the barge. The crane operator must constantly watch the load-radius combination. A common procedure is to employ tag lines to pull the load sideways in order to reduce this swing tendency. In case a load swings away and out of control, the crane operator may lower the load into the water. The act of lowering lengthens the period out of resonance, while immersion in water provides damping.

In recent years, computer monitoring systems have been developed to control the dynamic aspects of lifting operations. Many large crane barges are fitted with automatic warnings to alert violations of the proper combination of load and boom radius. In some systems, a naval architecture check on the floating stability of the barge will be continuously reported and updated to the crane operator.

In calm water, a crawler crane or truck crane with outriggers may be mounted onto a barge to work as a derrick barge. The design should consider a number of factors to ensure structural strength and stability:

a. The barge will list as the crane lifts a load over the side.

$b$. The crane's rotation gear will be subjected to heavy strains.

c. The swing action must raise the load as well as rotate it.

d. There will be lateral forces that act on the boom.

e. The crane's undergear must be adequately tied down to the barge.

Jack-up crane barges have proven to be effective in turbulent water or swift current. A jack-up barge is usually towed to the construction site, moored with a spread mooring, and then jacked free of water against spud piles. Thus, the barge provides a stable work platform capable of supporting conventional, land-based cranes.

Because of its inherent stability, a jack-up crane barge can place a prefabricated segment to much tighter positioning tolerances than other types of floating cranes. Figure 2-19 shows the jack-up barge Lisa-A placing a 2,100-ton caisson foundation of the Second Severn Bridge. In the construction, the barge was initially positioned with differential GPS and jacked up free of water. Two LTL-1500 Transi-Lift cranes acted in synchronization to lift the caisson off a transport barge and set it down onto prepared rock foundation. Throughout the lift-in operation, the crane operator depended on real-time readings of the actual position of the caisson, the position of the boom points, and boom point loads. With this procedure, all 37 caissons of the bridge were placed within alignment tolerances of $50 \mathrm{~mm}$ in all directions.

Among all the floating cranes, catamaran crane barges offer the greatest floating stability for lift-in installation. Since a catamaran crane barge lifts loads in a symmetrical position to its pontoons, lifting and setting large elements would not cause significant pitch or roll. 


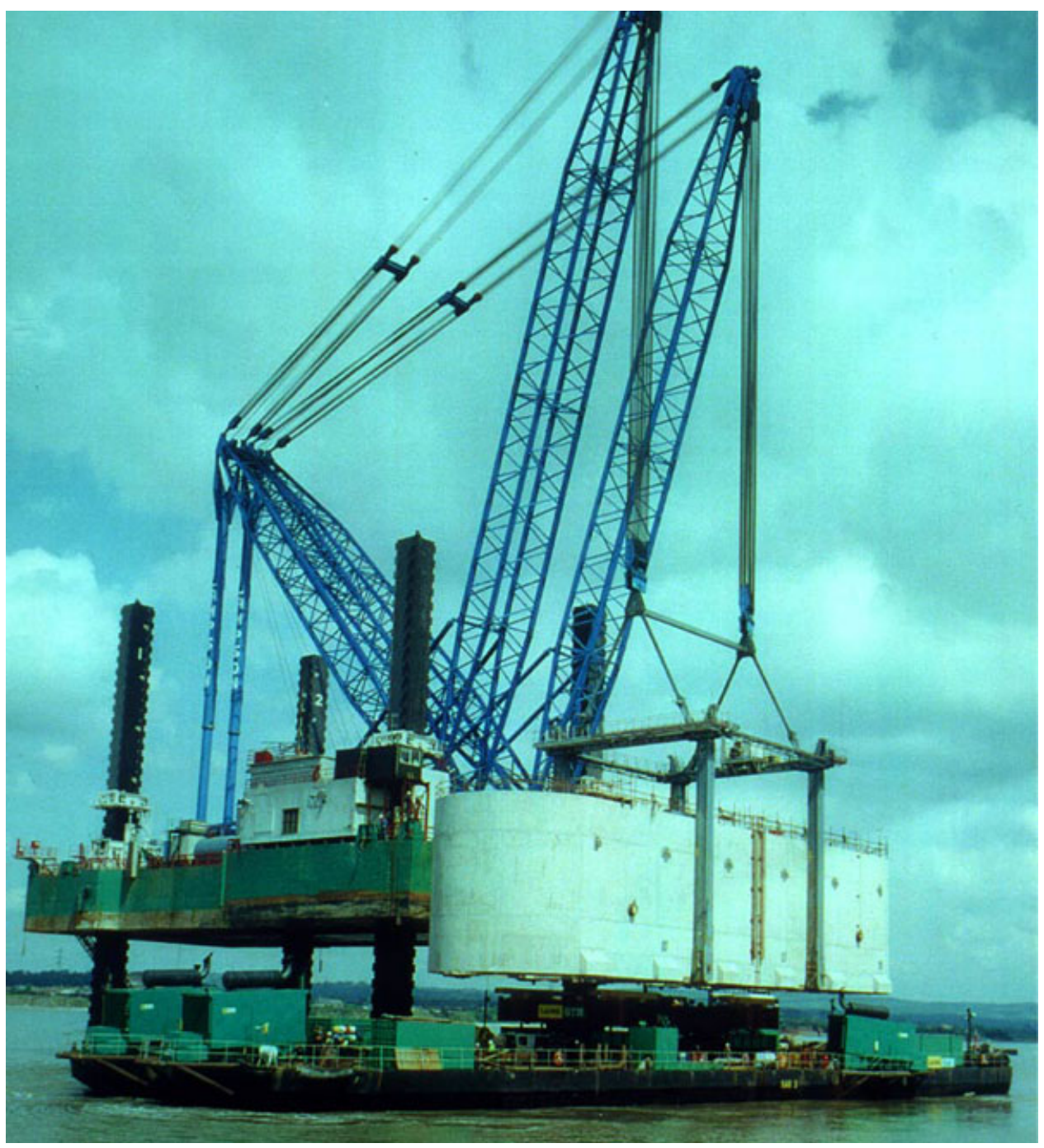

Figure 2-19. A 2,100-ton caisson was placed with jack-up barge Lisa-A

If a catamaran uses multiple strand jacks as its lifting equipment, the jack system must have the capability for sequencing and synchronization for anticipated jacking operations, particularly with repeated strokes. Strands, tension rods, chains, and similar lift apparatus require positive methods for synchronization of their regrip/recycle to eliminate out-of-phase interruption during setdown of loads. This is to prevent any jack from reaching stroke limits and subsequently defeating any force equalization function during the critical stage of lifting or lowering operations.

The jacking system should also be capable of equalizing forces at multiple simultaneous lift points between jacks as a group. Force control ability should set lifting forces of combined/grouped jacks at the center of gravity of each individual lift-in segment. This often requires spreader beams, or lift frames, and special element attachment details. 
In modern marine construction, a computer monitoring system is commonly provided for measurement of relative position at multiple lift points. Digital readouts at a central control station will show both jack stroke and jack pressure at an interval of several seconds during all active jacking operations.

A crane barge should be able to position large lift-in segments in a fully controlled manner. The lift-in operations entail positioning control of the crane barge as well as the lift-in segments. The common measures for positioning control are discussed below.

\section{2-4-1 Control of crane barge}

If a derrick barge or shear-leg crane barge is used in lift-in operations, the load and the crane barge should be treated as a coupled system. When a shear-leg crane reaches far out over the stern to pick up a heavy load, the crane barge will pitch down as the load is lifted. When lowering and setting the heavy load onto supports, the reverse occurs due to reduction in load. As a result, the boom tip of the crane will experience amplified motions due to the pitch of the barge.

Similarly, when a derrick barge is working over the side, motions of the boom tip are amplified by roll of the barge. The counterweight of a crane is usually designed to limit the pitch and roll under full load. Once load is released, the barge under no-load will tilt toward the opposite side.

To minimize any unanticipated boom tip displacements and accelerations during positioning, many crane barges are now equipped with mechanized counterweights that can be shifted laterally, or perhaps computerized ballasting systems that partially offset the pitch and roll motions caused by lifting heavy loads.

A crane barge is often fully moored in position during lifting operations. The mooring system must be rigid enough to hold the crane barge in a relatively fixed position against wind and current. A six- or eight-point mooring system is often needed to provide adequate control of the barge position. With torque-converter deck engines and taut line moorings, crane barges can be positioned to achieve a tolerance of $50 \mathrm{~mm}$ in rivers. Figure 2-20 illustrates the use of a six-point mooring system to position a shear-leg crane barge during lift-in construction of a navigation dam structure.

When a crane barge is working at a job site, the moorings are often laid out in a way that allows the barge to reorient and relocate so that the crane can reach as many locations of the site as possible. Figure 2-21 shows an example of using multiple pile anchors to accommodate repositioning of a crane barge. Although there are exceptions, as a general rule, mooring lines should never cross during a reorientation. Crossing of mooring lines prevents retrieval of the underneath line. Worst of all, it increases the possibility of one line snagging the anchor of the other line. 
To facilitate positioning control, a crane boom tip needs to quickly reach any point in three-dimensional space with one set of controls. Automatic or semiautomatic control systems are now available to provide real-time control commands for lift-in operations. These systems consist of sensors on the crane barge and on the crane boom to monitor lifting operations and feed the information to a microcomputer control board. The control board then gives readouts on information such as load on hook, outreach (radius), hook height, pitch and roll, crane capacity rating for the pitch/roll, hook speed, crane barge stability, automatic level luffing, and warning as to turns remaining on winch drum. As an example, a computer control system was used in installation of the 5,400-ton deck of the Esmond topsides. The deck was set by the derrick barge Balder, with its two cranes rated at 2,700 and 3,000 tons. Positioning was achieved using conventional taut mooring lines along with a computerized ballasting system on the crane barge. The entire operation took only $1 \mathrm{hr}$.

\section{2-4-2 Control of lift-in segment}

When suspended from a crane boom tip, a lift-in segment will act like a pendulum. As a crane boom swings and lowers to set the load down, the segment tends to swing and vibrate under external loads and its own inertia. While the load line length is usually too long for direct resonance, the segment tends to experience dynamic amplification induced from the low-frequency energy.

The vibration is more pronounced for flat-shaped segments such as the dam stilling basin segment in Figure 2-22. As these flat-shaped modules are being lowered into water, they could experience substantial fluttering and distortion due to their own flexibility. The deformation could induce high bending stresses around the picking points.

In practice, the positioning control of lift-in segments can be accomplished in several ways. Some common techniques are discussed below.

a. Use of the lift frame: Many flat lift-in segments are fitted with a temporary steel frame to facilitate the installation. The steel frame is usually secured to the top of the module before launching. The frame serves multiple purposes. First, it allows the crane operator to have good positioning control of the segments. Second, the frame distributes the lift force to the concrete segment through multiple picking points, thereby reducing bending moments in the segment. Third, the frame serves as a survey tower for land-based surveying to determine accurate positions of the segment during installation. Last, the frame can be used later as guides for lowering tremie pipes so that underwater concrete can be placed inside the segment.

b. Use of tag lines: A boom crane's capability of lifting and positioning a large segment is limited by the space between the crane boom and the segment or its lift frame. During lift-in operations, pitch of the crane barge tends to amplify fore and aft swing of the loads. These motions impose the risk for the segment to swing and hit the crane boom. In 
practice, the risks can be prevented with use of tag lines. As shown in Figure 2-23, a lift-in dam segment and its lift frame are pulled slightly toward the crane barge by two tag lines and winches. By this method, gravity is used to prevent fore and aft swing of the load. Swinging of the loads in the transverse direction can be snubbed by the use of tag lines as well.

For shear-leg crane barges, tag line winches are typically mounted on the decks. Since the derrick crane revolves, the relative positions between the load and the barge are constantly changing. Therefore, when tag lines and winches are used on a derrick crane, the tag line winches are mounted onto the crane body and revolve with it.

Tag lines are also frequently used on catamarans for positioning the segments, as shown in Figures 2-18 and 2-24.

c. Use of spotter hydraulic jacks: Hydraulic jacks can be used to adjust the positioning and inclination of lift-in segments. The jacks may be positioned between the hull of the crane barge and the lift frame or between the lift frame and the segment.

During lift-in installation of the caisson foundation of the Second Severn Bridge (Figure 2-19), six remotely controlled 300-ton hydraulic jacks were used to level and adjust the position of each caisson. These jacks were housed in the base of each lifting frame leg and acted as temporary supports to withstand the 270 -ton combined lateral wave and tidal current acting on the caisson.

In setting several segments on top of one another that are joined underwater, it is essential that the lower segments be correctly positioned and leveled. If the base consists of more than one segment, these segments should be connected to hold them together properly in alignment during subsequent construction operations. Guides are typically provided to position the next higher level segment as it is set. Sufficient tolerance must be provided to enable minor corrections to be made as the subsequent segments are placed. Since bearing of one segment on another may be uneven and consequently induce concentrated loads, asphalt-impregnated fiber strips and neoprene pads have been used to distribute the loads more uniformly over the bearing surface.

\section{2-5 Engineering Specifications for Positioning and Setting Operations}

In marine construction, contractors are frequently responsible for engineering the float-in or lift-in installation. To ensure the quality and minimize potential risks, the owner's engineers specify engineering requirements for the critical operations. This section discusses some general requirements for positioning and installation of large float-in or lift-in structures. 


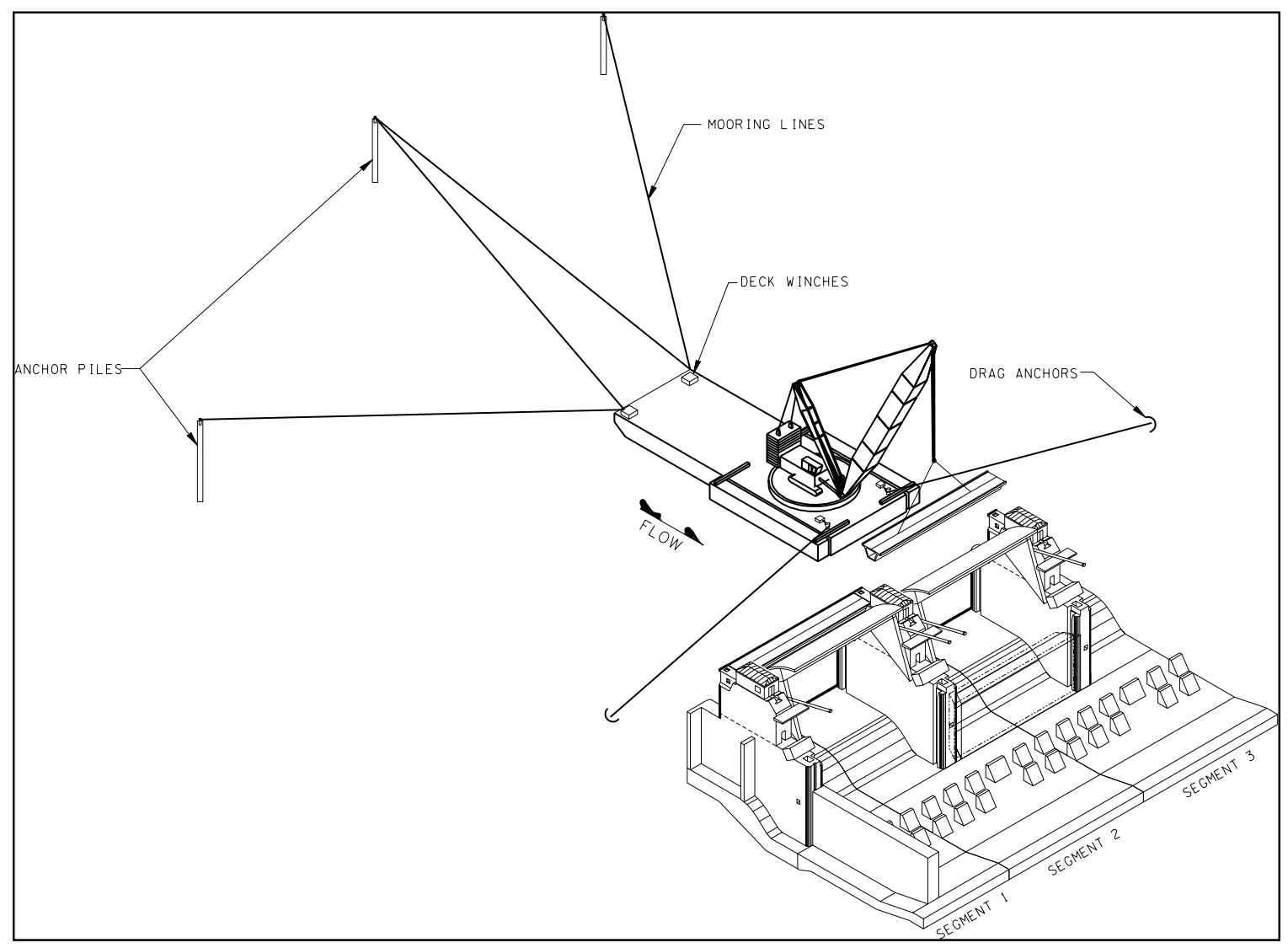

Figure 2-20. Moorings used to position a shear-leg crane barge for lift-in operations

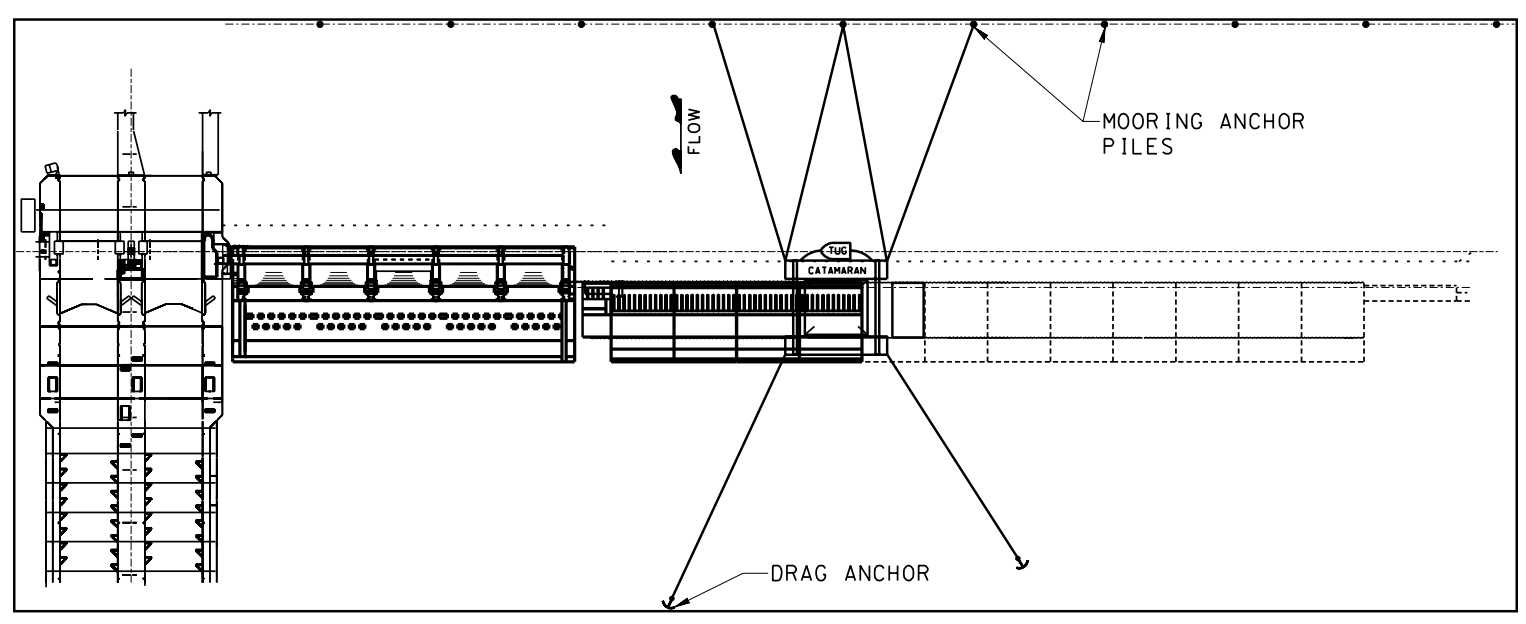

Figure 2-21. Mooring layout for a catamaran for lift-in operations 


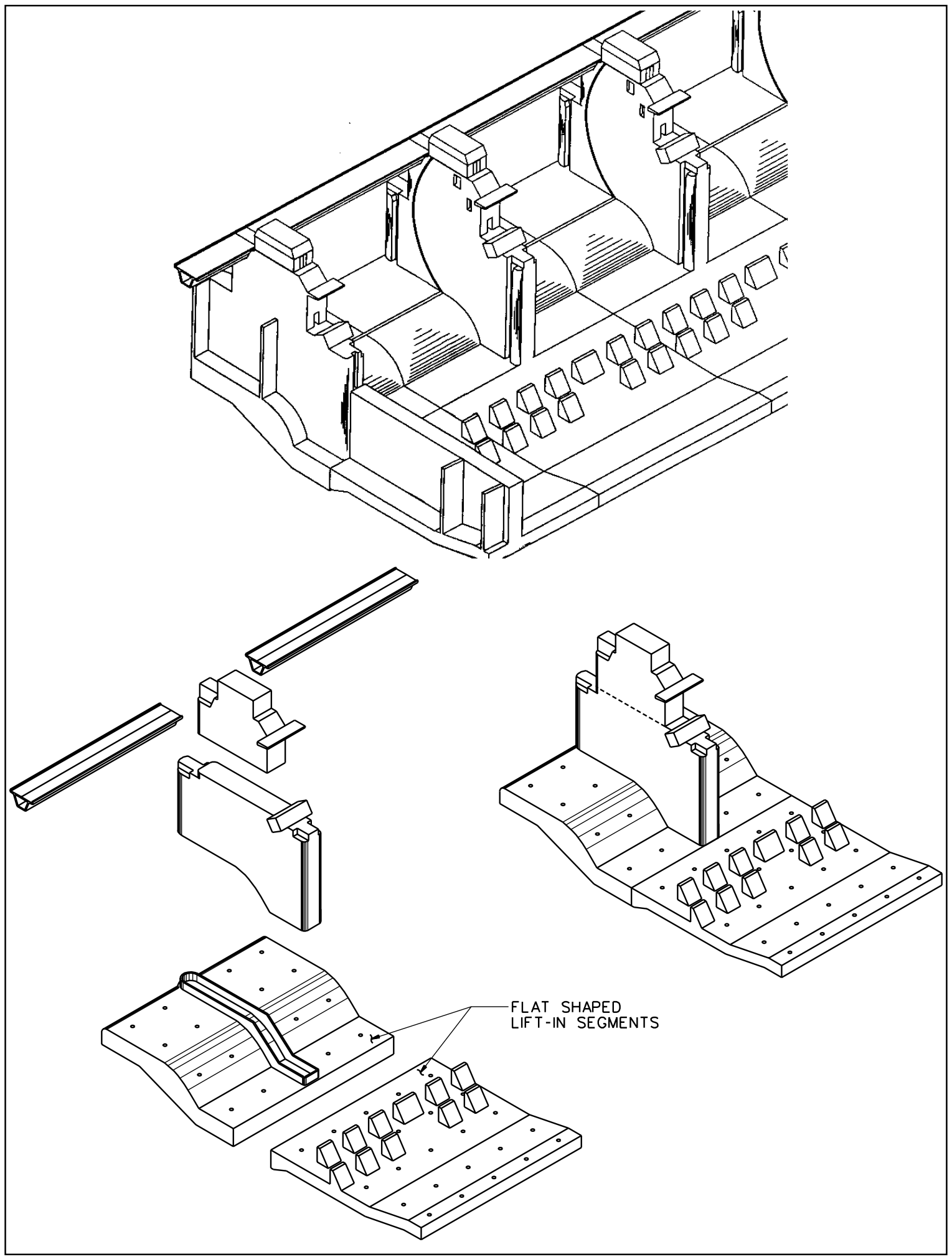

Figure 2-22. Erection plan and flat-shaped lift-in segments 


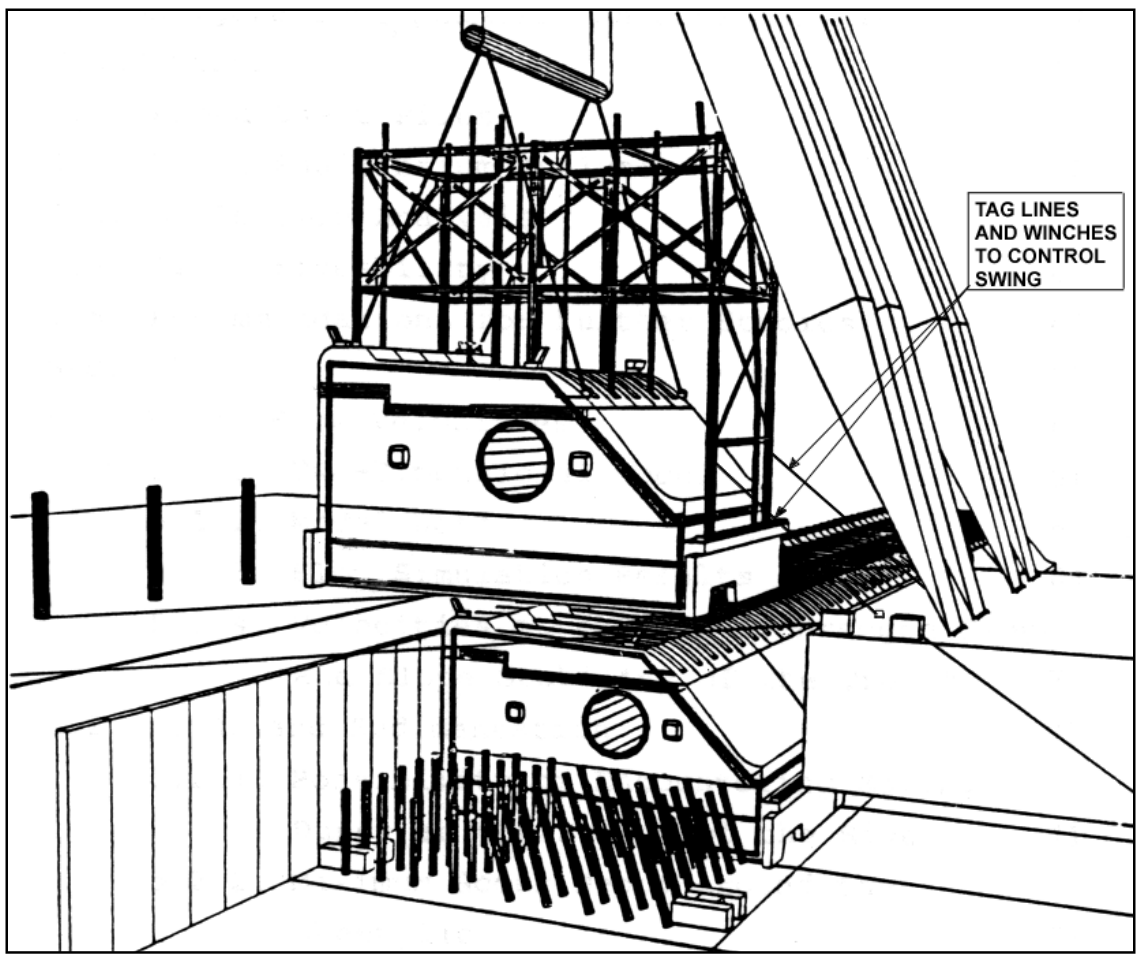

Figure 2-23. A shear-leg positions lift-in dam segment with lift frame and tag lines

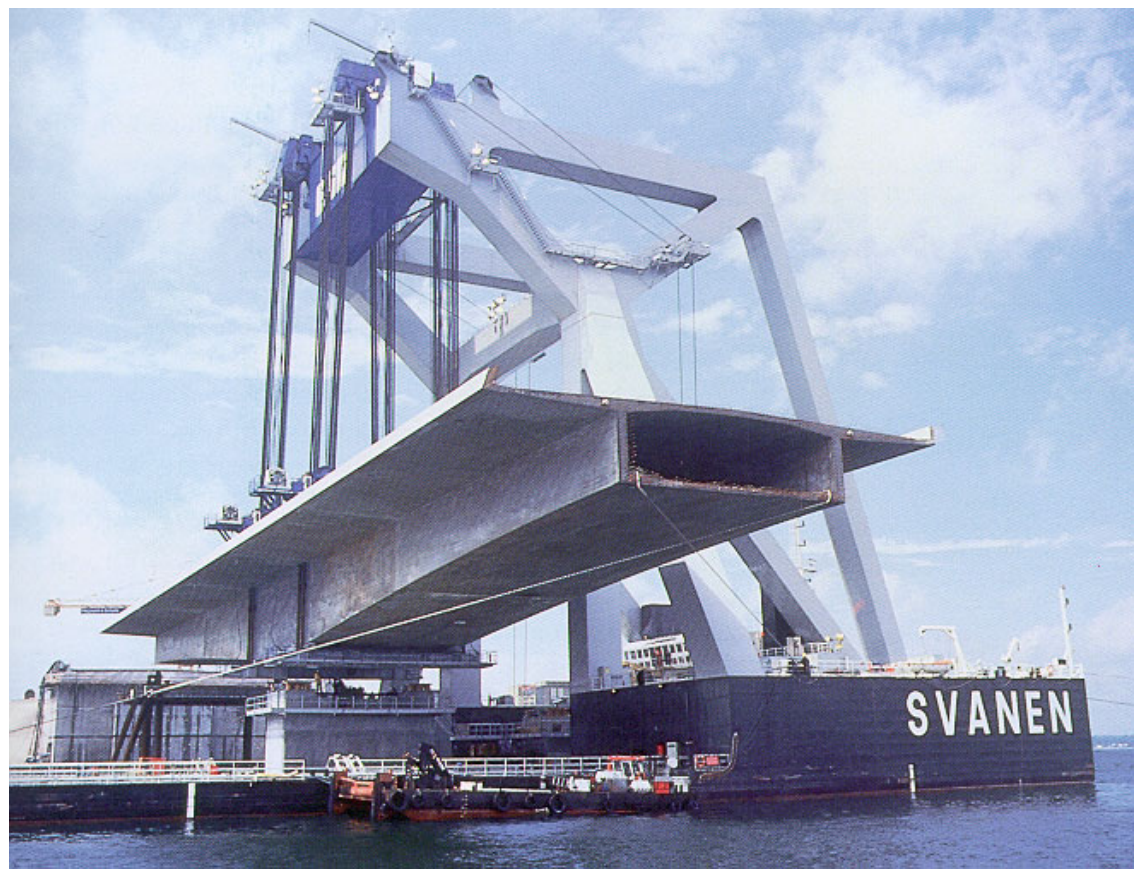

Figure 2-24. A catamaran positions bridge girder segment with tag lines at both ends 
The contract specification should identify the limiting environmental conditions under which float-in or lift-in operations will be permitted. Allowable flow conditions, river staging, wind speed, and wave criteria should be established. The positioning and setting operations should be carried out in a well-planned, fully controlled sequence. The contractor must develop in advance a step-by-step installation procedure, covering all aspects of the process.

A float-in or lift-in segment must be designed to carry all the critical loads and maintain stable behavior during the positioning, submerging, and setting stages. Analysis and design should consider the following loads, if applicable:

a. Hydrostatic loads.

b. Environmental loads.

c. Impact loads.

d. Self-weight and maximum acceleration of the modular segment in its translational and rotational motion.

e. Connecting line loads.

f. Soil or rock foundation reactions.

g. Reactions from preinstalled caissons or setdown piles.

$h$. Skew loads during lifting.

Preparation should be made in advance of the arrival of the float-in or lift-in segment at the site, including setting of marker buoys, communications and support vessel alerts, and removal of boulders or other obstructions from the riverbed. Anchors are usually installed with buoys to facilitate connection to the mooring lines

If guides, bumpers, or fenders are attached to the segments, they should have sufficient strength to resist the critical loading conditions that may be imposed during positioning and setting operations, including impact loads.

If a preinstalled guide system is used to position float-in or lift-in segments, the design must consider the interaction between the guide and mooring systems during the setting operations. Should actual loads exceed those assumed in the design, the guides should be designed to yield while the primary structure suffers minimum damage.

If there are more than three preinstalled landing points beneath one segment, a load distribution system (such as hydraulic flat jacks) needs to be used to ensure even load distribution among the supports.

The positioning brackets should have an ultimate strength of more than three times the static bollard-pull of the largest tug attached to such brackets. The 
brackets on a float-in segment or a crane barge must be designed to resist towline loads from any likely direction.

During the installation process, monitoring should be continuously performed to check important parameters, including

a. Environmental conditions. The current and wind conditions at the time of installation are of fundamental importance to the operations.

$b$. Orientation, positioning, and leveling of the segment.

c. Exact elevation of the segment above riverbed or prepared foundation.

d. Velocity and acceleration of the segment.

e. Nearby navigation traffic and construction activities. Attention should be given to possible disturbing effects from the passing barges or tugs on the positioning and setdown process.

f. Clearance between the preinstalled foundation elements or segments and the float-in or lift-in segment.

g. Crane hook loads for lift-in construction.

h. Ballasting operations and valve status for float-in construction.

i. Setdown impact.

During planning, provisions should be made to accommodate the special considerations of contingency actions needed for the following possible events during the installation process:

a. Deviation of as-built caissons or pile foundation from the positions as specified in the design.

b. As-built dimension and alignment of any adjacent segment previously set to ensure proper mating or correction of misalignment.

c. Inadequate clearance between the foundation elements/previously installed segments and the next segment to be placed.

d. Impact loads.

e. Failure of any one of the positioning mooring lines.

f. Breakdown of tugs, if used.

g. Accidental flooding of any one buoyant compartment of float-in segments. 
$h$. Repositioning and/or adjustment of the segment if the first setdown does not meet the required position tolerances.

$i$. Sudden changes in weather conditions.

Once the segment has been set to its final position within the required alignment tolerances, it must have adequate on-bottom stability against uplift, overturning, and sliding before disconnecting from the positioning systems.

For float-in construction, the installation procedure should include staged ballasting sequences with corresponding drafts, stability values, and time schedule. The stability analysis should consider the possibility of fluttering, heave, or pitching of the float-in segment during the immersion process. Any sudden and large movement during the touchdown should generally be avoided.

The ballast sequence and the amount of ballast at each stage are usually specified in the design. The layout of compartments and sequence of ballasting are designed to reduce the overall stresses in the structure. All compartment bulkheads and keel plates are designed to withstand the ballast loads at different stages of ballasting.

The ballasting/flooding system is selected to achieve an acceptable submersion rate within the required time period. The ballasting system should be fully reversible during the critical stages and have redundant routes in case of jammed valves. The ballasting system should also have feedback capability about actual position of valves, as well as automatic closure (or similar provisions) in case of control line failure.

To provide protection against accidental flooding during the ballasting stage, all manholes, hatches, and bulkheads in the compartments should be sealed watertight and designed to withstand the maximum pressure head of the accidental flooding. All pipes and ducts should also be closed off during nonusage periods so that any accidental flooding does not spread through those systems.

For the lift-in construction, the structural and operating capabilities of the essential equipment should be adequately evaluated. The important equipment for the lift-in operation includes

a. Crane.

b. Crane barges.

c. Mooring systems for the barges.

d. Lift gear (slings and shackles, etc.).

e. Spreader bars and/or lift frames.

The essential engineering requirements for specifying lift-in operations are discussed in detail in Gerwick et al. (2000). 
The position tolerances specified for a float-in or lift-in segment include the horizontal alignments, vertical alignments, surface leveling, and verticality of the final position of the segment. Typical alignment tolerances for installation of the float-in or lift-in segment after its setdown and final leveling and position adjustment with hydraulic jacks or flat jacks are as follows:

Horizontal tolerance: \pm 2 in.

Rotational tolerance about axis of dam: $\pm 0.016 \mathrm{deg}$

Vertical tolerance: \pm 0.25 to 0.5 in. (measured directly above setdown points)

In practice, the tolerances of the as-built segments are dependent on dimensional tolerances of each individual precast segment, erection tolerance, and interfacial tolerance between adjacent segments.

The dimensional tolerance of precast concrete components should generally comply with the industry standards, as described in Manual 116 of the Precast/ Prestressed Concrete Institute (1999).

In general, the dimensional tolerances should be used as guidelines for acceptance, but not as limits for rejection. The engineer should decide whether a deviation from the allowable tolerance affects safety and performance of the structure.

The erection tolerances should be determined in accordance with the current construction practice and the project site conditions. The erection tolerances for underwater positioning of large prefabricated segments must be economically attainable in construction. The criteria highly depend on the site conditions, the erection method and equipment, and the survey method and equipment. In determining the erection tolerances, attention should be given to possible deflection and/or rotation of the prefabricated components and the foundation members supporting the prefabricated component during erection.

The dimensional tolerance and the erection tolerance are interrelated and may be additive. For example, warping, bowing, and edge straightness of a precast concrete segment have a significant effect on the edge matchup and joint dimension with the adjacent segment during the erection. If the accumulated tolerance exceeds the total tolerance specified for the structure, adjustment must be made within the interface clearance between adjacent precast segments. That is, if two adjacent segments are out of alignment in opposite directions, the accumulated error tends to cancel out.

Interfacing tolerances and clearances are those required for joining different prefabricated elements. The fabrication dimensional tolerances and erection tolerances must be considered when specifying interfacing tolerances. The specified clearances between adjacent prefabricated elements are important details, because they provide a means to accommodate adjustments for possible size variation and misalignment. 


\section{Project Experiences}

For in-the-wet construction, successful planning and implementation of onsite positioning and installation require a substantial amount of engineering efforts and expertise in multiple disciplines, such as surveying, naval architecture, marine construction, and hydrological and weather forecasting. Thus, the development of the installation method and the selection of positioning systems are highly dependent on the technical capabilities as well as the onsite environmental conditions.

In the last three decades, significant advancements have taken place in the positioning technologies, including real-time survey data collection, computerized control systems for positioning, heavy-lift equipment, mooring systems, underwater sonic devices, and remotely operated vehicles. These technical advancements have led to fundamental evolutions of the positioning methods in marine construction. For example, three-sided braced dolphins had been used for many years as the primary positioning system for float-in segments. With advanced survey techniques and the computerized control system, the industry has trended toward the practice of adopting position moorings as the primary positioning systems, with the assistance of simple guides.

This chapter examines the positioning methods used in three recent large marine construction projects: the Great Belt Link in Denmark (1991-1998), the Oresund Crossing between Denmark and Sweden (1998-1995-2000), and Braddock Dam in Pennsylvania, United States (1999-2002).

\section{3-1 Great Belt Link-West Bridge}

The Great Belt in Denmark is across heavily trafficked seaway, with over 40,000 ships passing each year. The fixed link across the Great Belt consists of a 6.6-km-long West Bridge, a 6.8-km-long East Bridge, and an 8-km railway tunnel.

The West Bridge consists of prestressed concrete box girders spanning over 62 caisson foundations (Figure 3-1). The bridge was entirely prefabricated offsite and segmentally assembled onsite with heavy-lift equipment. The offsite fabrication and lift-in construction allow minimum onsite construction and more effective project control. 


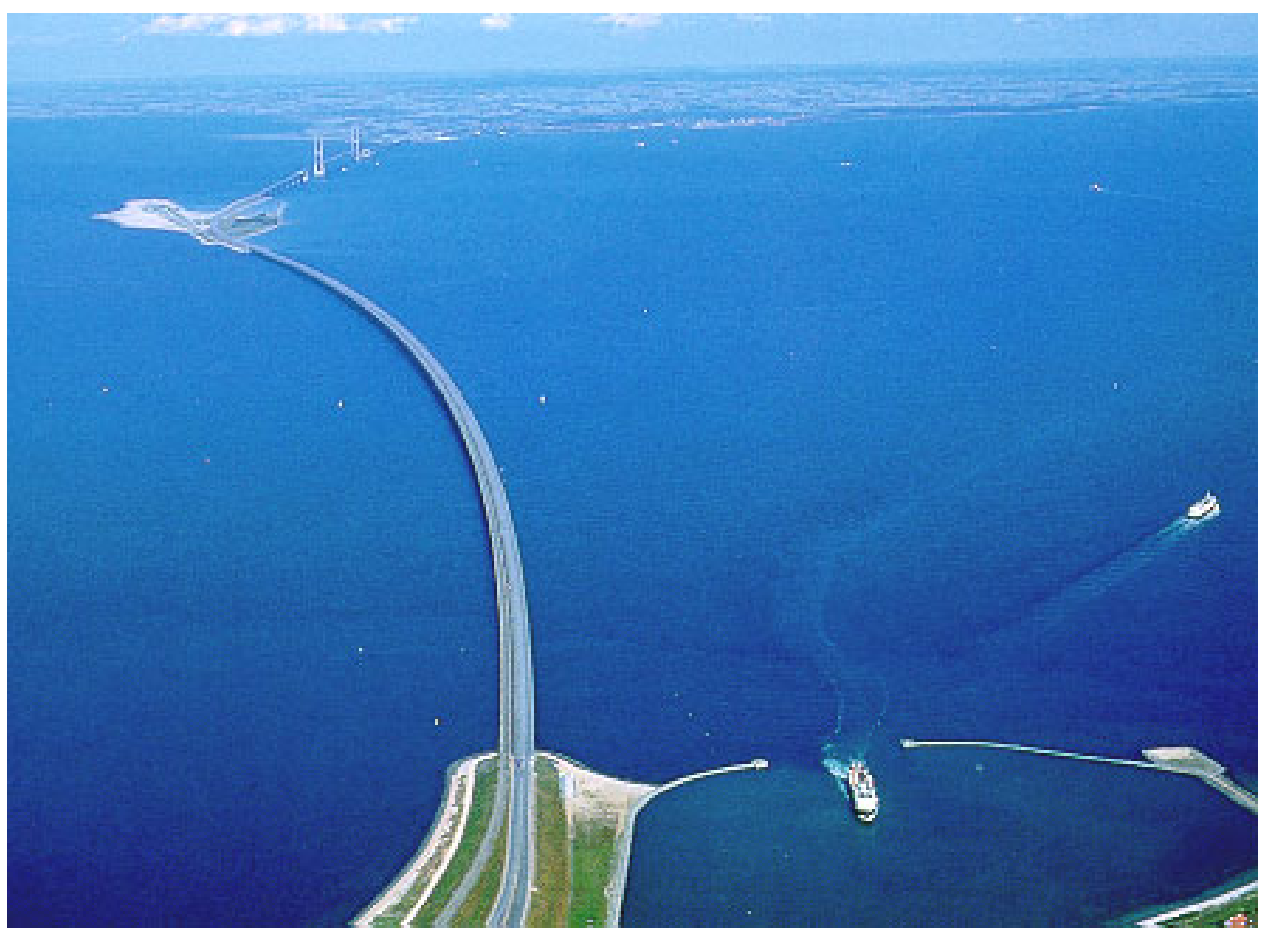

Figure 3-1. Great Belt Link-West Bridge and East Bridge

A typical bridge caisson is a 29 - by 17 - by 20 -m precast concrete box segment and weighs about 6,900 tons. The foundation beneath the caissons consists of a compacted and leveled layer of stonebed over the seabed. The caisson, with sand-filling ballast, was designed as a gravity-based system to support the bridge and to resist the environmental loads and ship impact.

The Svanen, a self-propelled catamaran crane barge, was selected for transporting and installing a total of 324 large precast elements over water. The Svanen is a 103- by $72-\mathrm{m}, 102-\mathrm{m}$-high catamaran with a hammerhead gantry, which provides substantial flexibility in lifting and placing objects underwater or at $80 \mathrm{~m}$ above the water surface. Using eight appurtenant windlasses, the equipment can achieve a positioning accuracy of $20 \mathrm{~mm}$. The positioning and installation of the bridge caissons and girder segments are discussed below.

The crane barge had to lower the caisson into the water to gain buoyancy during transport to get the weight below its sailing capacity (about 6,400 tons). During transport, the concrete caisson was restrained from horizontal movement by both hydraulic jacks and tug lines. The tow master on the crane barge received on-line information about the position of the vessel from a range-find microwave system as well as from the gyro. These data were automatically entered into a survey computer, which produced a graphic display of the crane barge and precast concrete segment positions on a digitized map.

After arriving at the site, the Svanen was fully moored to the placement position, as shown in Figure 3-2. Throughout the lift-in operation, the position of the catamaran was completely controlled by its deck winch and an eight-point 


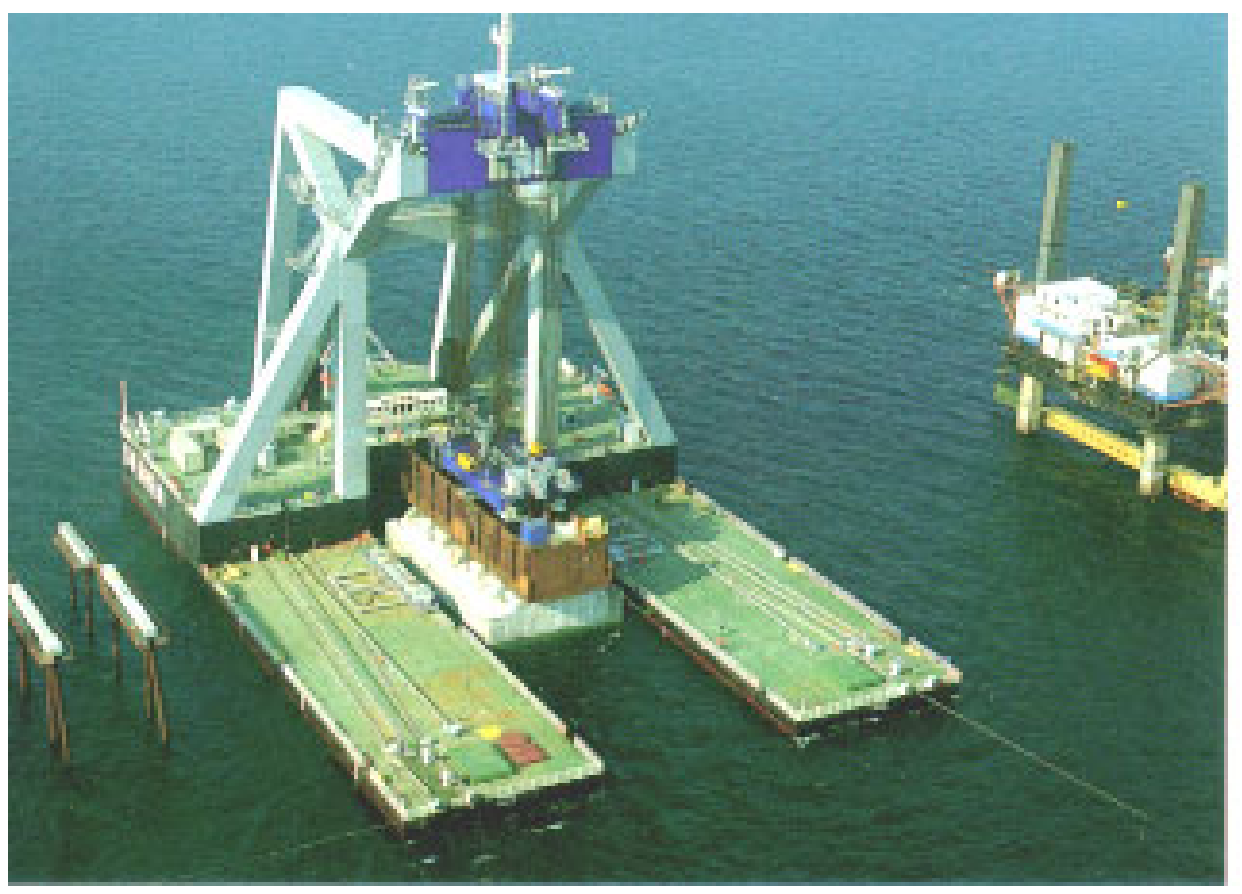

Figure 3-2. A caisson (West Bridge) was placed by the Svanen with an eightpoint mooring

mooring system. Figure 3-3 shows the arrangement of the deck winches and mooring lines on the Svanen.

A more precise positioning system was required for placing the caissons at this time. Three auto-tracking range-bearing instruments were located on one of the previously placed caissons. The instruments measured three-dimensional positions to three reflectors on survey towers placed on top of the caisson. The results were automatically transmitted to the survey computer on the crane barge via a telemetry link. Results from inclinometers on the caissons were also transmitted to the barge by cable connection. The survey data were then processed together with the as-build caisson geometry information, the stonebed geometry, and the final caisson position. Then, the computer displayed on-line information about the caisson position relative to the final intended position, the distance to be lowered, and pitch and roll, as well as suggestions for corrective action to bring the caisson to its final correct position. Figure 3-4 shows the computer monitor illustrating a positioning survey screen during placement of a bridge caisson foundation. The information from the auto-tracking system was checked at regular intervals by independent measurements using the theodolite and level instruments.

The caisson was lowered under close surveillance. Approximately $0.5 \mathrm{~m}$ above the stonebed, the lowering was stopped and an independent survey was performed to verify the automatic tracking system. If positions matched, the lowering continued. Immediately before touchdown, the caisson was stopped again and the final position adjusted through the positioning winches on the 


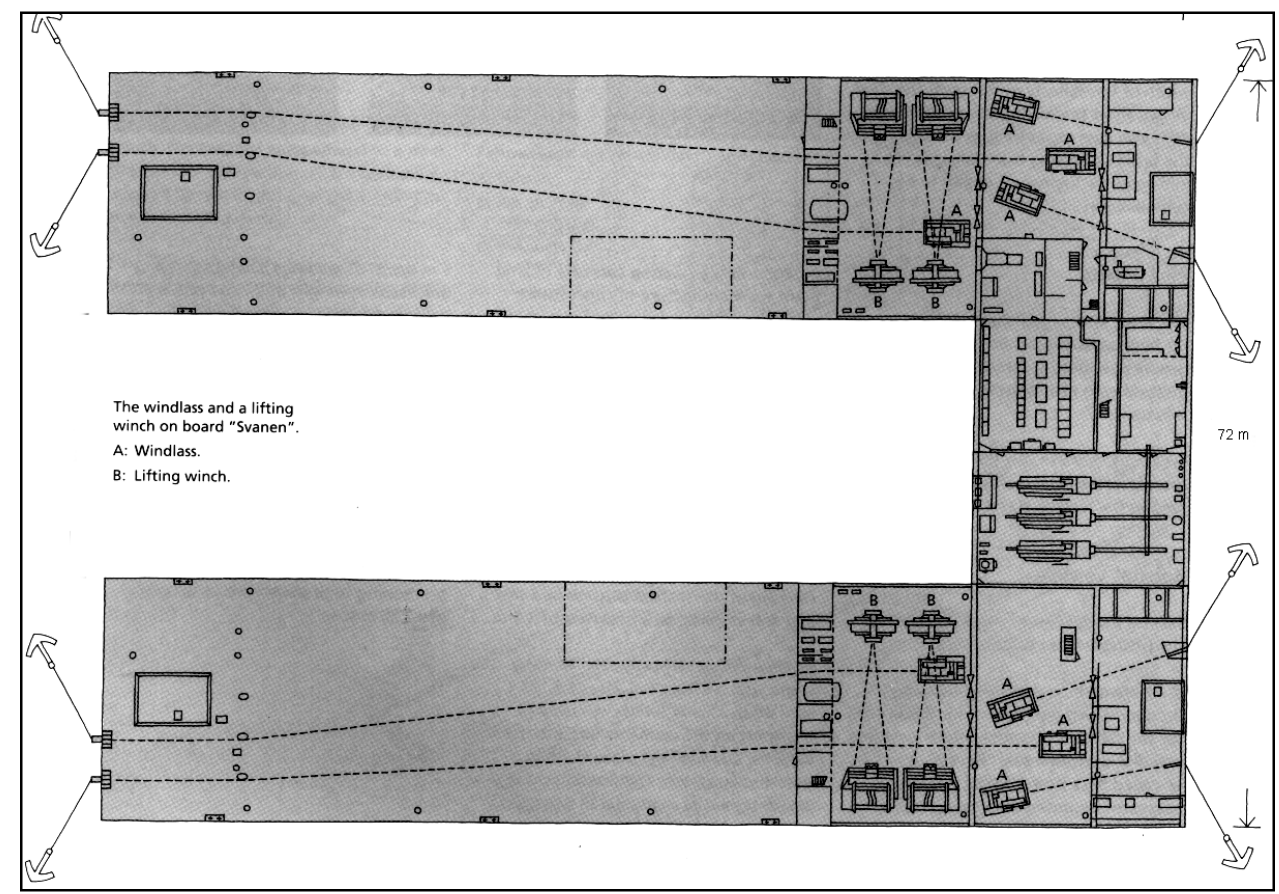

Figure 3-3. Deck winches and mooring arrangement on the Svanen

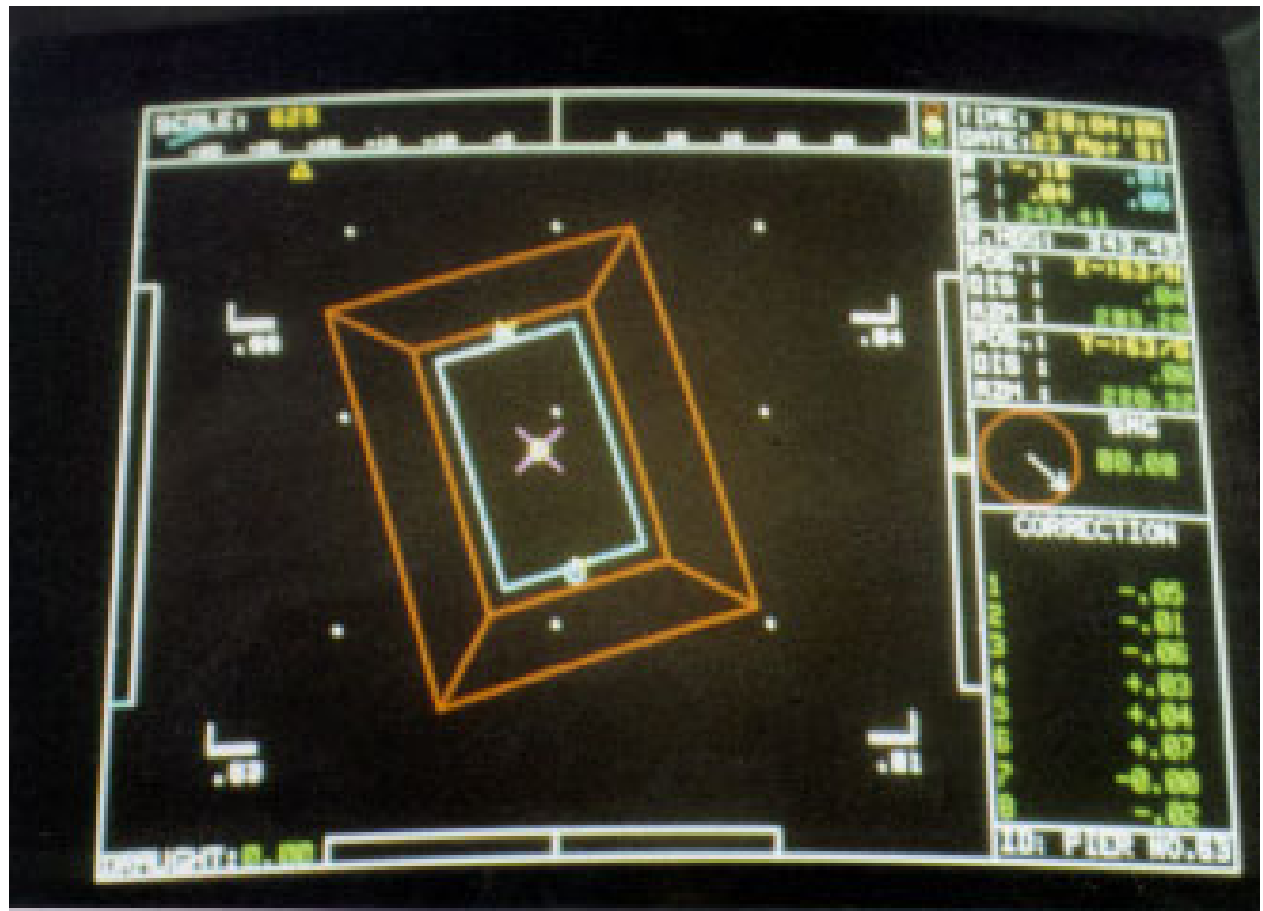

Figure 3-4. Real-time positioning data on the bridge caisson, on a monitoring screen 
catamaran. When it was well within the specified tolerances and its movements were controllable, the caisson was lowered to contact with the stonebed until the hook load had decreased by approximately 600 tons. A new check of the position was conducted, and if it was still within the defined tolerances, the remaining load was released from the crane. After placement, an independent check of the caisson position was made and, if satisfactory, the lift gear was released. All of the 62 bridge caissons were placed within a tolerance of $40 \mathrm{~mm}$ as opposed to the allowable tolerance of $200 \mathrm{~mm}$.

The bridge superstructure consists of haunched box girders, typically $110 \mathrm{~m}$ in length and 5,500 tons in weight. Each girder is seated on one pier and extends one-half span outward on each side of the pier. Figure 3-5 shows the Svanen placing a girder segment on the West Bridge. The lifting system for large and heavy loads must be designed to minimize the impact from the load onto a fixed seating pier. Typically, a heavy lift requires multiple parts of hoisting lines, which take time to overhaul as the load is transferred. As a result, overhaul is frequently not fast enough to release a load quickly and prevent some damaging impact.

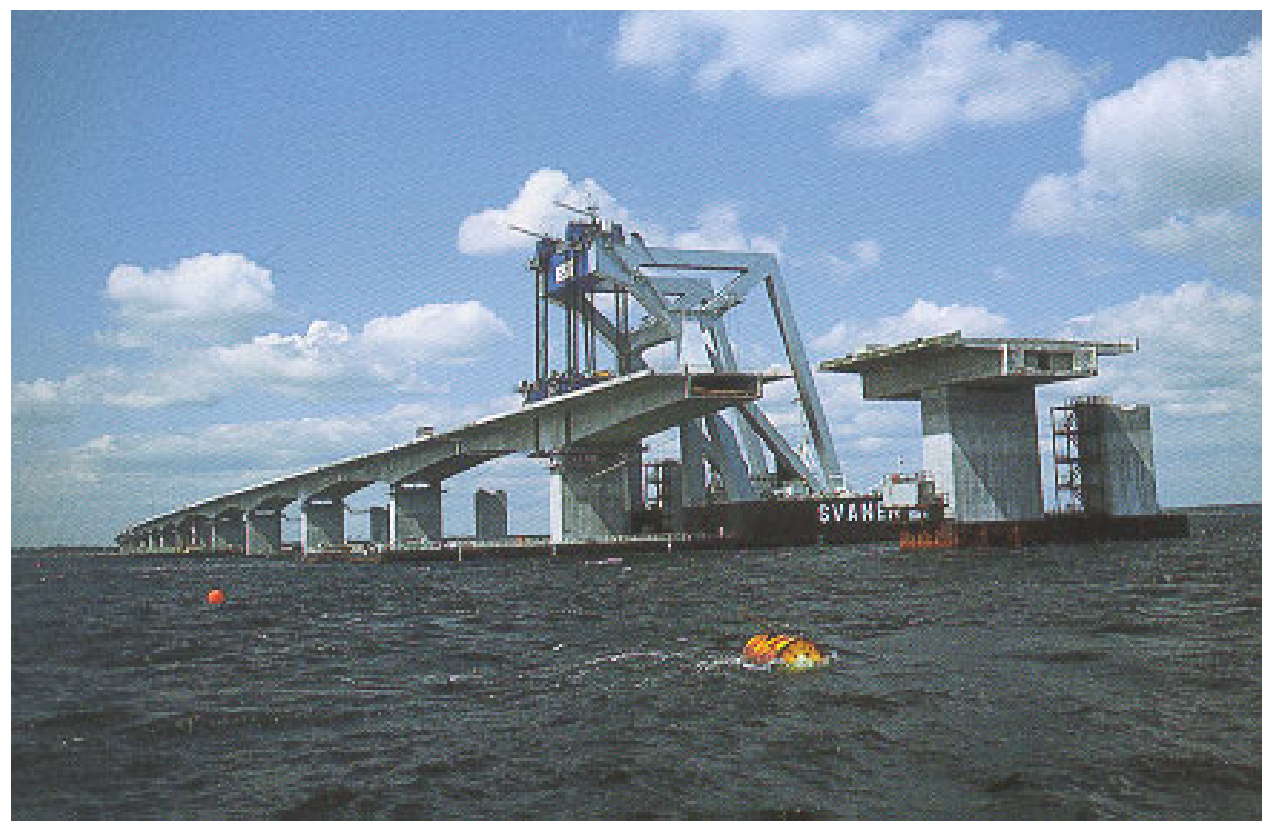

Figure 3-5. Placing a 5,500-ton girder segment with the Svanen

In this case, hydraulic jacks (with locking rings) were installed on top of the bridge pier as temporary support, as shown in Figure 3-6. To absorb energy, 40-mm plywood was placed on top of each jack.

Unlike the caissons, the girder segments were placed by visual survey guidance with assistance of GPS information. Vertical survey lasers were installed on support stools on the pier shafts to locate the center of the girder. At the same time, surveyors assisted to determine the girders' position relative to the pier with theodolites and GPS on the adjacent piers (Figure 3-7). 

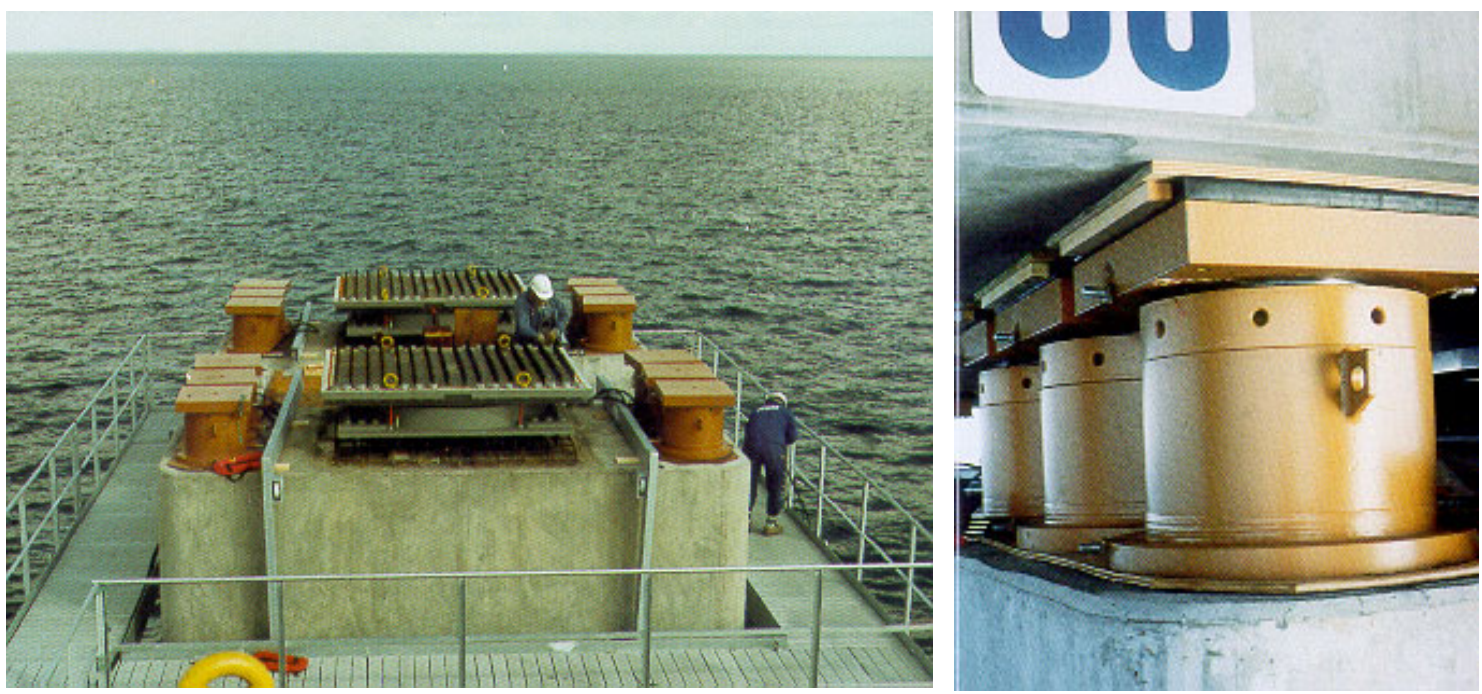

Figure 3-6. Hydraulic jacks as temporary support for positioning the box girders

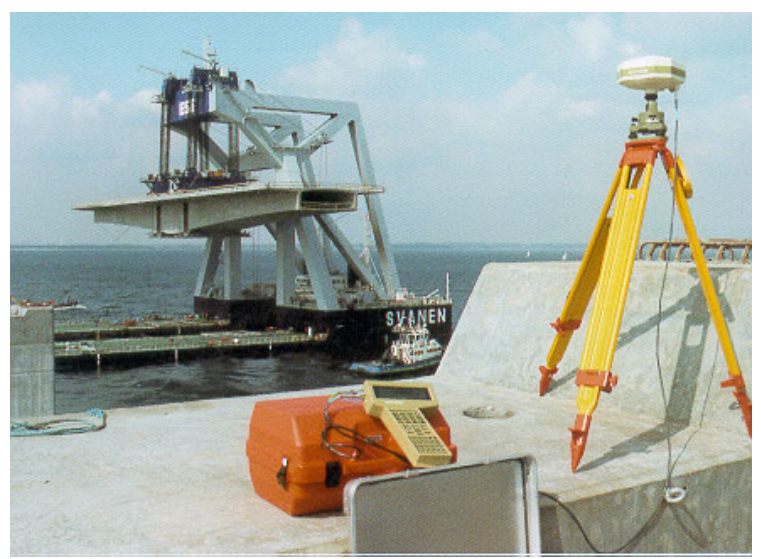

a. GPS check of pier position

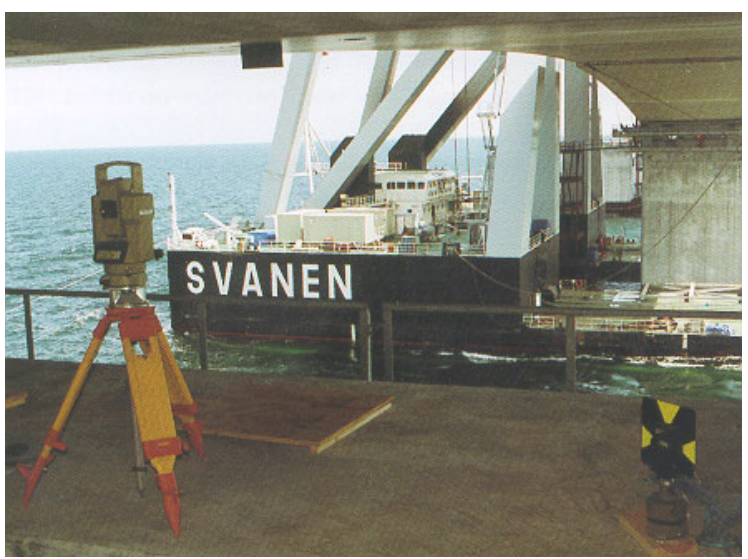

b. Theodolite

Figure 3-7. Survey positioning of the girders

Lowering of the girder was stopped when it was immediately above the temporary supports. In this position, tag lines were used to pull the girder into the correct position. When confirmed to be on the target by the lasers, the girder was lowered onto the support.

After the initial placement, the hydraulic jacks were engaged to equalize the loads on the top of the pier. If required, the orientation of the girder was adjusted by pulling in the tag lines attached to its ends. When the girder was positioned correctly, the jacks were capped off and the hydraulic system disconnected. The lifting gear could now be released to transfer the load to the pier. Initially, the girder is placed initially within 80 -mm tolerances at the ends. Then, it is readjusted to within $10-\mathrm{mm}$ tolerances with jacks. 


\section{3-2 Great Belt Link-East Bridge}

The East Bridge consists of a 2.7-km-long suspension bridge with two approach bridges of $4 \mathrm{~km}$ total length (Figure 3-8). Besides the suspension bridge pylons and deck, the bridge was primarily constructed with offsite prefabricated structural segments. Depending on the size of the segments and positioning requirements, different erection methods were applied to install various segments. Table 3-1 summarizes the typical structural components and installation methods.

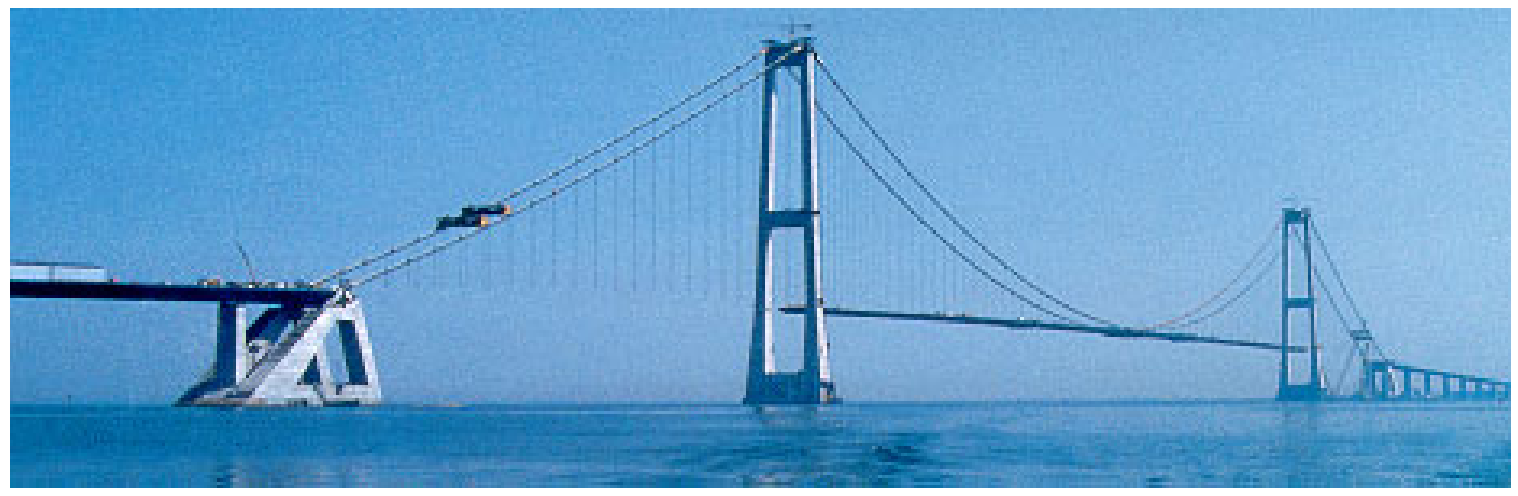

Figure 3-8. East Bridge under construction

\begin{tabular}{||l|l|l||}
\hline \hline \multicolumn{2}{||l||}{$\begin{array}{l}\text { Table 3-1 } \\
\text { Great Belt Link-East Bridge Structural Components }\end{array}$} \\
\hline \hline Structural Component & Typical Dimensions & Installation Method \\
\hline \hline $\begin{array}{l}\text { Suspension bridge: pylon } \\
\text { caisson }\end{array}$ & 78 by 35 by $20 \mathrm{~m}$ & $\begin{array}{l}\text { Float-in method with position } \\
\text { moorings and tugs }\end{array}$ \\
\hline $\begin{array}{l}\text { Suspension bridge: anchor } \\
\text { block }\end{array}$ & 122 by 55 by $16 \mathrm{~m}$ & $\begin{array}{l}\text { Float-in method with position } \\
\text { moorings and tugs }\end{array}$ \\
\hline $\begin{array}{l}\text { Suspension bridge: } \\
\text { deck spans }\end{array}$ & 25 by 48 by $7 \mathrm{~m}$ & $\begin{array}{l}\text { Strand jacks from gantry cranes on } \\
\text { the main suspension cables }\end{array}$ \\
\hline Approach bridge: caisson & 23 by 19 by $8 \mathrm{~m}$ & $\begin{array}{l}\text { Lift-in method with the shear-leg } \\
\text { crane barge Taklift } 8\end{array}$ \\
\hline Approach bridge: pier & $\begin{array}{l}\text { Various in sizes and } \\
\text { weights }(500 \text { to } 2,100 \text { tons) }\end{array}$ & $\begin{array}{l}\text { Lift-in method with two shear-leg } \\
\text { crane barges (Taklift } 4 \text { and Taklift } 7)\end{array}$ \\
\hline $\begin{array}{l}\text { Approach bridge: } \\
\text { span girder }\end{array}$ & 25 by 194 by $7 \mathrm{~m}$ & Dual lift with two shear-leg cranes \\
\hline
\end{tabular}

Although, for efficiency and economy, various installation methods and equipment were selected for different prefabricated modules, the positioning systems used were similar. For conciseness, the following discussion covers only the installation of the pylon caissons and the approach piers.

The pylon caissons in the suspension bridge were placed with the float-in method. The float-in caissons were positioned with moorings alone during the installation, so the placement accuracy achieved onsite is very sensitive to the 
environmental effects at the time. Although tidal effects were moderate, currents of 2 knots had to be considered for positioning and installation of prefabricated segments. Engineering evaluation of the positioning requirements led to the following environment criteria for selecting the "work window" for the operation:

a. Significant wave height: $1.0 \mathrm{~m}$.

b. Maximum current velocity: $0.8 \mathrm{~m} / \mathrm{s}$.

c. Maximum wind speed: $11.0 \mathrm{~m} / \mathrm{s}$.

The float-in caisson was transported with two leading tugs and two trailing tugs, each having a bollard pull capacity of 60 tons. Once arriving at the site, the caisson was held in position through mooring lines to deck winches on the four tugs and two other tow barges. The tugs and barges were in turn moored to preinstalled anchor piles, as shown in Figure 3-9.

To control the position of the caisson, the tow master depended primarily on the following real-time data:

a. Present caisson position.

$b$. Distance to the final position in centimeters.

c. Heading (orientation) in $0.10 \mathrm{deg}$.

d. Wire rope length correction for all six mooring lines.

After the caisson was pulled into its exact position, ballasting began with four externally mounted pumps, each with a capacity of $1,500 \mathrm{cu} \mathrm{m} / \mathrm{hr}$. The ballasting operation was divided into three phases:

a. Ballasting to a keel clearance of $0.5 \mathrm{~m}$.

$b$. Trimming to a level tolerance within 0.05 , both longitudinally and transversely; fine adjustments to the positioning were also carried out.

c. Once the pylon caisson was confirmed to be within the specified tolerance, ballasting was resumed and constantly monitored until setdown was achieved.

Under the pretensioned mooring system, the actual movements of the caissons were far less than anticipated in the analysis and model test studies. The caissons were placed less than $25 \mathrm{~mm}$ from the specified locations, and well within the specified tolerances. 


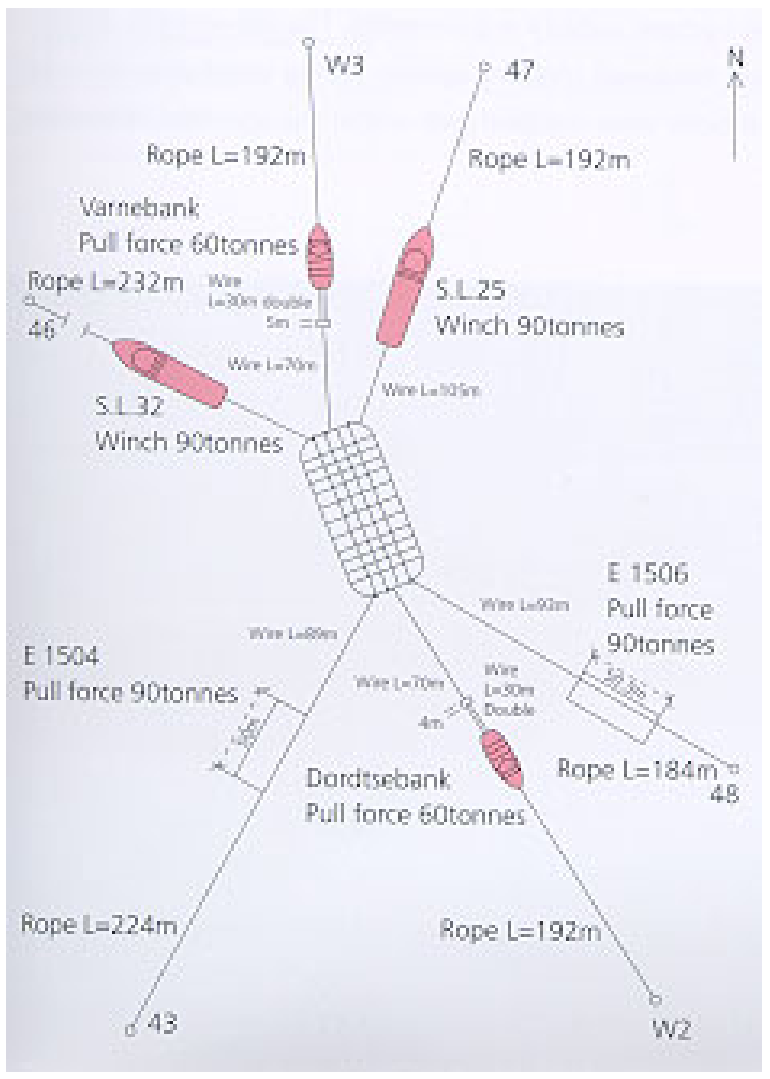

a. Mooring layout for positioning a float-in caisson

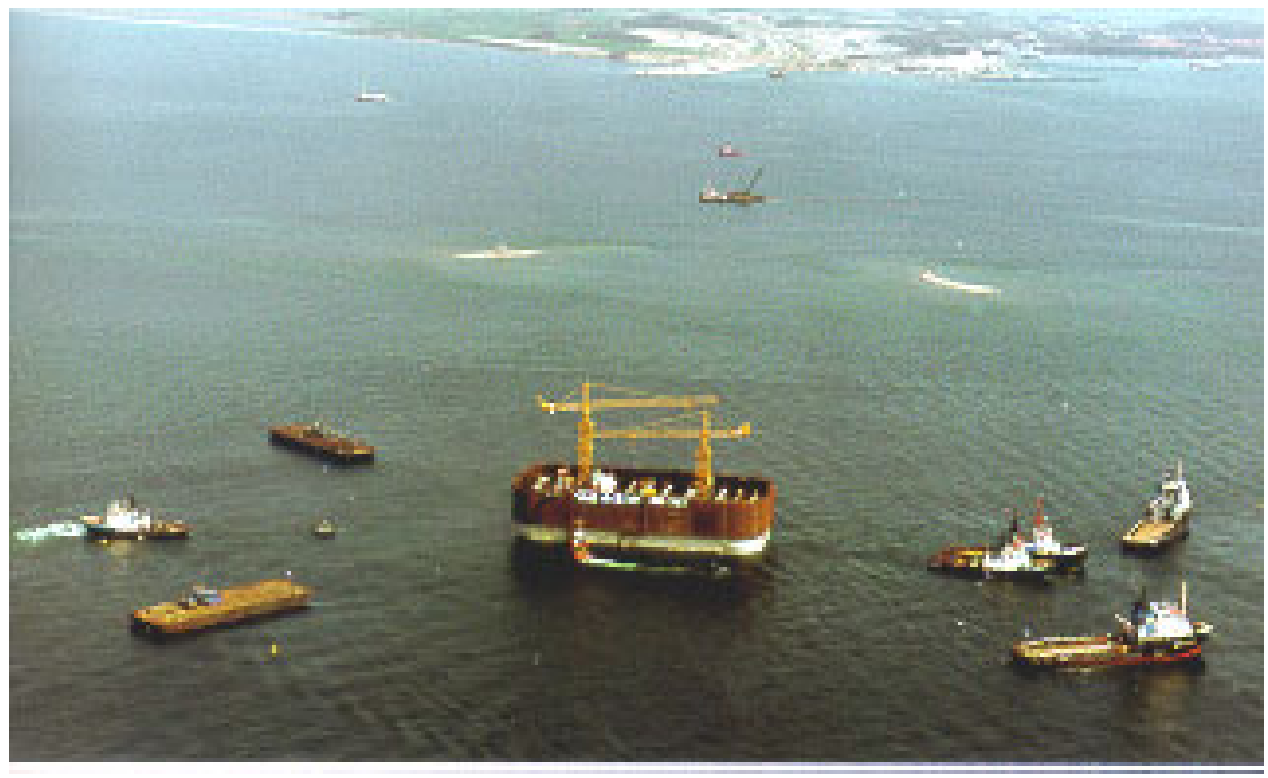

b. Taut line moorings and tugs position the caisson

Figure 3-9. At the site, caisson is held in position with mooring lines 
The bridge pier segments were erected with two shear-leg cranes-Taklift 4 and Taklift 7, with 1,600- and 1,200-ton lift capacity, respectively. Each pier segment was secured on a transport barge and towed to the site. Arriving at the site, the transport barge was moored between two shear-leg cranes that were also moored in prelaid anchor system. The mooring layout and tug arrangement are shown in Figure 3-10.

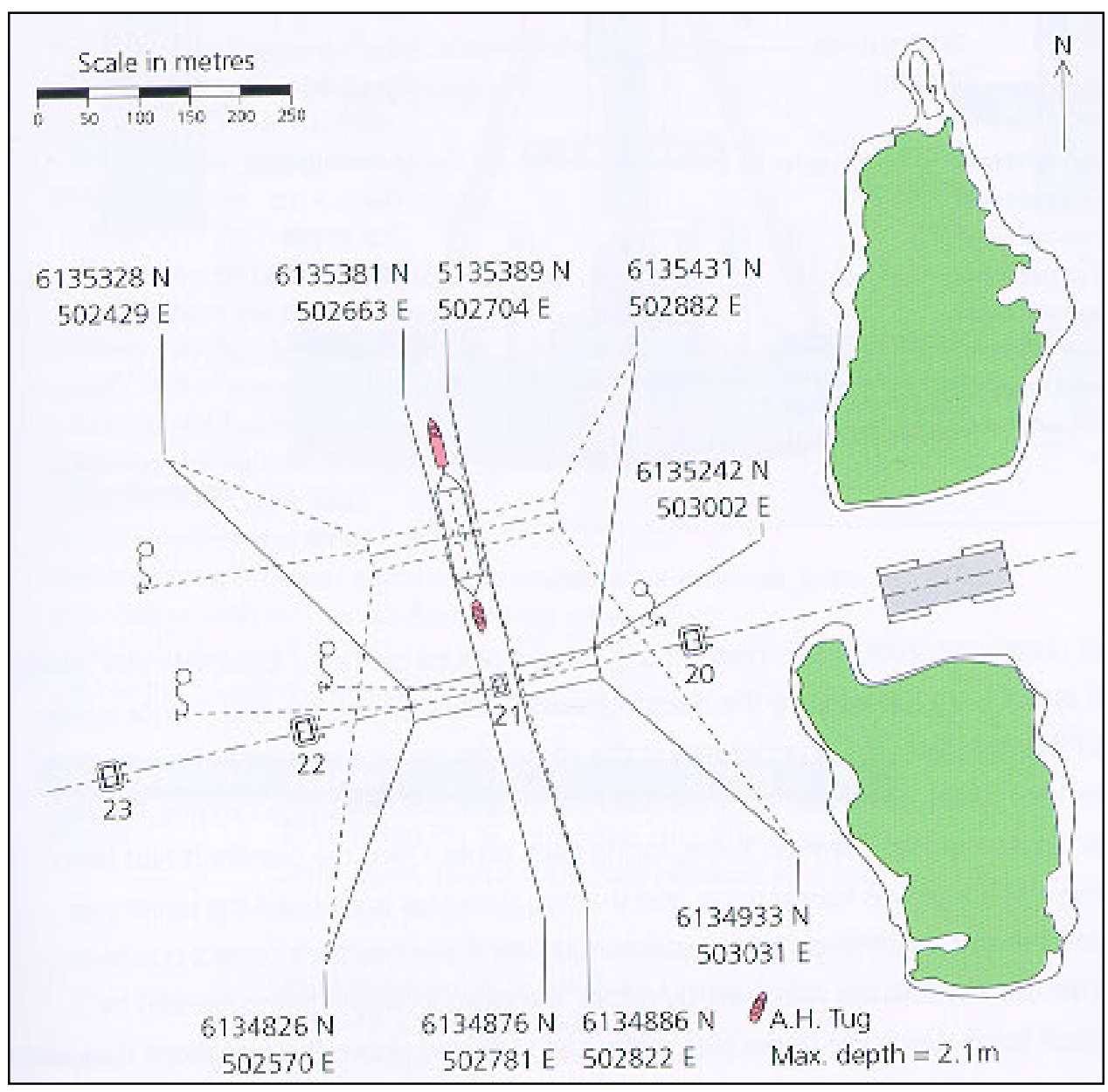

Figure 3-10. Mooring arrangement for placing a pier segment with two shear-leg cranes

The pier was then lifted off the barge by two shear-leg cranes, as shown in Figure 3-11. The lifting points on the pier were heavy steel pipe trunnions through the pier wall. Wire slings connected the trunnions to the spreader frame hanging in the hooks of the shear-leg cranes, as shown in Figures 3-11 and 3-12. Once the pier shaft had been lifted off the deck, the barge was towed away and the shear-leg cranes carrying the pier moved laterally to the pier position by means of deck winches. The exact location of the pier shaft was marked by vertical lasers. Once the pier shaft had stabilized above the pier base, it was lowered onto flat jacks that were previously placed on the pier base. The flat jacks were used for fine vertical adjustment. 


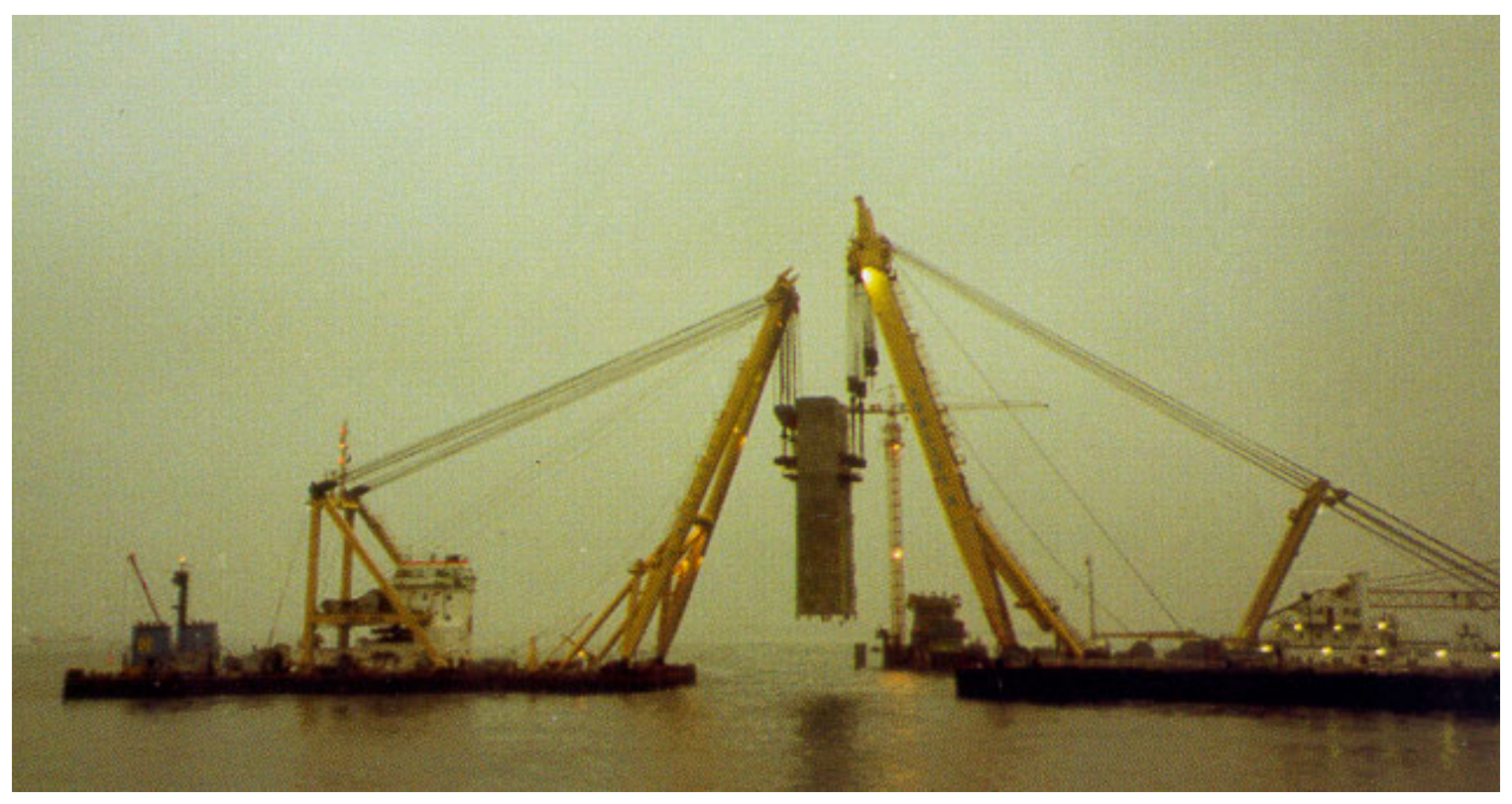

Figure 3-11. Transporting and placing a pier segment with two cranes

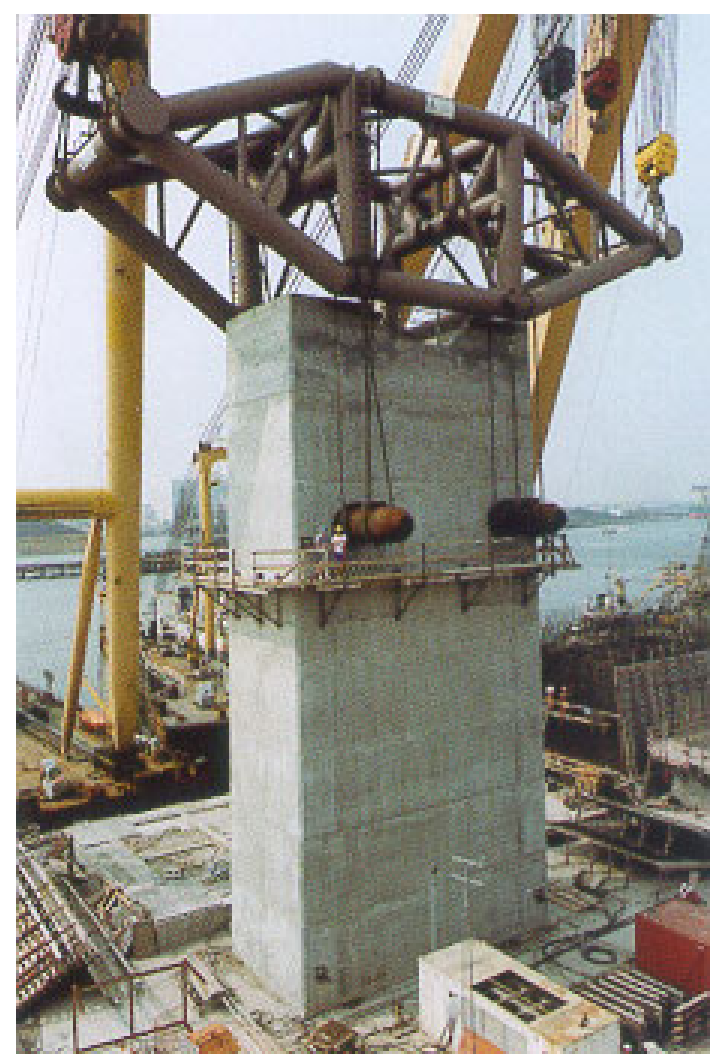

a. Dual lift of a pier

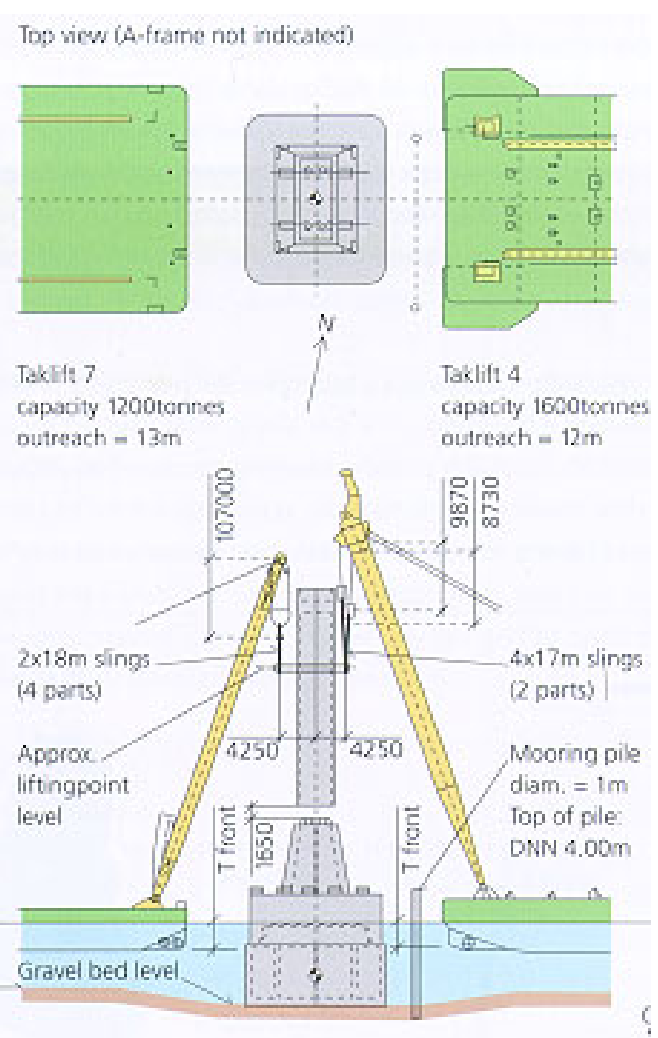

b. Dual-lift placement

Figure 3-12. Pier shaft-from barge to permanent pier base 


\section{3-3 Oresund Crossing-Immersed Tunnel}

The Oresund Crossing is a fixed traffic link between Denmark and Sweden. The link, completed in 2000, consists of a 4,050-m-long tunnel, a 4,044-m-long artificial island, and a 6,660-m-long bridge. The immersed tunnel was constructed primarily with immersed tunnel technology, with 20 precast/prestressed concrete segments, each about $175 \mathrm{~m}$ long and $550 \mathrm{MN}$ in weight.

Positioning and installing the immersed tunnel segments across the Oresund Strait was very challenging, because the currents at the site are variable and often very high. This led to the development of a new and versatile mooring system for positioning of the tunnel segment.

The common anchor system for positioning immersed tunnel elements is preinstalled anchor points. When transporting a segment through a trench, however, the cables have to be moved forward to mooring points, requiring disconnection and reconnection to the different points. This is a time-consuming, difficult underwater operation with high risk of failure.

For installing the immersed tunnel segments at Oresund Crossing, a more reliable and faster anchor system was applied. The anchor system consists of nine jack-up platforms, also known as "anchor islands." Each jack-up platform is a triangle frame supported by three legs (Figure 3-13). The triangle platforms were connected to the anchor cable, creating movable anchor points that could be shifted and positioned quickly by jacking down, moving, and jacking up.

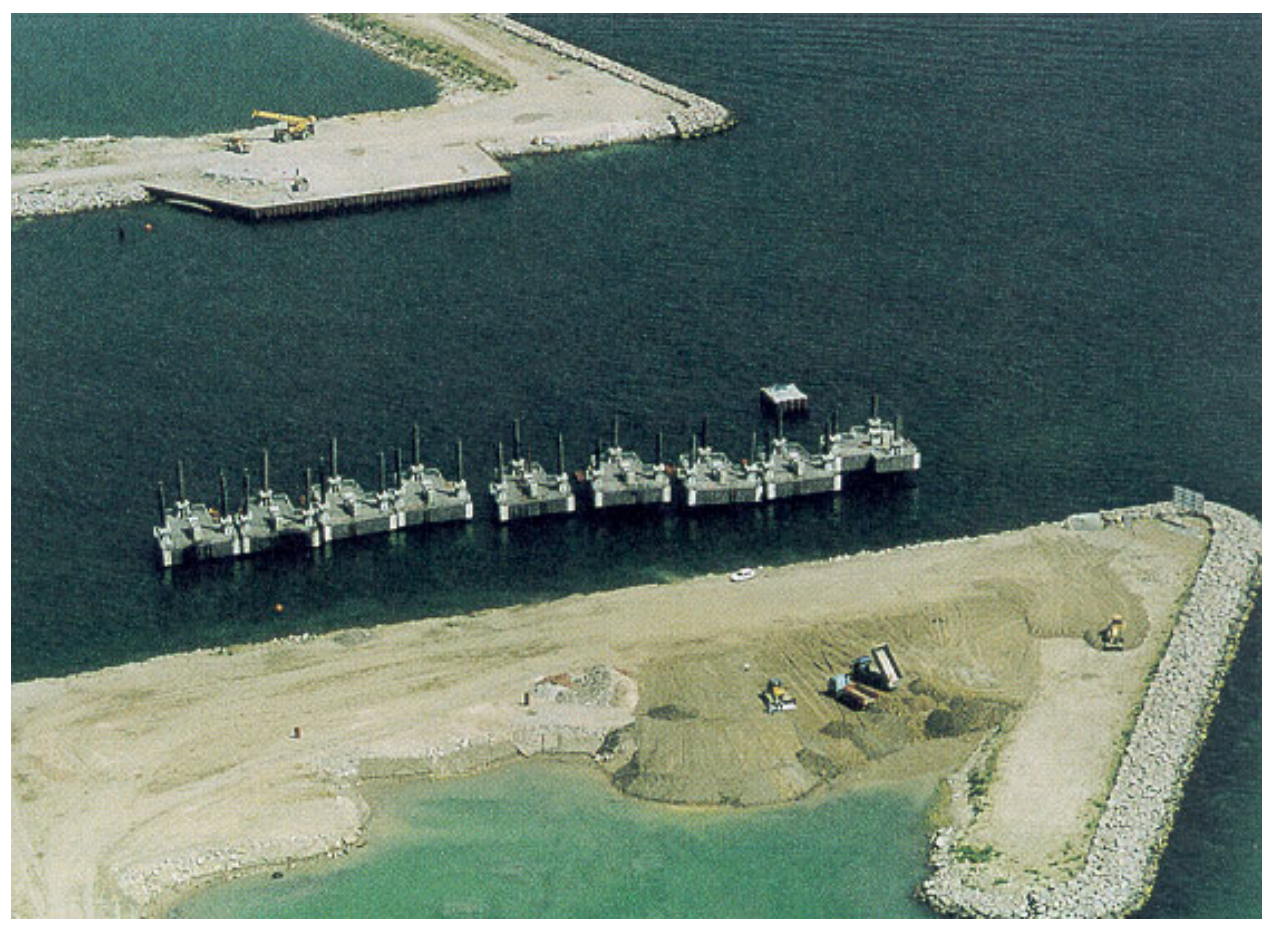

Figure 3-13. Jack-up platforms were used as "anchor islands" for positioning 
Two catamaran-type immersion pontoons were purpose-built for assisting transport and immersion of the tunnel segment. Each catamaran had two hulls linked by a deck supporting four 660-kN (150-kip) mooring winches for positioning and two $350-\mathrm{kN}$ lowering winches for immersing the tunnel segment (Figure 3-14). The winches were operated in pairs on each pontoon. The positioning winches adjusted the tunnel segment alignment through tag lines, while the lowering winches controlled the immersion speed and leveling of the segment. The winches' capacity was designed to accommodate $1 \mathrm{MN}$ of wave action on the immersion pontoons, $0.5 \mathrm{MN}$ imbalance current forces on the tunnel segment, and $2 \mathrm{MN}$ for the apparent weight of the segment. Each lowering point was equipped with digital load indicators and draft indication for the hull. All the monitoring information was instantaneously transferred to the winch operator and to the command tower.

The immersion pontoons are floated above the tunnel segment a few days before towing. Once the segment was towed to the site, the catamaran pontoons were moored to eight preset anchor islands. Figures 3-15 and 3-16 show the general positioning and immersion process.

During the operations, position monitoring was conducted by differential global positioning system (DGPS), real-time kinematic data from three antennas on masts on the roof of the segment, and data from land surveys of the preceding segment face. Through the real-time positioning data and skillful control of the deck winches, the pontoons were positioned within $200 \mathrm{~mm}$ of the specified location.

The ballasting was implemented immediately after the pontoons were positioned. The ballast tanks in the tunnel segment comprised three to four main tanks across the full width. Once all ballast was in place, the lowering winches on the pontoons were gradually released to lower the tunnel segment. When the segment was within the trench and $1 \mathrm{~m}$ above the gravel bed, it was pitched toward the previously placed segment and engaged with a horn guide on its roof for alignment. At that stage, it could be lowered to touch the gravel bed and pulled forward against the previous segment. The joint between the two segments was sealed by squeezing of the preinstalled Gina seal and dewatering.

After the segment had set and the joint chamber dewatered, surveys were made with DGPS antennas from inside the tunnel through the access shaft. If the survey showed the alignment deviated by more than $11 \mathrm{~mm}$, realignment had to be performed.

For realignment, winches on the immersion pontoon pulled the lowering wire ropes to slightly lift the segment in order to reduce friction on the gravel bed. Then, hydraulic jacks on the bulkhead were slowly pressurized to realign the segment. Once in position, the segment was fully ballasted to its final position.

All of the immersed tunnel segments were placed within tolerances of $10-\mathrm{mm}$ horizontal alignment and 5-mm vertical alignment. 


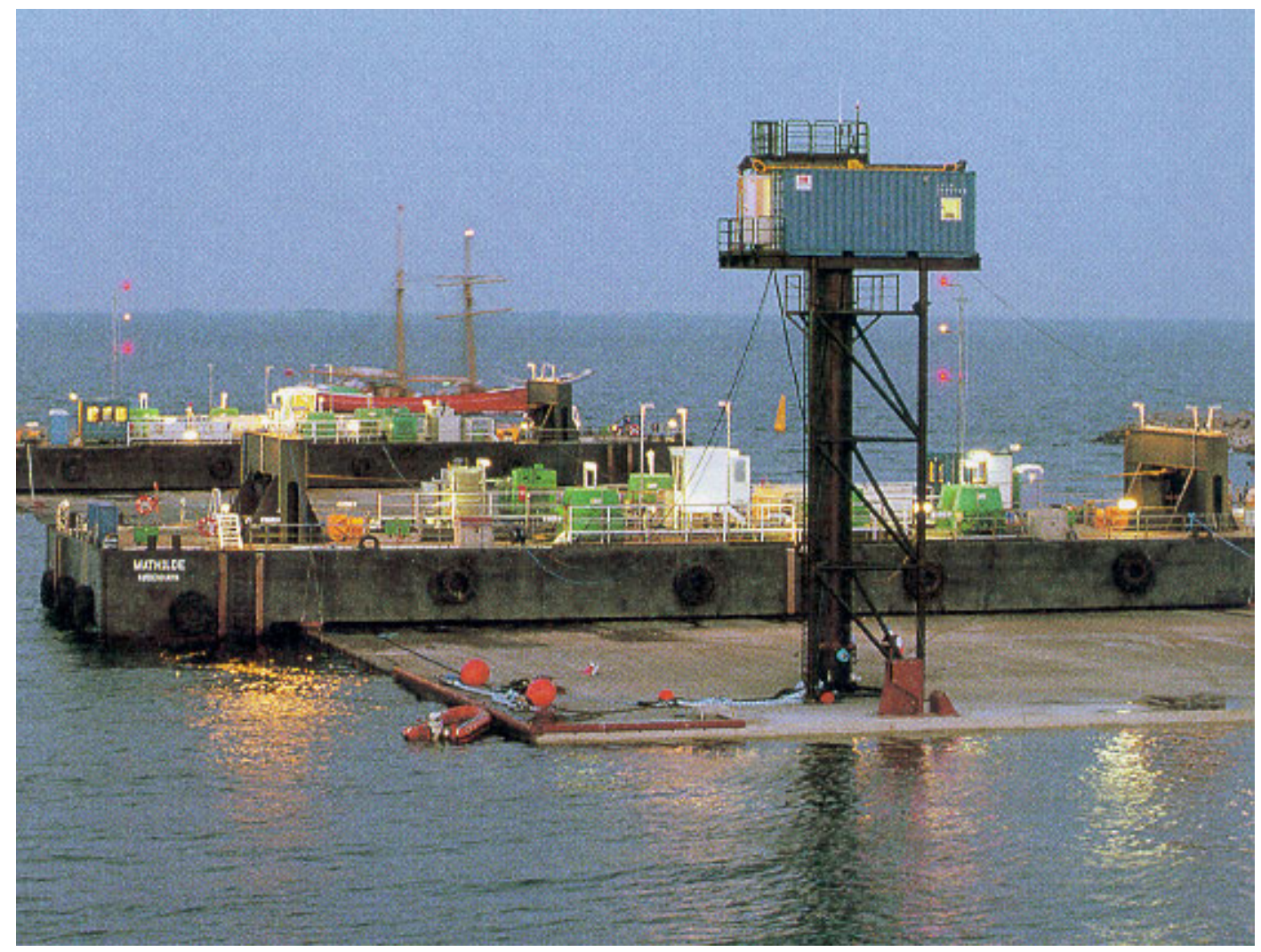

a. Two catamaran-type immersion pontoons above the tunnel segment

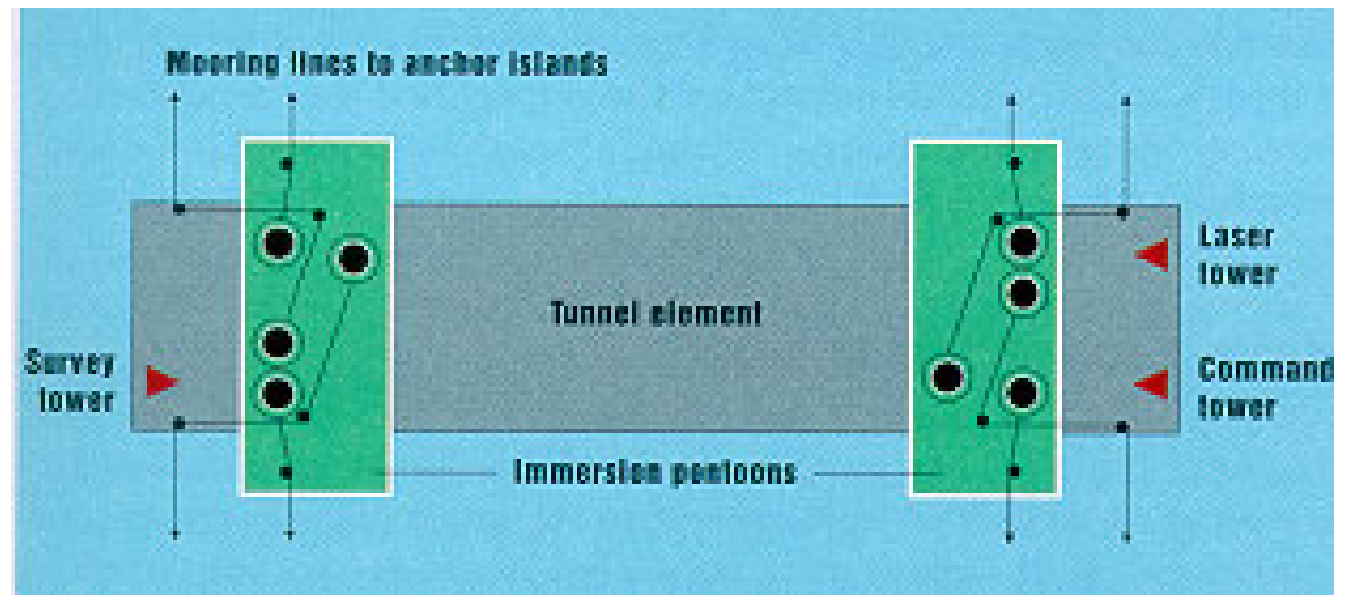

b. Mooring arrangement

Figure 3-14. Use of immersion pontoons 


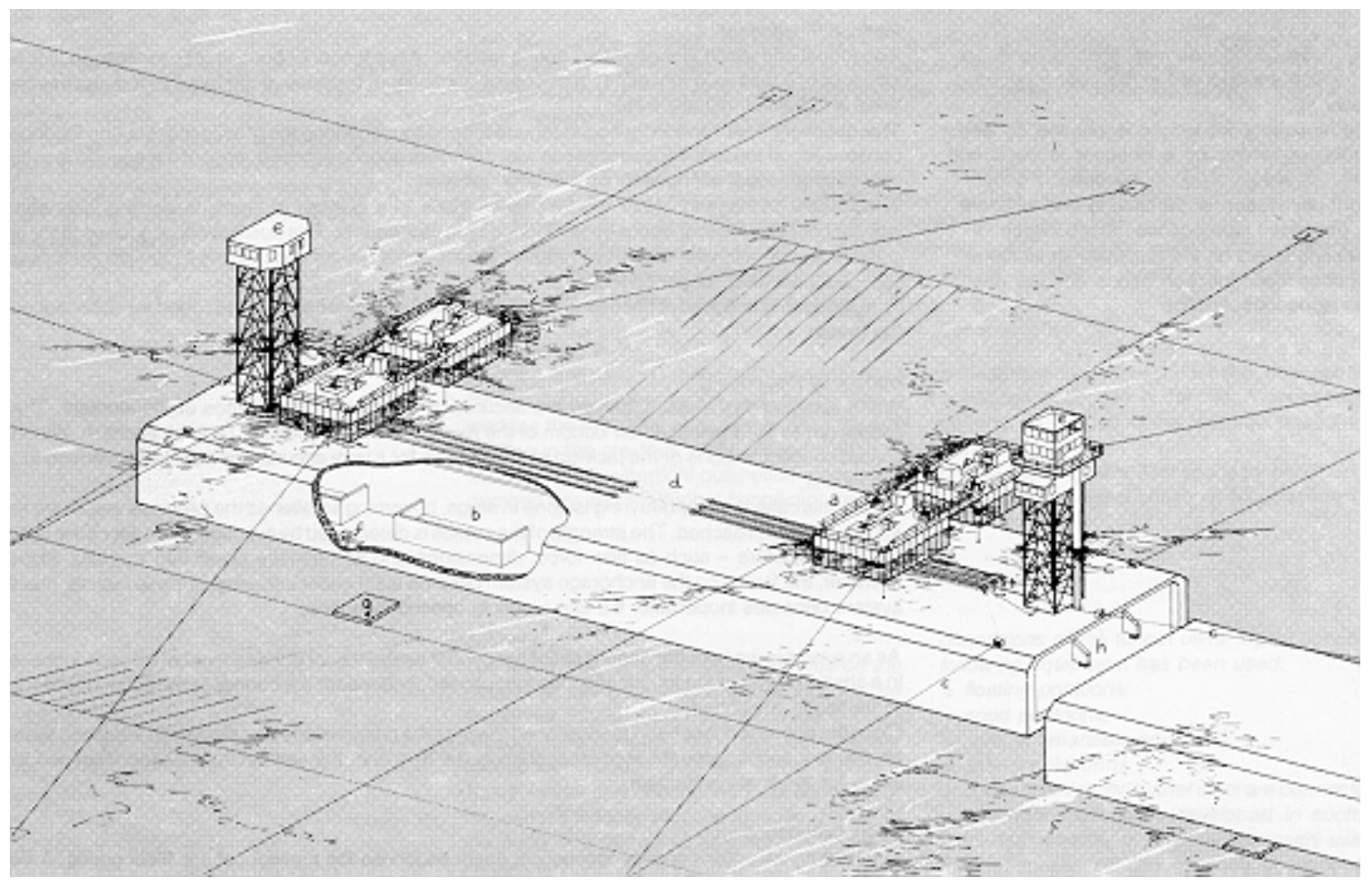

Figure 3-15. Schematic representation of immersion operation

\section{3-4 Braddock Dam-Float-in Construction}

The float-in portion of the Braddock Dam is approximately $600 \mathrm{ft}$ in length. This total length will be divided into two float-in segments. Float-in Segment 1, approximately $333 \mathrm{ft}$ long and $106 \mathrm{ft}$ wide, includes the fixed weir bay, the water quality bay, and one of the standard gate bays. Float-in Segment 2, approximately $265 \mathrm{ft}$ long and $106 \mathrm{ft}$ wide, includes two standard gate bays. Each floatin dam segment comprises the gate sills, a portion of the stilling basin, the pier walls, and bulkheads. The segments are positioned and ballasted down onto preinstalled setdown drilled shafts.

A positioning system is used to position the segments while they are being ballasted onto the setdown shafts. The positioning and installation system for each float-in segment consists of the following components:

a. An eight-point mooring system attached to anchor piles and anchors.

b. Type "A" (78-in.-diam) anchor piles with a 36-in.-diam insert pile and a steel collar placed around the insert pile that allows the mooring line to rotate freely.

c. Type "B" (42-in.-diam) anchor pile installed on the left bank.

d. Anchor bracket installed on top of the existing lock wall. 


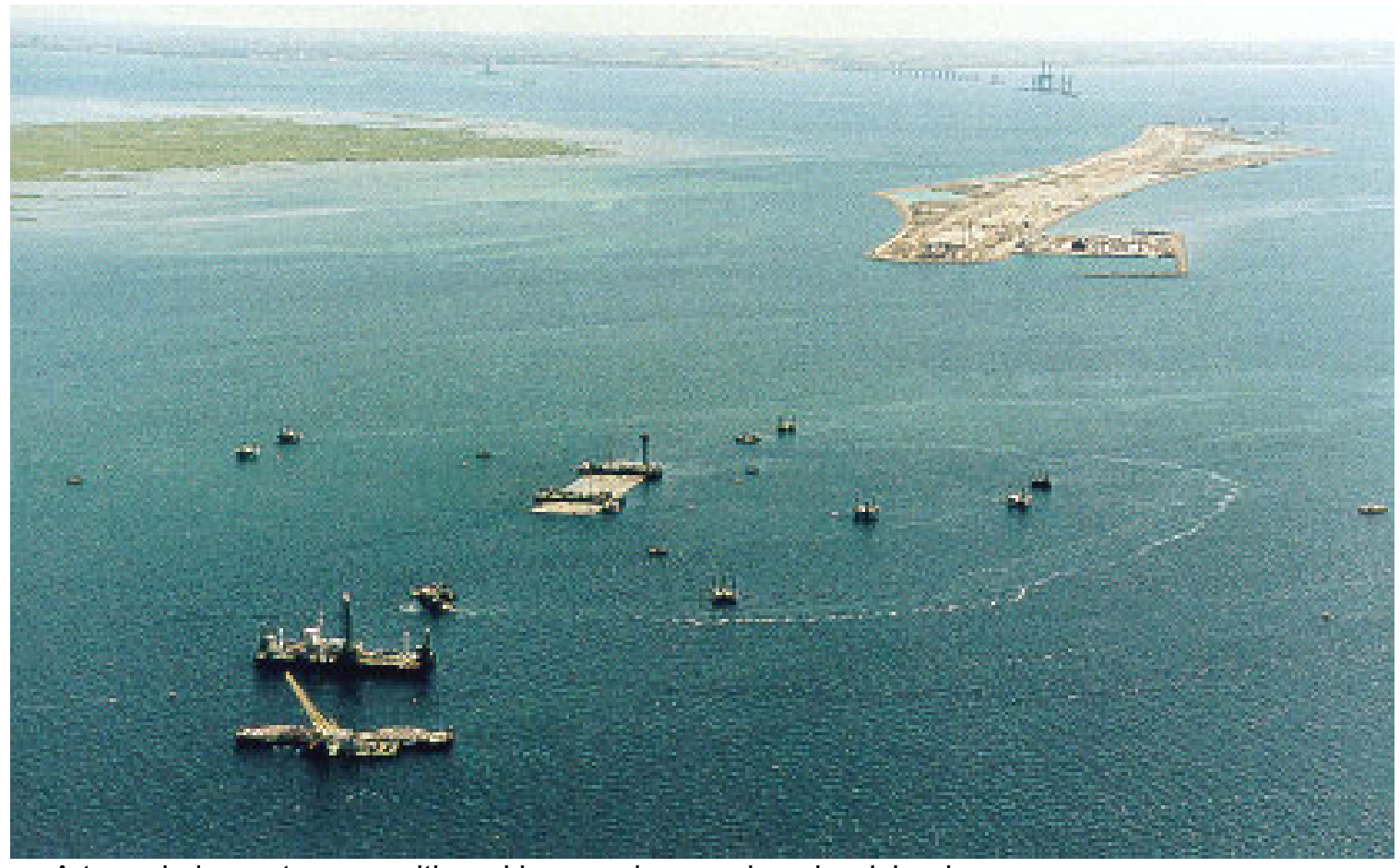

a. A tunnel element was positioned by moorings and anchor islands

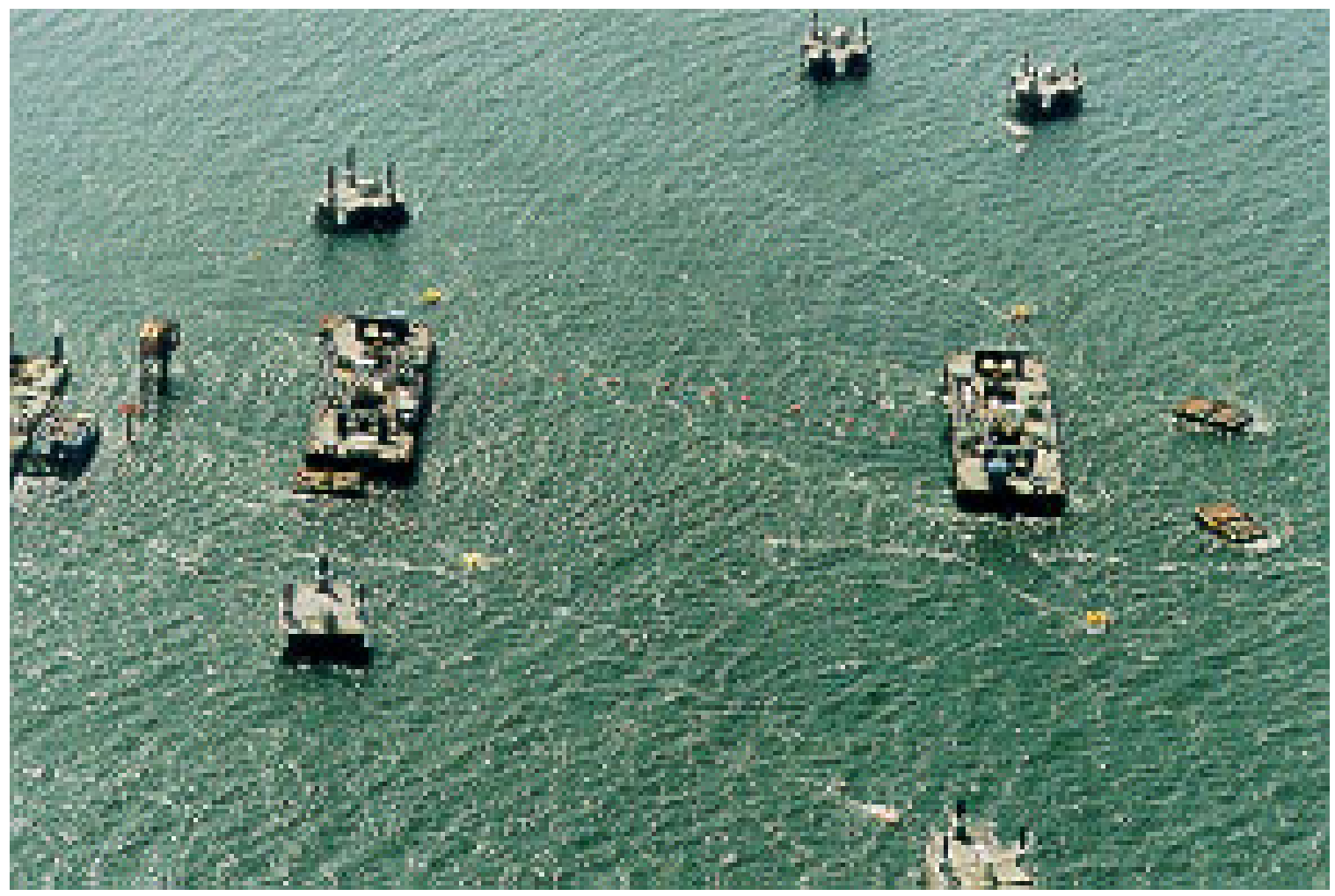

b. Immersion pontoons were surrounded by anchor islands

Figure 3-16. Immersion operation 
e. Stock-type anchors for the downstream mooring lines.

f. Two- and three-drum hydraulic-powered anchor winches placed on top of the piers.

g. Vertical and horizontal guide sheaves.

$h$. A fully reversible ballasting system for lowering the segments.

i. Two steel guide structures (horn guides) located above water.

j. Six 78-in.-diam preinstalled setdown drilled shafts.

$k$. A flat-jack leveling system prepositioned within the floating segments.

l. A land-based conventional survey system with targets on the floating segments.

The sequences for positioning Segments 1 and 2 are illustrated in Figures 3-17 and 3-18, respectively. Tugs transport each segment from the outfitting pier to the dam site when the riverflow is below $25,000 \mathrm{cfs}$, which corresponds to a maximum water surface elevation of about $722 \mathrm{ft}$ with the small floodway open.

For positioning operations, each segment is connected to eight mooring lines (four upstream, two downstream, and one line on each side of the river). The mooring line layouts for installation of Segments 1 and 2 are shown in Figures 3-19 and 3-20, respectively. Figure 3-21 shows the design details of the anchor piles. The positioning and installation process for Segment 1 is described below.

Once the segment arrived at the immersion site, the support tug was released from the upstream of the dam axis and started to run the upstream and transverse mooring lines to the anchor piles. The arrangement of the upstream mooring lines is shown in Figure 3-22. With the segment held parallel to the flow, Line 4 was

first to be connected, then Line $2 / 3$. The main tug assisted rotating the segment at angle of $45 \mathrm{deg}$, and Line 1 was connected. The two downstream anchors (Lines 7 and 8) were connected. Finally, Line 6 was extended from pier 2 to the anchorages on the left and right abutments. When the mooring lines were in tension, the main tug was released. The mooring lines were controlled by two 3 -drum hydraulic winches mounted on the top of the outside piers and one 2-drum winch mounted on the center pier. The mooring lines are directed through fairleads (self-aligning guide sheaves) mounted at the nose and tail end of the piers, as shown in Figure 3-23.

The mooring lines were used to position the segments over the setdown shafts during the first $15 \mathrm{ft}$ of immersion. The primary horizontal guide system during immersion and landing of the float-in dam segments was a pair of horn guides. The horn guides were 9-ft-high, tapered steel guide frames designed to direct the end of the segment into exact horizontal alignment in the 


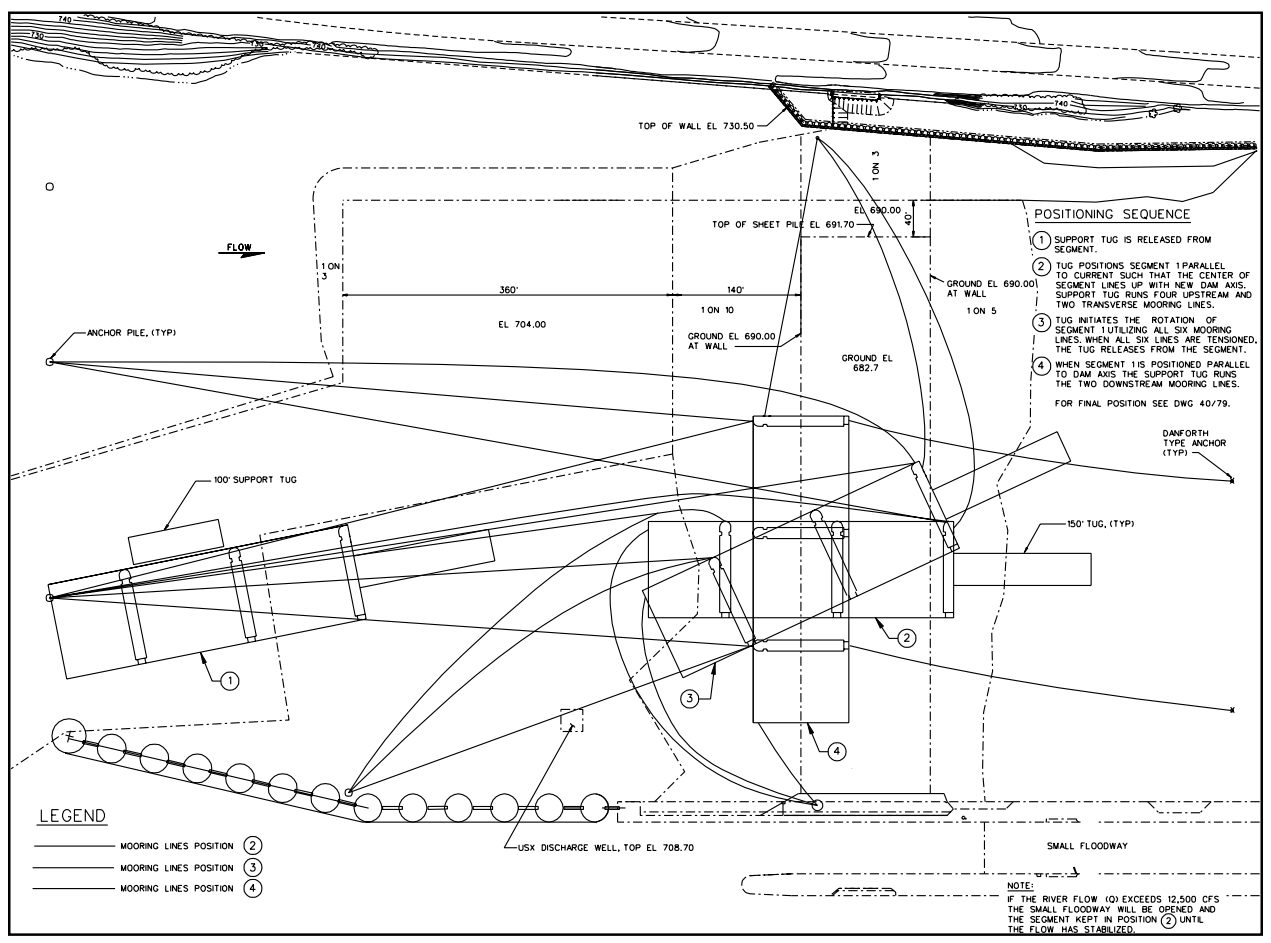

Figure 3-17. Construction sequences for positioning Segment 1

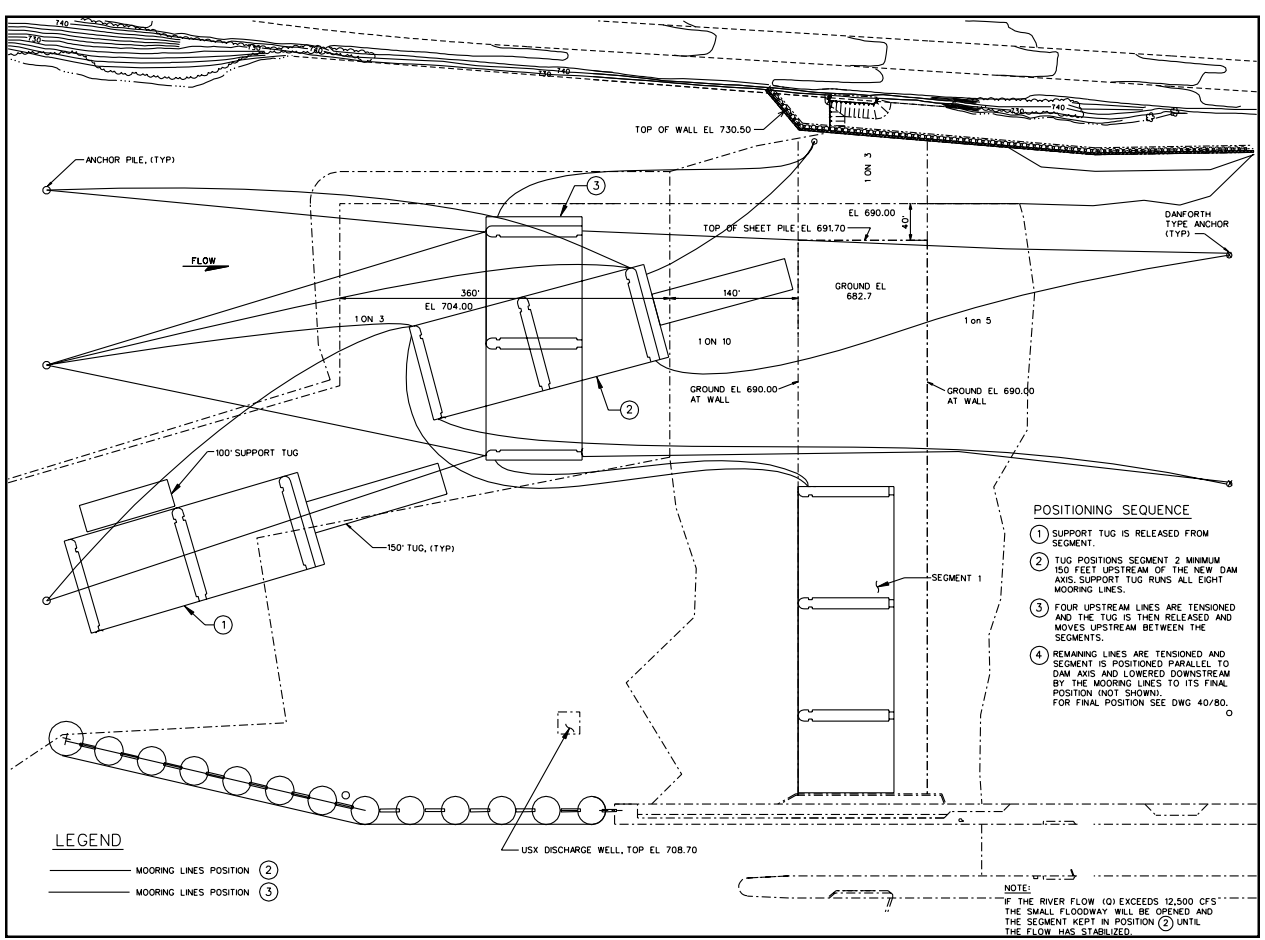

Figure 3-18. Construction sequences for positioning Segment 2 


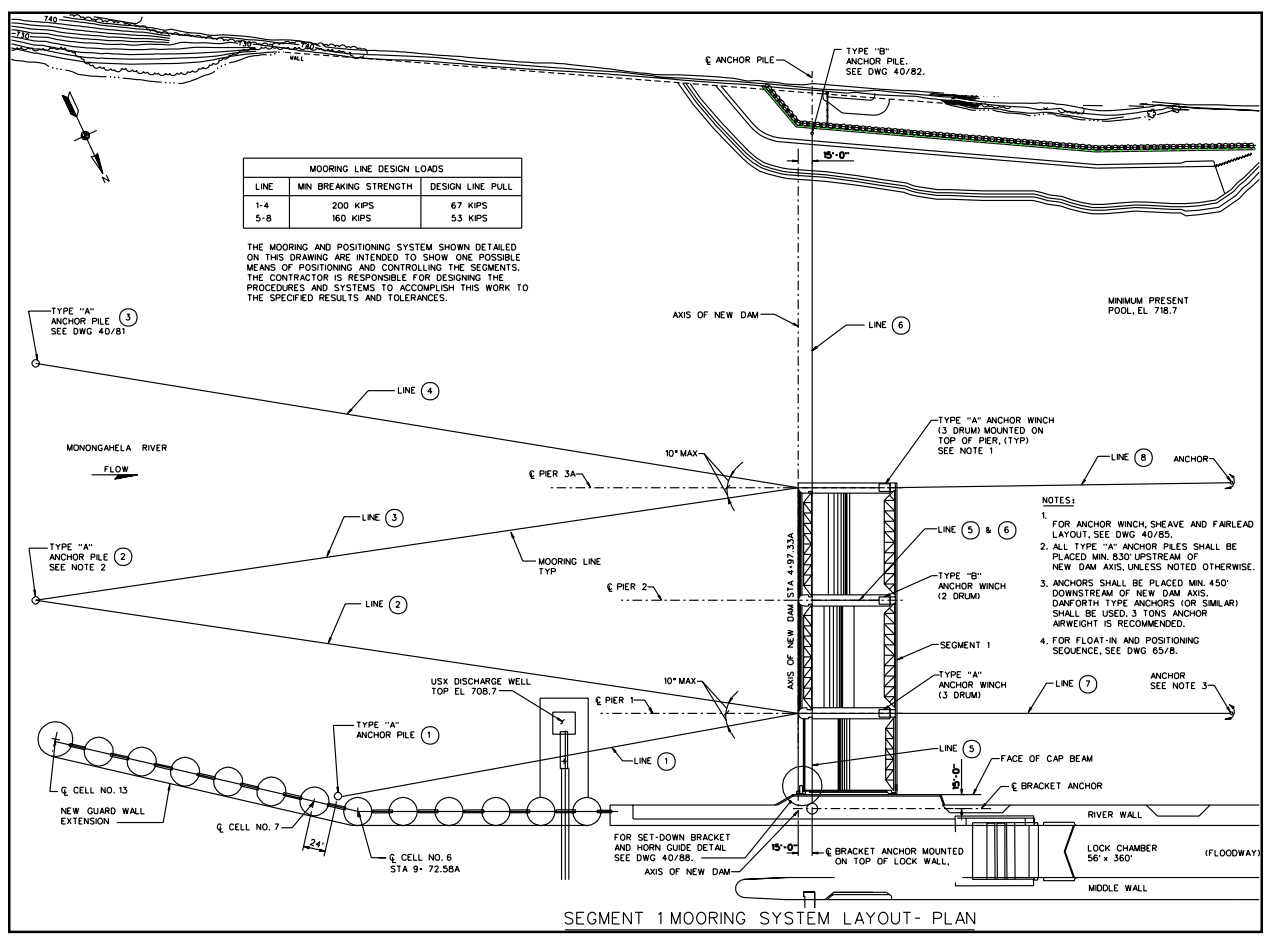

Figure 3-19. Mooring arrangement for placing Segment 1

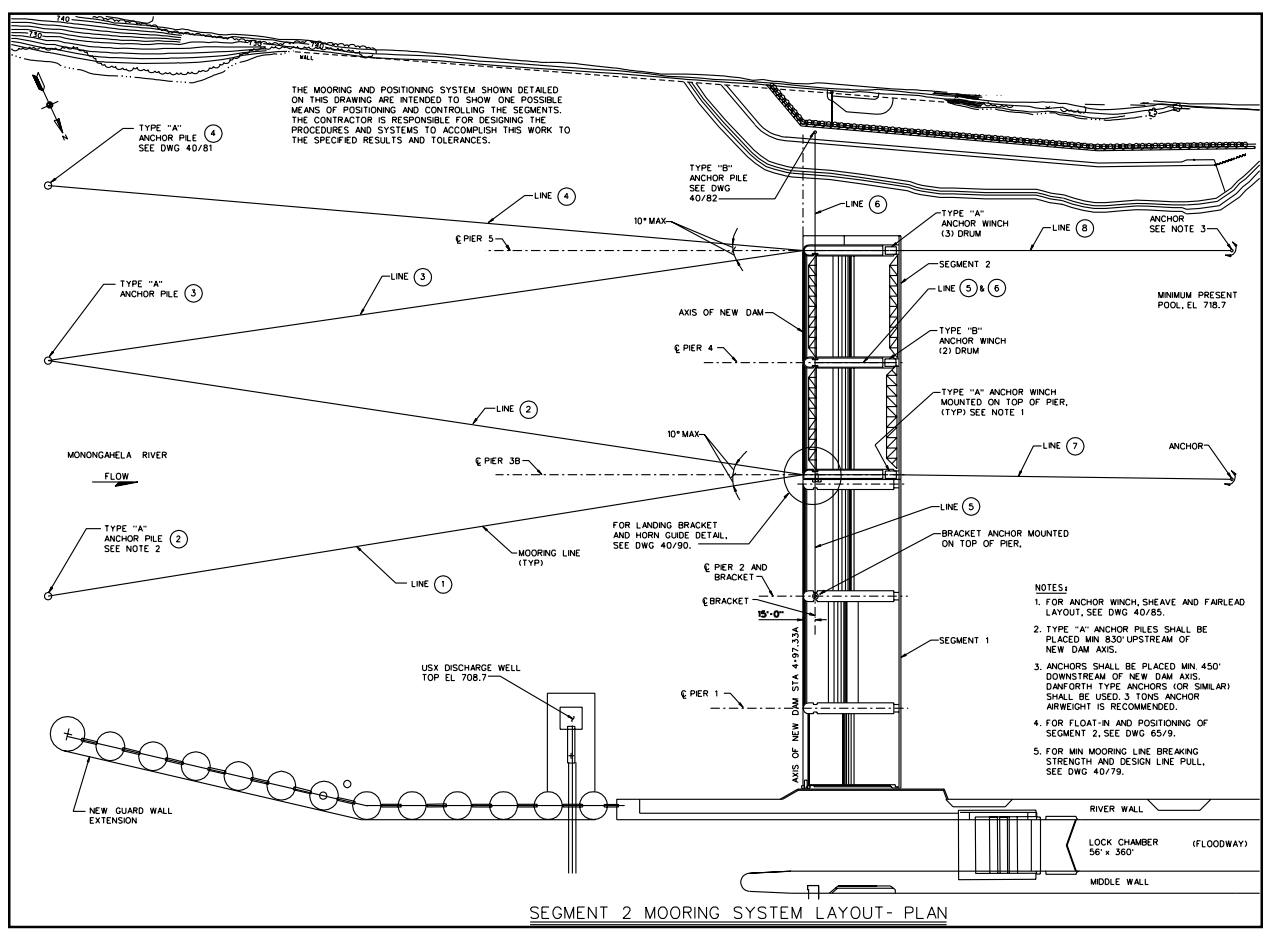

Figure 3-20. Mooring arrangement for placing Segment 2 


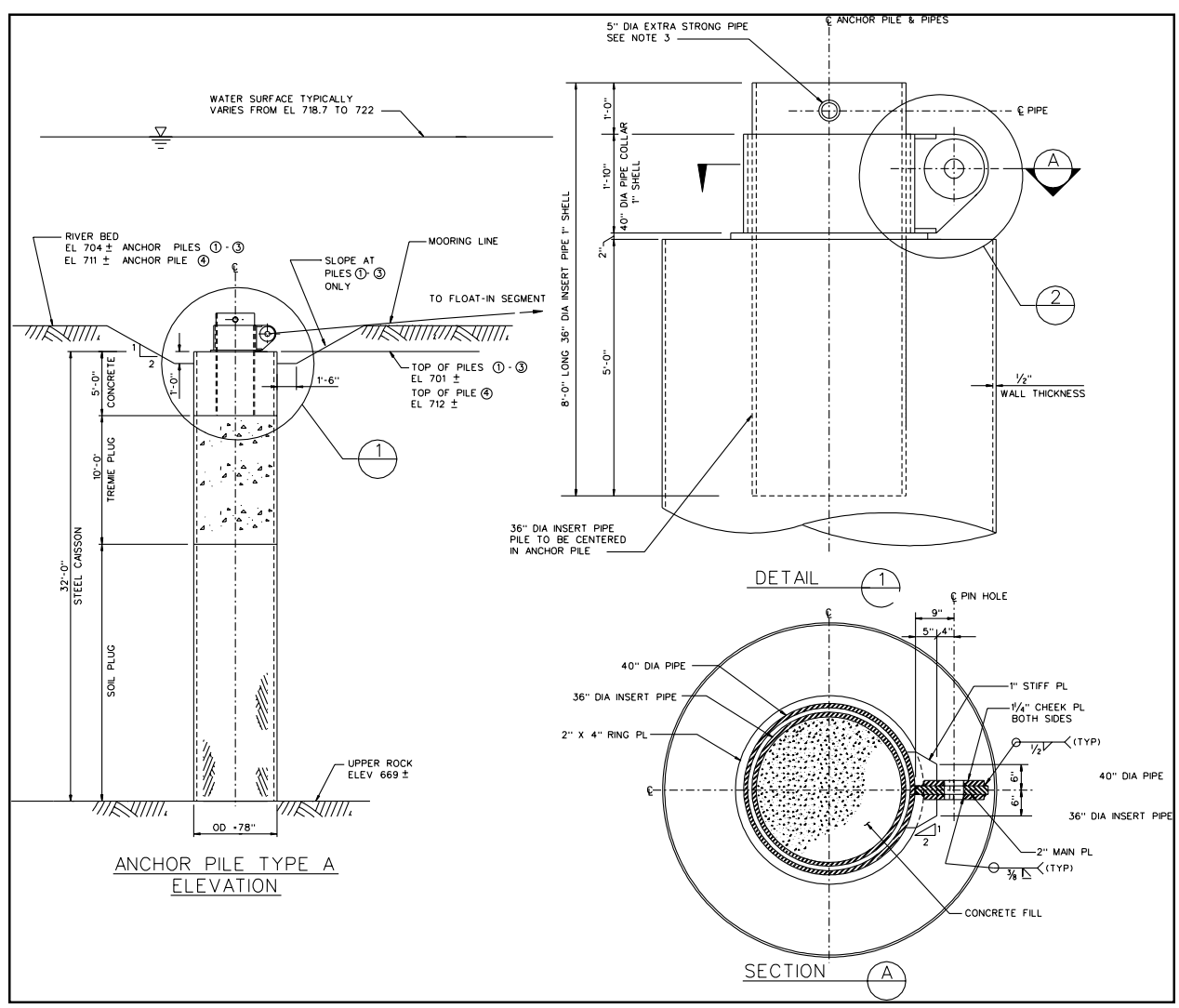

Figure 3-21. Details of anchor pile type "A"

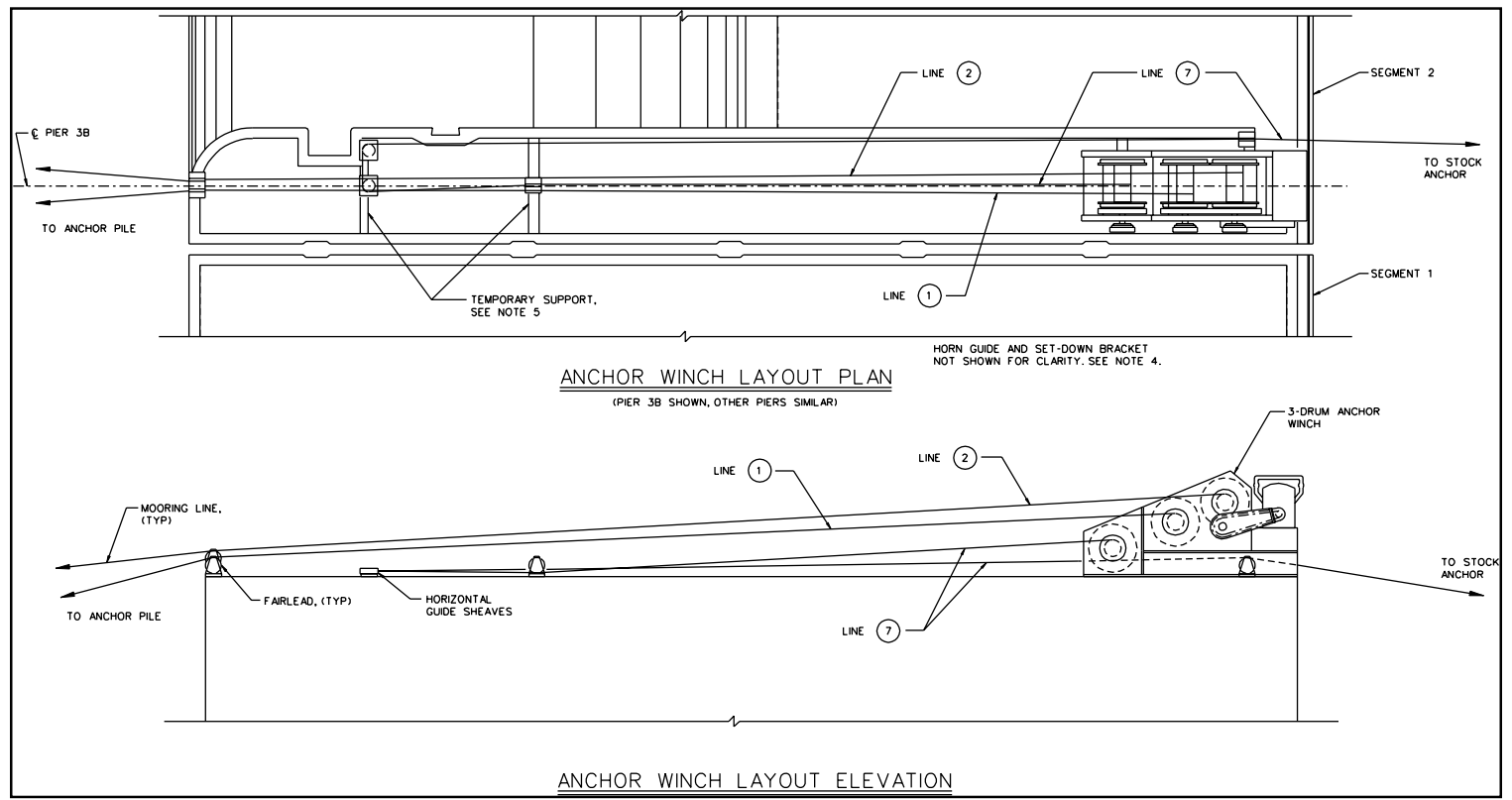

a. Anchor winch layout on pier top surface

Figure 3-22. Layout of upstream mooring lines for Segment 1 (Continued) 


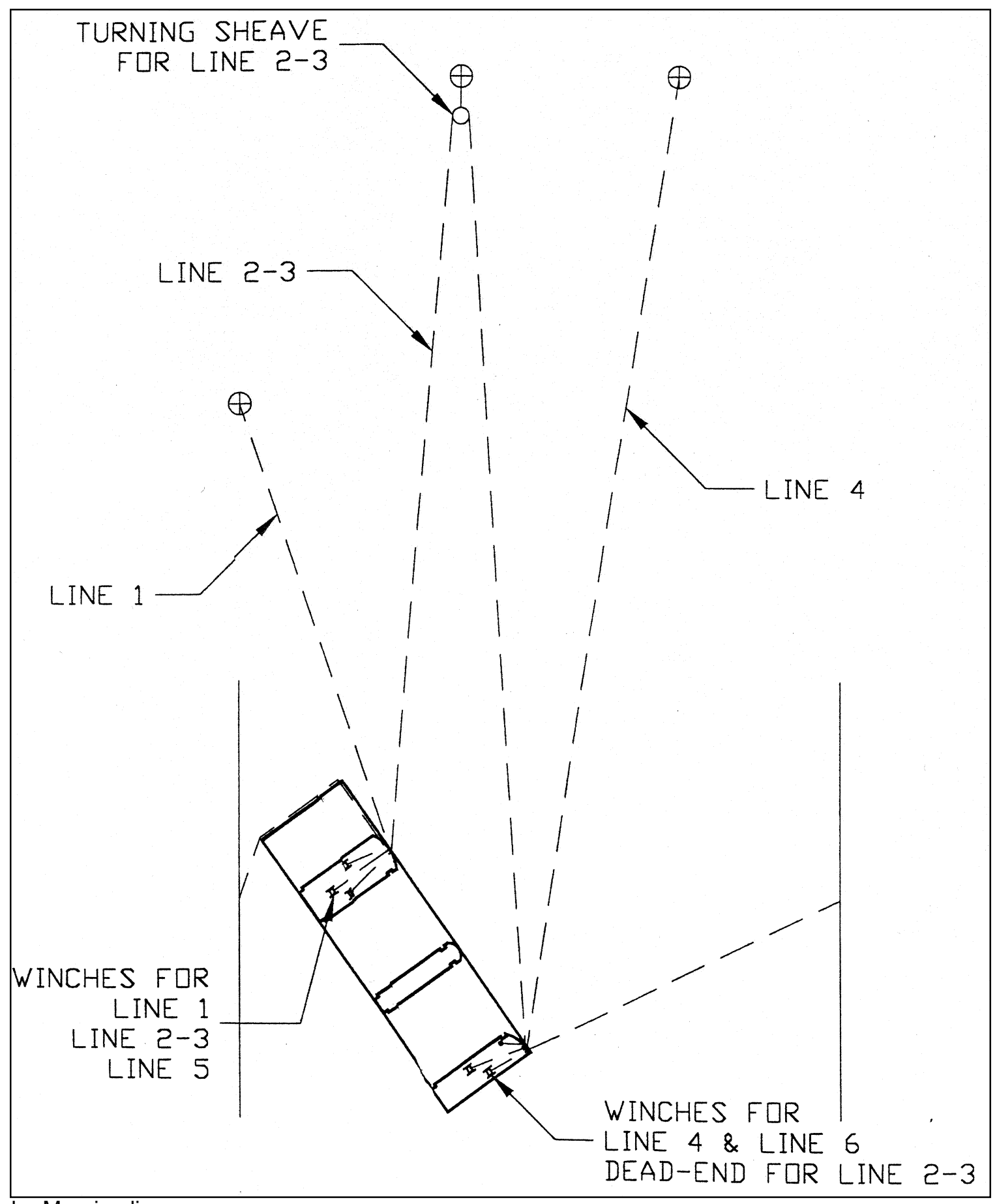

b. Mooring lines

Figure 3-22. (Concluded)

upstream/downstream direction as the segment was ballasted to grade. The guides are located above water and are bolted to the outside face of the lock wall for Segment 1. Figures 3-24 and 3-25 show use of the horn guides during the setdown of Segment 1. 


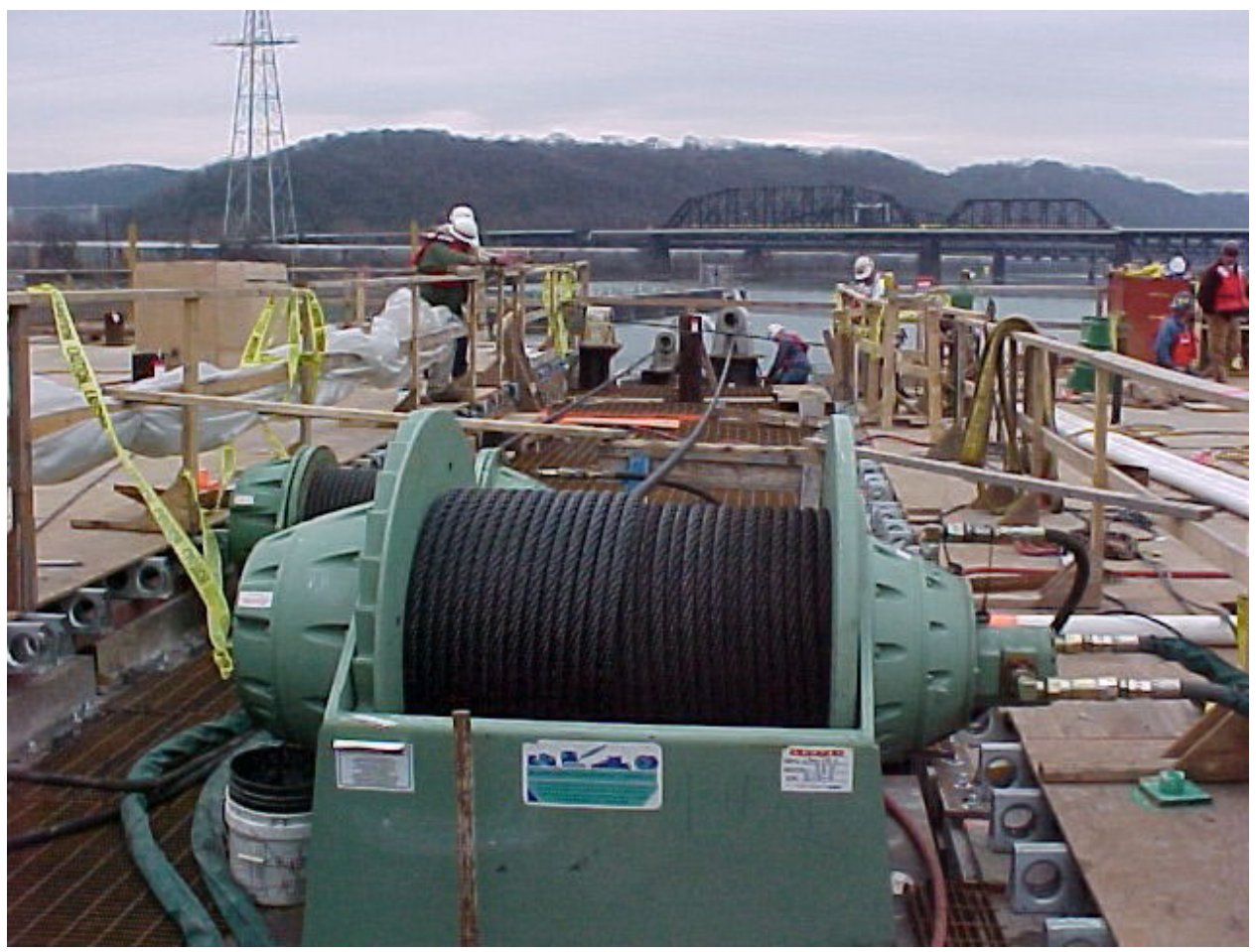

Figure 3-23. Winches on pier 1 of Segment 1

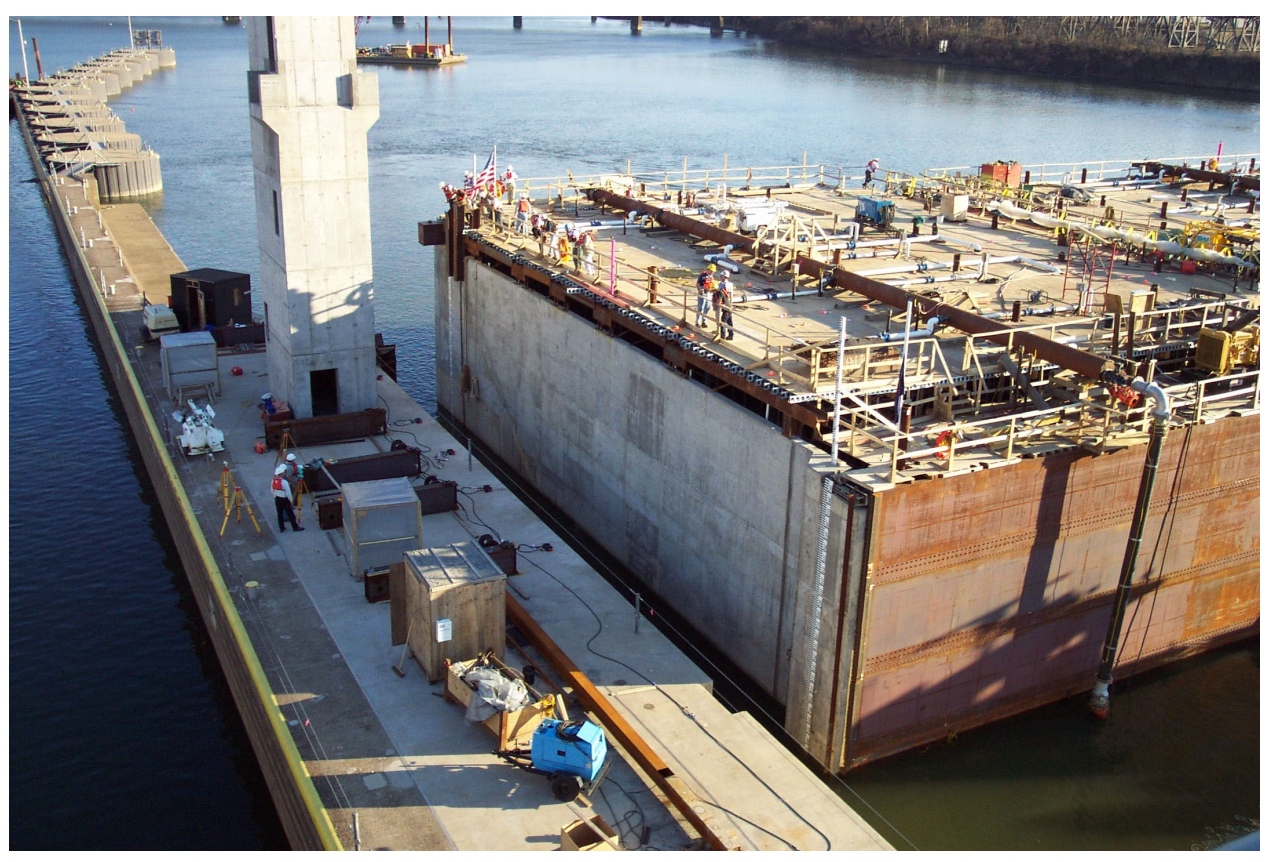

Figure 3-24. Positioning Segment 1 against the guide wall with a horn guide 

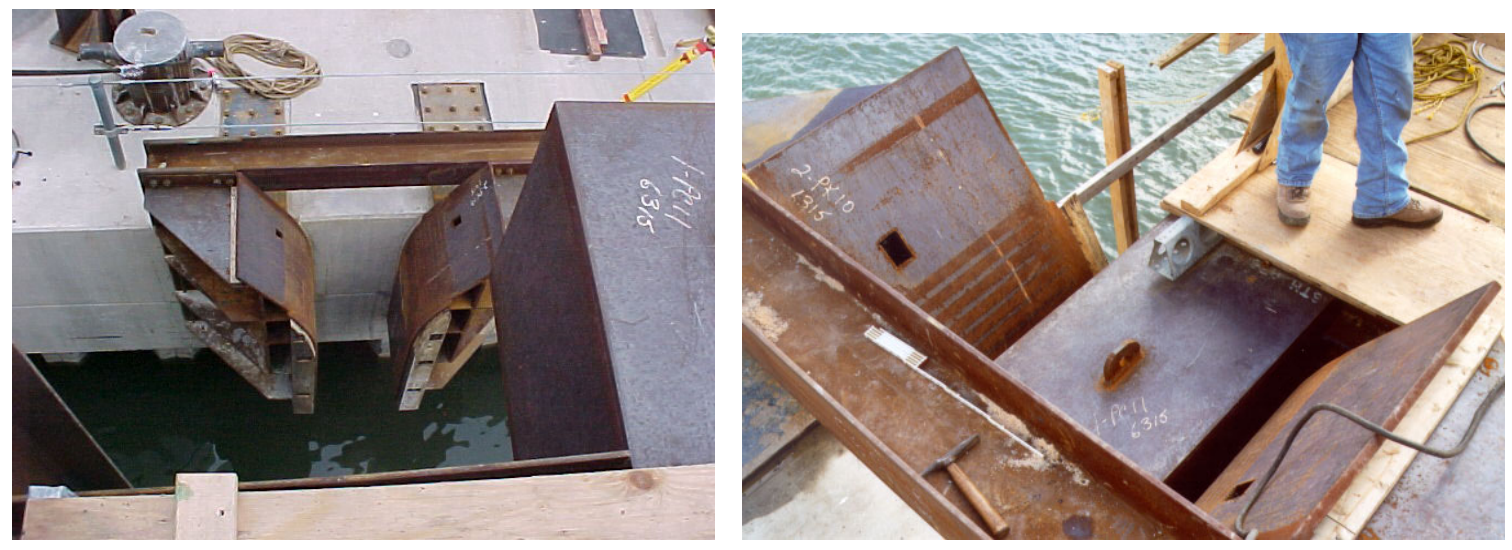

Figure 3-25. Horn guide used for positioning Segment 1 during setdown

Ballasting of the segment was performed by flooding the segment's interior compartments and bays. Water was introduced into the segments by a gravity feed system of pipes and valves (see Figure 3-26). The same piping system was used in conjunction with electrical submersible pumps to dewater the compartments and raise the segment if necessary. The ballasting system was designed for a ballast rate of $6 \mathrm{ft}$ per hour. In the event that water surface elevation increased unexpectedly during this process (exceeding the maximum immersion limit of $722 \mathrm{ft}$ ), the ballast system would be fully reversible and the segment would be deballasted at a rate of $4 \mathrm{ft}$ per hour.

The conventional survey methods were used to monitor the positioning process of the segment (Figures 3-27 and 3-28). Survey equipment consisted of total station units, automatic levels, and electronic distance measurement targets. Total stations were set up on the lock wall and also on the left bank. The instrument located on the lock wall was the primary survey control coordination point (Figure 3-27). The instrument located on the left bank was used for confirmation and backup.

Vertical lines were marked on the starboard side of the segment and on the temporary bulkhead on the port side. A 180-deg reflector prism was mounted on a survey tower that projects to a height of $40 \mathrm{ft}$ above the bottom of the segment on the starboard side. A horizontal control line was mounted along the top of the walls at the bow and stern ends of the segment. This line was marked, starting from " 0.00 feet" at the axis of the dam on the starboard side and progressing to "104.00feet" at the port side. Also, a horizontal control line was marked on the temporary bulkheads on both the starboard and port sides. It was marked in 10-ft increments, beginning at "0.00feet" at the vertical line and going to " 150.00 feet" at the stern of the segment.

As the segment was submerged, survey instruments were continuously monitoring to confirm that the axis of the segment stayed on the dam axis alignment as designed, and the setdown bracket was aligned for entry into the horn guide. 


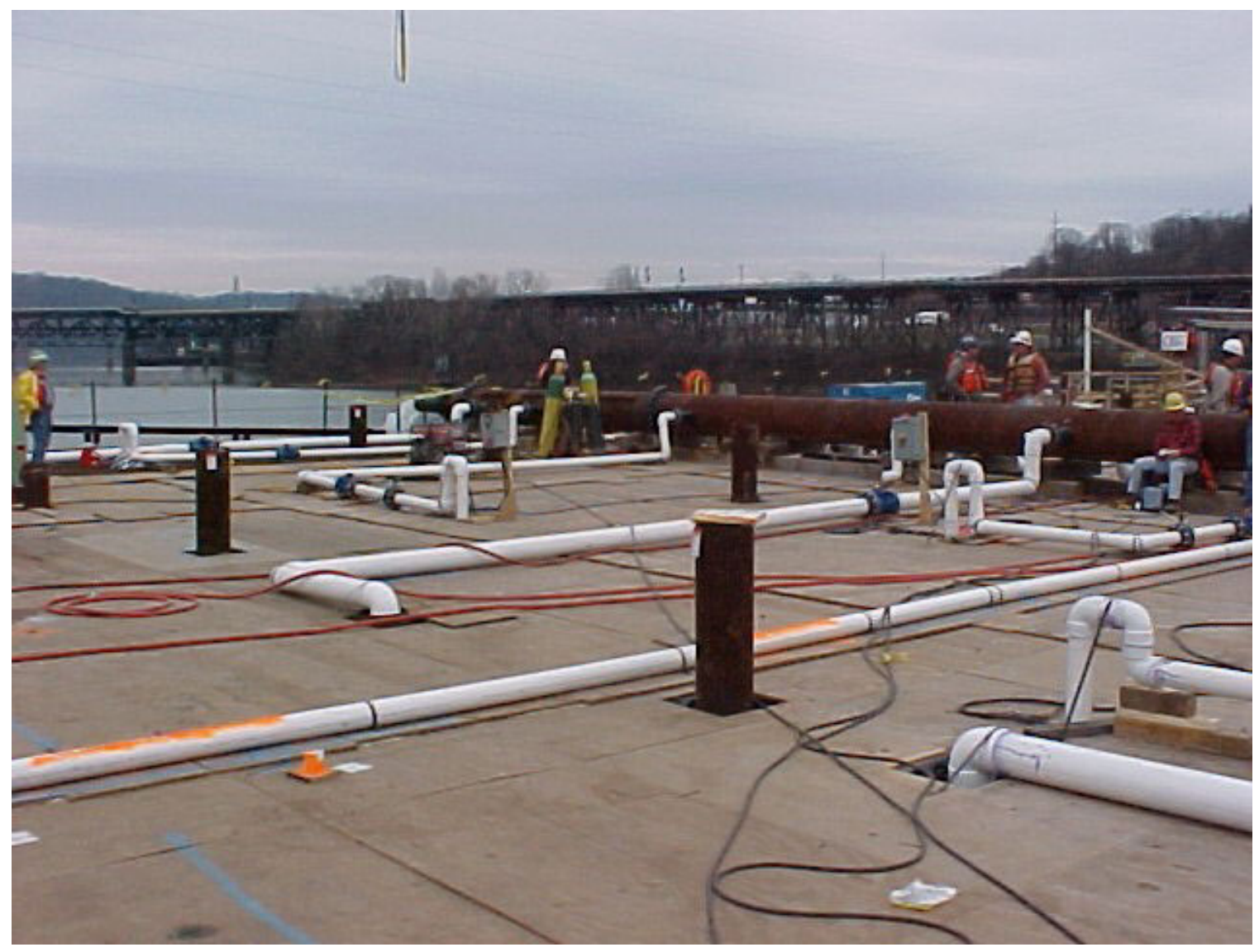

Figure 3-26. Ballasting pipes on the work deck of Segment 1

After alignment was confirmed, the segment was leveled to a tolerance of \pm 0.5 in. vertically with the flat jacks located directly over the six setdown drilled shafts.

Ballast water was then pumped into Segment 1 until the segment was ballasted to 15 percent negative buoyancy. From this point on, the six setdown drilled shafts provided the primary means of resisting horizontal loads until the main foundation drilled shafts were grouted into the structure. (The steel contact surfaces between the top of the landing pile and the underside of the flat-jack piston were sufficiently roughened to ensure a minimum friction factor of 0.50 ). The jacks were located in the dam segment rather than on the setdown drilled shaft in order to allow access to them, should any problems develop with the jacks or the hydraulic system. The jacks transmitted the leveling force through 36-in.-diam jacking pistons cast into the bottom of the precast pier shells. The pistons were mounted flush with the bottom of the drilled shaft and fitted with elastic O-ring seals to minimize leakage into the jacking compartments within the piers.

The setdown operations for float-in Dam Segment No. 1 began on December 5, 2001, and were successfully completed on December 8, 2001. Float-in Dam Segment No. 2 was set down at the site on June 18, 2002. 


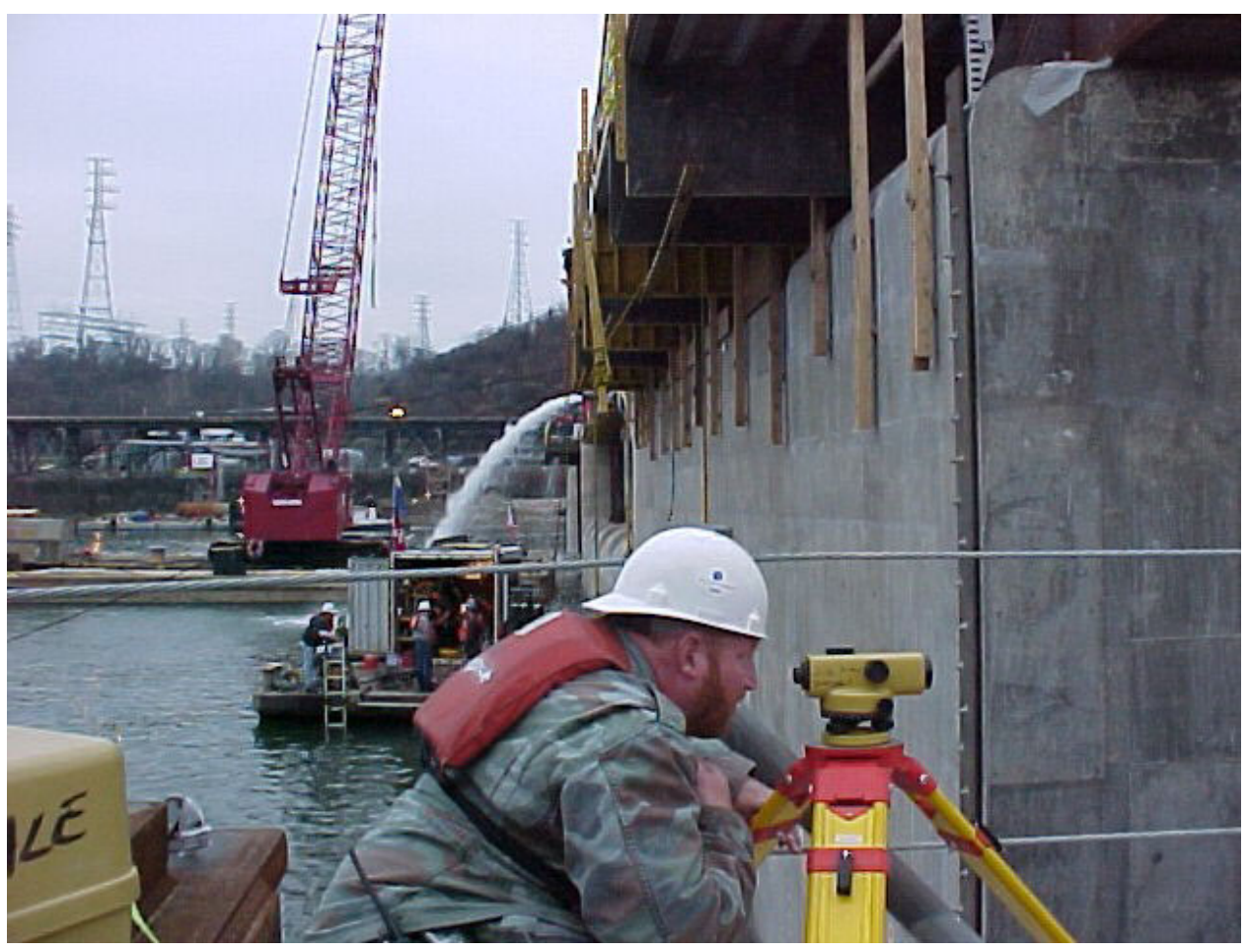

Figure 3-27. Survey instrument on the lock wall

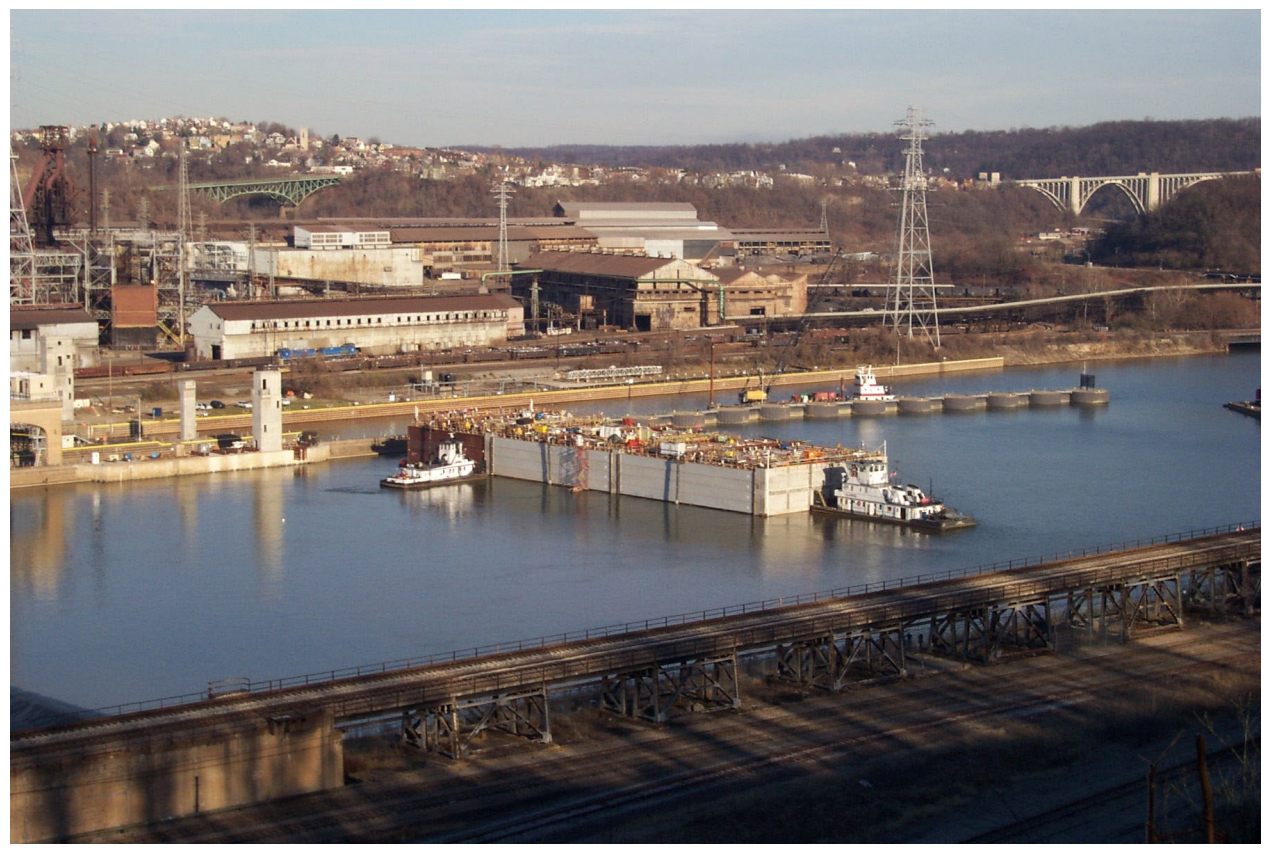

Figure 3-28. Positioning of Segment 1 


\section{Mooring Systems}

\section{4-1 Stationkeeping by Moorings}

A mooring system consists typically of mooring lines, anchors, anchor engines (winches), fairleads and, in some cases, buoys. In terms of their functions and responses to environmental forces, mooring systems are categorized into two classes: catenary and taut-line, as illustrated in Figure 4-1.

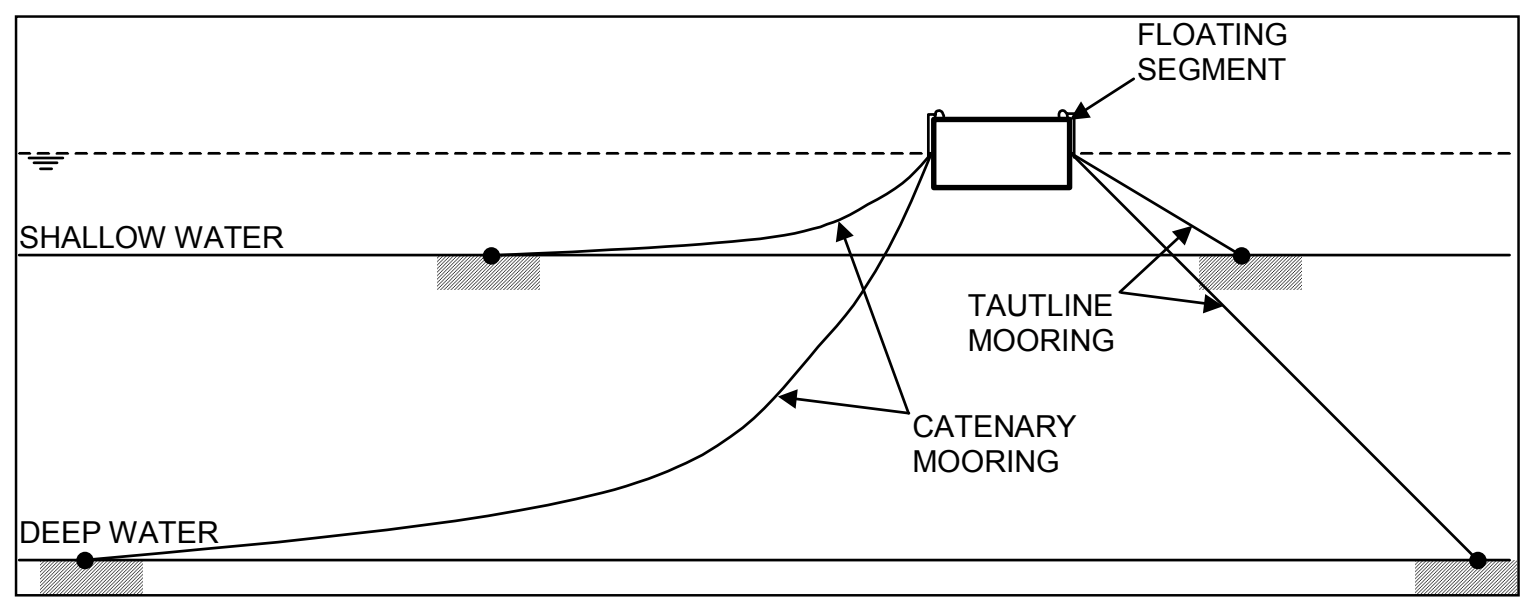

Figure 4-1. Mooring systems: catenary versus taut-line

Mooring systems have traditionally been used as the primary positioning system in offshore construction. For mooring ships in open sea, the mooring lines typically extend out thousands of feet in a catenary profile, and often connected to buoys, in order to reduce the dynamic wave loads during storms.

In riverine construction, moorings are frequently used for stationkeeping of construction vessels. In recent years, spread moorings are being increasingly used for positioning of float-in modules in inland waterways. For position mooring, mooring lines are relatively taut in order to minimize sway motions of a floating segment. In typical riverine applications, taut mooring lines run relatively straight from a vessel to anchors. Buoys are not used except for assisting connections of mooring lines and anchor chains.

Mooring design may employ either quasi-static or dynamic analysis. Since position moorings used in the float-in or lift-in construction are temporary 
moorings, the standard industry practice uses quasi-static analyses for calculating extreme loads and responses, such as the offsets, maximum mooring line tension, and anchor load.

A moored vessel always assumes an equilibrium position at which the restoring force from mooring lines equals the sum of the environmental forces. Figure 4-2a shows the equilibrium position of a moored vessel under wind and current forces. These loads displace and rotate the vessel until the mooring line tensions balance the external loads. The distances and rotation of a vessel under steady environmental forces are known as mean offset or mean quasi-static displacement $\delta_{\text {mean }}$.

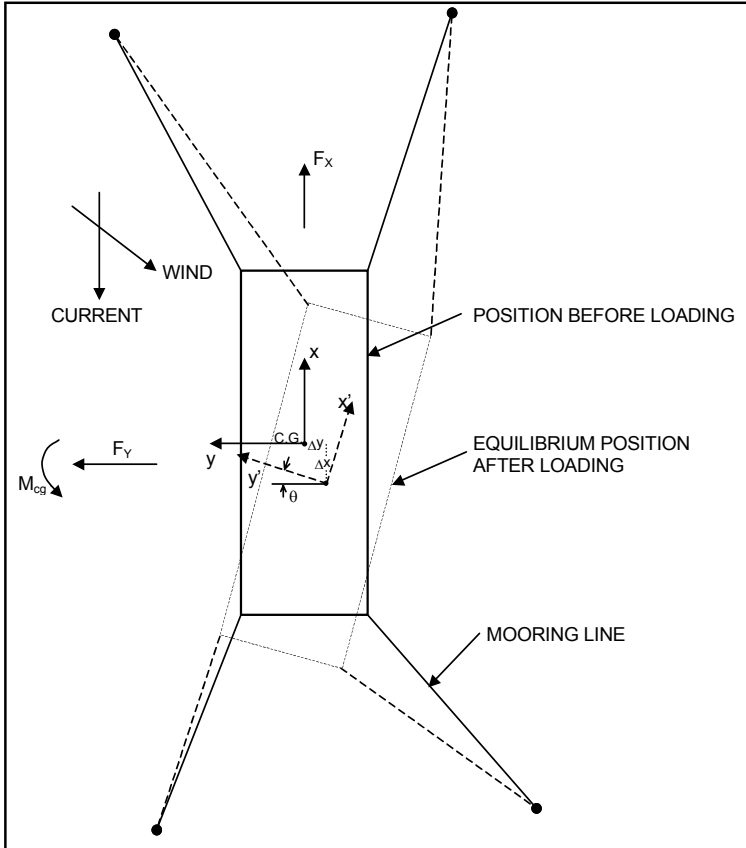

a. Deflection and rotation of a moored vessel

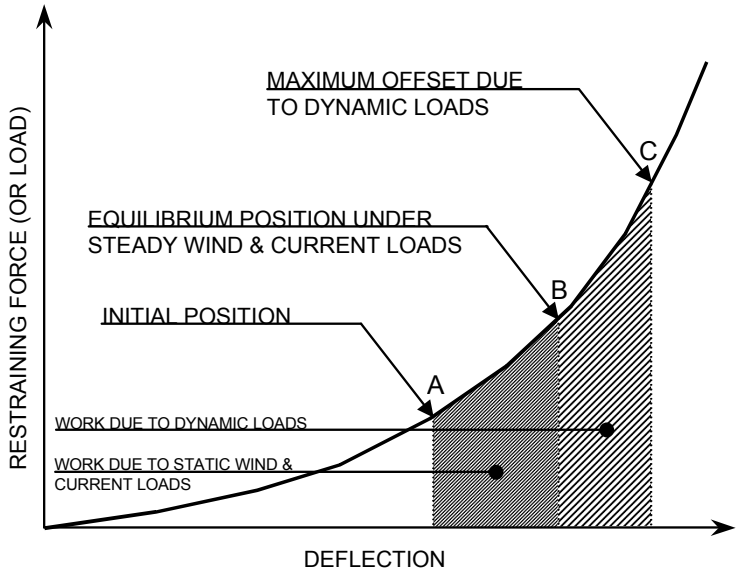

b. Load-deflection curve with catenary lines

Figure 4-2. Application of catenary mooring system

When a moored vessel is subject to unsteady or dynamic forces, it will oscillate about its equilibrium position with a dynamic amplitude $\delta_{\text {motion. }}$. The total offset is the sum of the mean offset and the dynamic motion amplitude:

$$
\delta_{\text {total }}=\delta_{\text {mean }}+\delta_{\text {motion }}
$$

Apparently, both the mean offset and total offset are dependent on the stiffness of the mooring lines. Offsets of moored vessels are usually quantified by a load-deflection curve. The load-deflection curve plots the mooring line forces as a function of the deflection of the vessel (see Figures 4-2b and 4-3b). In Figure 4-2b, point $A$ on the curve represents the initial position of the vessel prior to wind and current loads. Point B represents the equilibrium position after the steady environmental loads are applied. Point $\mathrm{C}$ denotes the maximum offset due 


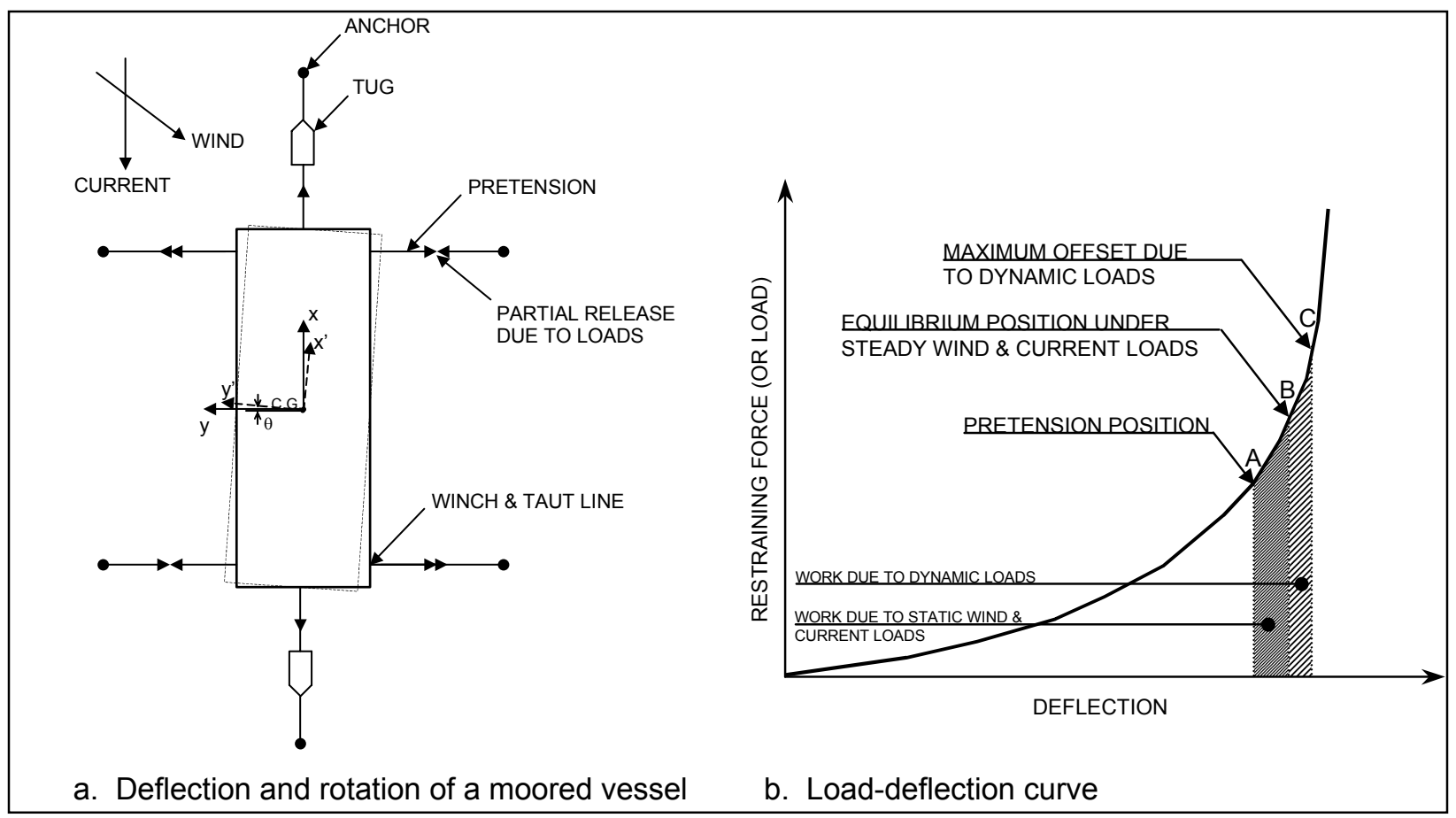

Figure 4-3. Application of a taut-line mooring system

to the dynamic loads. The area under the load-deflection curve presents the work (energy) applied on the vessel that must be absorbed by the mooring system.

Figures 4-2 and 4-3 show the load response characteristics of a catenary mooring and a taut-line mooring, respectively. The main distinction between the two systems lies in their responses to external loads. When a catenary mooring line is subjected to tension, it deflects primarily due to the geometric deformation that stretches the line from its catenary profile to a taut line. On the other hand, when a taut line is subjected to tension, the line deflects primarily because of the elastic stretching that depends on the elastic modulus of the mooring line.

For positioning operation, the geometric deformation of mooring lines is minimized, and taut-line mooring is used to ensure minimum dynamic offsets. On the other hand, because catenary lines absorb greater dynamic surge energy in an extreme event, they are frequently used as survival moorings. Figure 4-4 illustrates the use of catenary lines and taut lines to accomplish different tasks, as follows: the taut lines are used for stationkeeping of a vessel; a catenary mooring line with buoys is used as the survival mooring.

In the design of mooring systems, pretension loads must be included in evaluating the required holding power of the anchors and line pull capacity of the winches. The pretension force should never be greater than that required to overcome dynamic surge forces in the mooring lines. The total line load, including pretension load, should generally not exceed 50 percent of the lines' breaking strength. 


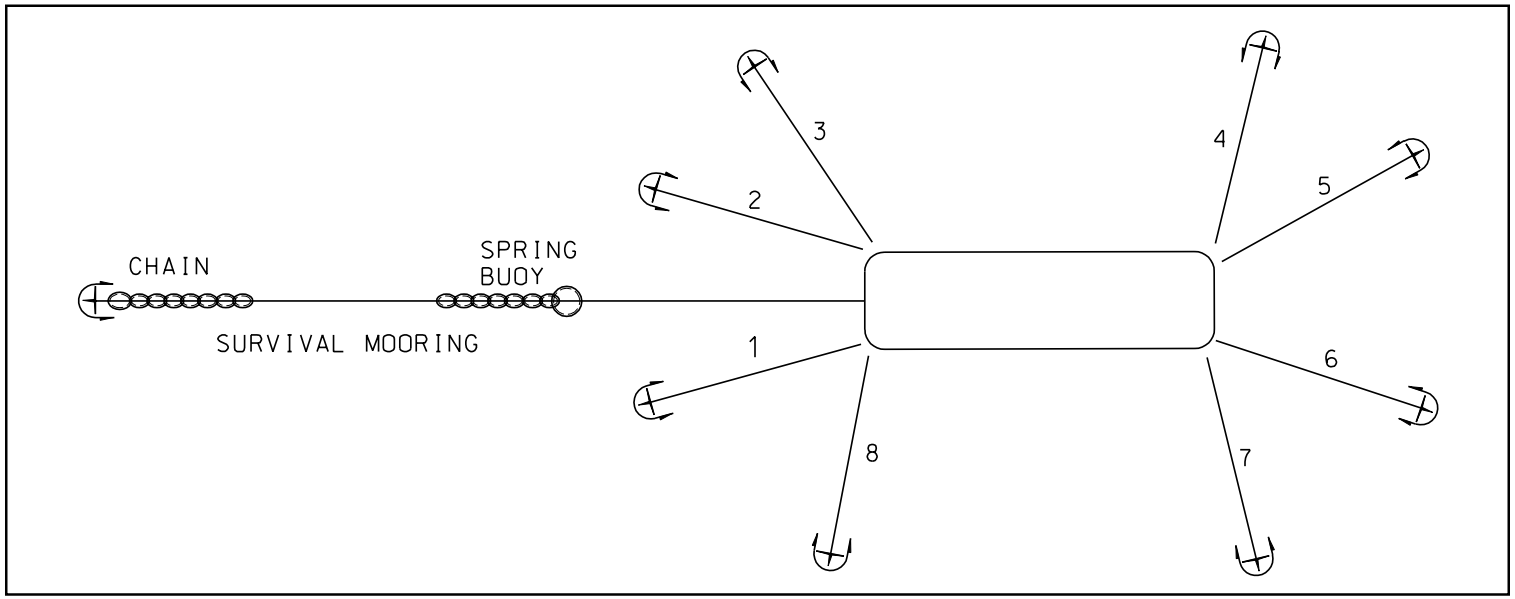

Figure 4-4. Eight-point spread mooring system used together with a survival mooring

Figure 4-5 shows the positioning of a gigantic offshore concrete platform for mating with its topside. A combination of taut-line mooring and catenary mooring is used for the positioning operations. The mating process starts with ballasting down of concrete substructure (platform) so that only the top 3 to $5 \mathrm{~m}$ of shafts extends above the water (minimum freeboard). The top deck sitting on a catamaran barge is slowly winched toward the shafts of the platform with vertical clearance of only 30 to $60 \mathrm{~cm}$. The concrete platform is positioned primarily through mooring systems, while the catamaran carrying the top deck is usually positioned through a combination of towboats, dynamic positioning system, and catenary mooring system. Once the horizontal positioning of both structures is verified, the concrete substructure is deballasted to lift the top deck up off the catamaran barge. The deck is then secured to the shaft by prestressing.

Positioning analysis requires consideration of stiffness of the mooring system. The analysis to determine an instantaneous position of a moored vessel is essentially a trial-and-error process. The calculation requires continuous adjustment of the vessel position and elongation of the mooring lines until the following equilibrium is reached:

$$
\sum F_{x}=0, \quad \sum F_{y}=0, \quad \sum M_{c g}=0
$$

A step-by-step calculation procedure can be outlined as follows:

a. Calculate the wind and current loads on the barge or floating segment in terms of the longitudinal force, lateral force, and yaw moment.

$b$. Determine the mooring line layout and the load-elongation relation of each line including the catenary effect, if any.

c. Assume an initial displacement and rotation of the barge or the segment under the loads. Then, calculate the elongation of each mooring line and mooring line tensions for the assumed configuration. 

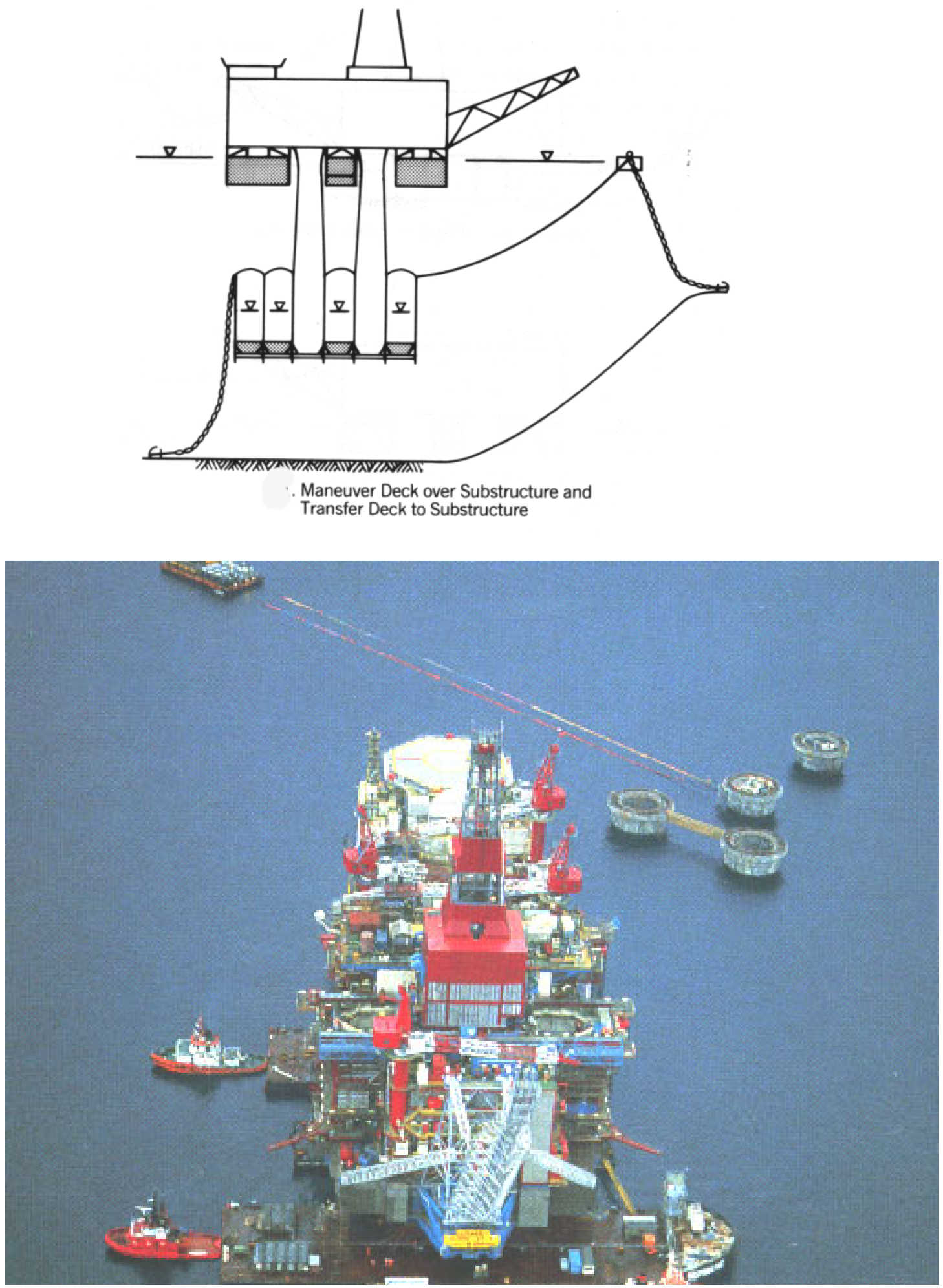

Figure 4-5. A platform joins its top deck using both taut and catenary lines 
d. Sum the forces and moments from the mooring lines and environmental effects in Equation 4-2.

$e$. If the sum is not equal to zero, the barge is not in equilibrium with the applied loads. Repeat iteration from step $b$ to step e until the sums of the forces and moments approach zero in Equation 4-2.

The above calculation procedure requires a number of iterations for an assumed wind direction and current direction. Thus, hand calculations could be very tedious. Computer programs are available for performing the analysis in mooring design (U.S. Navy 1985).

Design of a positioning mooring system mainly involves determining the optimum size, length, and configuration of the mooring lines for a specific site and operating requirements. This requires a thorough understanding of mooring principles, and clear appreciation of the operating limits that apply to the various positioning requirements. The general design and operating principles for position moorings are summarized below.

a. In developing design criteria, the site-specific data on load combinations and loading directions should be considered, especially the wind/wave and wind/current interactions and their relative directions. Apply proper safety factor to account for impact, service duration, wears and tears, corrosion, etc. The environmental conditions used for mooring design take into consideration the length and season of the exposure. A 10-year seasonal return period of an extreme event is commonly recommended for design of temporary mooring, while a 100 -year return period is often used for permanent mooring.

b. Sufficient anchor points should be provided for a satisfactory spread of moorings.

c. Anchor points should be disposed nearly symmetrically about the center point.

$d$. Wire rope should be the standard mooring line used for position moorings. In general, mooring lines of the same size and type should be used for all leads.

$e$. The length and size of the mooring lines should be determined based upon the required mooring stiffness for positioning. Short mooring lines are suitable for anchor piles that can resist substantial vertical pulls. If drag anchors are used, the outboard mooring line length should be sufficiently long to prevent anchor uplift.

$f$. It is necessary to install the mooring line load apparatus for position moorings. The instrument measures the line loads. Should the loads become high or the lines become slack, the operator can adjust the winches accordingly. Loads on any one mooring line should not exceed 55 percent of the minimum breaking strength. 
g. Prior to positioning operations, the mooring system should be tested with loading to ensure adequate line strength and the holding capacity of the anchors, to eliminate slack in the lines, and to detect any damage in the mooring system. The operator should ensure that all the lines are taut and that only one layer of cable lines is left on the tension drum of a splitdrum winch.

$h$. Fairleads or similar device should always be used to ensure correct alignment of moorings. Fairleads should have large-diameter sheaves to prevent stress concentration in the wire ropes. The diameter ratio of sheaves to wire ropes should generally be 20 or more.

i. Winches for handling the wire ropes should preferably be the split-drum type rather than undivided drum. Winches may be either automatic tension winches or manual winches.

j. Winch brakes should provide a minimum holding capacity of 60 percent of the minimum breaking strength of the wire rope on the first layer of wire of a split-drum winch and on the normal working layer of an undivided drum winch.

$k$. The operator of positioning systems should be provided with information on the design of the moorings, with examples to show the anticipated load conditions under operating conditions and to illustrate the situations under which the limitations of the system are reached.

In the remainder of this chapter, applications of individual mooring components are discussed.

\section{4-2 Mooring Lines}

Steel wire ropes are the most common mooring lines used in inland waterways. The wire ropes are composed of wires, strands, and a core. The basic material is cold drawn steel wires, or so-called improved plow steel. The wires are laid into strands. The strands are wound helically around a core, which may be fiber or another wire rope, as shown in Figure 4-6. Steel wire lines with an independent wire rope core (IWRC) are recommended for their greater stiffness and higher strength under bending. Short synthetic lines are sometimes used at the end of wire ropes to absorb dynamic energy, but they are not suitable for position mooring.

Wire ropes are typically designated by the number of strands and wires. For example, " $6 \times 19$ " class wire rope is six strands with 19 wires per

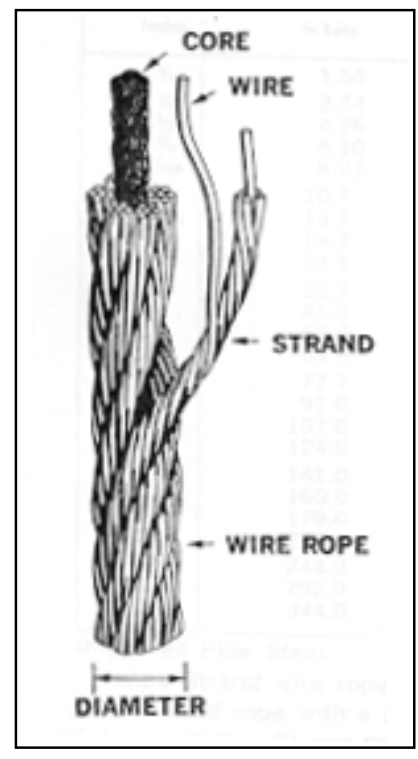

Figure 4-6. Making of a wire rope 
strand. The quality of mooring lines must satisfy the industry standards. The following mooring line properties should be documented:

a. Ultimate strength (minimum break load or MBL).

b. Yield strength.

c. Load-elongation stretching characteristics.

d. Fatigue resistance.

e. Notch toughness.

Positioning analysis needs to calculate stretching of mooring lines. The critical characteristic is the load-elongation stretching of wire ropes. Three kinds of stretch are considered in the calculation: constructional, elastic, and geometrical. Constructional stretch takes place largely in new wire ropes as a result of the adjustment of the seating of the strands upon the core. In the field, most of this stretching occurs within the first few days of operation. For common wire rope, constructional stretch will be approximately 0.25 to 1 percent of the length of the rope. Constructional stretch can be removed by prestretching, which is done as part of the wire rope manufacturing process. Prestretching is to apply predetermined loads to the rope and hold the load until the rope adjusts itself.

Elastic stretch is the temporary elongation of wire rope under load. It is a function of the geometric and material properties of the wire rope. Elastic stretch can be calculated as follows:

$$
\Delta L=\frac{P L}{A E}
$$

For six-strand wire ropes, as commonly used in mooring applications, the elastic stretch of the mooring chain $(\delta$, in feet) can be estimated as follows:

$$
\delta=\frac{T L}{7.7 \times 10^{6} D^{2}}
$$

where

$$
\begin{aligned}
& \mathrm{T}=\text { mooring chain tension (pounds) } \\
& \delta=\text { length of the mooring chain } \\
& \mathrm{D}=\text { diameter of the chain }
\end{aligned}
$$

For other types of wire ropes, the manufacturer should be consulted for assistance in estimating elastic stretching.

For mooring chains, the elastic stretch ( $\delta$, in feet) can be estimated as follows: 


$$
\delta=\frac{T L}{1.2 \times 10^{7} D^{2}}
$$

Geometric stretch of a wire rope is the tightening of a mooring line from its initial catenary profile to a straight line. There is a nonlinear relation between the line tension and its geometric stretching, as shown in Figure 4-7. The line tension can be calculated from the catenary profile using the catenary formula as follows (U.S. Navy 1985):

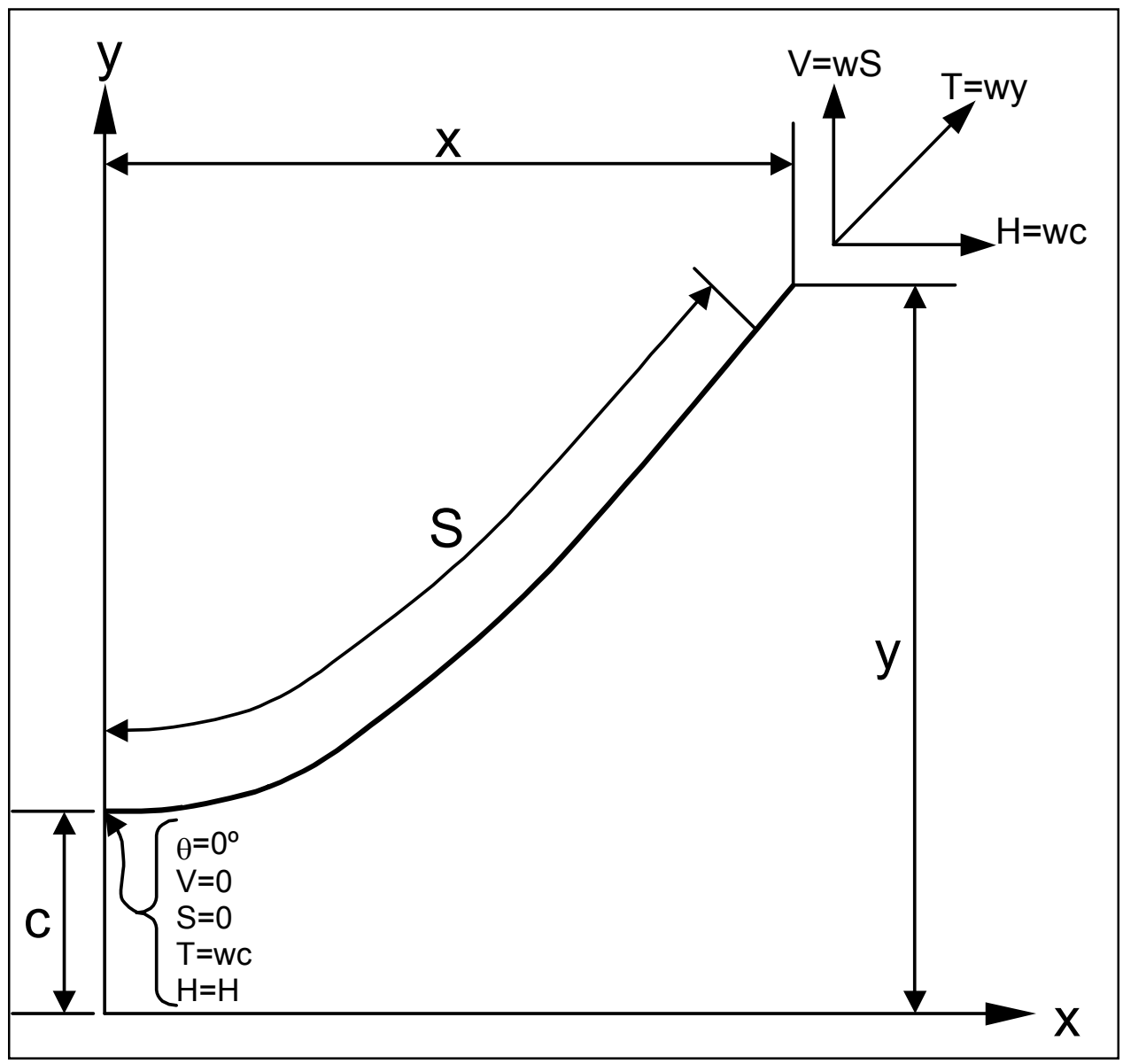

Figure 4-7. Definition for analysis of catenary line

$$
T=w y=w c \cosh \frac{x}{c}, \quad V=w S=T \sin \theta, \quad H=w c=T \cos \theta
$$

where

$$
\begin{aligned}
& T=\text { line tension } \\
& w=\text { submerged unit weight of mooring line } \\
& c=\text { distance from origin to y-intercept }
\end{aligned}
$$


$V=$ vertical component of line tension at point $(\mathrm{x}, \mathrm{y})$

$S=$ length of the catenary curve from $(0, \mathrm{c})$ to point $(\mathrm{x}, \mathrm{y})$

$\theta=$ angle of mooring line with the horizontal axis at point $(\mathrm{x}, \mathrm{y})$

$H=$ horizontal component of line tension at point $(\mathrm{x}, \mathrm{y})$

In general, the breaking strength of a wire rope should be derated according to the bending curvature in use. Derived from standard test data, Figure 4-8 shows the wire rope strength efficiency for various ratios of drum-sheave diameter to rope diameter $(\mathrm{D} / \mathrm{d})$. The curve is based upon static load test data for $6 \times 19$ and $6 \times 37$ wire ropes. According to the curve, for example, a wire rope should be derated approximately 11 percent due to strength loss of rope bending over sheaves or drums of 14 times rope diameter.

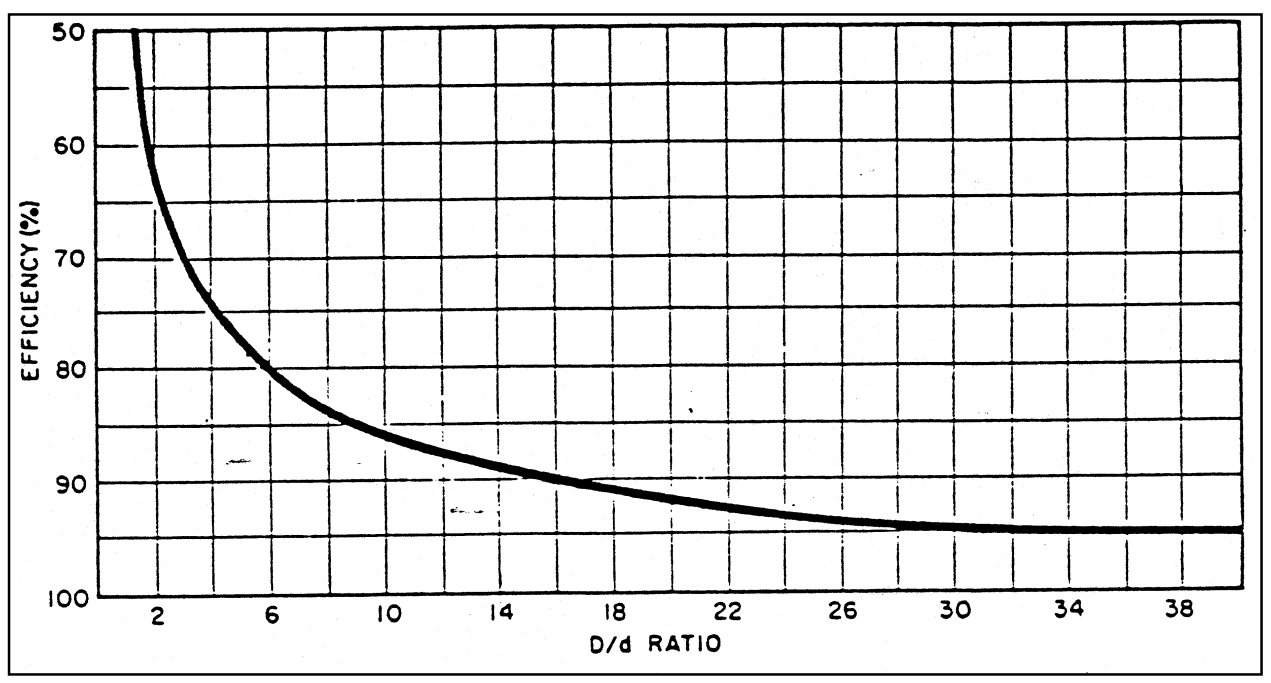

Figure 4-8. Efficiency of wire rope strength when bent over various radii

\section{4-3 Winch Systems}

A position mooring system controls a vessel or a float-in segment through paying-out and heaving-in mooring lines. Winch equipment is at the heart of the mooring system, because it adjusts mooring line tension and mooring line length. Figure 4-9 shows a winch and a power pack used in positioning of the Braddock Dam float-in segments.

The selection of winch equipment for a particular mooring system depends on the type of mooring lines to be handled, where the winches are installed, and magnitude of the pretension line forces. In general, an adequate number of winches must be installed for the mooring lines layout. A sufficient number of drums must be provided to cater for the mooring wire requirements. The winch brakes must be designed to provide the required holding load capacity. 


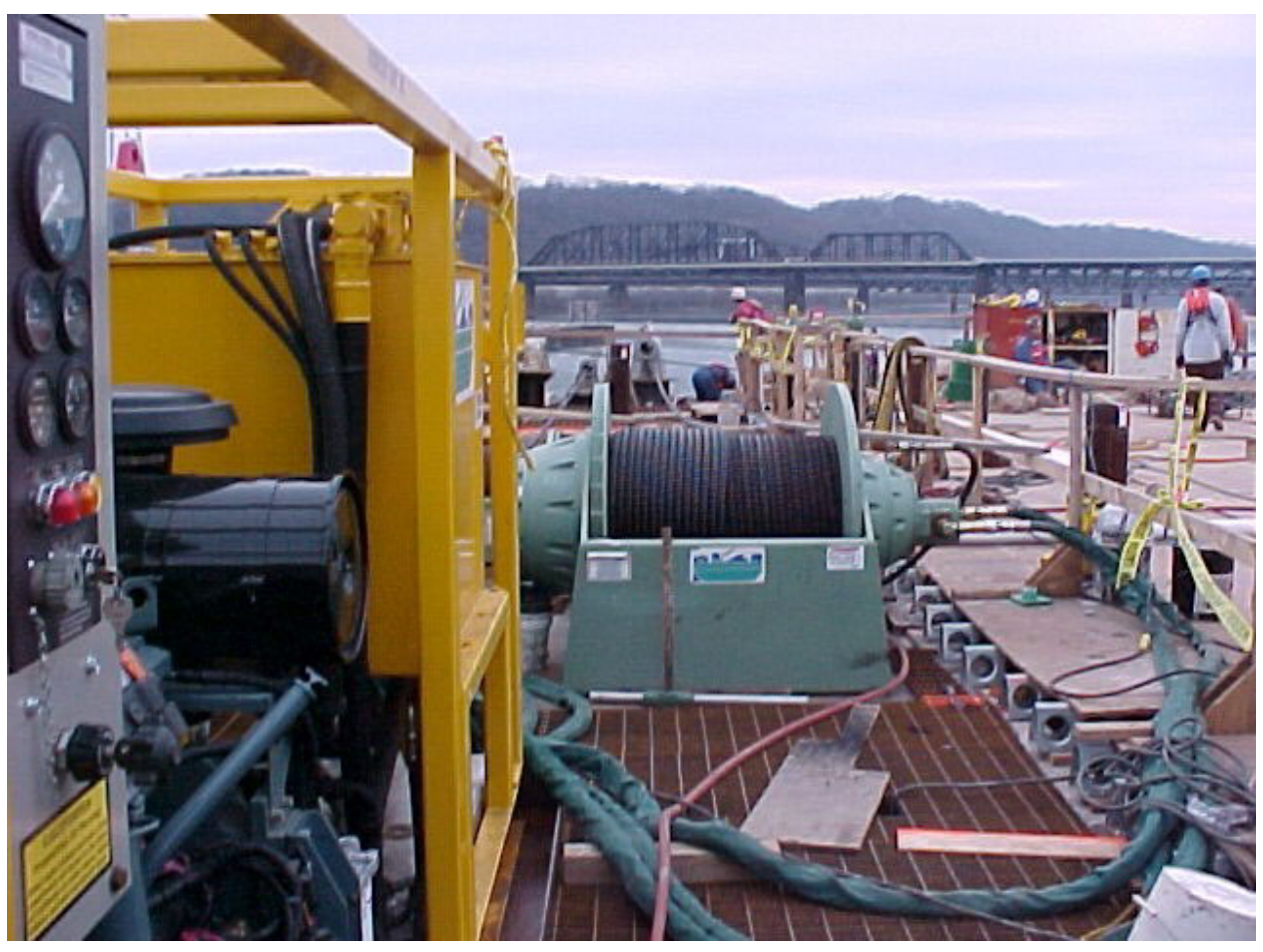

Figure 4-9. Lantec Model 750 winch and its power unit on Braddock Dam, Segment 1

Most winches are powered by steam or diesel reciprocating engines, although a limited number of them are electrically or hydraulically powered. The use of two cylinders with crank set at $90 \mathrm{deg}$ to each other ensures that the power is available under load conditions and crank positions. For positioning operations, winches should use torque converters and reversing power shift transmissions.

Winch brakes should be set to hold a minimum load of 60 percent of the MBL of the wire, because IWRC wire lines would yield at 65 to 75 percent of MBL. With friction in the fairlead, the 65-percent level could be readily obtained in the outboard portion of the mooring lines. If the brake is set for a higher level, the level established should permit slippage of the wire rope before breaking.

In terms of the brake mechanism, winches can be divided into two general types: automatic tension winches and manual winches. Automatic tension winches are designed so that a specified line tension can be preset and the winch will render (pay out) whenever this value is exceeded by a set amount. The winch will then recover (heave in) whenever the line tension falls below the preset value. Automatic tension winches must always be equipped with manual brakes.

Manually operated deck winches, on the other hand, require that the mooring wires be hauled in and the brake set mechanically to a predetermined torque or pressure setting, to ensure design holding capacity. 
Three types of winches commonly used in positioning operations are discussed below. Other types of winches, such as chain jacks and linear winches, are relatively slow to operate and are not commonly used in positioning moorings.

\section{4-3-1 Drum-type winch}

The conventional drum-type winch is the most common device used for handling wire ropes. Operation of the drum-type winch is fast and smooth. A drum-type winch consists of a large drum on which the wire rope is wrapped. The base of the drum is often fitted with special grooves sized specifically to the size of wire rope. The grooves control the positioning of the bottom layer of wire rope on the drum. For subsequent layers of wire rope, an external guidance mechanism such as a level-wind is sometimes used to control positioning of the wire rope on the drum.

Drum winches can be divided into single-drum and split-drum winches, as shown in Figures 4-10 and 4-11, respectively. The singledrum winch is most suitable for positioning small vessels. When wires are handled directly off drums, the final turns of the outer layer tend to bite into the lower layers, resulting in possible wire damage. The split-drum winch is designed to overcome this spooling problem. In the split-drum winch, a common drum is divided with a notched flange into a wire storage section and a tension section. In operation, the wire rope is paying out first from the tension drum and then from the storage drum. As the wire heaves in, it is wound directly on the stowage until the only sufficient slack wire is available to provide a sufficient number of turns on the tension drum to hold the tension alone. At that time, the wire rope is fed through the slot from the storage portion to the tension portion.

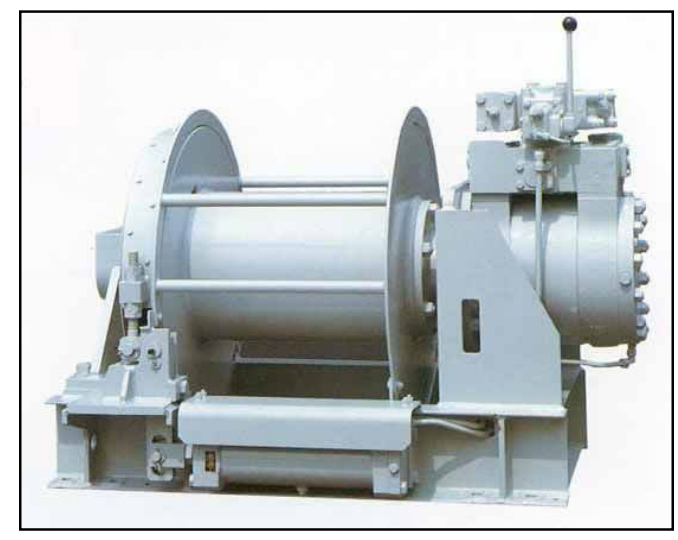

Figure 4-10. Single-drum winch

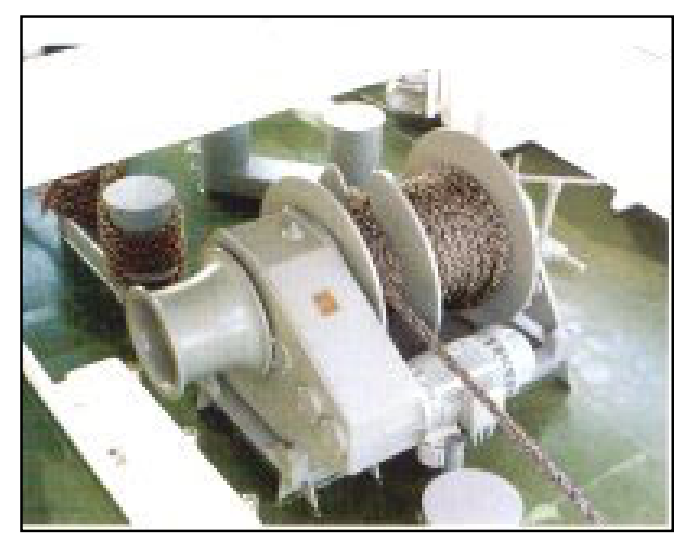

Figure 4-11. Split-drum winch

The hauling load capacity of a winch with one layer on the drum typically does not exceed 33 percent of the mooring wire's MBL. The preferred no-load speed measured on the first layer on the drum is $1.5 \mathrm{~m} / \mathrm{s}$. For positioning 
operations, it is essential that this speed be never less than $0.5 \mathrm{~m} / \mathrm{s}$. Design speed at maximum hauling load should be $0.5 \mathrm{~m} / \mathrm{s}$ for position mooring.

As the requirement for line sizes and lengths increases, the size of the winch can become impractical. Thus, the drum-type winch can be a cumbersome device for handling wire rope for high-capacity mooring systems. In addition, when wire rope is under tension at an outer layer on the drum, spreading of preceding layers may occur, resulting in wire rope damage.

\section{4-3-2 Traction winch}

The traction winch has been developed for high-tension mooring applications as well as for handling combination mooring systems. It consists of a powered drum on which the wire rope makes just six or seven wraps (Figure 4-12).

Tension in the wire rope causes the wire rope to grip the drum. The wire rope is coiled on a take-up reel, which is required to maintain a nominal level of tension in the wire rope (typically 3 to 5 percent of

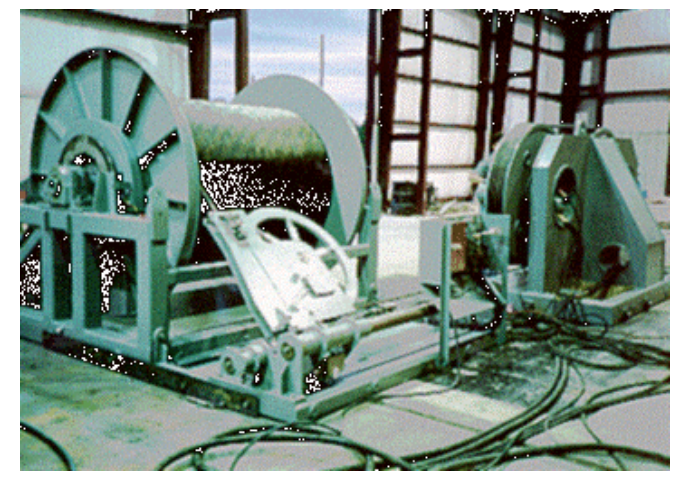

Figure 4-12. Traction winch working tension) to ensure that the proper level of friction is maintained between the wire rope and the traction winch. The system has been favored for use in high-tension applications because of its compact size, capability to provide constant torque, and ability to handle very long wire rope without reduced pull capacity.

\section{4-3-3 Windlass}

The most common method of handling and tensioning a chain mooring line is through the use of a windlass. The windlass consists of a slotted "wildcat," which is driven by a power source through a gearreduction system (Figure 4-13). As the wildcat rotates, the chain meshes with the wildcat, is drawn over the top of the wildcat, and lowered into the chain locker. Once the chain is hauled in and tensioned, a chain

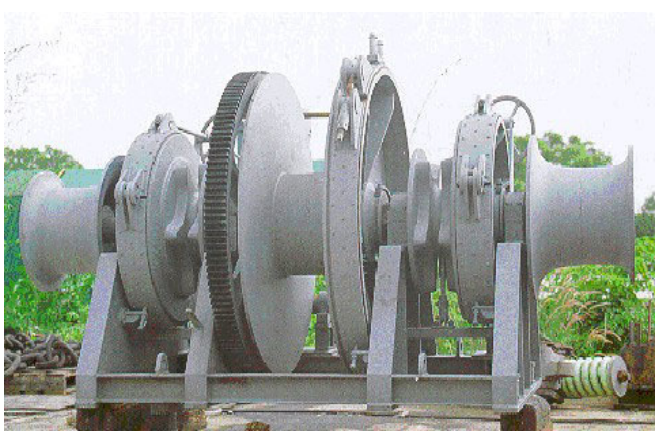

Figure 4-13. Windlass stopper is engaged to hold the chain. Windlass has proven to be a fast and reliable method for handling chain lines. 


\section{4-4 Anchoring Systems}

A variety of anchor options are available for use in position moorings. Common anchor types include drag embedment anchors, pile anchors, caisson foundations, and gravity anchors. In selecting the proper type of anchor, adequate consideration should be given to the required performance of the mooring systems, soil conditions, reliability, installation, and proof loading. The basic features and applicability of the common types of anchors are discussed in this section.

\section{4-4-1 Drag embedment anchor}

The drag embedment anchor, the most common type, develops its resisting force by mobilizing the passive pressure of the soil. If drag anchors are used for taut mooring lines, the outboard mooring line length should be sufficiently long to prevent anchor uplift. This requirement is especially important for anchors in hard soil where anchor penetration is shallow.

The holding capacity of a drag anchor represents the maximum horizontal steady pull that can be resisted by the anchor at continuous drag. Drag anchor holding capacity depends on many variables, such as anchor type, burial depth of the fluke, soil behavior, and stability of the anchor under the drag pull. The drag anchor offers advantages in overconsolidated soils, if the anchor can bite into them. For unconsolidated, soft soils, embedment anchors need to have a very large area of engagement to develop sufficient resistance. A particularly difficult situation arises when soft mud overlies very dense soil, such as overconsolidated silts or glacial till. Then, a drag embedment anchor would tend to skid across the surface of the hard materials.

The drag anchor's capacities have been extensively investigated, and various design charts have been developed for various types and weights of anchors and various soil types. Readers are referred to an applicable Navy Techdata Sheet (U.S. Navy, 1983) for preliminary analysis in design. The Navy data are typically very conservative for some types of soils. If the soil data are known, the anchor holding power can be calculated by soil mechanics as a sum of the following three components:

a. Frictional resistance due to weight of anchor $(\mu=0.3)$.

$b$. Resistance due to shear strength of soil on planes radiating out at angles of $\left(45^{\circ}-\frac{\phi}{2}\right)$, or approximately $30 \mathrm{deg}$.

c. Resistance due to passive strength of soil.

Of these components, the shear strength of the soil amounts to approximately 90 percent of the holding power. However, the anchor must be able to penetrate a sufficient depth into the soil in the first place. To achieve these holding 
capacities, drag anchors should generally penetrate about one fluke length in sand and three to six fluke lengths in mud. The anchoring capacity is almost directly proportional to the anchor embedment depth in mud and embedment depth squared in sand.

Because of the wide variation of these influencing factors, the prediction of a drag anchor's holding capacity is the most difficult part of the mooring system design. In practice, therefore, the sufficiency of the drag anchor's capacity must be verified after the anchor is deployed and test loaded.

The factors of safety for anchors are usually about 2.0, which is substantially lower than values for mooring line tension. The rationale is to allow the anchor to move, instead of breaking the mooring line in the event of overloading. This anchor movement would normally result in favorable redistribution of the mooring loads among the mooring lines, helping the mooring system to survive an extreme design event.

Drag embedment anchor technology has advanced considerably in recent years. Engineering and testing indicate that the new generation of fixed fluke drag embedment anchors develops high holding power even in soft soil conditions. The high-efficiency drag embedment anchors are generally considered to be an attractive option for mooring applications because of their easy installation and proven performance. It is recommended that high-efficiency anchors use 50-percent efficiency for design.

\section{4-4-2 Pile anchor}

Short mooring lines are suitable for anchor piles that can resist substantial vertical pulls. A pile anchor's resistance to uplift and lateral loads is primarily a function of pile size, the soil conditions, and the way the pile is installed and loaded. Horizontal capacity can be increased considerably by adding special elements such as skirts or wings to the pile top. Pile anchors can be designed to develop high lateral and vertical resistance, and can be very stable over time. Piles are generally installed by means of driving, although other methods such as jetting/drilling and grouting have been used. Installation of jetted/drilled and grouted piles can be performed by using a conventional drilling rig. However, disturbance of in situ soil during jetting and drilling operations should be carefully evaluated.

Anchor piles should account for pile bending stresses as well as ultimate lateral capacity of the piles. A proper analysis model to account for both aspects of pile behavior is a beam-column on an inelastic foundation, such as the $p-y$ analysis model.

\section{4-4-3 Gravity anchor}

Gravity anchors are deadman anchors that usually consist of concrete or steel blocks, scrap metal, or other materials of high density. Design uplift capacity is 
dependent on the submerged weight of the anchor. Horizontal capacity is a function of the friction between the anchor and the soil, and the shear strength of the soil beneath the anchor.

\section{4-4-4 Caisson foundation (suction anchor)}

A caisson foundation is installed by using a suction embedment technique and, therefore, is often called a suction anchor. A caisson foundation can take many forms, ranging from a gravity base with skirts to a "no ballast" caisson, which resists all applied loads by soil friction and lateral resistance.

Generally, a caisson is technically feasible for soft to medium hard soils. For very soft soils, such as some Mississippi delta areas, the caisson must extend so deep into the soil to reach competent load-bearing material that the structure becomes unwieldy and difficult to handle. For very hard soils, it may not be possible for the skirts to penetrate enough to provide adequate in situ strength.

Figure 4-14 illustrates a method of caisson installation. When lowered to the bottom, the caisson will penetrate to a certain depth by its own weight and create a seal to allow the suction operation to commence. Water is evacuated from inside the caisson with a submersible or surface vacuum pump through an umbilical attached to the caisson. This causes the pile to be anchored into the riverbed or seabed. Embedment of the caisson is completed prior to placing ballast material in the caisson's upper chambers. In general, suction anchors require deep water in order to achieve the driving head required to force the anchor into the soil.

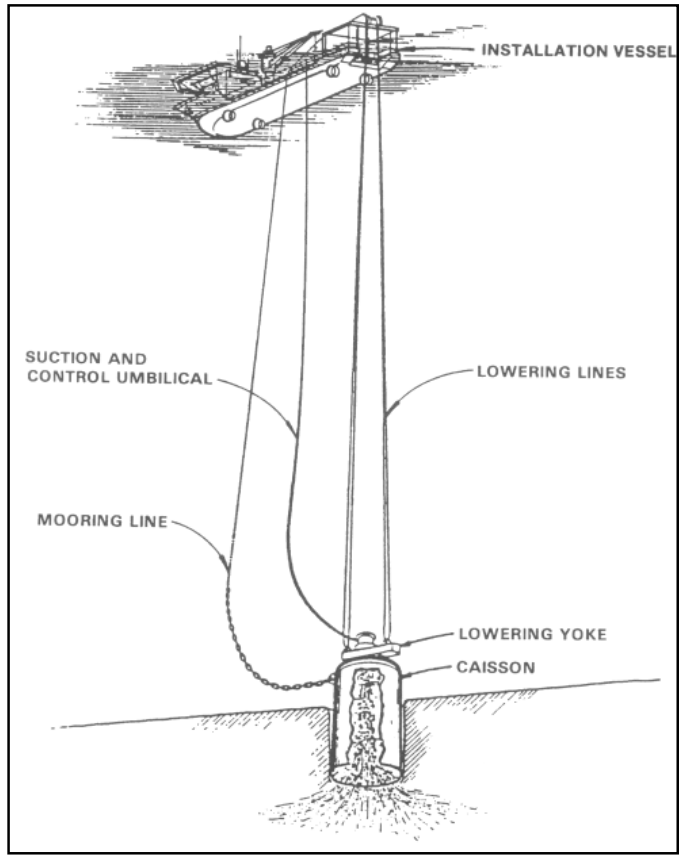

Figure 4-14. Installation of suction anchor

\section{4-5 Fairleads}

Mooring lines are subjected to high wear and stress at the fairlead and stopper arrangements. The long-term service of a mooring system requires that fairlead and stopper arrangements be carefully designed to minimize wear and fatigue.

Mooring chains and wire ropes are often stopped off at the floating module in order to take direct mooring loads off the winch. Chain stoppers and wire rope grips used for permanent mooring systems must be designed so that the stress 
concentration and wear within the chain or wire rope are kept at acceptable levels.

Since bending over a sheaf or fairlead increases the tension in the outer wires, lines usually break in the fairlead. Thus, the fairlead should provide sufficient sheaf to rope diameter ratio to minimize tension-bending fatigue, typically in excess of 20, as shown in Figure 4-15. Typically, seven-pocket wildcat sheaves are used for chain. Sheaves for wire rope have D/d ratios of 16/25 for mobile moorings and 40/60 for permanent moorings.

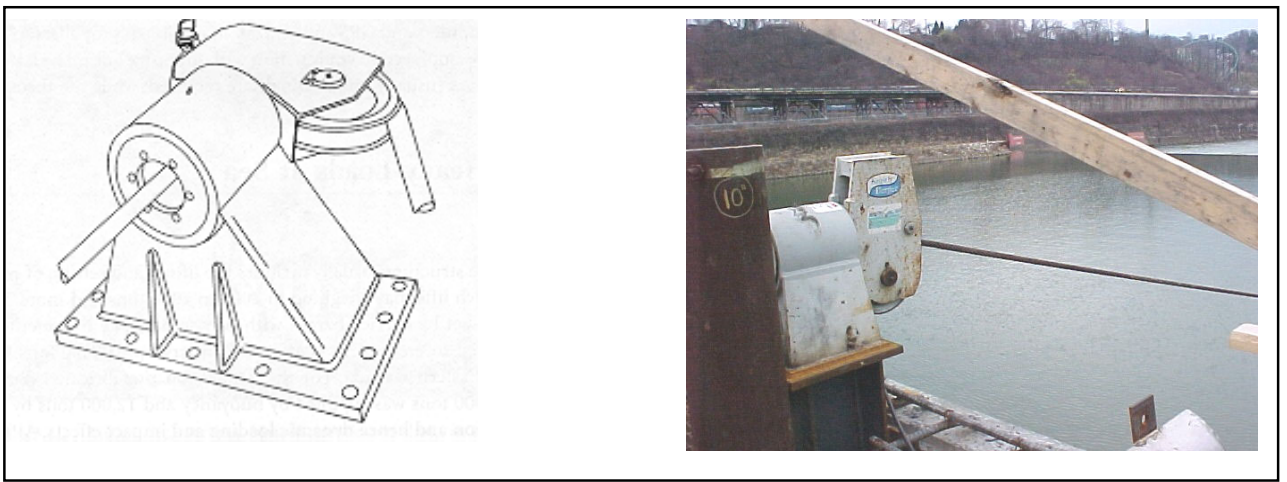

Figure 4-15. Fairlead 


\section{Dynamic Positioning}

Dynamic positioning is intended to keep a floating vessel in position within certain design excursion limits under the design environment. It is a technique of automatically maintaining the position of a vessel by controlling onboard thrusters that generate forces to resist wind, current, and wave forces. This is accomplished by a position reference system with computer-controlled thrusters around the vessel.

A dynamic positioning system primarily consists of four elements: (1) the sensor system, (2) the control system, (3) the thruster system, and (4) the power system. In operation, the control system processes the vessel position information provided by the sensors at regular time intervals, typically about once every second. The computer then calculates any deviation from the required position and commands the thruster to provide necessary forces to counter the environmental forces. This dynamic positioning process is shown in as a flowchart diagram in Figure 5-1.

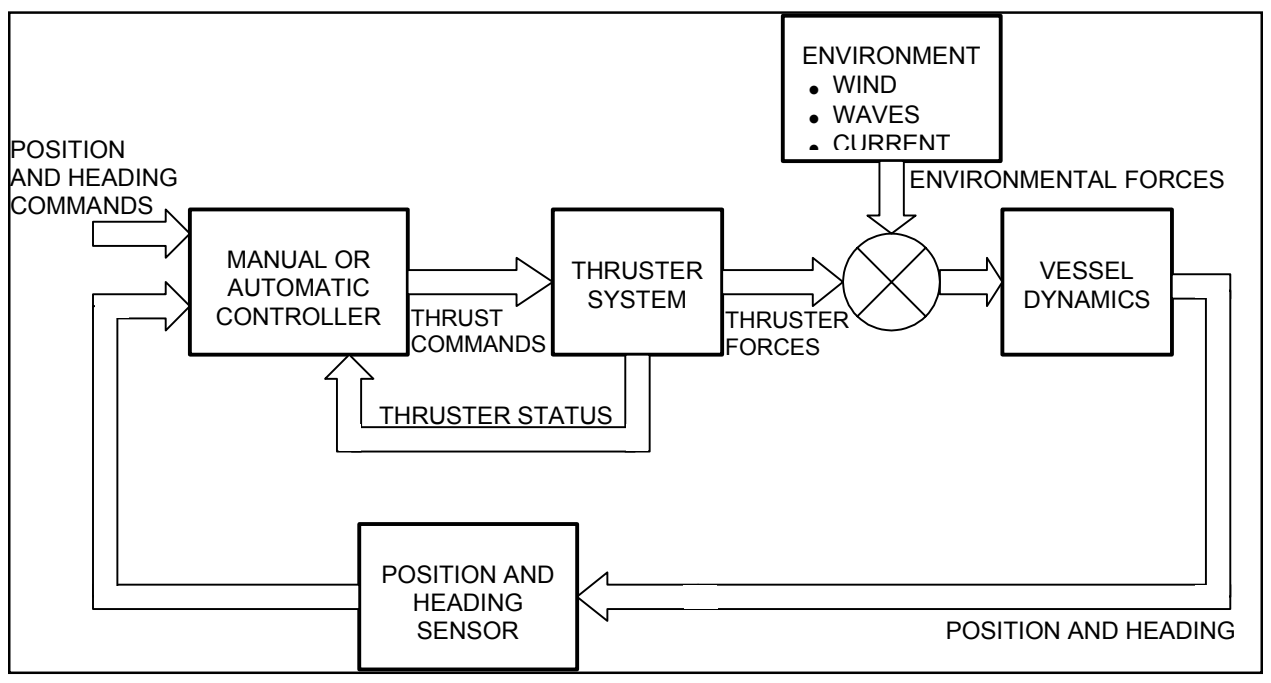

Figure 5-1. Flow diagram of a dynamic positioning system

The position sensors continuously measure the position of the vessel for input to the controller. The measurement has to be highly accurate and repeatable. For surge and sway measurements, the most commonly used sensor systems are the acoustic, taut wire, and riser angle systems. The acoustic system has 
traditionally been the primary position sensor because of its reliability and accuracy under a wide range of environments. The taut wire and riser angle systems are sometimes used as the backup sensors. In recent years, the differential global positioning system has been used widely for dynamic positioning.

The control system is an onboard digital computer. Its main functions are to process the sensor information and compute the instantaneous vessel position; to calculate the forces required to counter the environment and minimize the position deviation; and to allocate the thruster forces according to some programmed logic.

The thrusters keep a vessel on station by providing the forces and moments to counter the wind, wave, and current forces on the vessel. The most common thruster system is a group of open or conducted propellers (Figure 5-2). Each propeller may be fixed in direction or, alternatively, can change in direction continuously, as shown in Figure 5-3. Figure 5-4 shows a typical thruster configuration on a catamaran with eight azimuthing thrusters.

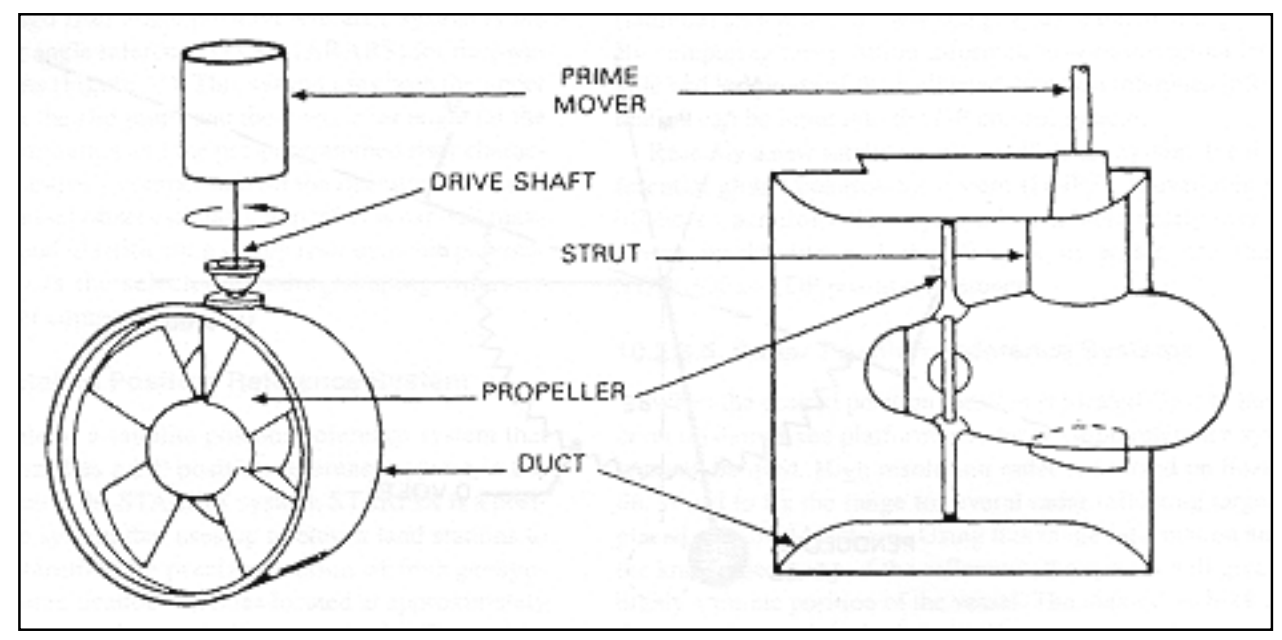

Figure 5-2. Typical ducted propeller

There are two types of thruster level controls: controllable pitch with fixed speed, and fixed pitch with controllable speed. Controllable-pitch thrusters with fixed speed are normally driven by constant speed alternating current motors that do not require any rectifier to convert AC to DC. The main disadvantage of the $\mathrm{AC}$ system is the requirement for a separate hydraulic system for the pitch control. In many ships, the main thruster is often driven by diesel engines, with pitch control for the thrust variation.

The power system on a dynamic positioning vessel consists of the diesel engines, the generators, the control system, and the power distribution system. The power system is usually configured with multiple units and redundant features to handle power demands that range from very little in light weather to maximum in heavy weather. 


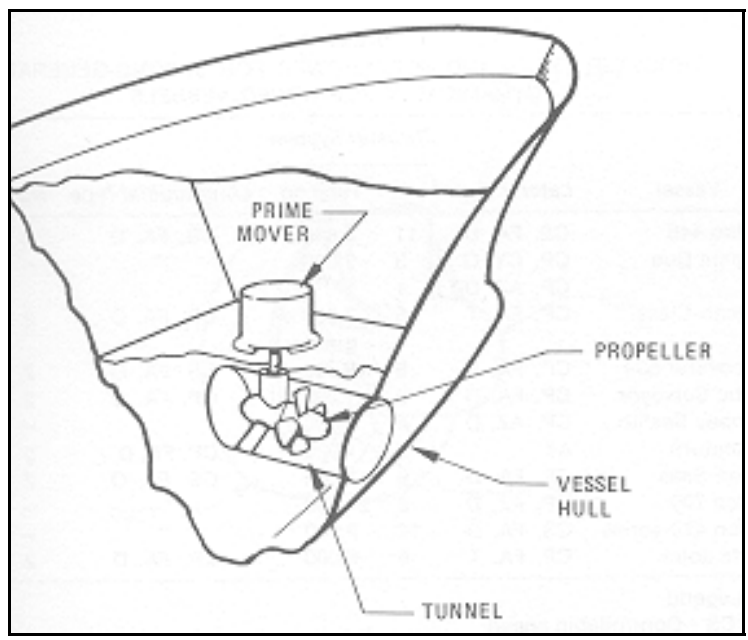

Figure 5-3. Typical ducted propeller in a tunnel type installation

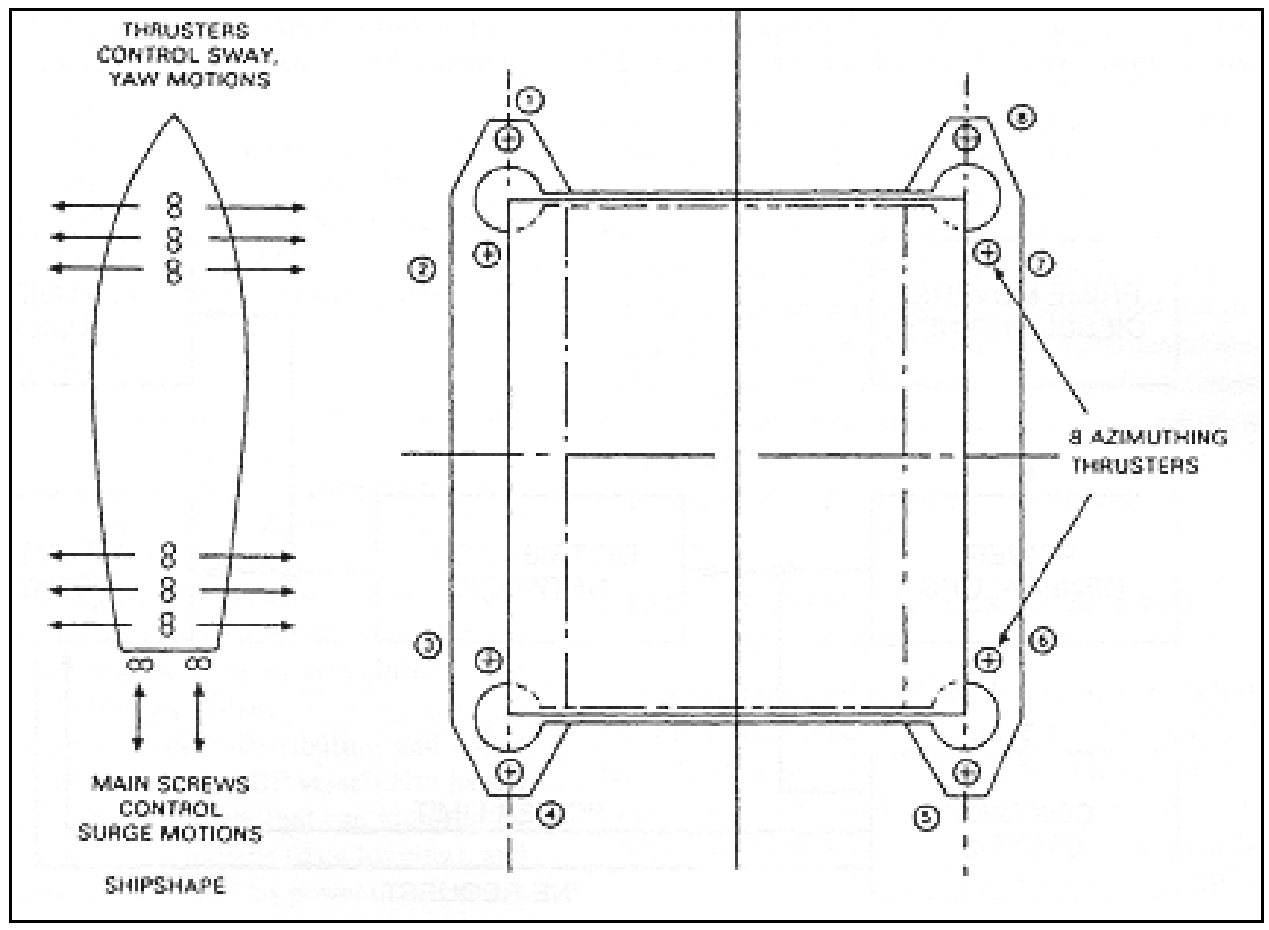

Figure 5-4. Common thrust configurations in ships and catamaran

Dynamic positioning can be used as the sole source of stationkeeping or used to assist a mooring system for positioning. When dynamic positioning is used in conjunction with a mooring, it is called "DP-assisted mooring."

Dynamic positioning systems are highly complex and maintenance-intensive systems. Although typically designed to be automatic, these systems must be continually monitored by operators to ensure proper operation and coordination 
among its different components. As a result, the dynamic positioning system has been used mostly for complex deepwater operations, such as offshore drilling exploration and operation.

Nevertheless, dynamic positioning can be applied in inland waterways with several advantages. Dynamic positioning is well suited for positioning of a vessel that changes locations frequently. Some large crane barges and catamarans are equipped with self-propelled thrusters and dynamic positioning systems. A typical DP-assisted mooring of a crane barge consists of three mooring lines at the bow and two thrusters, often referred to as "sea mulls," at the stern for maintaining orientation of the barge. Dynamic positioning is also effective in controlling a vessel moving along a preset track. Thus, this positioning system has been found useful for underwater dredging and foundation preparation, exploratory drilling, and dynamic mooring assistance. At present, an increasing number of vessels are equipped with thrusters and can be manually controlled for positioning in rivers. These thrusters are "outboard" type with engine on deck and vertical drive shafts. This positioning system is often used in congested waterways. In many cases, these vessels can be efficiently used for float-in and lift-in construction.

With the rapid advancement of the computer control system and dynamic positioning technologies, the industry will see increasing applications of dynamic positioning for assisting derrick crane barges and other heavy marine lift equipment. 


\section{$6 \quad$ Guide Systems}

In marine construction, typical guide devices used for installing prefabricated modules include master piles, horn guides, and stabbing systems. These devices can be used to guide installation to a tolerance less than 1 in. If more stringent tolerances are required for positioning control, guide devices such as flat jacks and hydraulic rams may be used to adjust the position after initial setdown of the elements.

Selection of guide systems should consider the environmental conditions, the size and configuration of the module to be installed, and the installation process. Adequate consideration should also be given to the interaction between guide systems and mooring systems during the installation process. Overloading, especially by impact, may lead to breakup of the guides and loss of control of a float-in or lift-in module. This chapter presents an introduction to the design and selection of various common guide systems.

\section{6-1 Hydraulic Jacks}

Hydraulic jacks are commonly used for underwater positioning of float-in or lift-in structural elements when tight alignment tolerances are required. Hydraulic spotter jacks may be installed in pairs at different locations to adjust orientation of a segment. The jacks can also hold a segment in a fixed position against current and wind forces while ballast is being placed.

Figures 6-1 and through 6-3 illustrate the use of hydraulic jacks in mating immersed tunnel segments. The jacks are typically installed on the external walls or bulkheads of the immersed tunnel elements. After a tunnel element is positioned and ballasted down onto prepared bed, it is engaged and pulled by the hydraulic jacks toward the previously installed adjacent element. The mating surface usually consists of a soft rubber nose on a solid rubber strip (Gina seal) to function as a gasket all round the perimeter of the tunnel. The space between the bulkheads, enclosed by the cantilevering walls, is subsequently dewatered. This causes the hydrostatic head to push the newly stalled element against the adjacent element, creating a watertight seal around the space.

If an initial positioning of the element is not within specified tolerances, the hydraulic jacks are also used for realignment. To allow for realignment, the element is slightly lifted up with winches to reduce bottom friction with the bed. 


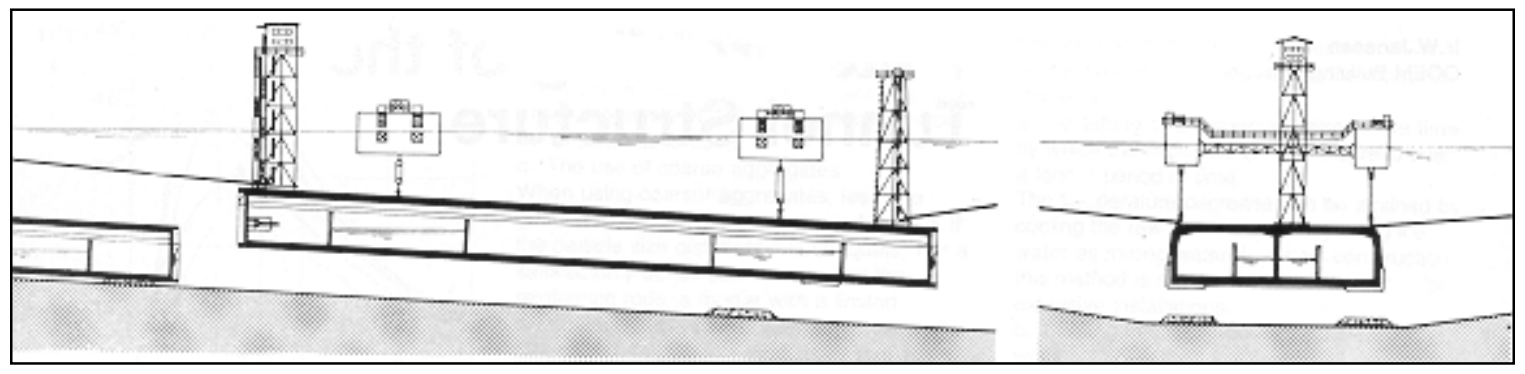

Figure 6-1. Mating of immersed tunnel segments

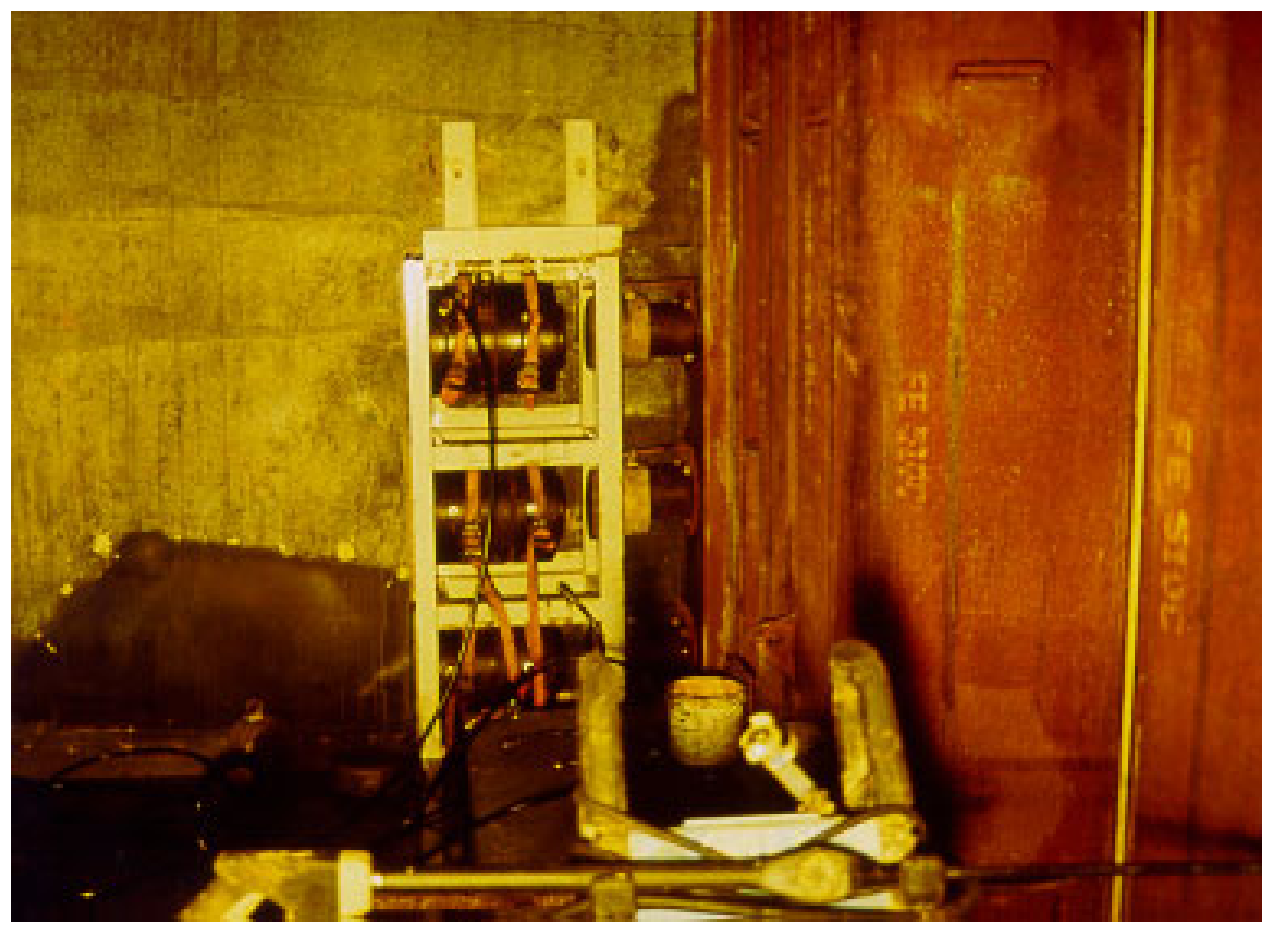

Figure 6-2. Use of hydraulic jacks to realign two adjacent tunnel segments

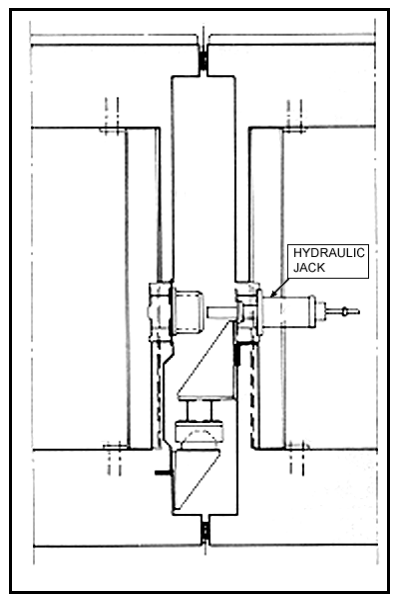

Figure 6-3. Details of hydraulic jack used to align immersed tunnel elements 
The jacks are then slowly pressurized to realign the element. A final survey is made before the element is lowered back into position, and full ballast is applied to stabilize the element in its final position.

For many applications, hydraulic jacks are designed so as to minimize stresses on the piston. For example, Teflon pads may be employed to facilitate sliding of the prefabricated module. Neoprene cushion may also be used to allow the sliding.

\section{6-2 Horn Guides}

Horn guides are typically used to align two adjacent float-in or lift-in segments. Proper use of the horn guides facilitates placement of segments within alignment tolerance as tight as $\pm 0.5 \mathrm{in}$. In a typical arrangement, a horn and a guide are built into two adjacent precast segments at properly aligned positions. As one segment is gradually lowered to its final position, the horn guide installed on the previously installed segment will engage the horn on this segment, guiding the segment to its correct alignment. Figure 6-4a shows a concept of the horn guidance system for installation of a tainter gate sill segment. The horn guide is used together with a hydraulic jack to position the lift-in sill segment (Figure 6-4b). Figure 6-5 shows a horn guide that was mounted on an immersed tube segment prior to its transport and installation.

Figure 6-6 shows the horn guide used in positioning of the Braddock float-in Dam Segment No. 1. The segment, with the setdown bracket (on top of the fixed weir bay of Segment 1), is positioned directly over the top of the horn guide assembly (located on the face of the lock wall). While the segment is ballasted down, its position is checked and confirmed by survey. Within approximately $8 \mathrm{ft}$ of the touchdown position, the setdown bracket is fully engaged within the horn guides and controls the alignment of the segment through the remainder of the immersion.

\section{6-3 Stabbing Systems}

A stabbing system is essentially a male-female locking system. It consists of cast-in-place steel pintle/stabbing cone fittings, which is also known as pin/ socket fittings. This pintle/cone system provides positive, mechanical alignment of two separate segments when they join together over water or underwater. The stabbing system usually serves multiple purposes, including (1) guidance and alignment of two joining segments, (2) a shear key once two adjacent segments are engaged, (3) a compression bearing, and (4) provision of torsion resistance.

The stabbing system has been commonly used in matching and joining two floating structures over water, such as the joining of FlexiFloat units (shown in Figure 6-7). Figure 6-8 shows several pintles preinstalled on a concrete pontoon 

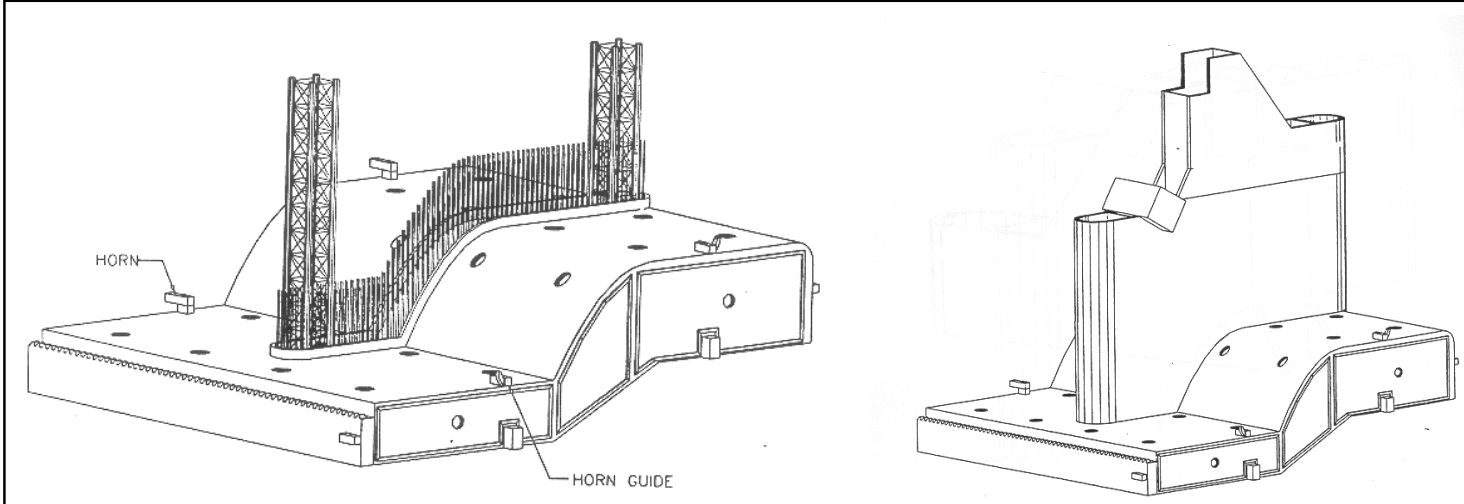

a. Horn guides used to position tainter gate sill segments
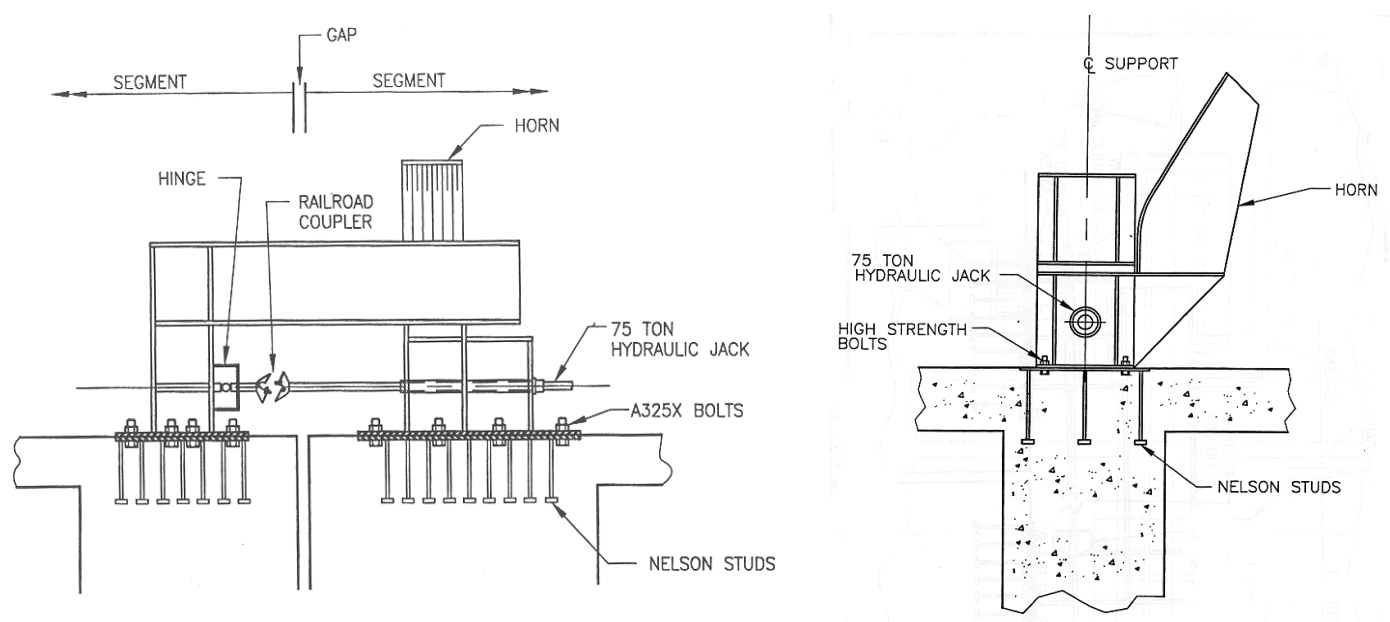

b. Details of horn guide with a hydraulic jack

Figure 6-4. Use of horn guides
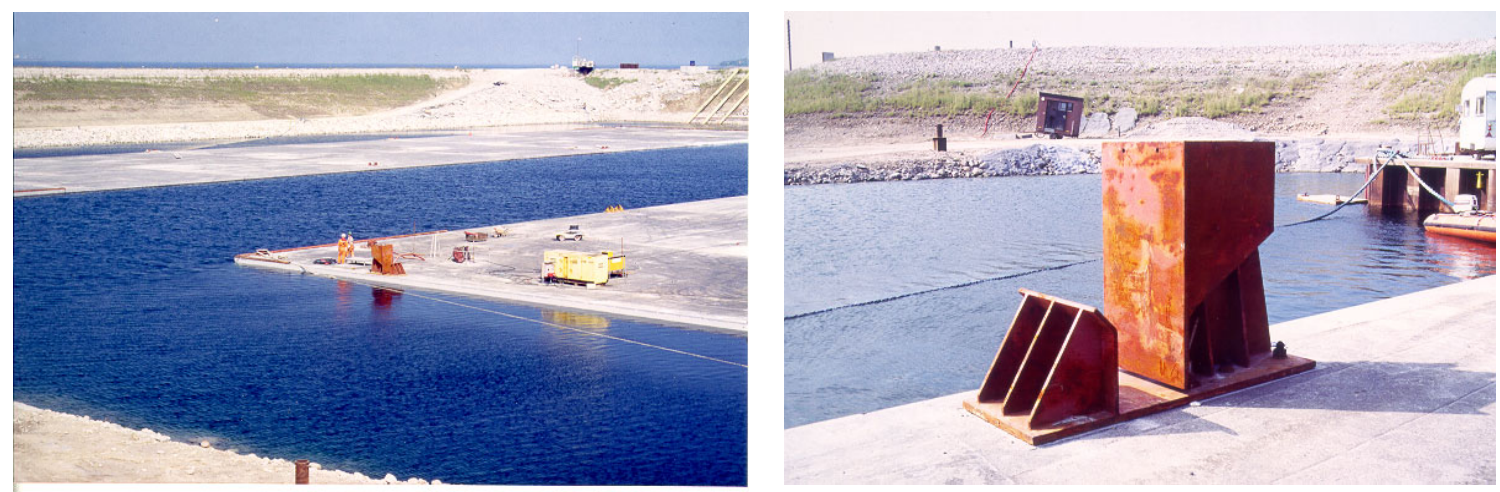

Figure 6-5. Horn guides are used in immersed tube segments (Oresund Crossing) 


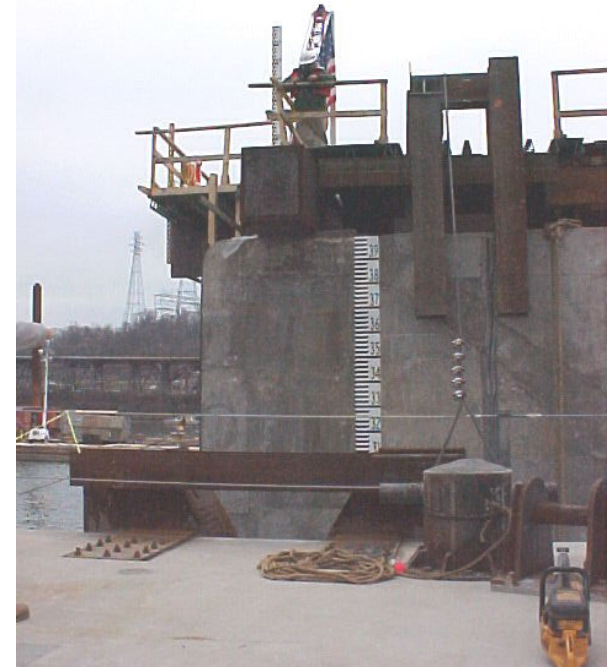

a. Horn installed, Segment 1

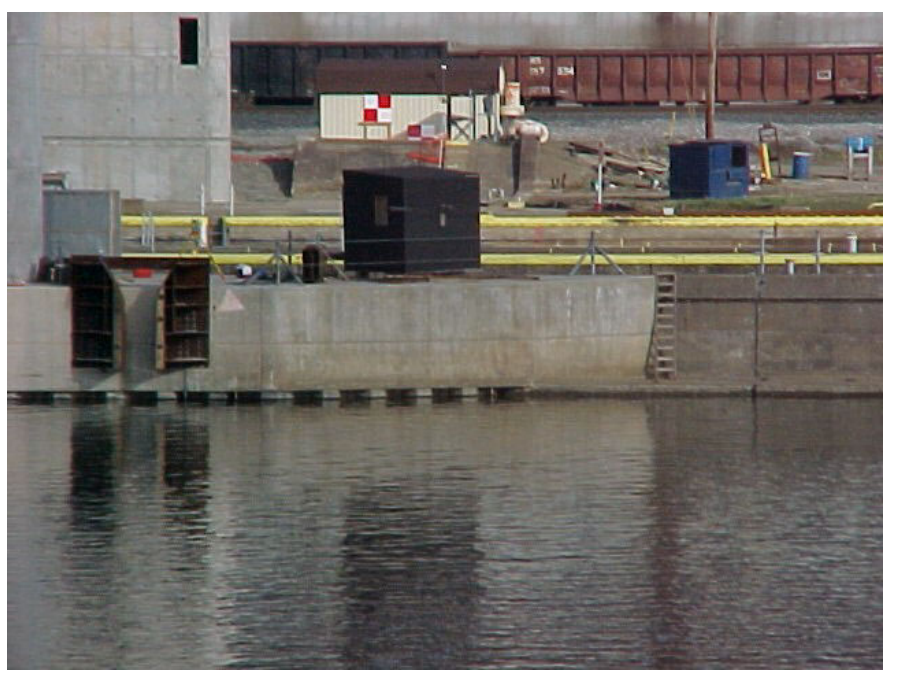

b. Guide on adjacent lock wall

Figure 6-6. Horn guide was used in positioning Braddock Dam float-in Segment 1

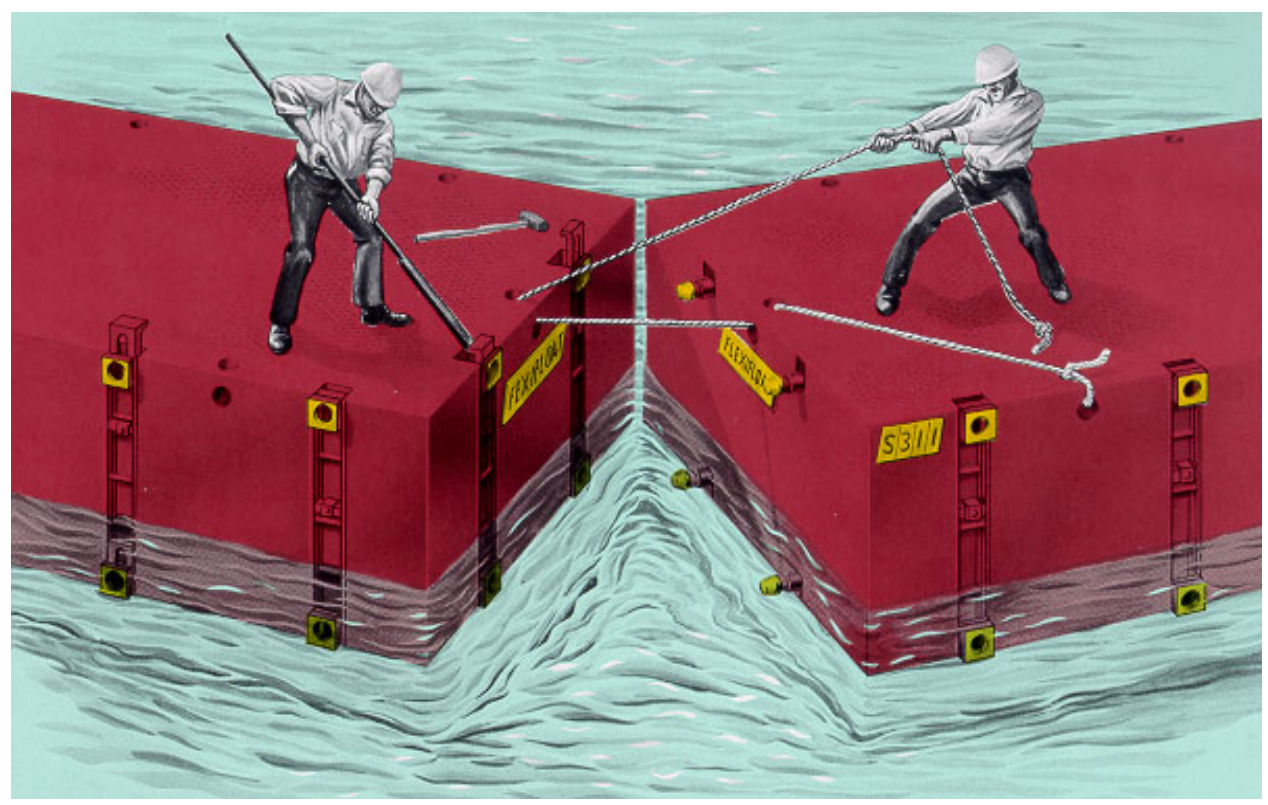

Figure 6-7. Pintle/cone stabbing device used to join FlexiFloat units

segment that is ready to float out and join other pontoon segments over water. Figure 6-9 shows the use of the pintle connection as a guide for joining floating pontoons.

As shown in Figure 6-10, the stabbing system consists of a tapered steel tube/cone with the following key features: (1) a notch as its base for latching to the receptacle, (2) a duct passing through its interior, and (3) an O-ring seal around the perimeter of the base of the tube/cone. The receptacle guide has the following key features: (1) a leading funnel, (2) a trailing flexible flanged 


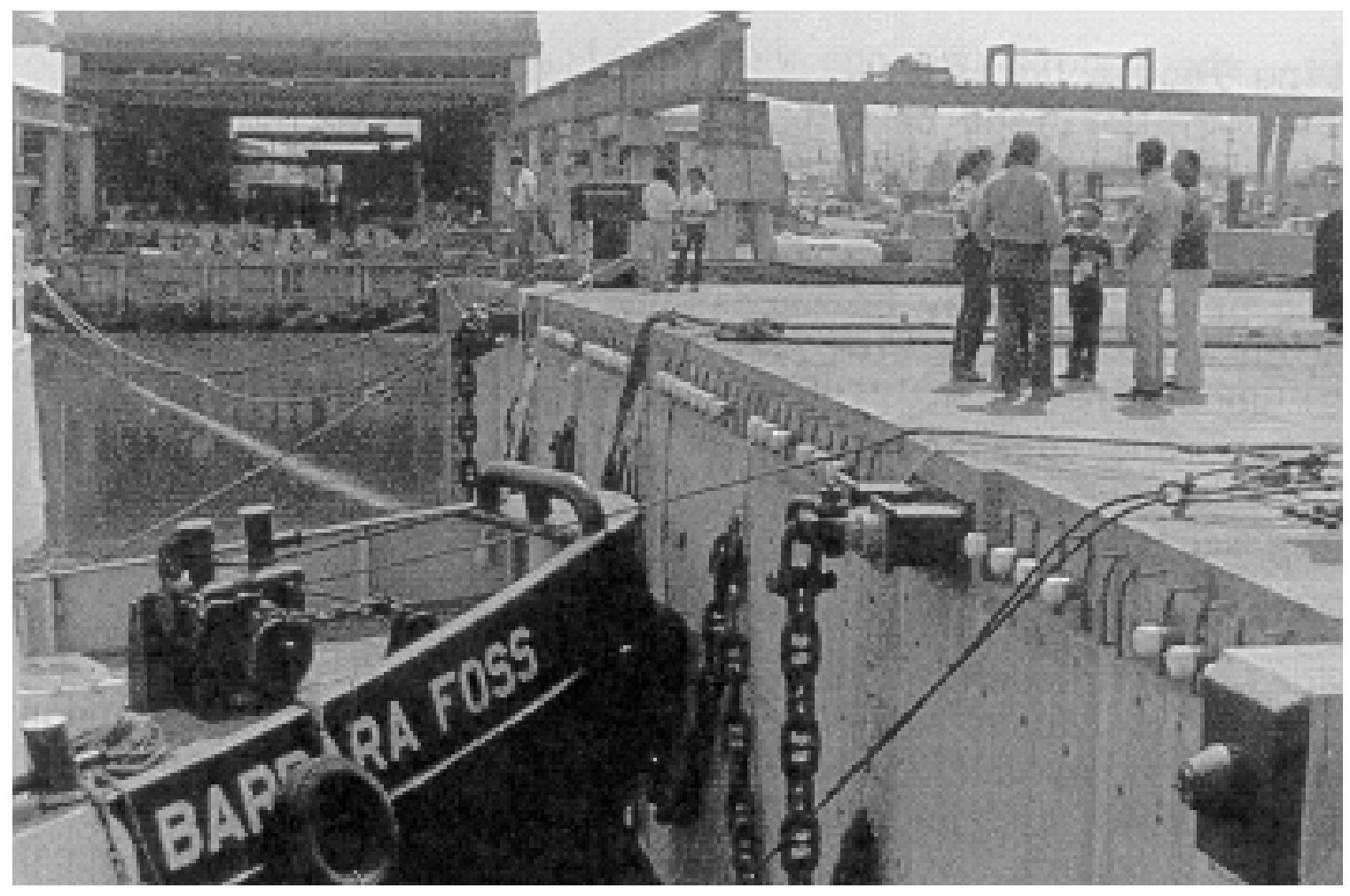

Figure 6-8. Pintles mounted on precast concrete pontoons for joining offshore (floating Valdez container terminal, Alaska)

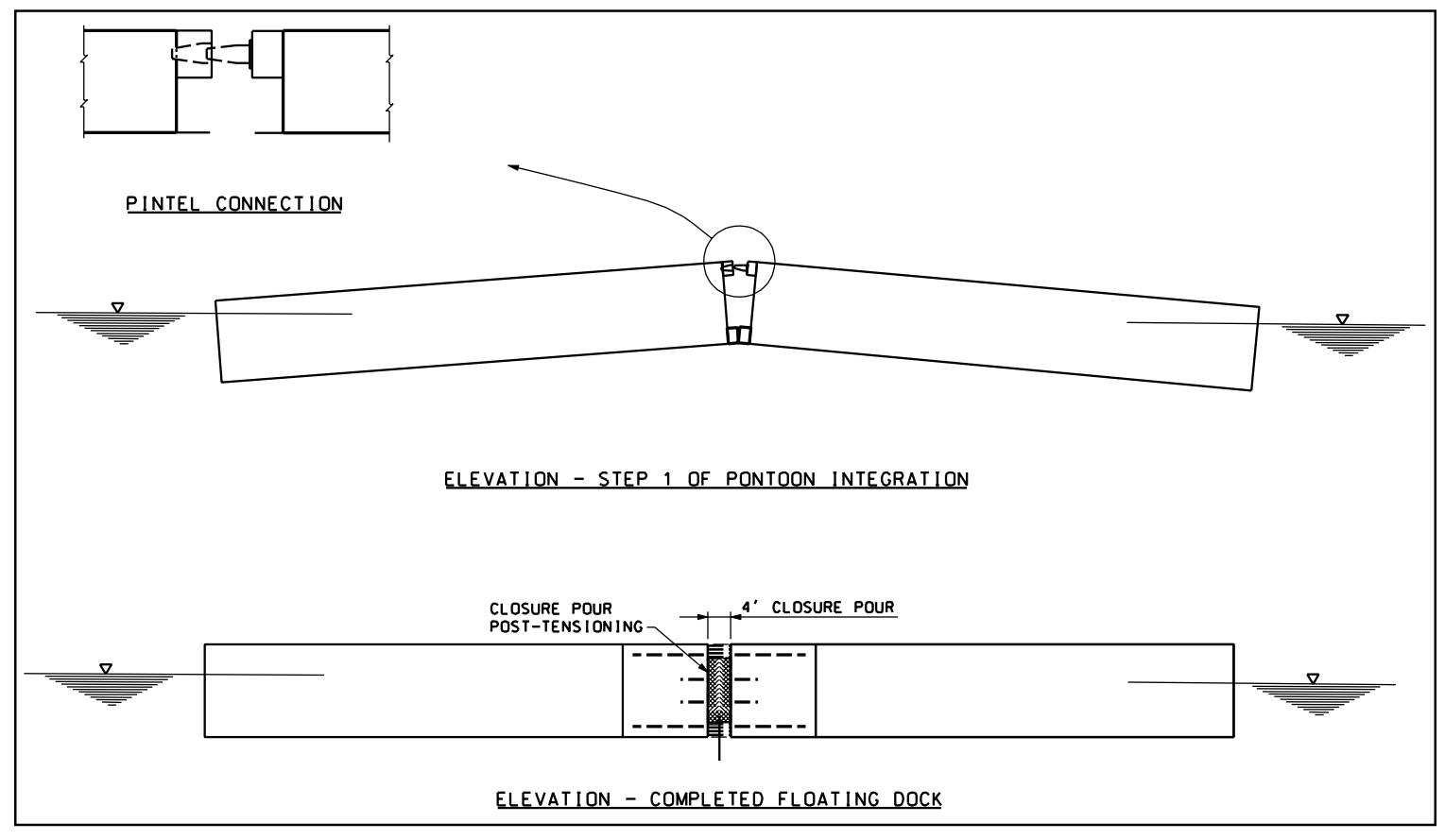

Figure 6-9. Joining concrete pontoons over water by use of stabbing connection 


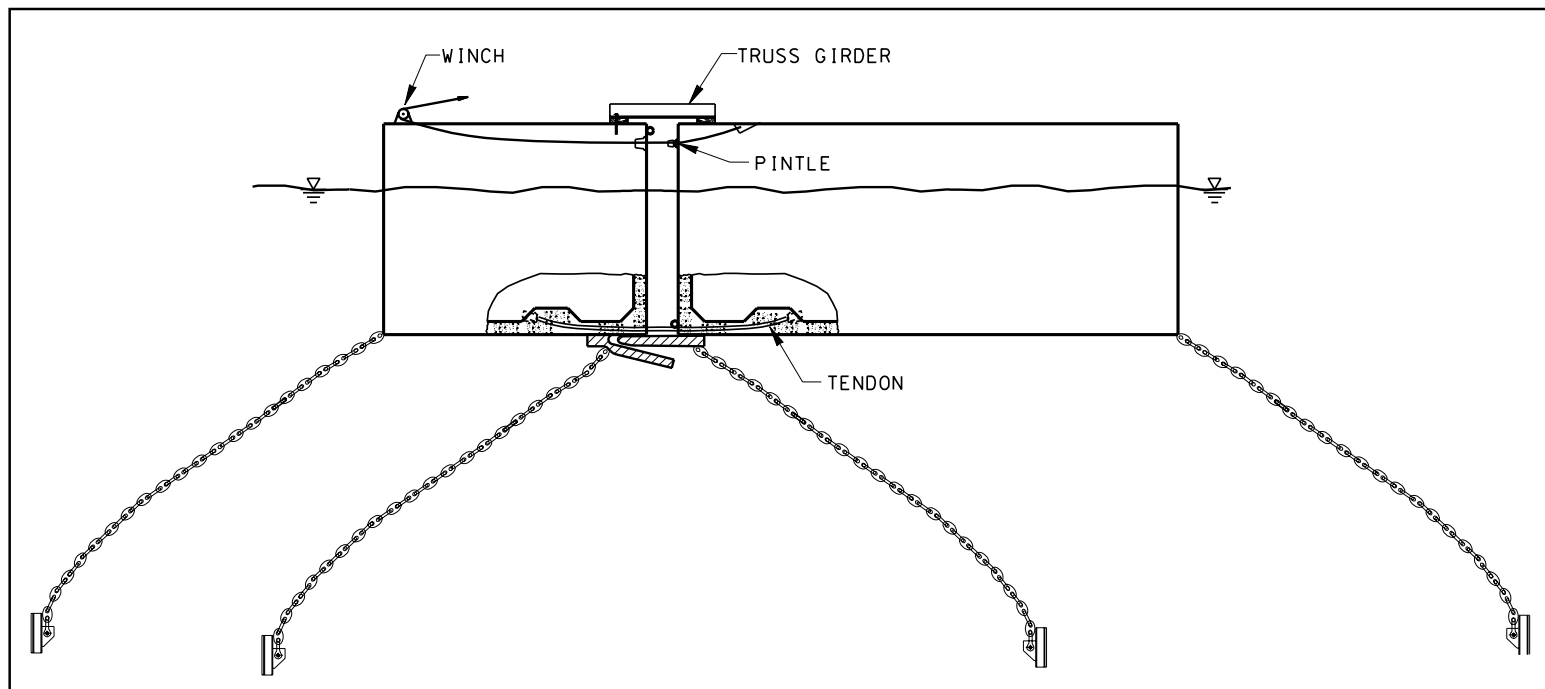

a. Schematic
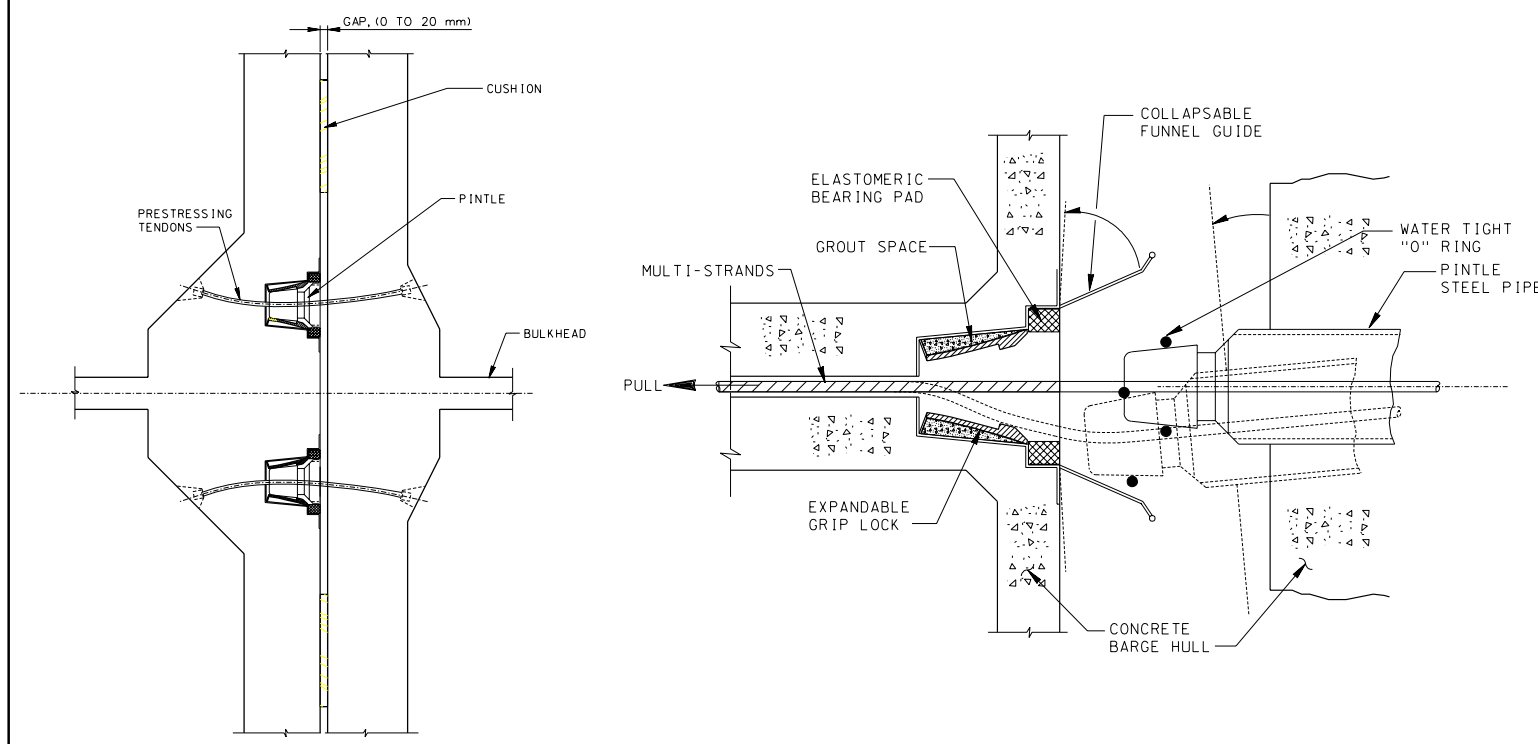

b. Details

Figure 6-10. Pintle/receptacle for joining concrete pontoons

receptacle for the pintle, and (3) grouting systems for both infilling the exterior perimeter of the receptacles and encapsulating the post-tensioning tendons that pass through the pintle/receptacle guide system. In joining of floating pontoons, the pintle/flexible receptacles would serve as stabbing guides to align two adjacent individual segments. The leading edge of the receptacle would be funnelshaped to help guide the pintles into the flexible flanges in the interior of the receptacles. Then, the flexible flanges would provide some guidance in all six degrees of freedom. The stabbing of the pintles within the flexible receptacles combined with the increasing pulling (squashing) of the thick wall tubes by 
winches would progressively restrain the relative movement of the two adjoining segments to almost zero. Figure 6-11 shows the use of a similar pintle/cone stabbing system for lift-in installation of a dam sill segment.

The stabbing system has also been used as a key component in float-over construction, as shown in Figure 6-12. The float-over operations have been used to install a fully integrated deck module onto a preinstalled jacket (Figure 6-13). The float-over operations involve marine transport of a deck module with a barge to the project site. The barge is maneuvered to position the deck between the supports of a preinstalled jacket. Then, the deck is installed to the jacket through a series of jacking/ballasting operations. The barge is ballasted down, free of the deck, and towed away.

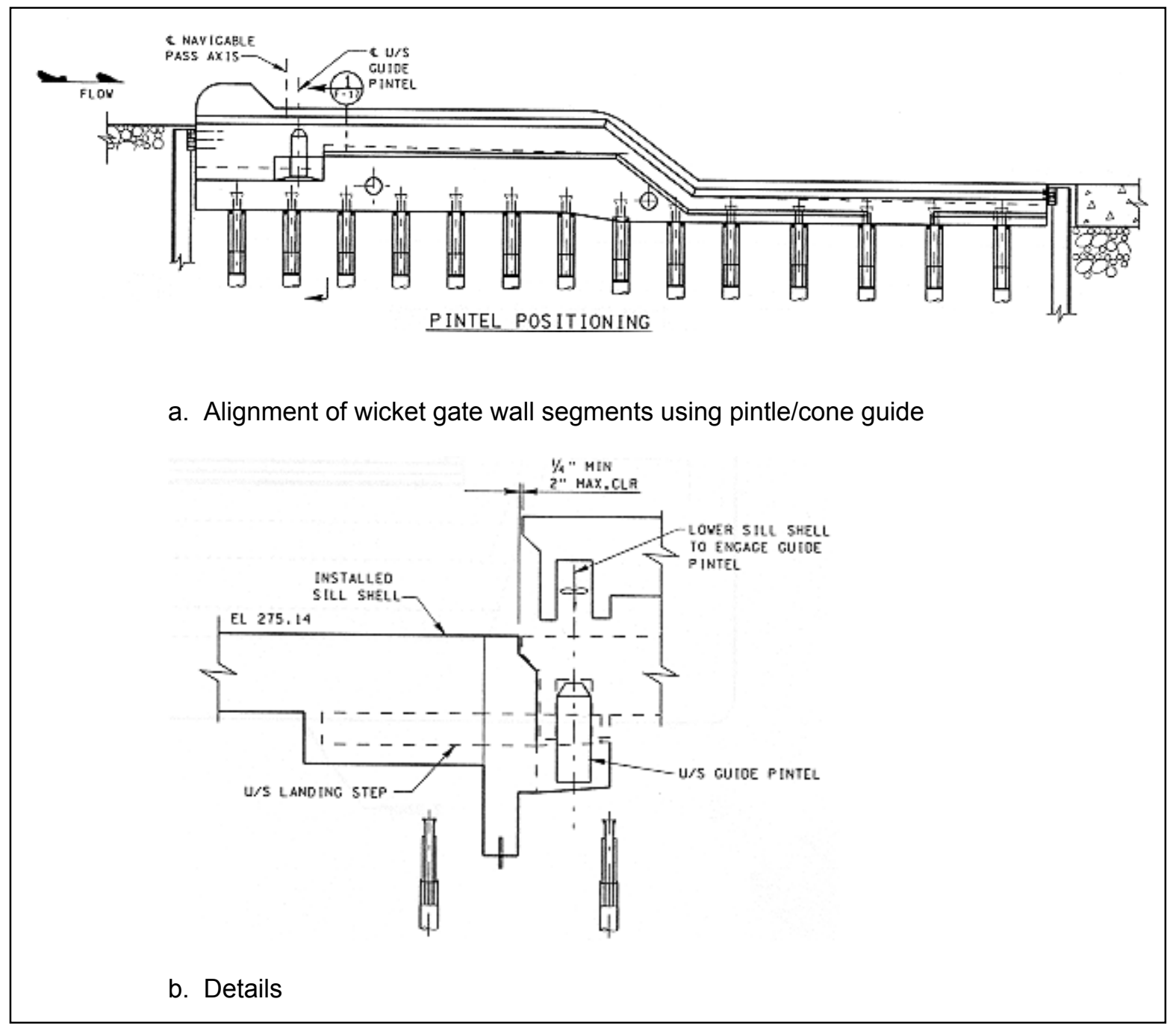

Figure 6-11. Use of pintle/cone guide 


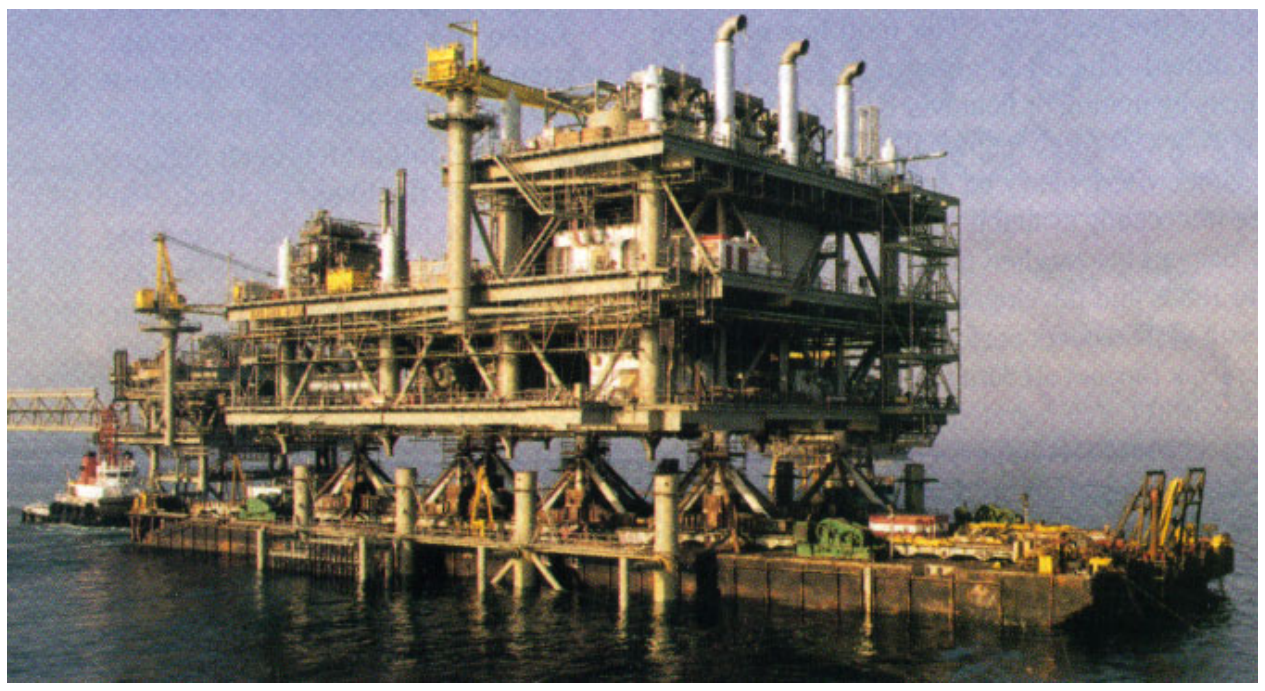

Figure 6-12. Alignment of a 5,000-ton integrated deck module with stabbing cones

During the float-over operation, the stabbing guide is designed for several purposes. First, it provides a smooth positive guide of the lift-in module into the supports during the ballasting phase. At the end of the ballasting, the module will be safely engaged onto the supports without generating excessively hard impact. This requires that the stabbing guide provides appropriate axial and lateral rigidity to transfer the weight of the module and to accommodate the motion of the barge. Second, the stabbing guide must progressively control the relative motion of the module with respect to the supports during the jacking-down operation. The third purpose of the stabber is to provide a precise guide for the mating of the module to the supports.

The potential vertical impact loading can be substantially reduced by a "motion-based" system in the stabbing guide, as shown in Figure 6-14. The impact-absorbing system is composed of sand valves and shock absorbers. The shock absorbers are cylindrical telescoping rams projecting below each deck leg. As the barge is ballasted down to mate the deck with the jacket, shock absorbers land on "flat tops" and react against a stack of rubber disks inside each deck leg. Thus, the axial load in the rams is limited by the rubber disks, as determined by the load versus distortion relation. This eliminates any vertical impact loading as the deck lands on the jacket. The "flat tops" is at the top of a piston inside a "sand can" (see Figure 6-14). Once the float-over is completed, the sand is drained through the valves causing the piston to travel downward, stabbing the deck legs into the sand cans. The deck legs are girth-welded onto sand cans to complete the installation. 


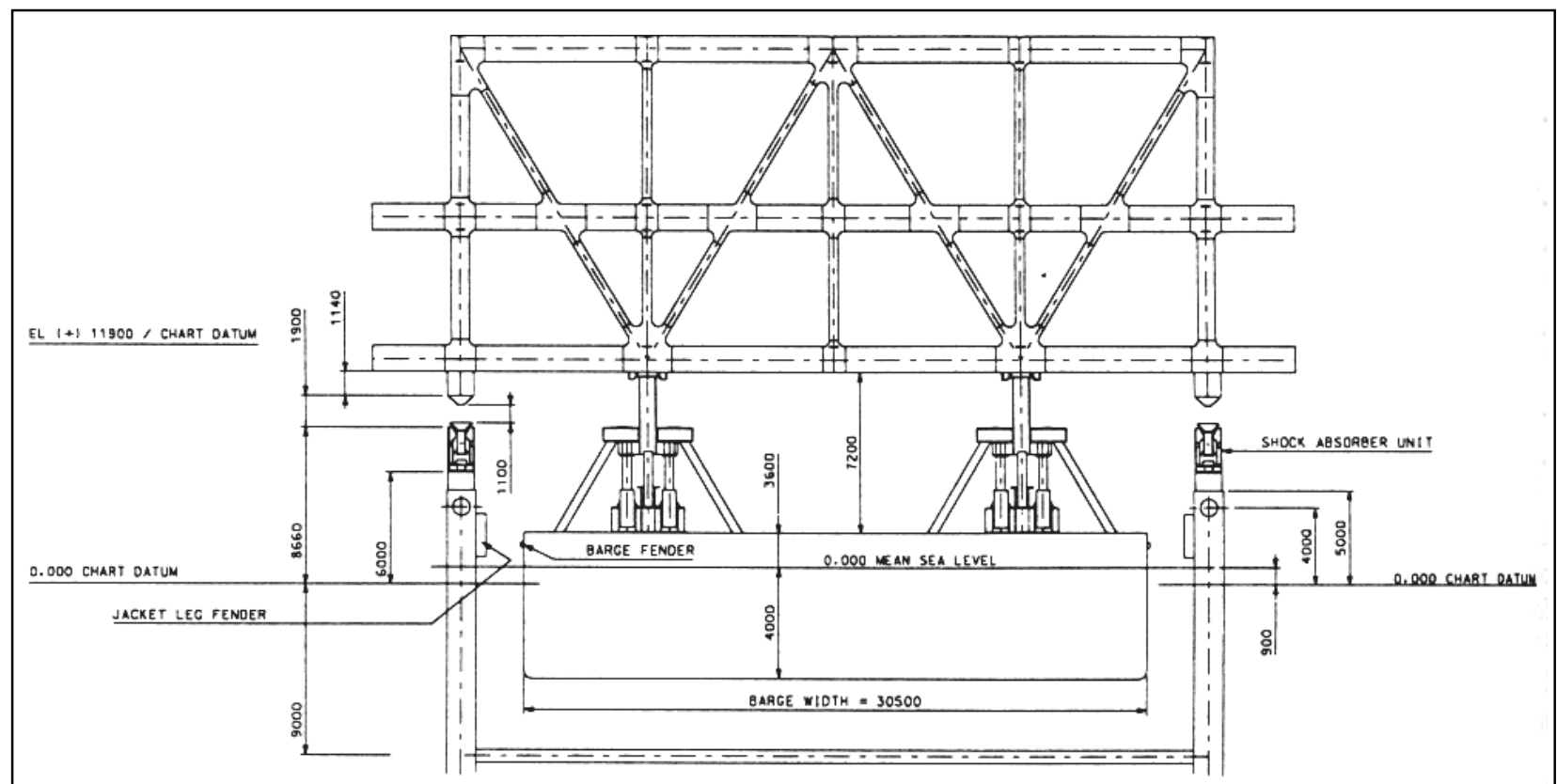

a. Mating of a topside module and jacket supports

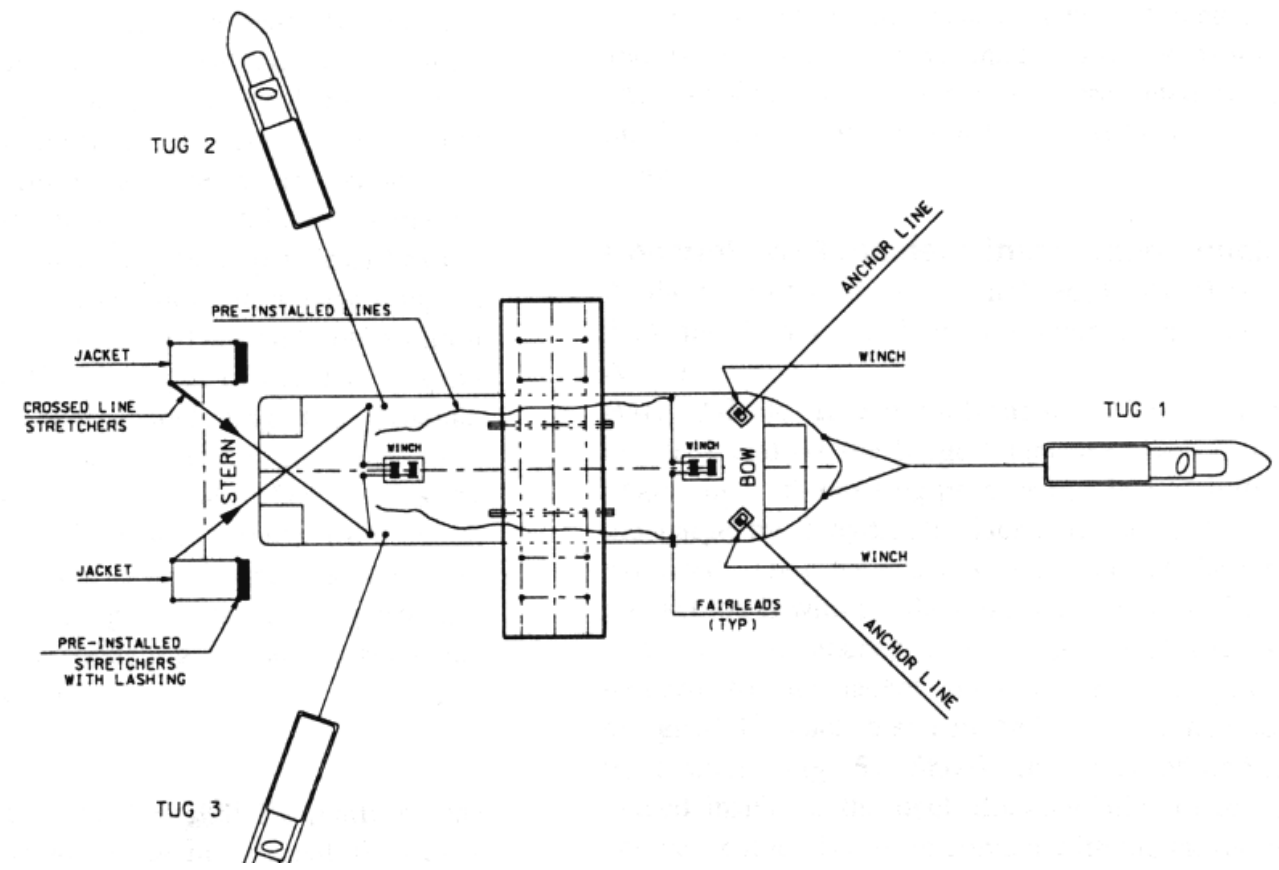

b. Positioning the prefabricated module over the jacket

Figure 6-13. Installation of fully integrated deck module onto a preinstalled jacket 


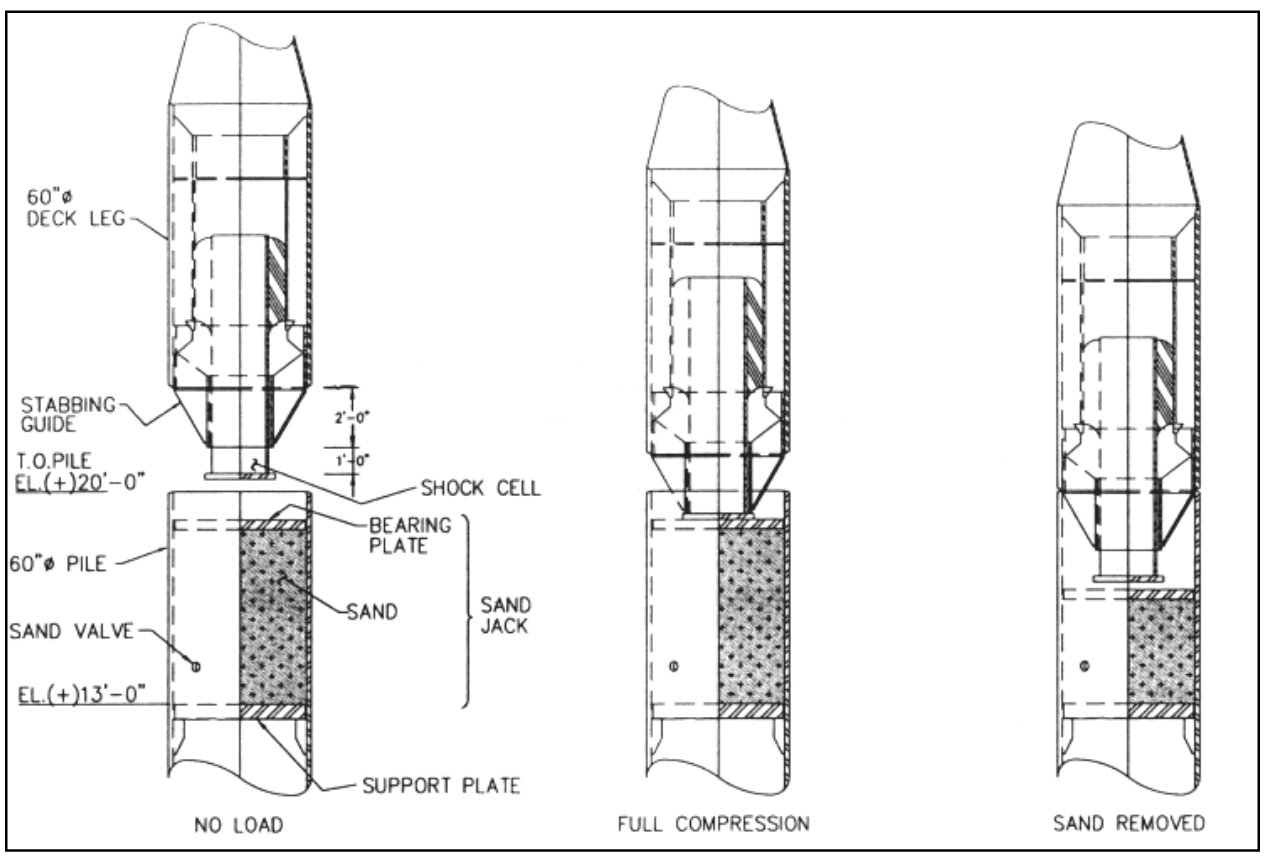

Figure 6-14. Stabbing guide assembly details

\section{6-4 Flat Jacks and Grout Bags}

Both flat jacks and grout bags are commonly used for making underwater adjustments of float-in or lift-in modules. Flat jacks can provide leveling adjustments to a very high degree of accuracy. Grout bags, on the other hand, are primarily used as underwater seals. However, when used in groups with proper arrangement, grout bags may be effectively used as a leveling device to adjust the position of the structure they support.

A flat jack usually consists of a mild steel capsule, circular in plan, with a cross section that is initially dumbbell-shaped. The dished portions are fitted with ground steel thrust plates before the jack is placed between the surfaces to be jacked apart. Two pipe connections are welded into the jack rim, usually at a 90-deg angle to one another. One pipe connection provides the inlet for inflation, and the other serves as a vent during filling. When the jack is inflated with a liquid, the hydrostatic pressure is transmitted by the flat portions of the capsule through the thrust plates to allow the flat faces to move apart, as shown in Figure 6-15. This movement forces the bearing plates away from one another, thereby pushing the load away. The force applied by the jack is a calibrated function of internal pressure and the size of the jack. The rated capacity of a flat jack is based upon the maximum

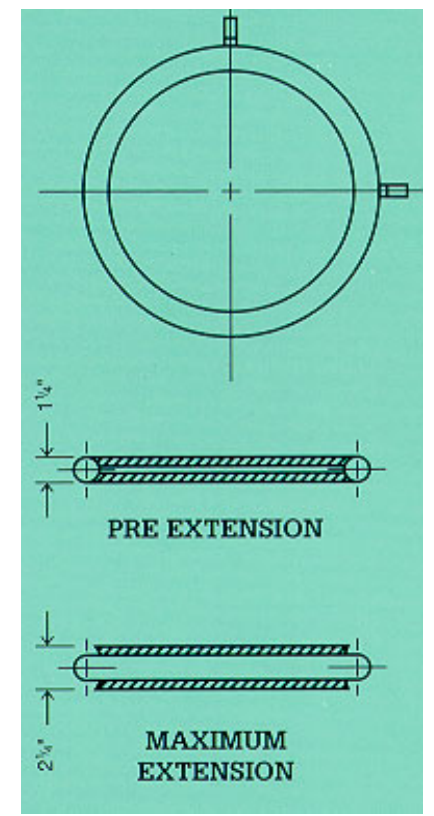

Figure 6-15. Flat jack 
allowable pressure of the liquid, typically 150 bars (2,200 psi). To provide large jacking forces, flat jacks up to several meters in capsule diameter have been used.

The maximum extension (opening stroke) of commercial flat jacks is usually $25 \mathrm{~mm}$. To provide a longer stroke, several flat jacks are commonly used. Figure 6-16 shows the use of multiple flat jacks on a landing pile to adjust the final leveling of the precast element. Multiple jacks can be inflated individually or on interconnected circuits.

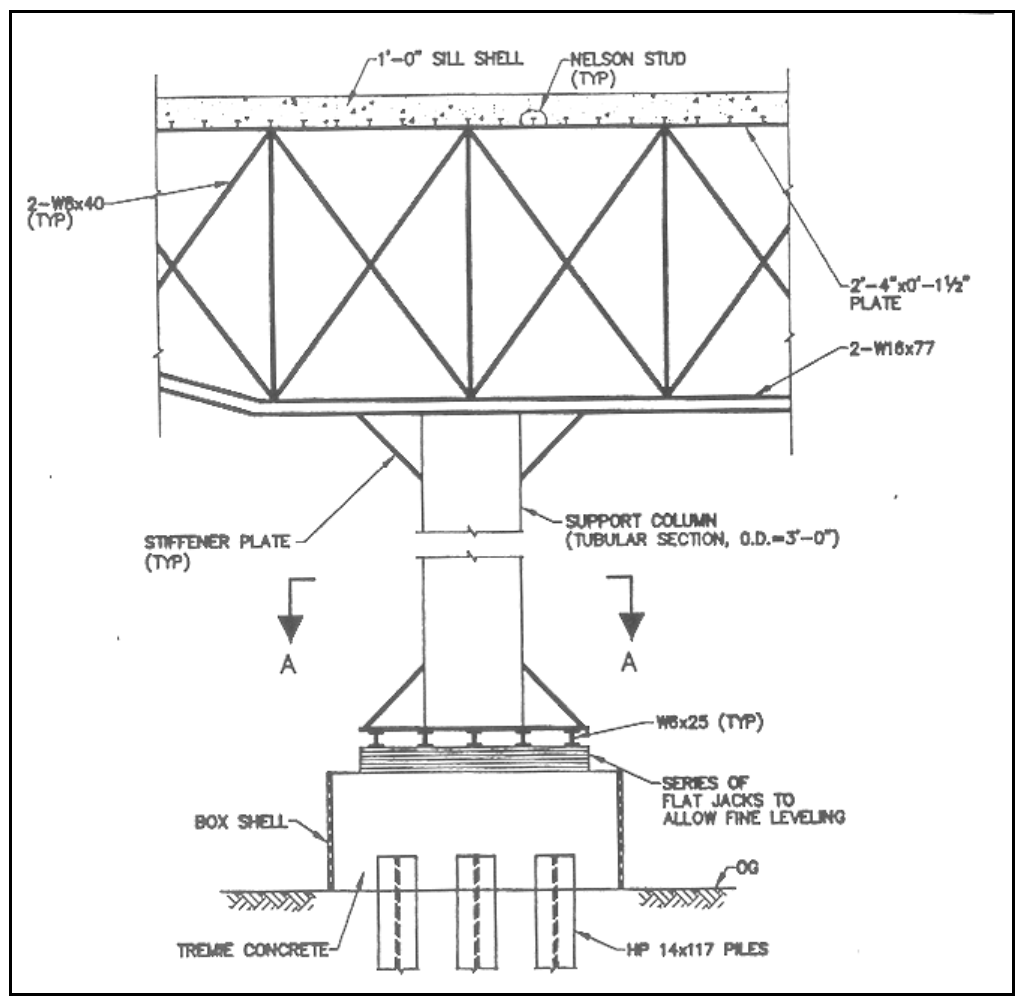

Figure 6-16. Use of flat jacks on a landing pile

When flat jacks are temporarily installed to help position an element, inflation of the jack is normally done with oil. When flat jacks need to be permanently installed to a structure, flat jacks are usually inflated with an epoxy resin. The epoxy resin hardens over time to maintain the jacking force permanently in position. Sometimes, it may be necessary to carry out the initial inflation on hydraulic oil or water and adjust the jack as necessary until the required condition is achieved. Then, the hydraulic oil or water in the flat jack is replaced with resin inflation. In such cases, a specially designed oil-to-resin transfusion system is required to balance and maintain the pressure throughout the transfusion process.

A grout bag is typically made of double layers of woven fabrics with one or more filling tubes and vents for grout injection. Grout bags have been used primarily as inflatable seals, but may also be effectively used as a leveling device. Empty bags are attached to strategic locations on a prefabricated module, preferably fixed to a recess area to prevent mechanical damage during 
installation. Once the module is installed underwater, the empty bags are inflated by pumping grout through the inlet. Figure 6-17 illustrates the use of multiple grout bags to control vertical alignment of a pile-supported tunnel tube.

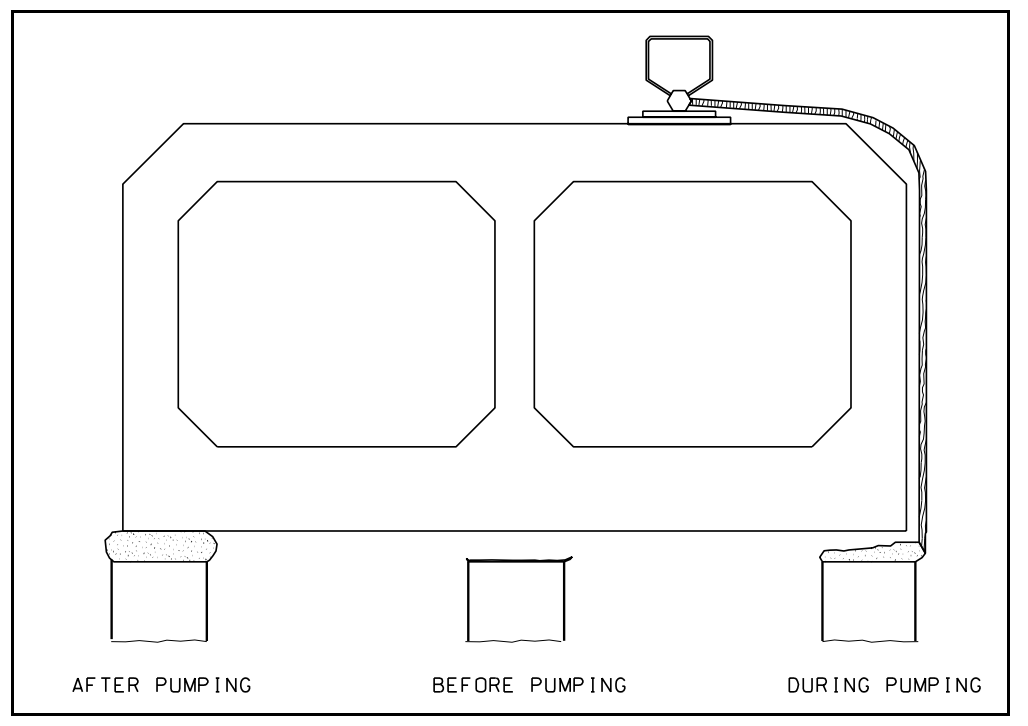

Figure 6-17. Use of flat jacks to control the leveling of an immersed tunnel segment

Successful application of grout bags as a leveling device usually requires a combination of three key elements: arrangement of installed grout bags, grout mix, and filling arrangement. For large grout bags, grout is usually placed from one end to the other using filling tubes and vent tubes. Internal pressures are monitored from the vent tubes in order to ascertain the complete filling of each unit. A long horizontal seal is generally filled with highly fluid neat cement mixes. Grout bags for leveling typically use a sand grout mix that bleeds rapidly to a mechanical set, facilitating the dissipation of potential highly fluid pressure.

In construction of the Confederation Bridge in Canada, each main bridge pier foundation was positioned and leveled by three "hard pads," as shown in Figure 6-18. The hard pad is a 4.5-m-diam concrete dish. To ensure the alignment of the bridge piers and superstructure, these three hard pads must be adjusted and kept in absolute leveled positions. The underwater adjustment of the hard pads was done with grout bags. Empty grout bags were prefixed to the underside of each hard pad and connected with pump hoses. Prior to construction, these grout bags were tested in full-scale models for their capability to support and level the hard pads, as shown in Figure 6-19.

Figure 6-20 shows a floating crane placing three hard pads with a special three-legged frame. At the bottom of each leg, the frame held a hard pad. As the crane lowered the frame into the water, DGPS positioned it so that the three hard pads were located within the predredged circular trench and $0.6 \mathrm{~m}$ above the rockbed. At this point, grout was pumped to inflate the bags onto the rockbed. The frame was checked to see if all three hard pads were level with each other. After the grout hardened sufficiently, the precast pier base was placed onto the three hard pads and the rest of the bridge was erected, as shown in Figure 6-18. 


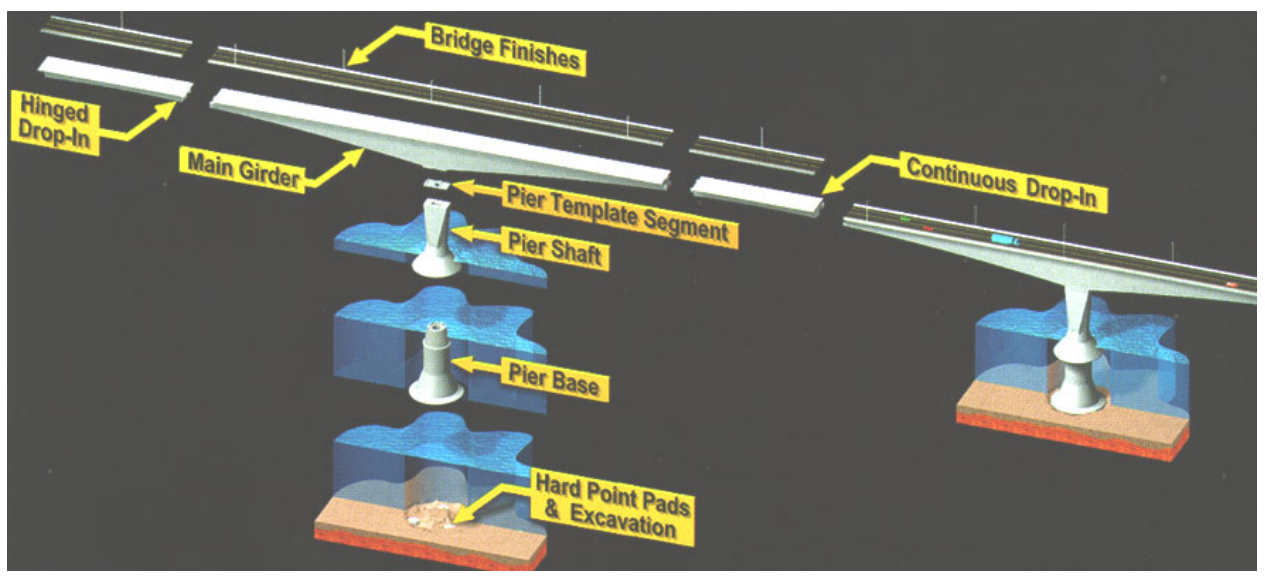

Figure 6-18. Bridge pier and superstructure rest on three hard pads

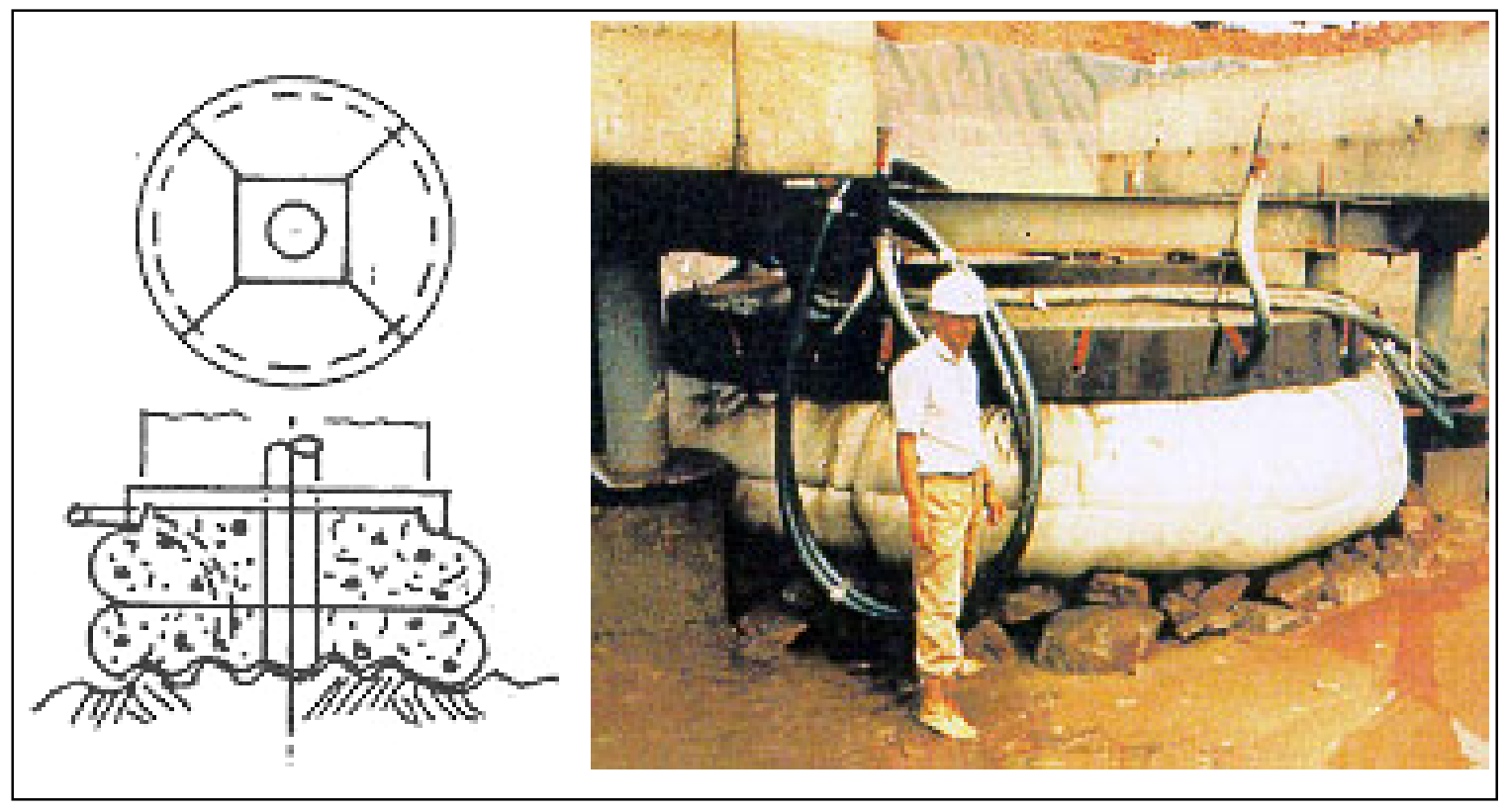

Figure 6-19. Preconstruction trial resting of grout bags as a leveling device

\section{6-5 Master Piles, Spud Piles, and Dolphins}

Master piles or dolphins are frequently used to position large prefabricated float-in modules or crane barges. As a temporary system, master piles are installed to their designated locations, typically within tolerances of \pm 3 in. and 2 to 3 percent inclination. The master piles or dolphins usually work together with taut lines and winches to act as guides for positioning and subsequent sinking of float-in or lift-in modules. 

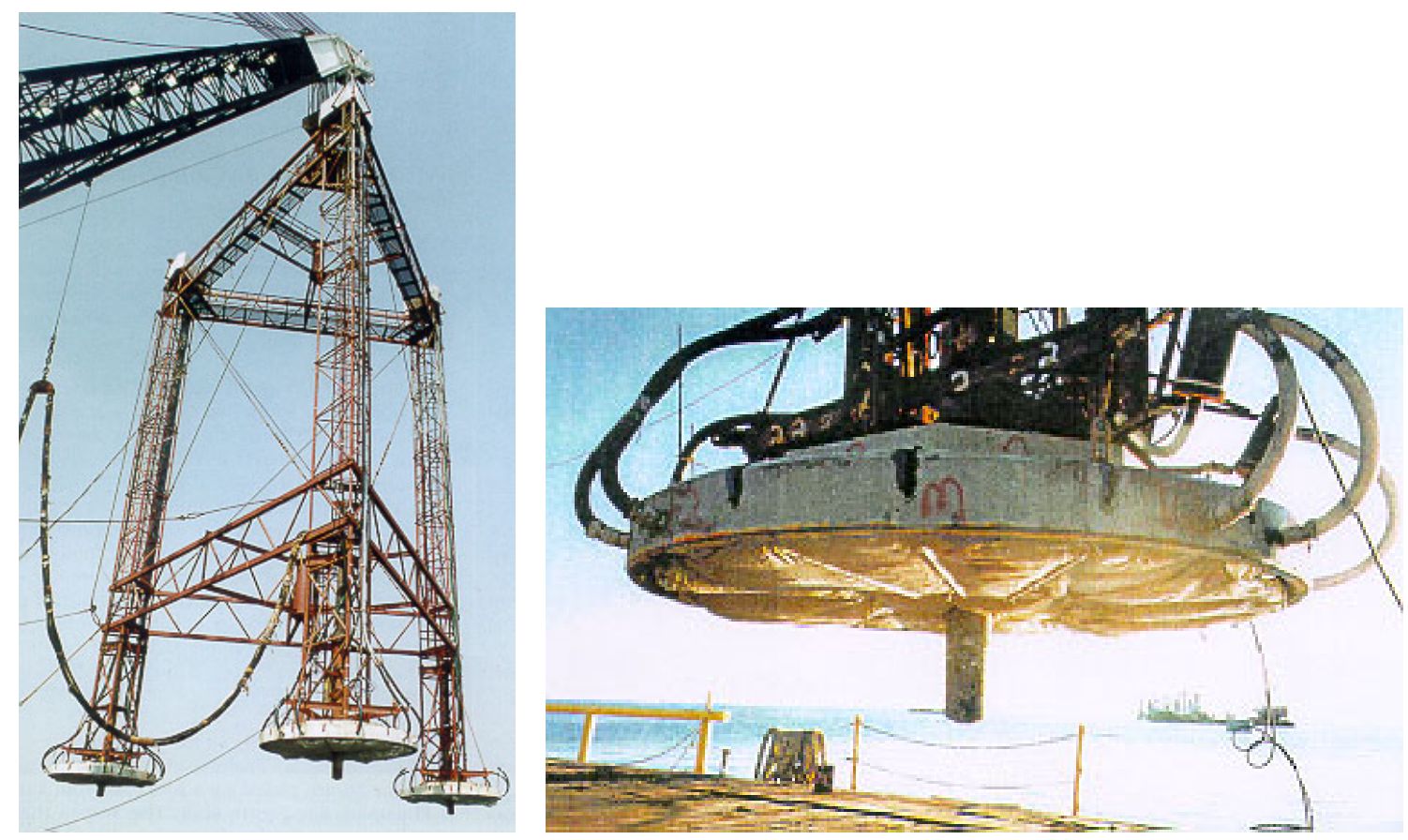

Figure 6-20. Placement of hard pads, with grout bag attachment, by three-legged frame

Figure 6-21 illustrates a concept of using master piles for positioning and installation of a U-shaped float-in miter gate sill segment. Two master spud steel piles are preinstalled at the location. The precast gate segment is pushed over by a tugboat. As the sill segment approaches the master piles, it is attached to deck winches on barges 1 and 2 through taut lines. The winches slowly pull the sill toward master pile 1, until one of the steel yoke plates on the sill is positioned right above master pile 1 . Then, the yoke plate will sleeve into the master pile so that the pile can act as a pilot for the subsequent rotation of the sill. Afterwards, the winch on barge 2 will pull the other end of the sill so as to rotate the sill until it meets master pile 2. The other yoke plate on the sill then locks onto master pile 2. The two master piles act as vertical guides for the subsequent sinking of the sill.

When master piles are used to position a crane barge, they are sometimes spud piles for jack-up barges. Jack-up crane barges are usually outfitted with three to six legs, built either of tubular or latticed steel (see Figure 6-22). Spud piles and the barge-pile connections are designed to adequately support the weight of the barge, cranes, and lift loads. Under normal circumstances, spud piles penetrate the riverbed under their own weight. In some soils, pile penetration can be aided by jetting and vibration. The jacking system that is built into the leg supports can also be used to force the spuds into the soil. It is essential that soil bearing capacity be verified to ensure acceptable levels of pile settlements. Of particular concern are layered soils, in which a spud may gain temporary support but yield suddenly under heavy loads. Pretreatment of soil with grouting may sometimes be required to enhance soil capacity. 


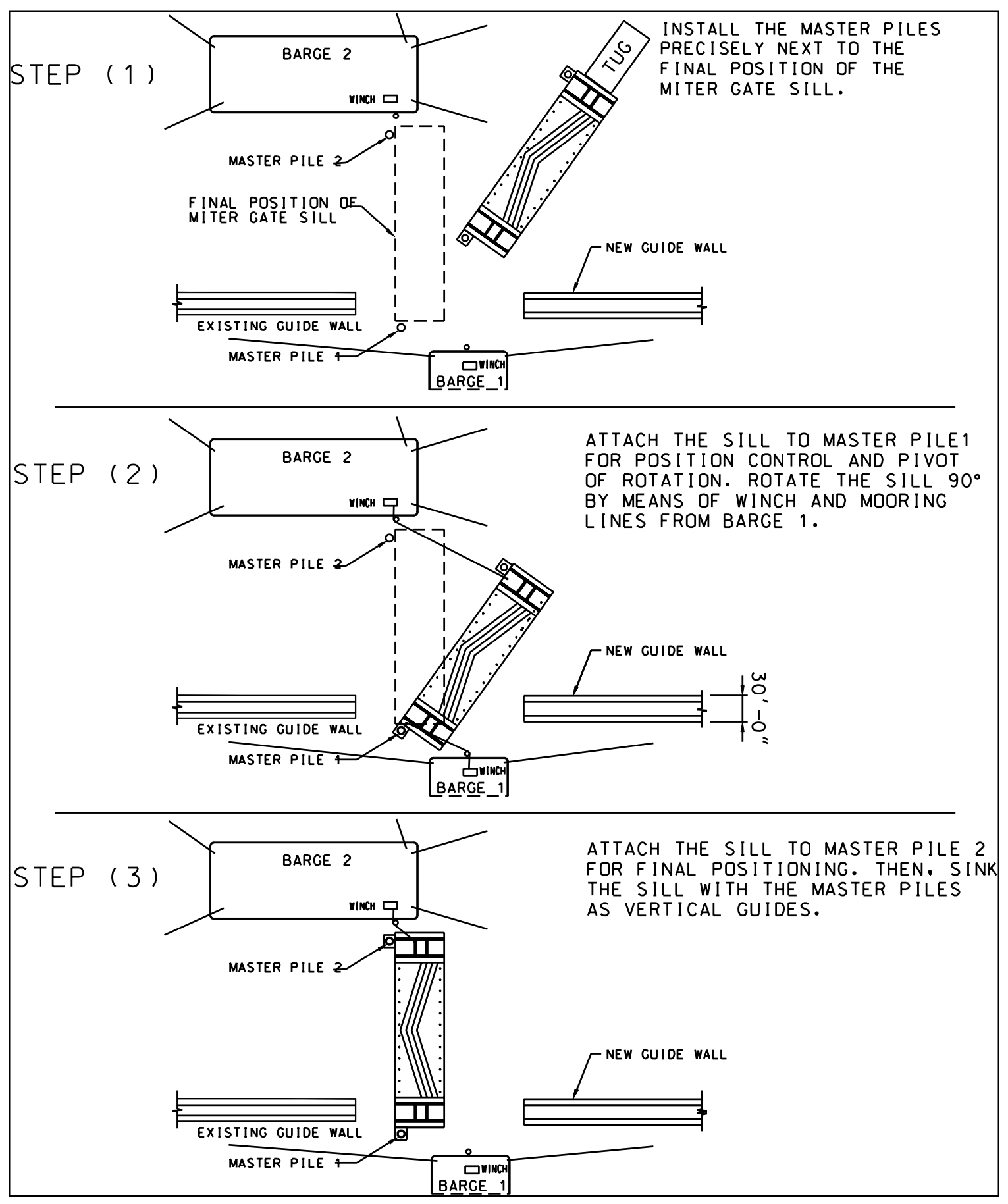

Figure 6-21. Use of master piles and taut line/winches to position miter gate sill 

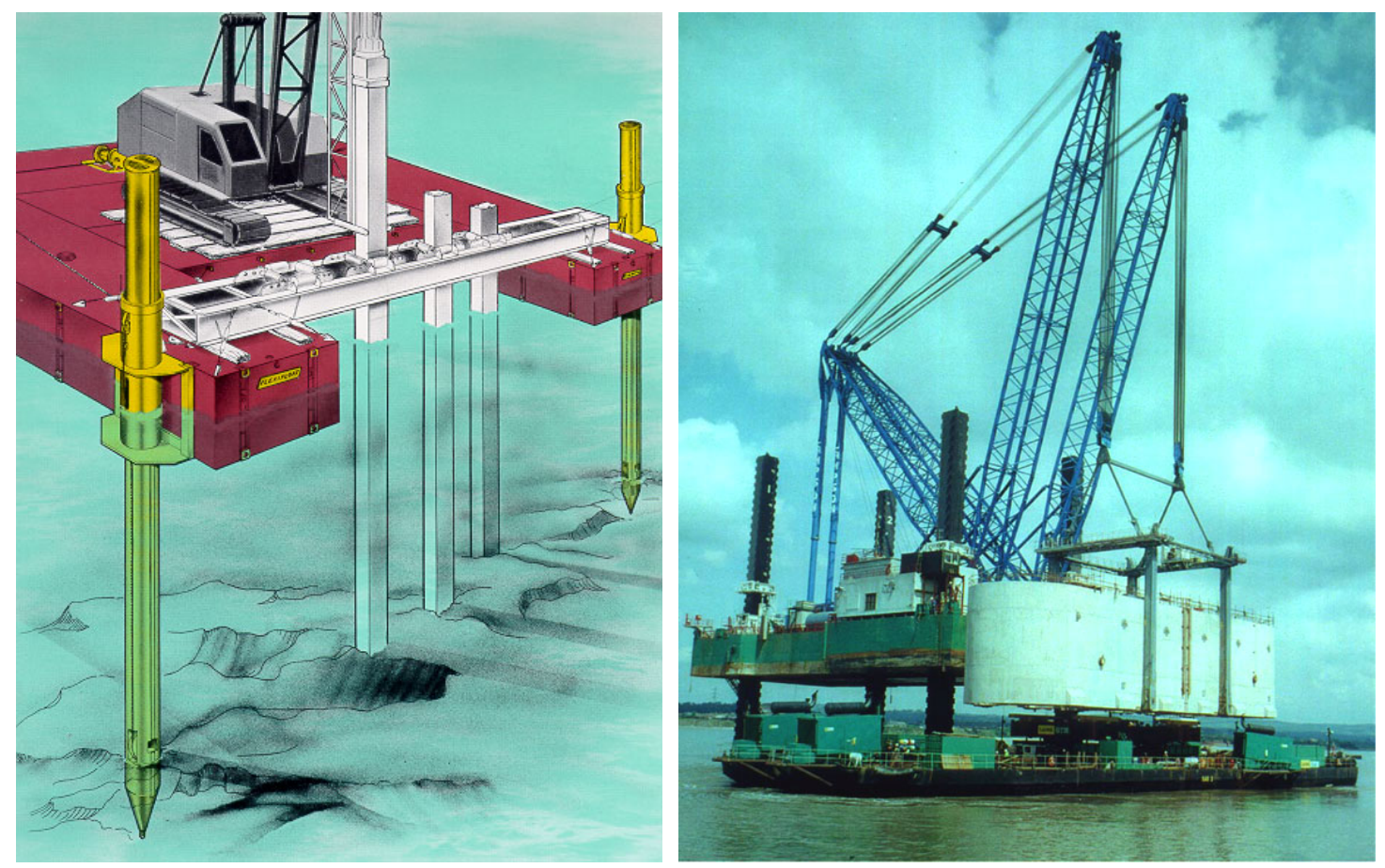

Figure 6-22. Positioning construction vessels with spud piles

\section{6-6 Landing Piles and Landing Steps}

For float-in or lift-in construction, landing piles and landing pads are often used together with flat jacks as the seat to support prefabricated modules and to provide the vertical adjustment to the modules. Their typical applications for liftin construction of lock walls are illustrated in Figures 6-23 and 6-24.

The landing piles are usually constructed as follows: several H-piles or pipe piles are driven to the required depth with pile heads exposed above the mudline. A steel open box (typically 6 by $6 \mathrm{ft}$ or 6 by $3 \mathrm{ft}$ ) is placed to form an enclosure to the piles. Tremie concrete is then placed to fill the open steel box and grout the piles at the same time. A pile cap with flat jacks on top is placed over the tremie concrete plug, as shown in Figure 6-25. The flat jack will be used to adjust the leveling of the prefabricated segment. Landing steps are installed in the same way, except that they seat on previously placed precast segments rather than on piles.

Typically, there are three to four landing piles and steps for each individual precast segment. One hard landing pad is installed on the previously placed adjacent segment, and two or three adjustable landing piles with flat jacks are used to adjust the precast segment to an acceptable vertical tolerance. 


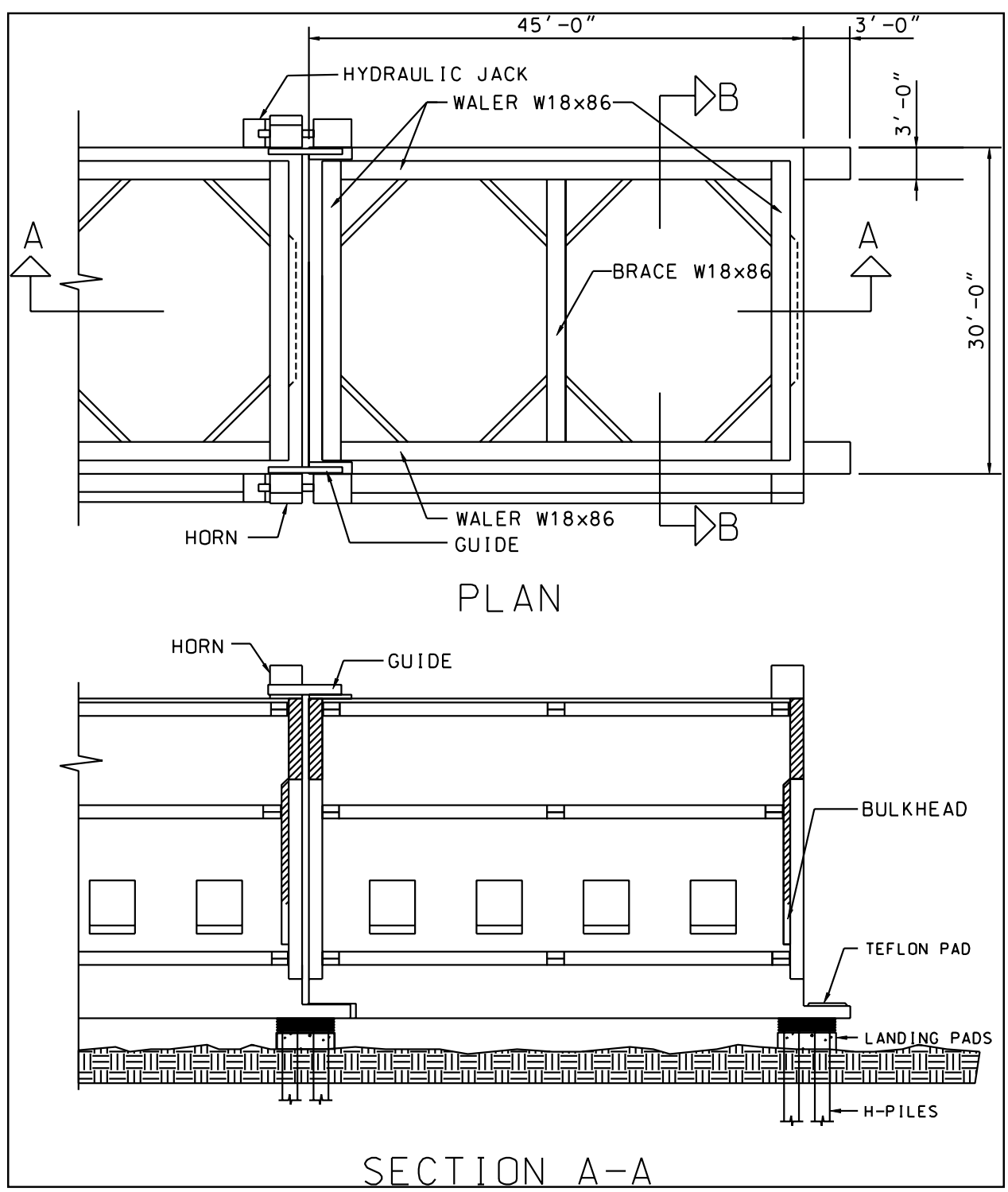

Figure 6-23. Two adjacent lock wall modules on landing piles and landing pads 


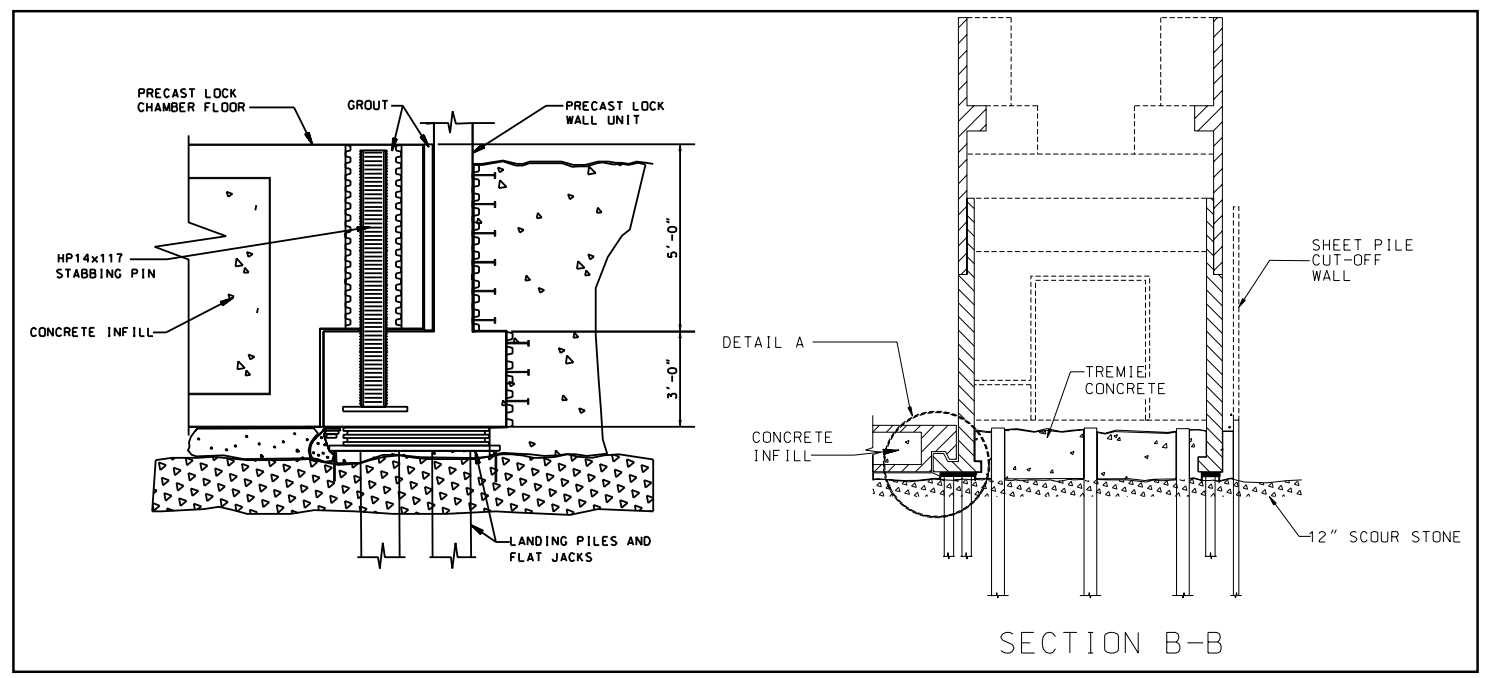

Figure 6-24. Lock wall module on landing pile and its connection to lock floor

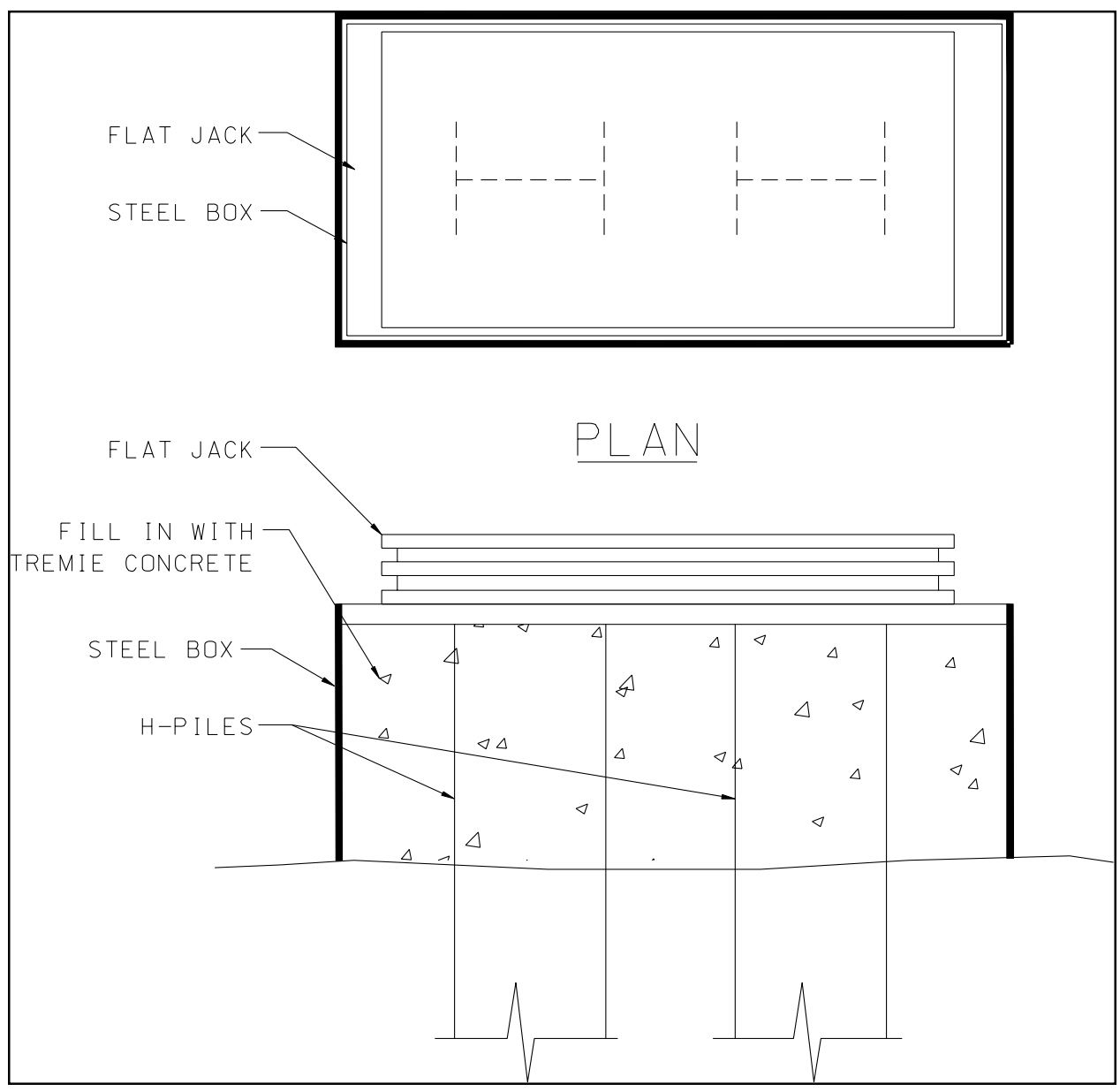

Figure 6-25. Landing pile with flat jacks 


\section{References}

American Bureau of Shipping. (1985). "Rules for building and classing mobile offshore drilling units," Houston, TX.

Gerwick, B. (2000). Construction of marine and offshore structures. CRC Press, Boca Raton, FL.

Gerwick, B. C., Yao, S. X., Berner, D. C., and Bittner, R. E. (2000). "Assessment of heavy-lift equipment for in-the-wet construction of navigation structures," ERDC/GSL TR-00-2, U.S. Army Engineer Research and Development Center, Vicksburg, MS.

Mann, R. G., and Chiarito, V. P. (2000). "Technologies for positioning and placement of underwater structures," ERDC TR-INP-00-1, U.S. Army Engineer Research and Development Center, Vicksburg, MS.

Maruo, H. (1960). "Drift of a body floating in waves," Journal of Shipping Research 4.

Precast/Prestressed Concrete Institute. (1999). "Manual for quality control for plants and production of structural concrete," Manual 116, 4th ed., Chicago, IL.

U.S. Army Corps of Engineers. (1984). Shore protection manual, 4th ed. Coastal Engineering Research Center, Vicksburg, MS.

U.S. Navy. (1985). "Fleet moorings: Basic criteria and planning guidelines," DM-26.5, Naval Facilities Engineering Command, Washington, DC.

. (1987). "Drag embedment anchors for Navy moorings," Techdata Sheet No. 83-08R, Washington, DC. 


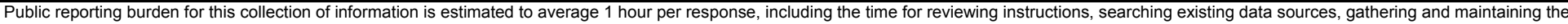

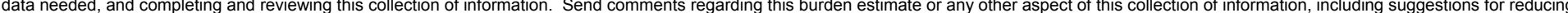

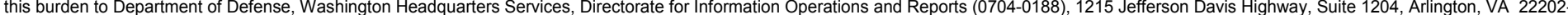

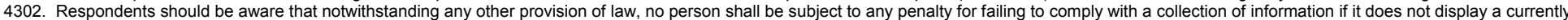
valid OMB control number. PLEASE DO NOT RETURN YOUR FORM TO THE ABOVE ADDRESS.

\begin{tabular}{l|l|l|l} 
1. REPORT DATE (DD-MM-YYYY) & 2. REPORT TYPE & 3. DATES COVERED (FrOm - To)
\end{tabular}

December 2002

Final report

\section{TITLE AND SUBTITLE}

Positioning Systems for Float-In and Lift-In Construction in Inland Waterways

5a. CONTRACT NUMBER

6. AUTHOR(S)

Sam X. Yao, Ben C. Gerwick

5b. GRANT NUMBER

5c. PROGRAM ELEMENT NUMBER

5d. PROJECT NUMBER

5e. TASK NUMBER

5f. WORK UNIT NUMBER

33274

\section{PERFORMING ORGANIZATION NAME(S) AND ADDRESS(ES) AND ADDRESS(ES)}

8. PERFORMING ORGANIZATION REPORT NUMBER

Ben C. Gerwick, Inc.

20 California Street

ERDC/GSL TR-02-22

Suite 400

San Francisco, CA 94111

\section{SPONSORING / MONITORING AGENCY NAME(S) AND ADDRESS(ES)}

U.S. Army Corps of Engineers

Washington, DC 20314-1000;

U.S. Army Engineer Research and Development Center

Geotechnical and Structures Laboratory

3909 Halls Ferry Road

Vicksburg, MS 39180-6199

\section{DISTRIBUTION / AVAILABILITY STATEMENT}

Approved for public release; distribution is unlimited.
10. SPONSOR/MONITOR'S ACRONYM(S)

11. SPONSOR/MONITOR'S REPORT NUMBER(S)

\section{SUPPLEMENTARY NOTES}

\section{ABSTRACT}

This report provides an introduction to the positioning construction techniques used in marine construction. This information is intended to provide guidance for developing and evaluating the positioning systems used for in-the-wet construction of navigation structures. The focus of the report is on assessing various methods for positioning large prefabricated segments, including the stationkeeping and guide systems.

The report is divided into two major portions. The first part provides an overview of positioning operations and general engineering requirements for the design and specification of positioning systems. The second part provides descriptions and evaluation of the most common stationkeeping and guide systems that are used to position prefabricated modules in marine construction. The evaluation of each method includes essential equipment, operation requirements, general applicability, and constraints for lift-in and float-in construction in the inland waterways.

\section{SUBJECT TERMS}

Anchor system

Float-in construction Guide system 16. SECURITY CLASSIFICATION OF:

a. REPORT

UNCLASSIFIED b. ABSTRACT

UNCLASSIFIED
Lift-in construction

Mooring system Prefabricated module
Positioning system

Stationkeeping

Winch system

\begin{tabular}{l|c|l|}
$\begin{array}{l}\text { 17. LIMITATION } \\
\text { OF ABSTRACT }\end{array}$ & $\begin{array}{l}\text { 18. NUMBER } \\
\text { OF PAGES }\end{array}$ & 19a. NAME OF RESPONSIBLE PERSON \\
\cline { 3 - 3 } & 114 & $\begin{array}{l}\text { 19b. TELEPHONE NUMBER (include area } \\
\text { code) }\end{array}$
\end{tabular}

